SPACE DIVISION
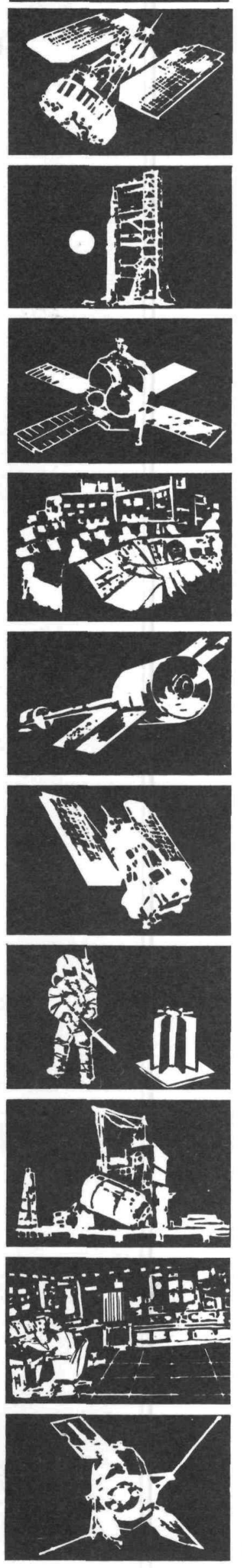

CONTRACT AEC SNSO-6
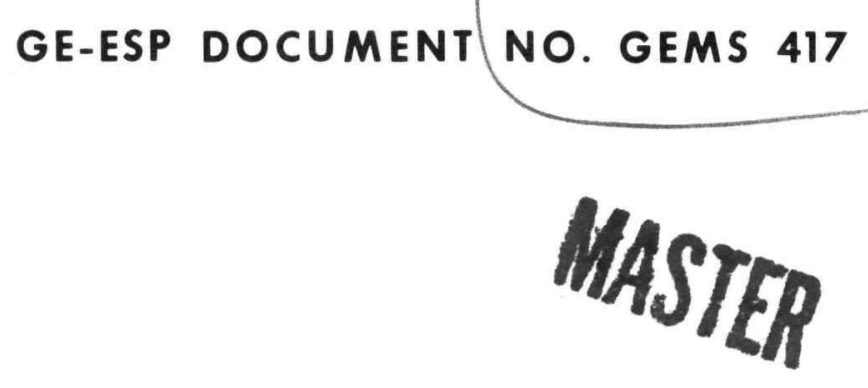

\section{MINI-BRAYTON ECONOMIC RTG STUDY FINAL REPORT}

JANUARY 1974

ACc3-765F 8000?

Prepared For

ATOMIC ENERGY COMMISSION

SPACE NUCLEAR SYSTEMS

W ASHINGTON, D.C. 20545

DO NOT MICROFILM COVER 


\section{DISCLAIMER}

This report was prepared as an account of work sponsored by an agency of the United States Government. Neither the United States Government nor any agency Thereof, nor any of their employees, makes any warranty, express or implied, or assumes any legal liability or responsibility for the accuracy, completeness, or usefulness of any information, apparatus, product, or process disclosed, or represents that its use would not infringe privately owned rights. Reference herein to any specific commercial product, process, or service by trade name, trademark, manufacturer, or otherwise does not necessarily constitute or imply its endorsement, recommendation, or favoring by the United States Government or any agency thereof. The views and opinions of authors expressed herein do not necessarily state or reflect those of the United States Government or any agency thereof. 


\section{DISCLAIMER}

Portions of this document may be illegible in electronic image products. Images are produced from the best available original document. 
CONTRACT AEC SNSO-6

GE-ESP DOCUMENT NO. GEMS 417

DOE/SE/80007--T1

DE82 005358

MINI-BRAYTON ECONOMIC RTG STUDY

FINAL REPORT

JANUARY 1974

PREPARED FOR

ATOMIC ENERGY COMMISSION

SPACE NUCLEAR SYSTEMS

WASHINGTON, D.C. 20545

\section{ENERGY SYSTEMS PROGRAMS SPACE DIVISION}

P.O. BOX 8661 PHILADELPHIA, PA. 19101

GENERAL ELECTRIC

PORTIONS OF THIS REPORT ARE ITLEGIBLE. It copy to permit the brod the best availablo ability.

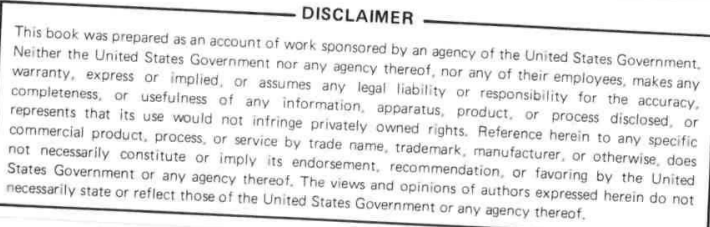

DISTRIBUTION OF THIS DOCHMENT IS UALIMITED 


\section{FOREWORD}

This study was conducted by the General Electric Company under Atomic Energy Commission contract AEC SNSO-6. Mr . Robert T. Carpenter of the Atomic Energy Commission's Space Nuclear Systems Division was the Study Manager。 
Blank Page 
1.2 Cycle Description..........................

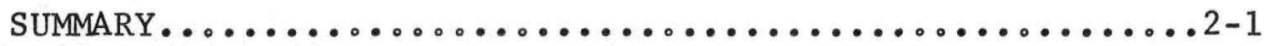

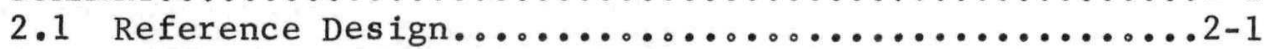

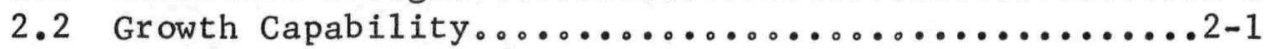

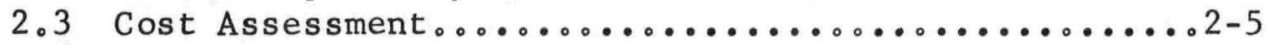

2.4 Reference Design Component Characteristics.........2-8

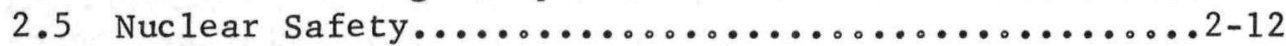

2.6 Spacecraft Integration....................... 12

DESIGN REQUIREMENTS AND APPROACH...................

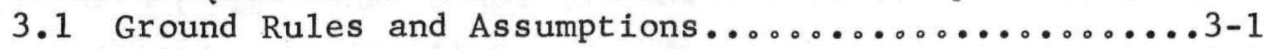

3.1.1 USAF System Performance Objectives......... 3-1

3.1.2 USAEC/SNS Nuclear Safety Criteria............

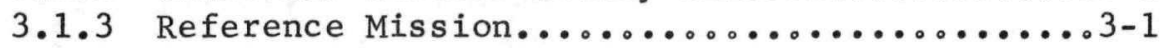

3.2 Study Approach........................... $3-6$

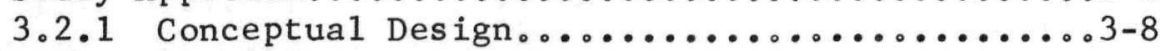

3.2.2 Technology Assessment....................... 38

REFERENCE DESIGN_............................ $4-1$

4.1 Component Selection...........................

4.1.1 Heat Source Selection..................4-1

4.1.2 Heat Source Heat Exchanger Selection........4-5

4.1.3 Emergency Cooling System Selection.........4-11

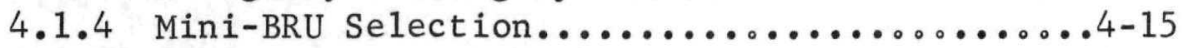

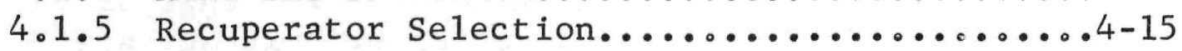

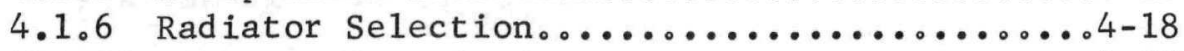

4.2 MB-ERTG Systems Descriptions................. 4-20

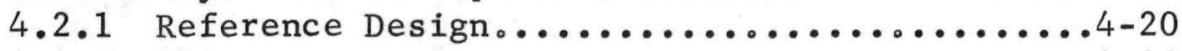

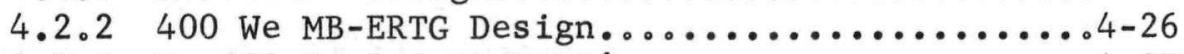

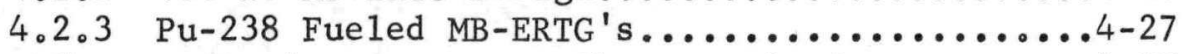

4.3 Reference Design Component Characteristics........4-27

4.3.1 Reference Heat Source Design..............4-27

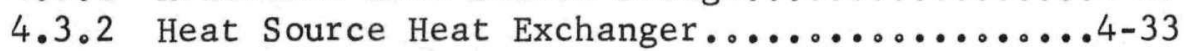

4.3.3 Heat Source Assembly Insulation System......4-40

4.3.4 Mini-BRU...........................4-40

4.3.5 Recuperator........................4-46

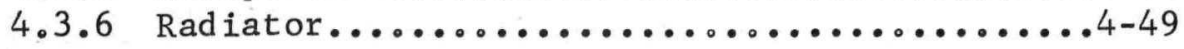

5.0 MB-ERTG GROWTH CHARACTERISTICS..................

5.1 400-3300 We MB-ERTG Performance Evaluation........5-1

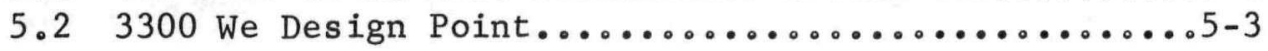


$\underline{\text { Section }}$

6.0

7.0

8.0

9.0

10.0

REFERENCE DESIGN NUCLEAR SAFETY ASSESSMENT_..........6-1

6.1 On-Pad Cooling System........................

6.2 Emergency Cooling System....................6-6

6.3 Potential Accidents and Aborts................6-7

6.4 Definition of Environments................. $6-12$

6.5 Response of Heat Source to Environments..........6-22

6.5.1 Reentry Analyses....................... 6-25

6.5 .2 Impact Analyses...................... $6-28$

6.5 .3 Post-Impact Behavior................. 6-35

SPACECRAFT INTEGRATION ........................

7.1 Dynamic Interaction with Attitude Control System.....7-1

7.1.1 Mini-BRU Start-Up.......................

7.1.2 Rotor Induced Torques................... 7-2

7.1.3 Working Fluid Momentum Changes.............. 7-5

7.2 Nuclear Shielding........................

7.3 Structural Integration.....................

7.4 Thermal Integration.......................

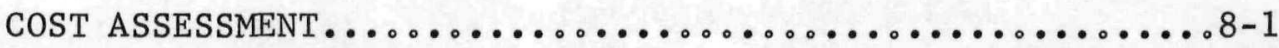

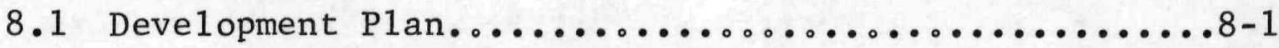

8.1.1 Development Program....................

8.1 .2 Development Plan Option................... $8-4$

8.1.3 Production Program...................... 8-7

8.2 Development Costs............................ $8-7$

8.2.1 Component Development and Assumptions........8-7

8.2.2 MB-ERTG Development Costs................. 8-19

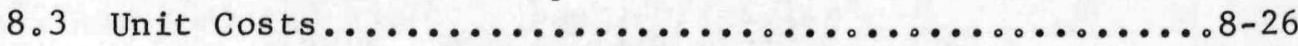

8.3.1 Reference Design Unit Costs..............8-27

8.3.2 Variation of Unit Costs with Power Level .....8-27

REFERENCES ................................

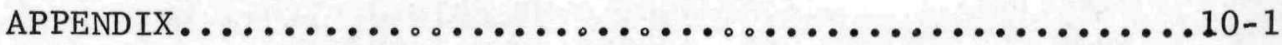


1-1

2-1

2-2

2-3

2-4

2-5

2-6

2-7

2-8

3-1

3-2

3-3

3-4

3-5

3-6

3-7

3-8

3-9

3-10

3-11

3-12

3-13

3-14

3-15

3-16

3-17

3-18

3-19

3-20

3-21

3-22

4-1

4-2

4-3

4-4

4-5

4-6

4-7

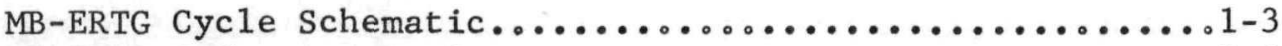

MB-ERTG Reference Design.......................... 2-2

Mini-Brayton-ERTG Design Configuration................... 2-3/4

MB-ERTG Development Plan and Costs....................

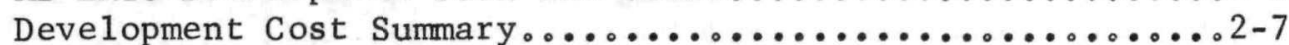

MB-ERTG Heat Source Assembly ....................... 2-9

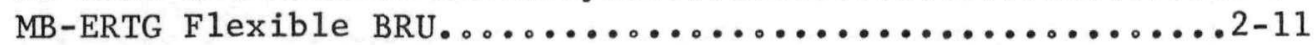

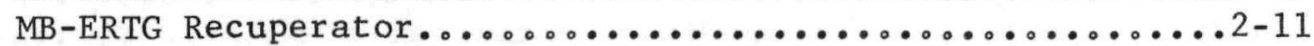

Radiator Panel Us ing Offset Fin-Tube Geometry..........2-13

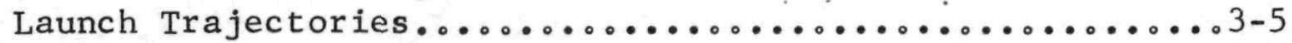

Reference Ascent Ground Trace....................... 3-5

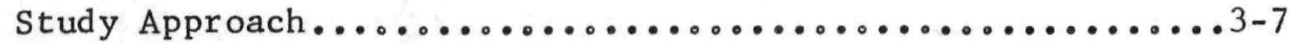

Multi-Hundred Watt Heat Source.......................

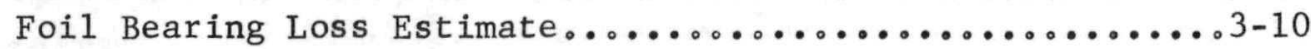

MB-ERTG Specific Weight Versus Efficiency................ 3-14

MB-ERTG Conceptual Design Cycle Conditions.............. 3-15

Conceptual Design Heat Source Assembly..................

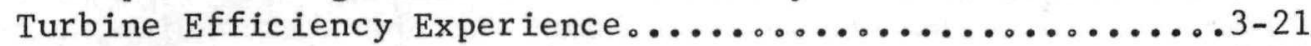

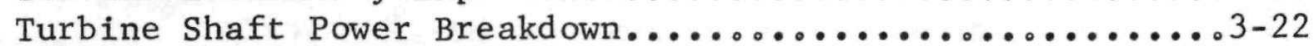

Typical 4 Pole Rice Alternator Design...................3-23

Effect of Compressor Size on Efficiency...............3-25

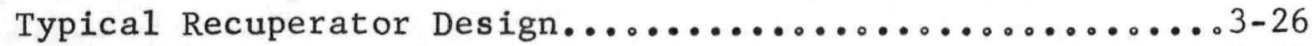

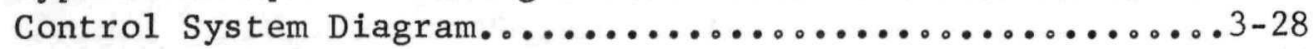

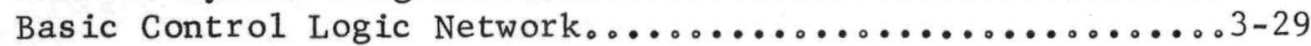

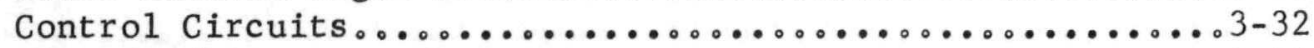

Receiver/Driver Configurations....................... 3-33

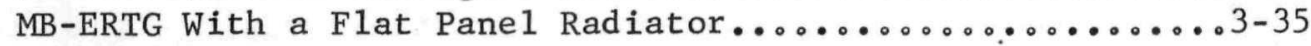

Effect of Fluid Pressure Drop on Radiator Weight........3-39

Conceptual Design Radiator Fin-Tube Geometry............3-4I

Heat Source Heat Exchanger Concepts........................ $3-42$

Radial Gap Permanent Magnet Generator.................... 3-44

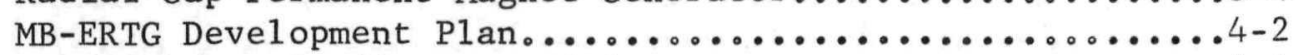

Candidate Fuel Liner Materials....................... 4

Temperature Drop Across a Spherical Cm-244 Fuel Impact

Body......................................

Temperature Drop Across a Cylindrical Cm-244 Fuel Impact

Body.......................................

Effect of Geometry and Weight-to-Area Ratio on Terminal

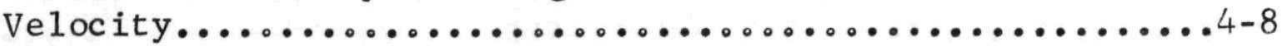

Effect of Weight-to-Area Ratio on Terminal Velocity for

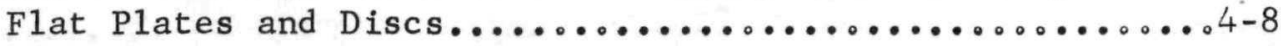

Candidate Heat Source Assembly Concepts..............4-9 


\section{LIST OF ILLUSTRATIONS (Cont'd)}

Figure

4-8

4-9

4-10

4-11

4-12

4-13

4-14

4-15

4-16

4-17

4-18

4-19

4-20

4-21

4-22

4-23

4-24

4-25

$5-1$

5-2

5-3

5-4

6-1

6-2

6-3

6-4

6-5

6-6

6-7

6-8

6-9

$6=10$

6-11

6-12

$6-13$

6-14

6-15

6-16

6-17

6-18

6-19

6-20

Heat Source Heat Exchanger Design Concept.............4-13 Transient Temperature of Melting Insulation Blanket......4-14 Comparison of Radiator Weights...................... $4-19$ Beryllium Radiator-Pu0 2 Cost Trade-off................4-21 MB-ERTG 400We Reference System Design Optimization........4-22 Reference Design Cycle Conditions......................4-24 Heat Source Design for Reference System...............4-29 FIB Impact Capability................................ $4-34$ Cm-244 Heat Source Operational Temperatures............4-35 Pu-238 Fueled MB-ERTG Heat Source Design...............4-36 $\mathrm{Pu}_{2}$ Heat Source Operational Temperatures............4-37 Heat Source Heat Exchanger Design.................... 4-38 Operational Temperature Profile Through HSA Insulation....4-41 Heat Flux Versus Hot Side Temperature for Nickel Multi-

Foil Insulation............................. 4-42

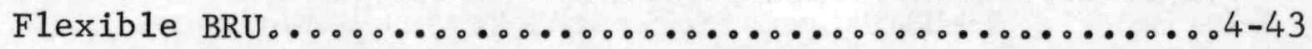
Comparis on of Haynes -188 and Hastelloy-X............. 4-47 Advanced Recuperator Design......................4-48 Double Fluid Containment Recuperator Design Concept......4-49 Effect of Power Leve1 on MB-ERTG Performance............5-2 Effect of Power Level on Alternator Efficiency..........5-3 Effect of Cycle Efficiency Upon System Weight at $3.3 \mathrm{kWe} . .05-4$ 3.3kWe MB-ERTG Cycle Conditions .................... 5-7 Curium-244 Heat Loading Procedure...................6-2

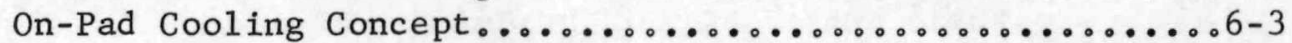
On-Pad Heat Source Temperatures................... 6-4 MB-ERTG Heat Source Launch Transient................6-5 Operational Temperature Profile Through HSA Insulation....6-8

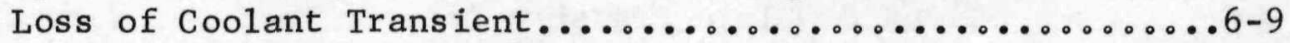
Static Overpressure in the Transtage..................6-15 Static Impulse in the Transtage...................6-16 Fireball Temperatures and Heat Flux as a Function of

Time for Titan IIIC ............................. 6-17 Solid Fire Model, Titan IIIC......................6-19 Static Overpressure versus Time After Liftoff..........6-20 Static Impulse versus Time After Liftoff..............6-21 Steep Angle Reentry Heating Profile................6-26 Steep Angle Reentry Temperature Response...............6-27 Minimum Gamma Reentry Heating Profile................ 6-29 Minimum Gamma Temperature Response.................6-30 Effect of Thornel-50 Cover Modulus on Impact Capability...6-31 Estimated Thoria Clad Impact Capability...............6-31 Thoria Impact Test Result.........................6-34 FIB Post-Impact Temperatures.................... 
7-1

7-2

7-3

7-4

7-5

7-6

8-1

8-2

8-3

8-4

8-5

8-6

8-7

8-8

8-9

8-10

Change in Momentum Vector During Orbit................ Effect of Rotor Orientation on Spacecraft ACS...........7-4 Attitude Error Caused by Rotor Speed Variations......... 7-6 ORNL Shielding Results for the MB-ERTG...............7-8 Pu-238 Neutron Shielding Requirements................. MB-ERTG Support System.......................... 7-10 Summary Schedule MB-ERTG Development Plan.............8-2 Fue 1 and Fuel Clad Development Options.............. Development Cost Summary.......................8-8 Heat Source Development Tasks...................8-9 Heat Source Development Plan......................8-11

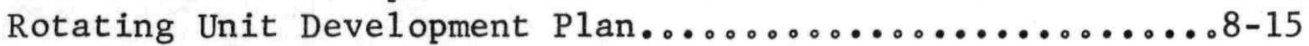
Systems Contractor Costs by Fiscal Year...............8-20 ORNL Costs by Fiscal Year.......................8-21 ORNL Heat Source Assembly Procedure..................8-29 Variation of Unit Costs with Power Leve1..............8-30 
SECTION 1.0

\section{INTRODUCTION}

This study was performed by General Electric's Advanced Space Power Systems in fulfillment of contract AEC SNSO-6, "Evaluation of an Economic Radioisotope Thermodynamic Generator based on Brayton Cycle Power Conversion", directed by the Atomic Energy Commission's Space Nuclear Systems Division. This study was one of a group of studies, referred to as the ERTG Studies, undertaken by the $A E C$ to evaluate the applicability of various nuclear power systems to the SURVSATCOM Mission. The emphasis of this 6 month program was directed towards the assessment of Brayton power system technology for the application of interest.

The General Electric Company was supported in this effort by the AiResearch Manufacturing Company of Arizona.

\subsection{PROGRAM OBJECTIVES}

The principal objectives of this study were to:

- Design a Mini-Brayton Economic Radioisotope Thermodynamic Generator (MB-ERTG) which meets the United States Air Force System Performance Objectives.

- Prepare a development plan and cost estimate to bring the MB-ERTG from its present technology level to a flight ready system.

- Prepare unit cost estimates of the Reference Design MB-ERTG.

The USAF System Performance Objectives are shown in Table 1-1; these objectives were formulated for an assessment of the candidate nuclear power systems for the SURVSATCOM Mission and therefore, constituted the basic system requirements for this study. Of particular importance to the design of the MB-ERTG is the requirement for a 400 We, 205 pound system packaged within a 3 feet diameter and 5 feet high envelope. Previous studies of isotope Brayton power systems had focused upon higher power levels leaving the performance at the 400 We level virtually uncharacterized; therefore, a major output of this study was the performance evaluation of the MB-ERTG at this power level.

A major objective was to minimize the development and unit costs of the MB-ERTG; therefore, cost was a major selection factor in determining the MB-ERTG Reference Design characteristics.

\subsection{CYCLE DESCRIPTION}

The Brayton power conversion system, pictured schematically in Figure 1-1, is a closed loop recuperated cycle which utilizes a single phase, gaseous, working fluid. 
Table 1-1. USAF System Performance Objectives

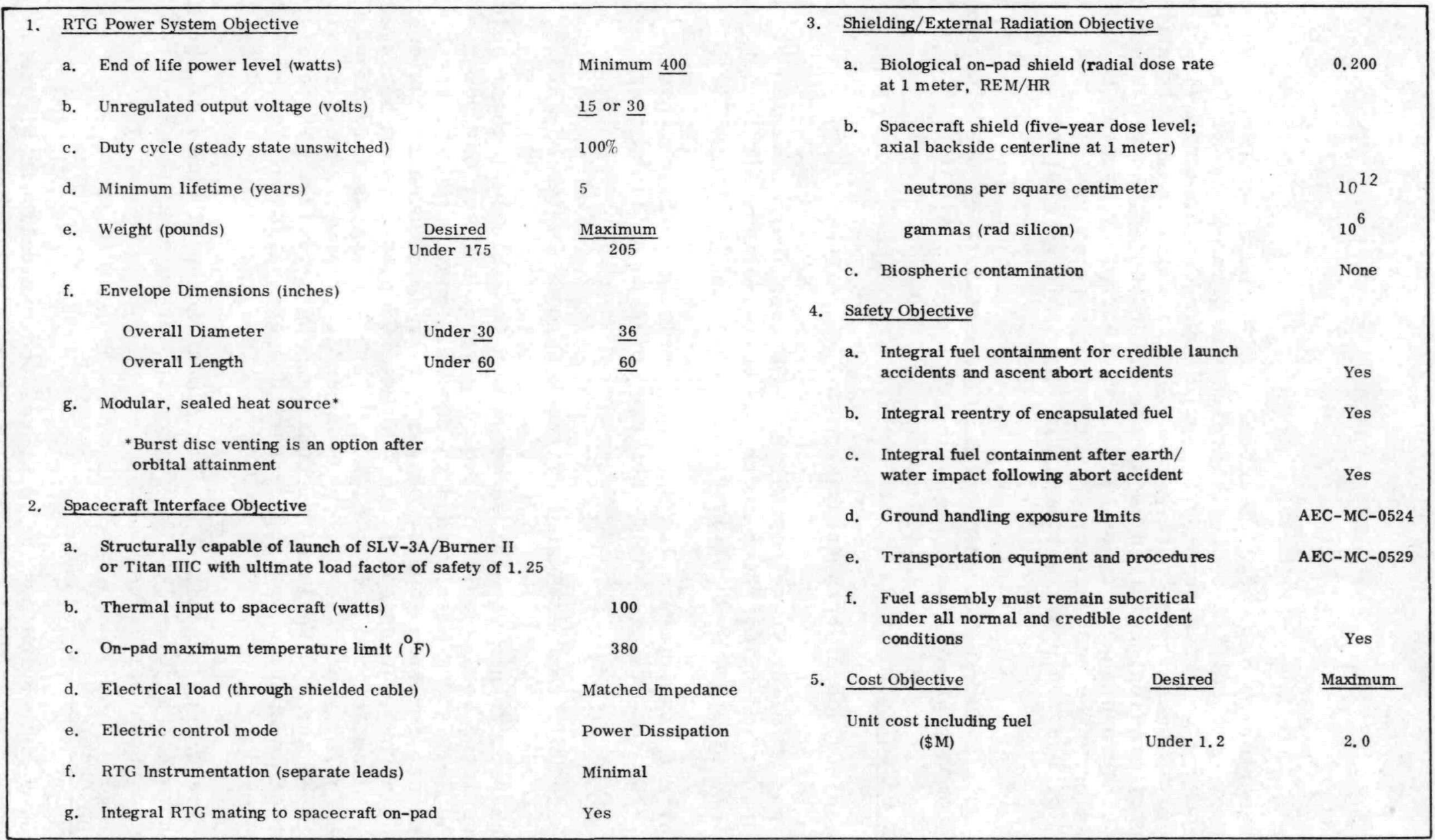




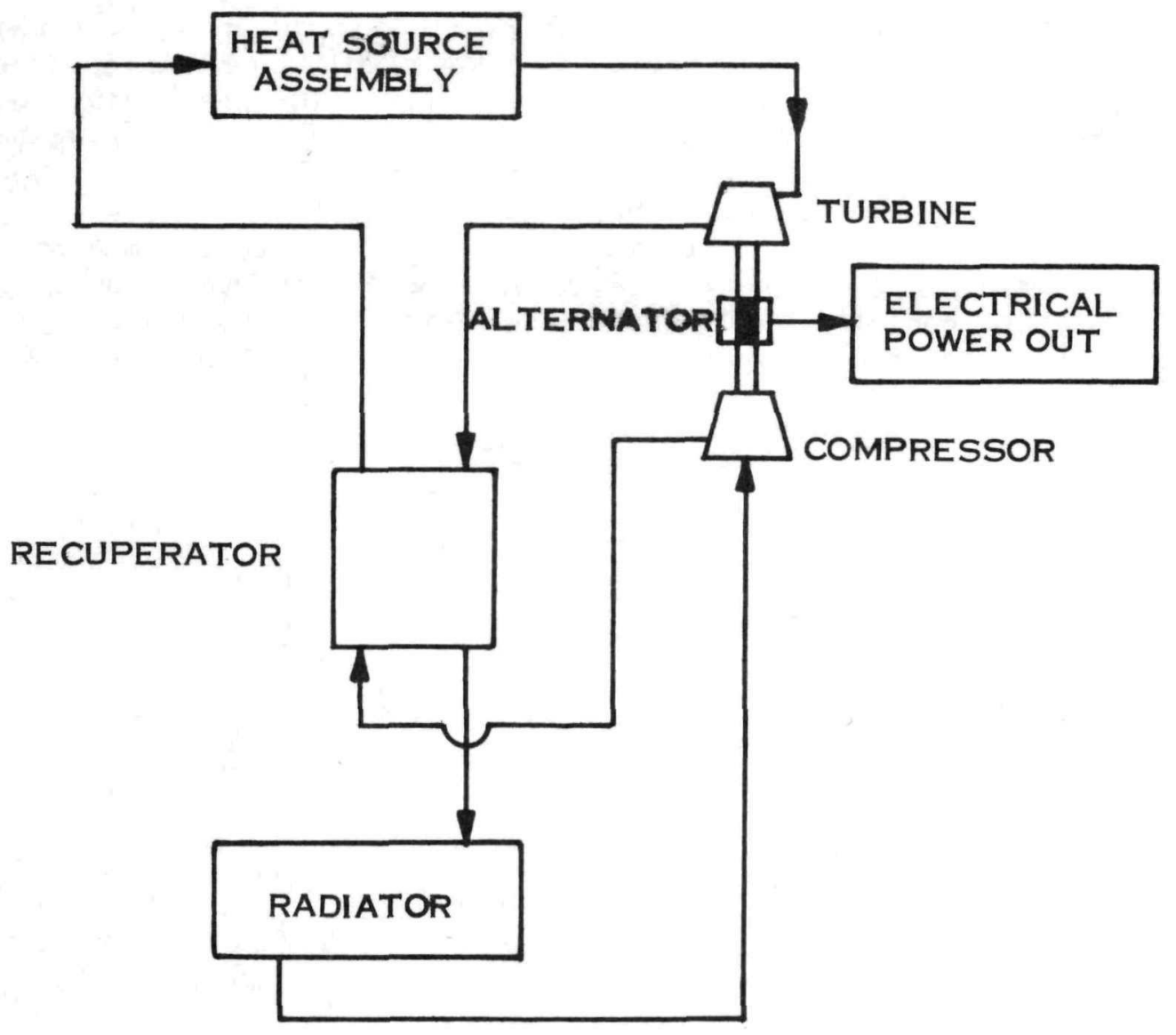

Figure 1-1. MB-ERTG Cycle Schematic 
The principal components in the system are the Heat Source Assembly (HSA), the Brayton Rotating Unit (BRU), recuperator, radiator and controls package. the HSA consists of a heat source heat exchanger (HSHX), radioisotope heat source and insulation system. The BRU utilizes a single shaft having a turbine, alternator and compressor and is supported on self-acting, foil gas bearings. The recuperator is a high effectiveness, counterflow heat exchanger which increases the efficiency of the cycle. Cycle waste heat is rejected from the system by a radiator.

Energy is transferred to the working fluid from the radioisotope in the HSA. The gas exits from the HSA in the $1600^{\circ}-1700^{\circ} \mathrm{F}$ range and enters the turbine portion of the BRU where heat energy is converted into kinetic and subsequent1y, electrical energy. The gas, an inert helium/xenon mixture, enters the recuperator where it preheats the counterflow stream entering the HSA. Upon exiting from the recuperator the gas enters the radiator at approximately $2000-300^{\circ} \mathrm{F}$ and the cycle waste heat is rejected from the system. The gas then enters the compressor where it is raised to a higher temperature and pressure. Prior to leaving the compressor the gas is passed over the alternator stator to cool the windings. The gas is then returned to the lower temperature end of the recuperator where it returns to the HSA. 
SECTION 2.0

SUMMARY

The objective of this study is to demonstrate the applicability of a radioisotope heated Mini-Brayton power system to the 1973 USAF/AEC requirements established for the SURVSATCOM Mission. Principal requirements of the power system, taken from the USAF System Performance Objectives, Table 1-1, are:

$\begin{array}{ll}\text { Power Leve } 1 & 400 \text { We } \\ \text { Weight } & 205 \text { lbs., maximum } \\ \text { Cost } & \$ 1.2 \text { to } 2.0 \text { million per unit } \\ \text { Mission Duration } & 5 \text { years }\end{array}$

In addition, the radioisotope heat source is required to meet the AEC Nuclear Safety Criteria presented in Section 3.0. Of particular importance is the groundrule to contain the radioisotope for 10 half lives.

The following sections present a summary of the major aspects of the Reference Design MB-ERTG covered in the report.

\subsection{REFERENCE DESIGN DESCRIPTION}

The Reference Design meets and exceeds the USAF system weight and cost objectives and is designed to meet the AEC Nuclear Safety Criteria. Figure 2-1 illustrates the Reference Design; system weight is 186 pounds and unit cost, including the curium - 244 fue 1 , acceptance testing and delivery is $\$ 748,000$. An additional 14 pounds is required for a lithium hydride neutron shield, to meet the 5 year dose limit of $10^{12}$ nvt.

The Reference Design, shown in Figure 2-2, utilizes a "flexible" Brayton rotating unit (BRU), a $\mathrm{Cm}-244$ heat source with ceramic clad fue 1 cylinders and an aluminum radiator. The flexible BRU has a variable power output capability, $400 \mathrm{We}-3000 \mathrm{We}$, and is an important factor in the formulation of a cost effective development plan. The programmatic advantages derived from the use of this concept are explained in Sections 4.1 and 8.1.

Another aspect of the flexibility of the Reference Design is that it can accomodate either a curia $\left(\mathrm{Cm}_{2} \mathrm{O}_{3}\right)$ or plutonia $\left(\mathrm{PuO}_{2}\right)$ fueled Heat Source Assembly (HSA). The Reference Design hardware with a plutonia fueled HSA has a system weight of 207 pounds and a unit cost of $\$ 1.67 \mathrm{M}$. The higher plutonia fueled system unit cost is attributable to the difference in the cost between curia and plutonia, $\$ 100$ per watt and $\$ 630$ per watt, respectively.

\subsection{GROWTH CAPABILITY}

Higher power level systems were also evaluated during the study. The results showed that an increase in power from 400 We to the 3000 We level provided 
REFERENCE DESIGN

- BRU CAPABILITY, We

- Cm FuEL, w

- Fuel Clad

- RAdIATOR MATERIAL

- SYSTEM WEIGHT

- SHIELD WEIGHT

- total system weight

- NET SYSTEM EFFICIENCY

- UNIT COST, WITH FUEL

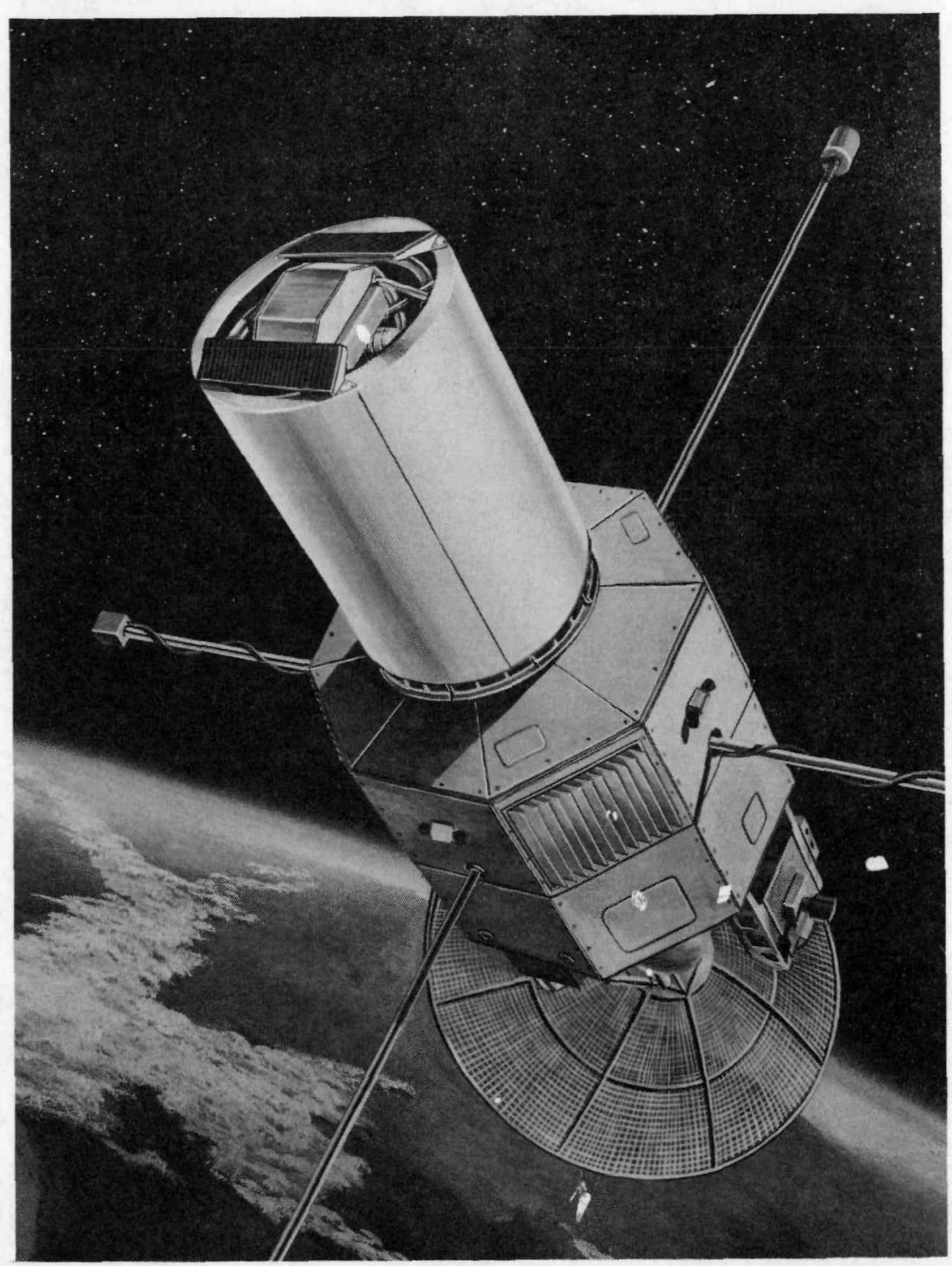




\section{MINI BRAYTON - ERTG DESIGN CONFIGURATION}

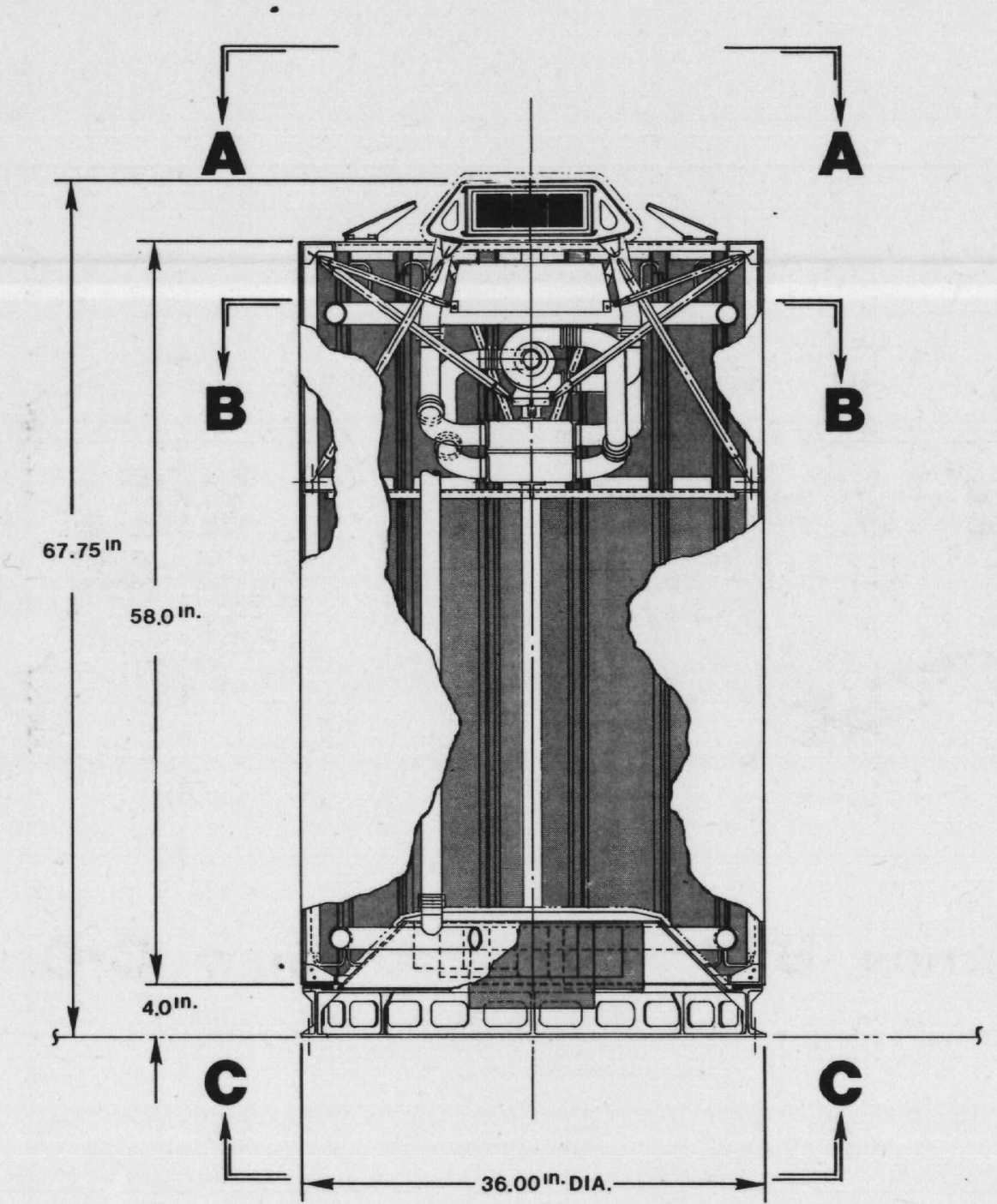

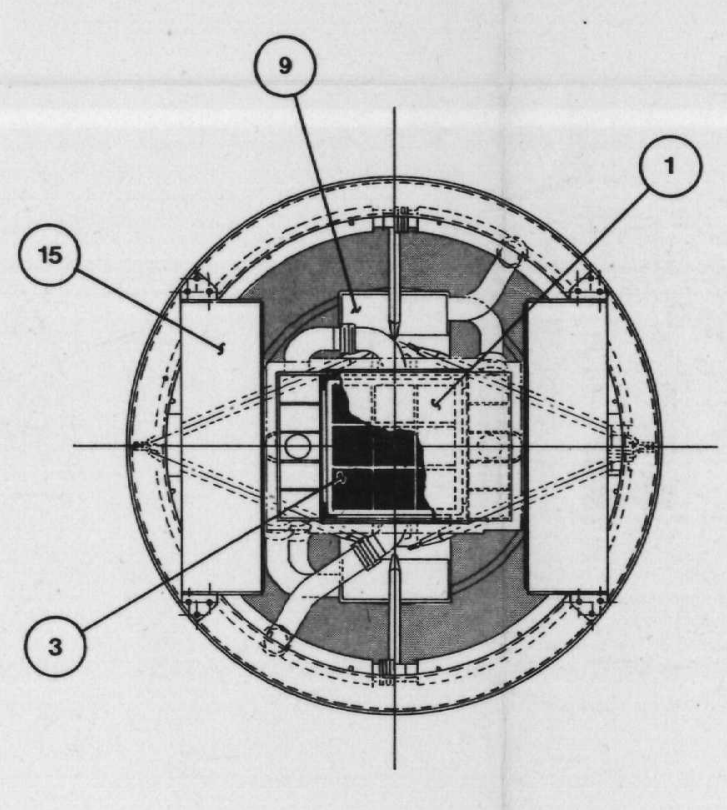

VIEW A-A

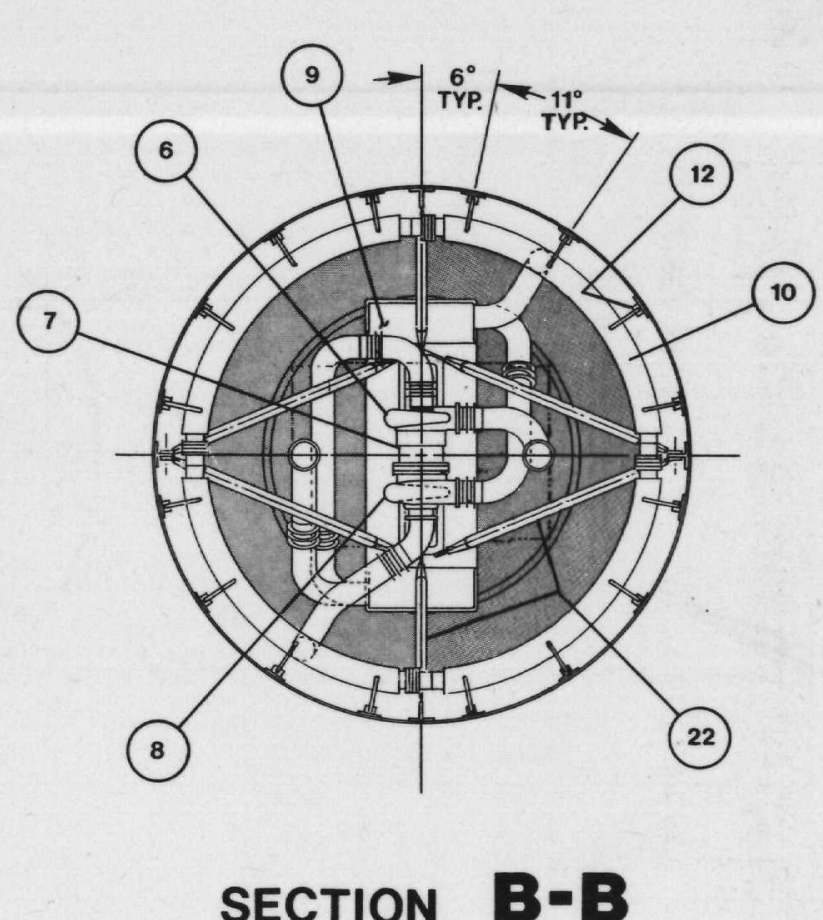

ITEM DESCRIPTION

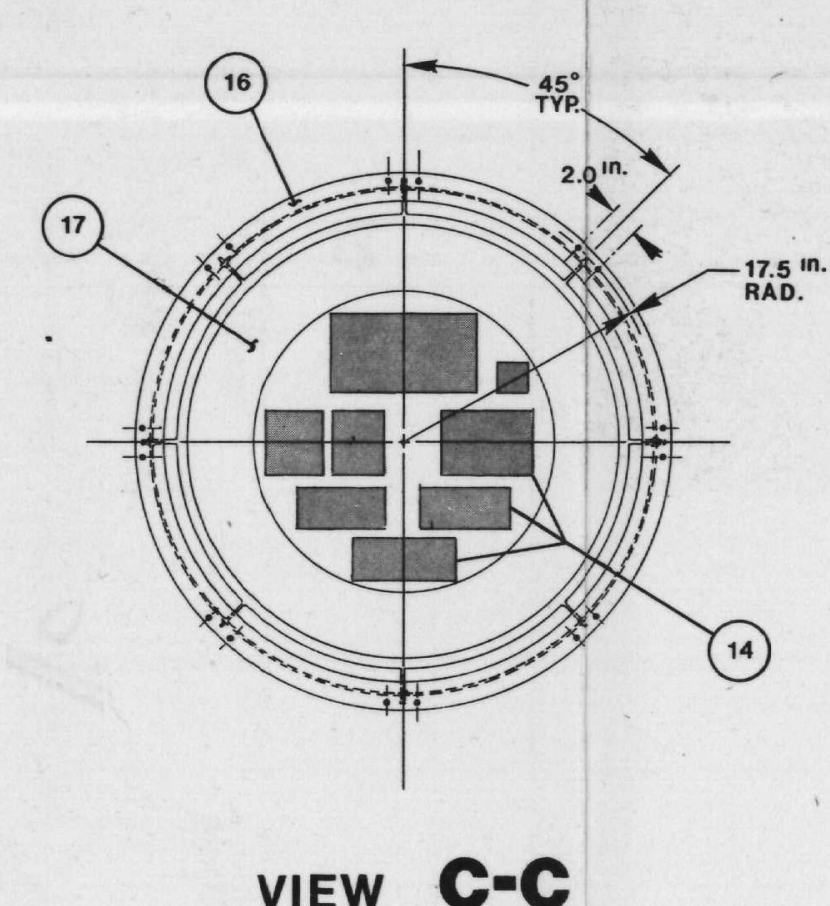

VIEW C-C

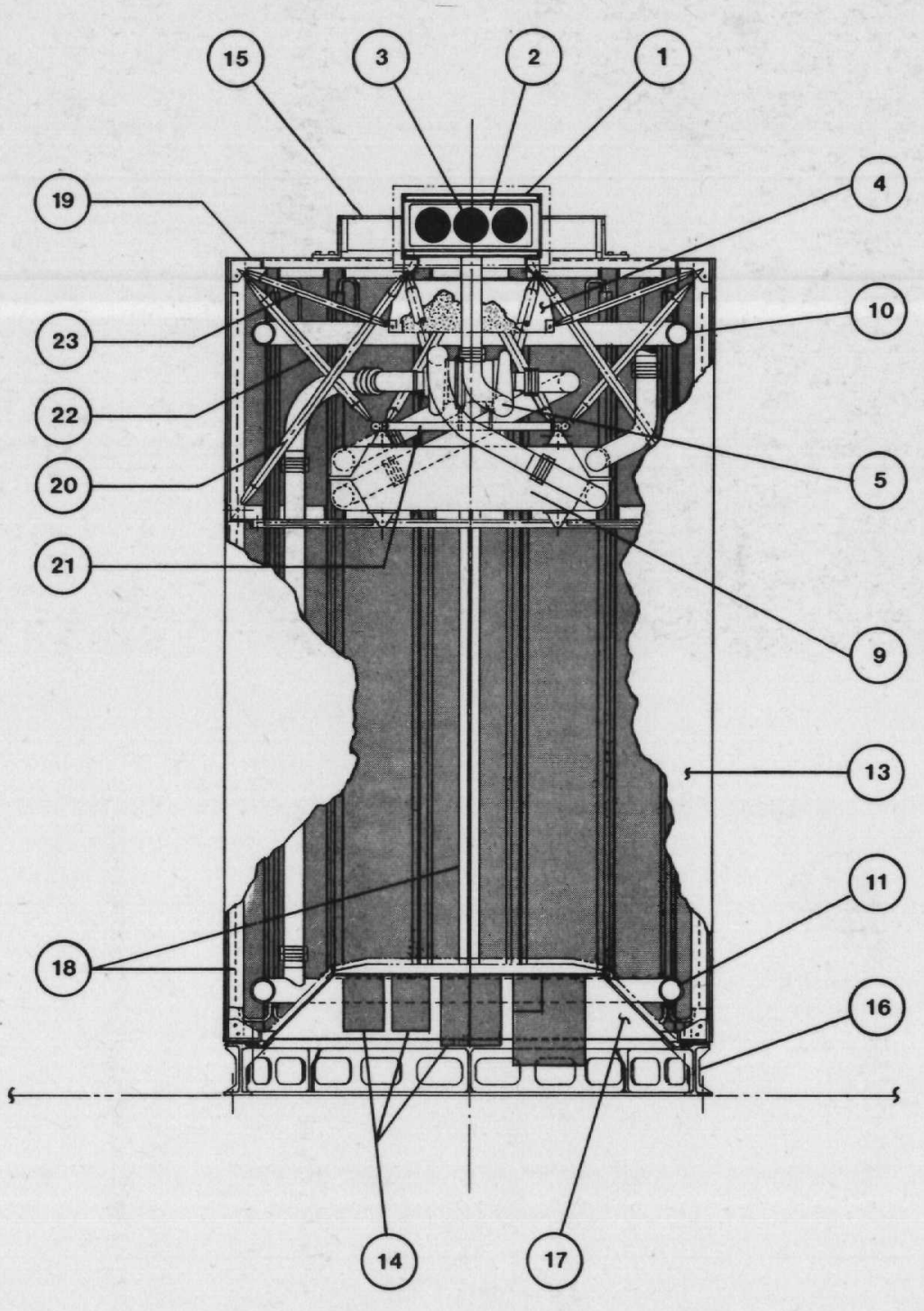

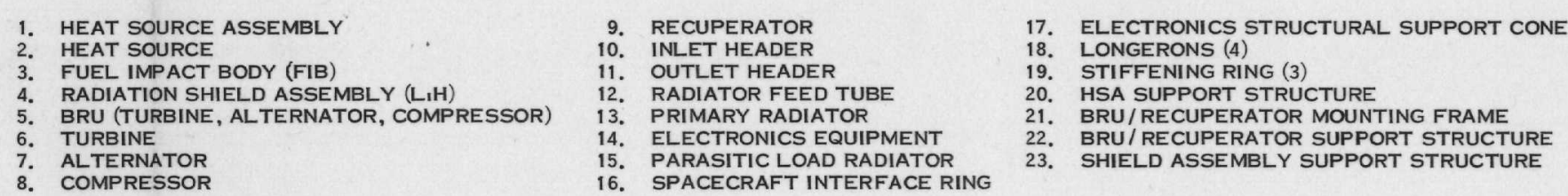


Blank Page 
an increase in specific power from 2 watts per pound to 5 watts per pound, and an increase in efficiency from 23 to 35 percent. This trend is illustrated in Figure 5-1. The higher system efficiency at the higher power levels is derived from the increased turbomachinery efficiencies available at higher flow rates and the reduction in bearing losses as a fraction of output power.

A detailed summary of a 3300 We MB-ERTG is presented in Section 5.0.

\subsection{COST ASSESSMENT}

The detailed development and unit cost assessment for the Reference Design MB-ERTG was based on groundrules provided by the AEC and key inputs from the Oak Ridge National Laboratory (ORNL) and the AiResearch Manufacturing Company. Additional consulting was provided by NASA-Lewis, Los Alamos Scientific Laboratory and the Savannah River Laboratory.

The total development cost is estimated at $\$ 16.4 \mathrm{M}$ with an additional $\$ 6.5 \mathrm{M}$ required by ORNL for $\mathrm{Cm}-244$ heat source development support, $\mathrm{Cm}-244$ fuel, heat source fabrication and capital equipment expenditures.

The development plan is divided into four phases plus a production phase as follows :

$$
\begin{aligned}
& \text { Phase } 1 \text { - System Studies } \\
& \text { Phase } 2 \text { - Technology and Component Demonstration } \\
& \text { Phase } 3 \text { - System Development and Qualification } \\
& \text { Phase } 4 \text { - Flight System Fabrication } \\
& \text { Phase } 5 \text { - Production }
\end{aligned}
$$

The initial portion of the Phase 1 system studies have been completed and Phase 2 has been assumed, by the AEC, to start in the first quarter of calendar 74. The AEC established date for a DOD Requirement Letter is 7/75; General Electric has assumed a first flight date of $7 / 78$.

The development schedule including, cumulative pro gram costs is shown in Figure 2-3. Figure 2-4 illustrates the program cost by development phase; the major costs are incurred in Phase 2 and the prototype development portion of Phase 3 .

Unit costs for the MB-ERTG are based on an AEC directed production schedule of 1 unit every two months with a total of 20 units. The complete unit cost for the Reference Design MB-ERTG is $\$ 748,000$. Component costs are $\$ 311,000$, including the heat source piece parts; fabrication and assembly of the heat source at ORNL is $\$ 77,000$. An additiona $1 \$ 141,000$ has been included to account for costs associated with the management of the production effort, assembly of the system, acceptance testing, transportation and ground personnel costs. A more detailed breakdown of the unit costs is given in 


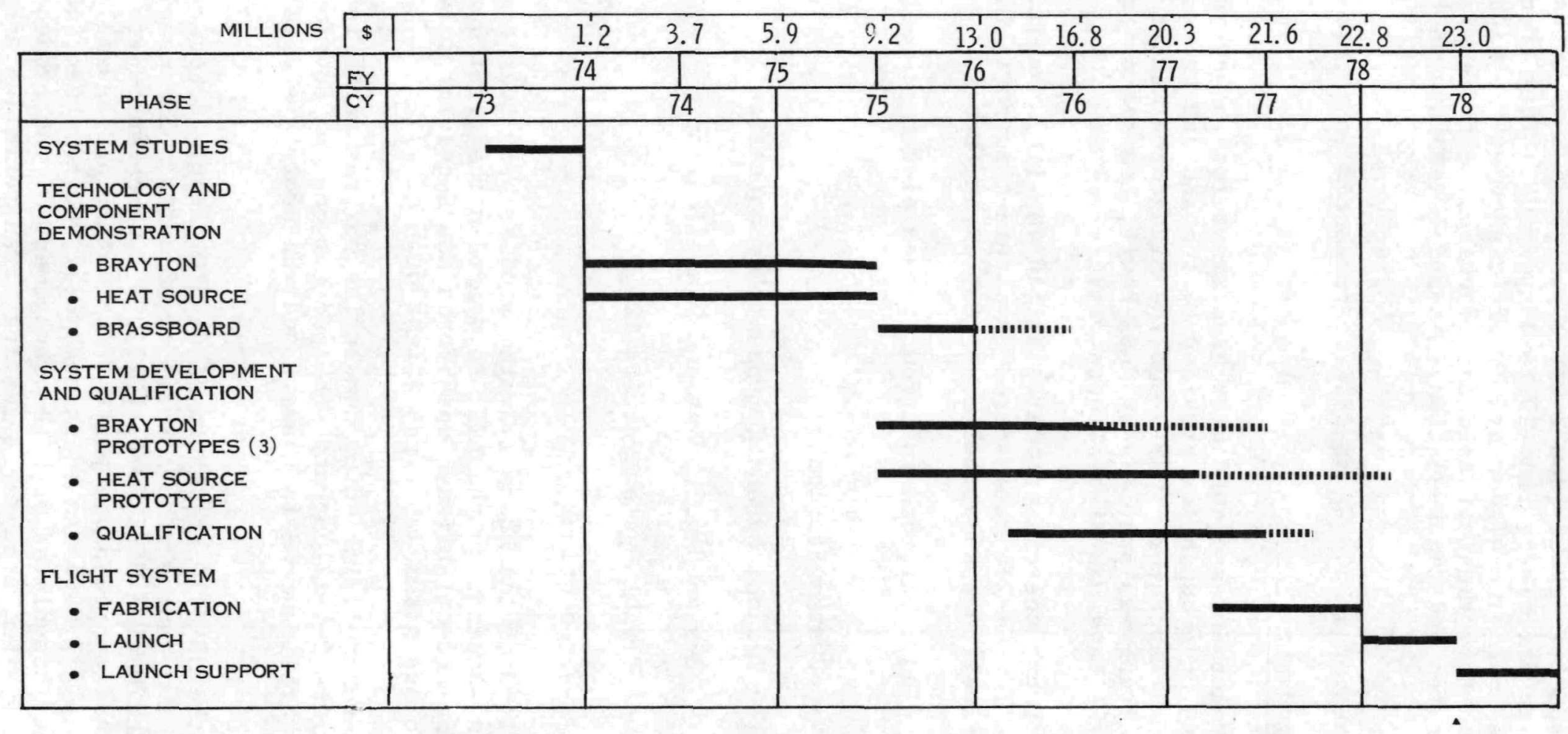




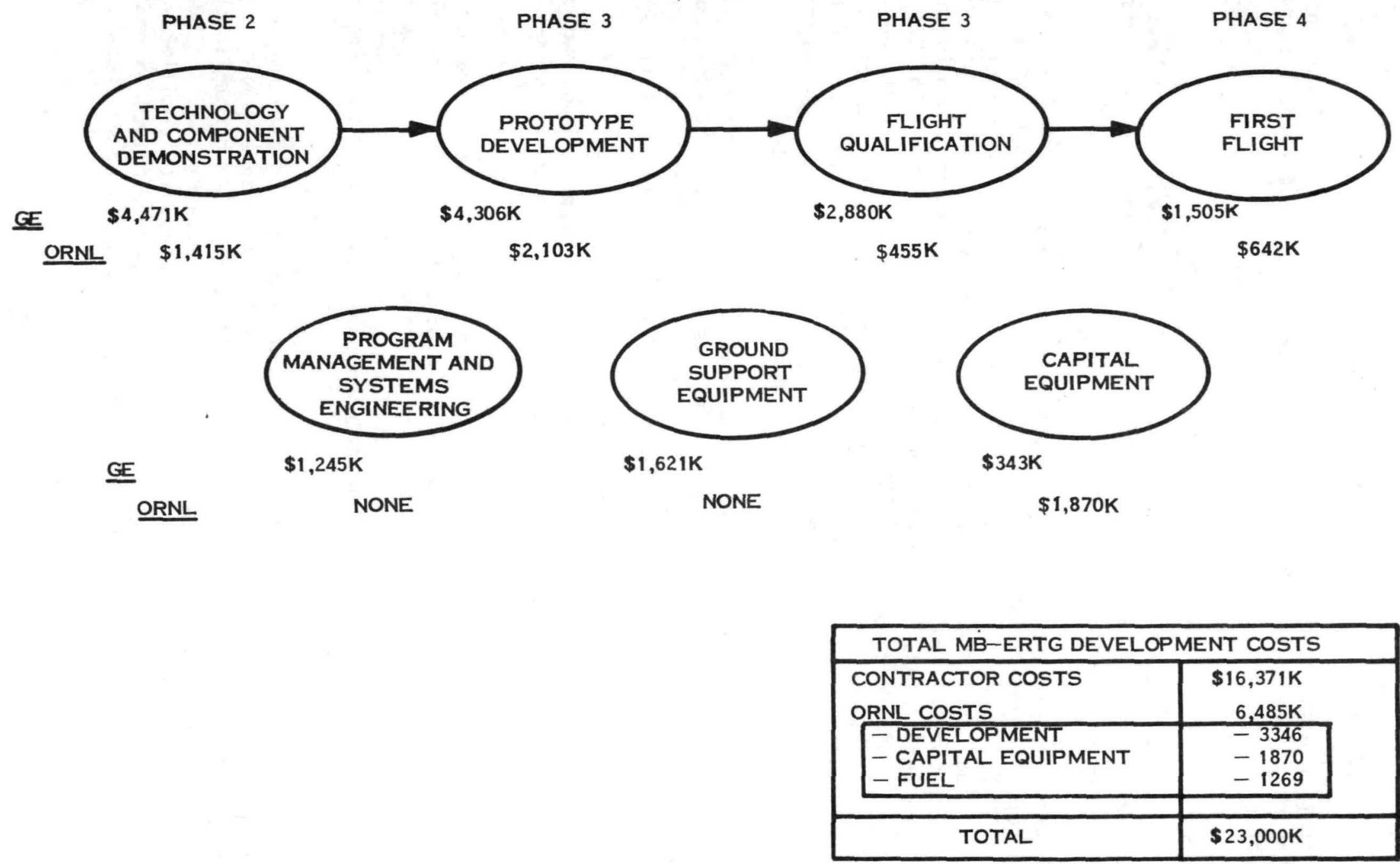


Table 2-1.

\subsection{REFERENCE DESIGN COMPONENT CHARACTERISTICS}

This section summarizes the features of each of the principal components in the Reference Design MB-ERTG. A detailed description of these components is presented in Section 4.3。

Heat Source Assemb1y

The heat source assembly consists of a heat source, heat source heat exchanger and an emergency cooling system. Each of these component elements is described below.

The heat source is comprised of 9 fuel impact bodies (FIBS) which fit within the aeroshell impact core which is encased in the POCO graphite aeroshell, (Figure 2-5). Each FIB consists of 244 watt $\mathrm{Cm}_{2} \mathrm{O}_{3}$ cylinders encapsulated in ceramic clad; preliminary investigations have identified thoria as the most attractive for this application. Impact protection is provided by cylindrical thorne1-50 impact she11s similar in concept to that used in the MHW heat source fuel sphere assemblies. The resulting FIB is given additional impact protection by the thorne1-50 aeroshell impact core which also acts as a thermal insulation barrier in the event of a re-entry. Re-entry protection is provided by a POCO aeroshe11 in a rectangular prism configuration. Expected terminal velocity of the heat source is below $175 \mathrm{fps}$.

The rectangular heat source geometry shown in Figure 2-5 can also accommodate spherically shaped FIB's or Multi-Hundred-Watt heat source fuel sphere assemblies. Therefore, various options exist to the Reference Design depending on the results of the Phase 2 technology program and curium availability.

The heat source fits within a heat exchanger with finned flow passages for the working fluid situated above and below the heat source. The heat exchanger construction materia1 is Niobium 103.

Oxidation of the graphite aeroshell and refractory metals is prevented on the launch pad by use of an inert gas cover. The inert gas is transferred to the HSA by means of a quick-disconnect attachment mounted on the outer insulation clad. In addition to providing a protective cover, the inert gas thermally short circuits the insulation blanket and lowers the temperature level throughout the HSA.

An emergency cooling system (ECS) for the heat source is required in the event that the MB-ERTG becomes inoperative. The Reference Design system uses the HSA multifoil insulation system as the ECS. This is accomplished by selecting a foil material which melts before the integrity of the heat source is compromised. The selected nickel multifoil insulation (melting point, $2650^{\circ} \mathrm{F}$ ) prevents the maximum fuel centerline temperature from exceeding $3750^{\circ}$ F during a loss of cooling situation, thereby maintaining the heat source integrity. 


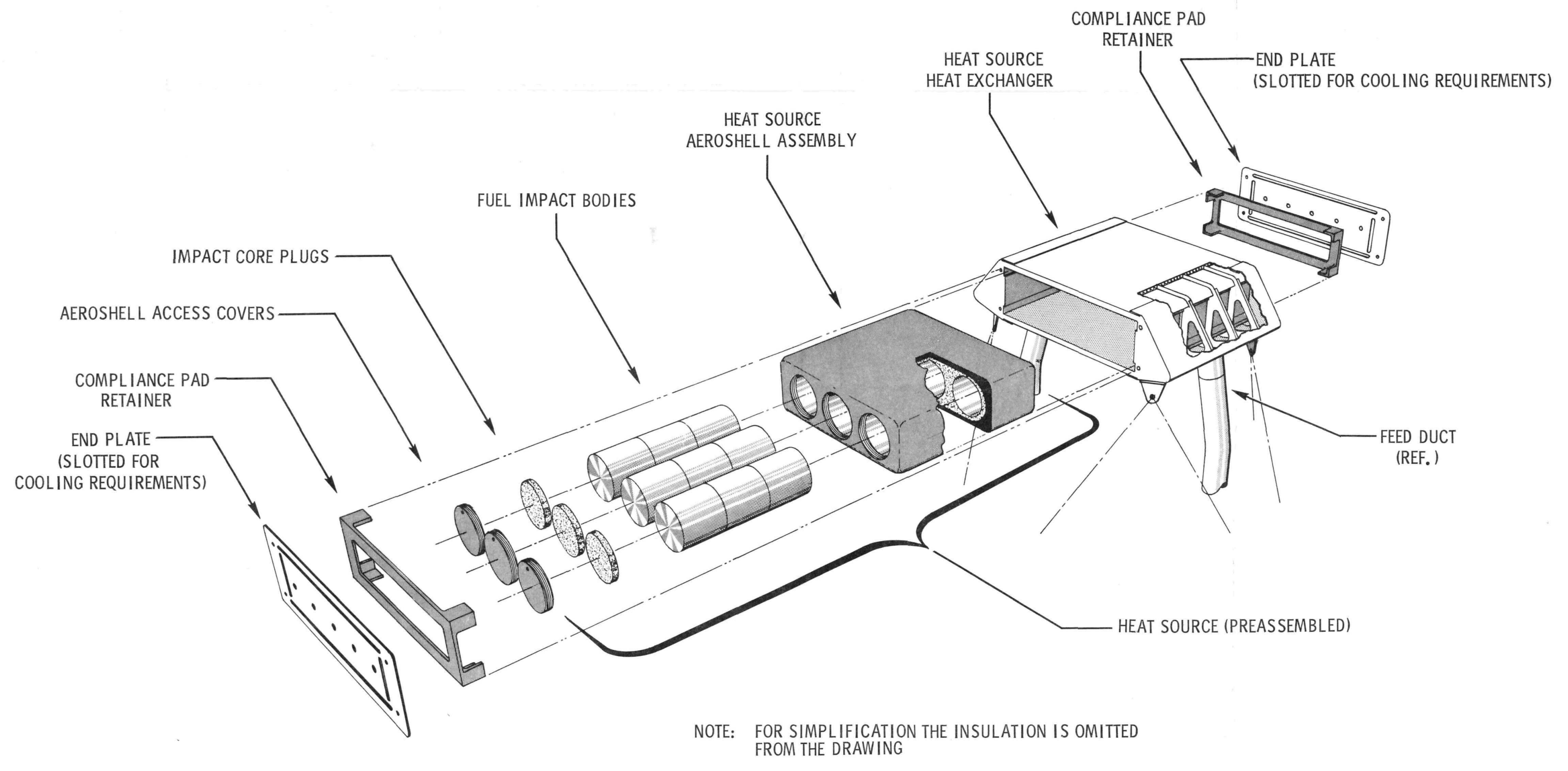




\section{Flexible BRU}

The rotating unit recommended for the Reference Design is a 35 pound machine which is capable of operating at power levels in the 400 We to $3 \mathrm{kWe}$ range, a schematic of the flexible BRU is illustrated in Figure 2-6. This feature permits the power level decision to be delayed until Phase 3 of the development program without requiring a redesign of the BRU. The turbine, alternator and compressor are mounted on a single shaft which is supported on self-acting foil gas bearings. At the right end of the journal the radial inflow turbine can be seen, while the centrifugal compressor is illustrated at the left end of the journal; turbine and compressor wheel efficiencies are 79 and 75 percent, respectively at the 400 We operation condition. The Rice alternator, pictured at the center of the journal has an efficiency of 86 percent at the 400 we condition.

There are no identifiable wear-out modes for the BRU due to the elimination of rubbing parts. Turbine stresses are low (turbine tip speed is on $1 \mathrm{y} 680$ fps) and alternator temperatures are below $350^{\circ} \mathrm{F}$.

\section{Recuperator}

The recuperator is a highly effective heat exchanger which increases the efficiency of the overall cycle by preheating the HSA inlet gas thus reducing the amount of waste heat. The Reference Design recuperator has an effectiveness of 0.96 and weighs about 46 pounds.

The recuperator, shown in Figure 2-7, consists of layers of heat transfer fins separated by plates to form a series of counterflow passages. Haynes188 construction allows the recuperator to operate at $1450^{\circ} \mathrm{F}$ with less than 1 percent creep during the 5 year mission. The double containment feature of the recuperator design ensures retention of the working fluid over the 5 year mission.

\section{$\underline{\text { Radiator }}$}

The radiator is designed to reject the waste heat from the system and support the MB-ERTG during launch. Aluminum is the material of selection due to its low cost, multiple sources of procurement, high modulus to density ratio and excellent thermal conductivity. Reference Design radiator weight, including a radiation hardened coating, is 47 pounds; heat rejection area is $48 \mathrm{ft}$. 2. An illustration of a radiator panel using the offset fin-tube concept is provided in Figure 2-8. Coolant flow passages are offset from the heat rejection surface to provide micrometeoroid protection in a weight effective manner. The radiator in the Reference System is designed for a 0.99 probability of no puncture over the 5 year, synchronous orbit mission. This design accounts for a 2 percent increase in the radiator coating absorptivity during the mission. No other system degradation mode has been identified. 


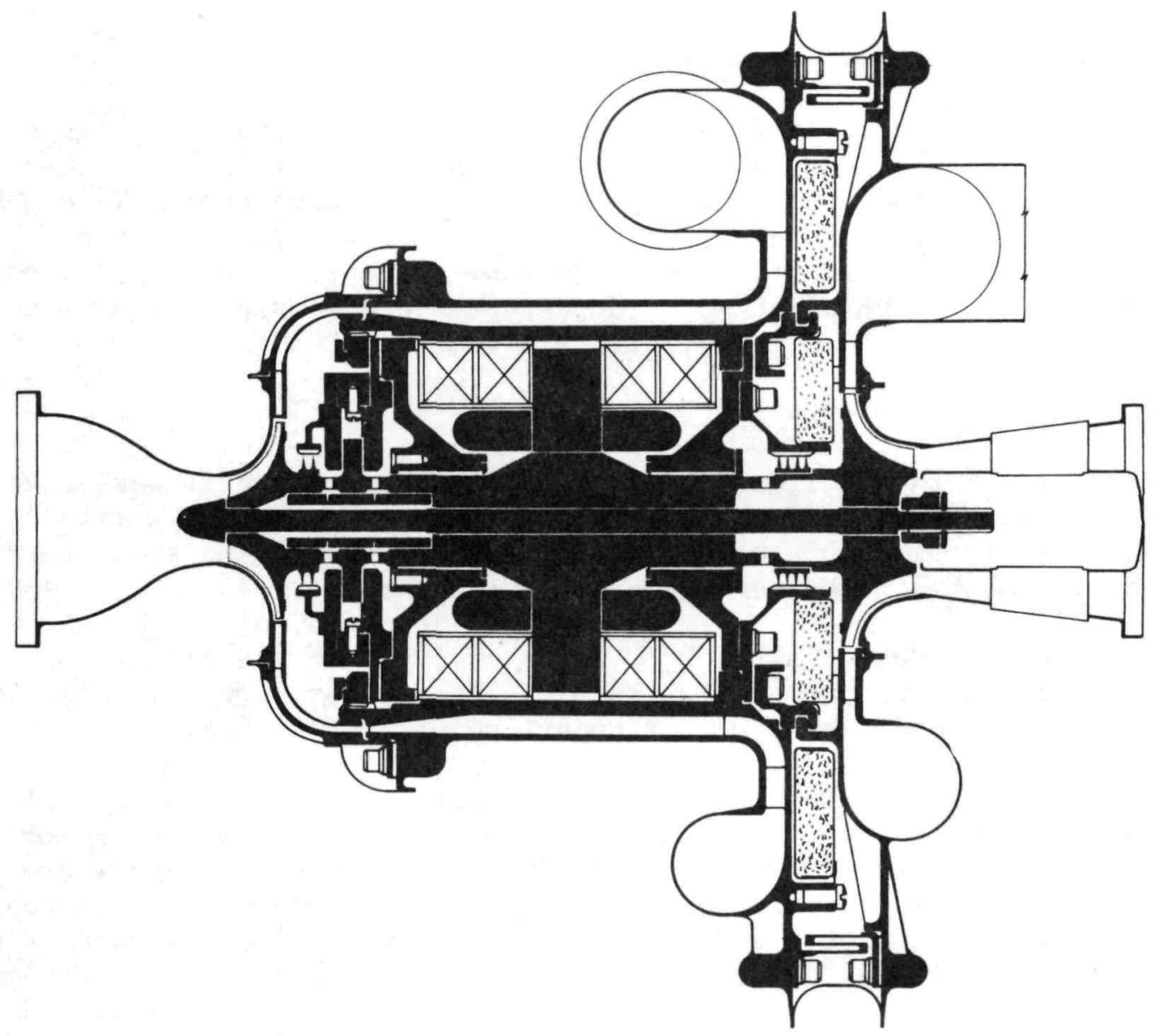

Figure 2-6 MB-ERTG Flexible BRU
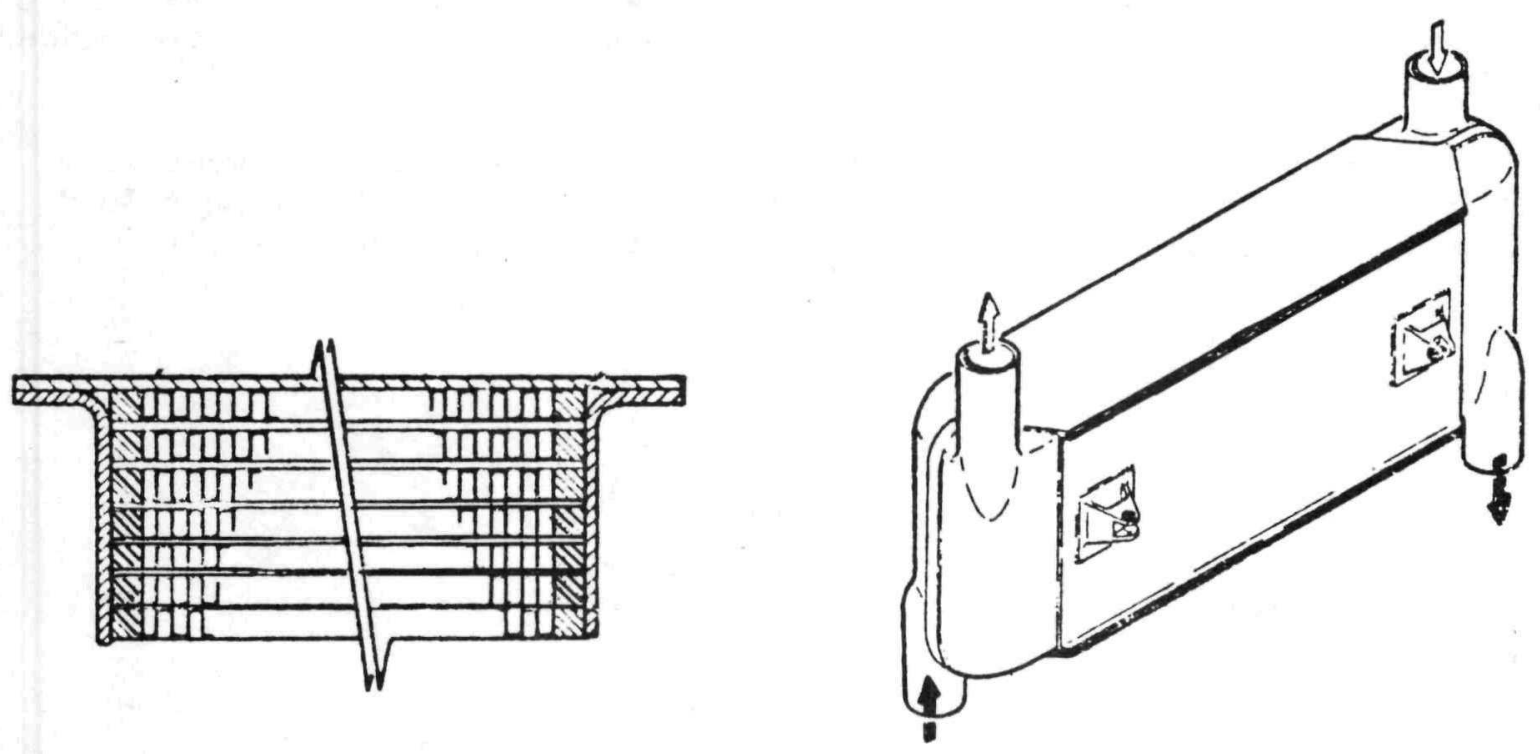

Figure 2-7 MB-ERTG Recuperator 


\subsection{NUCLEAR SAFETY}

A preliminary investigation was conducted for the Reference Design heat source based on the IES $8 / 9$ Mission. The results of this preliminary assessment indicates that the ceramic clad heat source design is capable of meeting the AEC Nuclear $\mathbb{S}$ afety Criteria. In addition, the high efficiency of the MB-ERTG minimizes the fuel inventory required, reducing the potential radiation hazard. Detailed work in the areas of re-entry performance, impact capability and long term compatibility effects is required.

\subsection{SPACECRAFT INTEGRATION}

Four aspects of integrating the MB-ERTG with the spacecraft were investigated: shielding requirements, dynamic interaction with the attitude control system, structural requirements and thermal leaks into the spacecraft. No integration problems were encountered in these areas.

The USAF neutron dose limit, $10^{12}$ nvt over 5 years, was met with a $10 \mathrm{~cm}$ thick, 14 pound, lithium hydride shield. Total system weight including the shield is 200 pounds, or 5 pounds under the USAF objective.

An evaluation of the MB-ERTG dynamic interaction with the spacecraft indicates that the attitude control system can accommodate the minor torques imposed upon the spacecraft by the MB-ERTG. By proper integration of the MB-ERTG the dynamic interaction can be completely eliminated. Steady state dynamic effects between the MB-ERTG and spacecraft are eliminated by orienting the rotor axis of the BRU perpendicular to the orbital plane. Previous hardware experience has shown that BRU rotor speed variations are less than 1 percent in 0.2 seconds; this will not cause any disturbing torques on the spacecraft (See Section 7.1).

The MB-ERTG design includes 17 pounds of structure which support the various components during launch. The HSA, shield and recuperator/BRU are each supported independently in order to alleviate any thermal stresses induced during system start-up.

Higher temperature components have been placed away from the spacecraft interface and are we 11 insulated to reduce heat leaks. Assuming a $70^{\circ} \mathrm{F}$ spacecraft, the heat input to the spacecraft is below 100 Watts. 


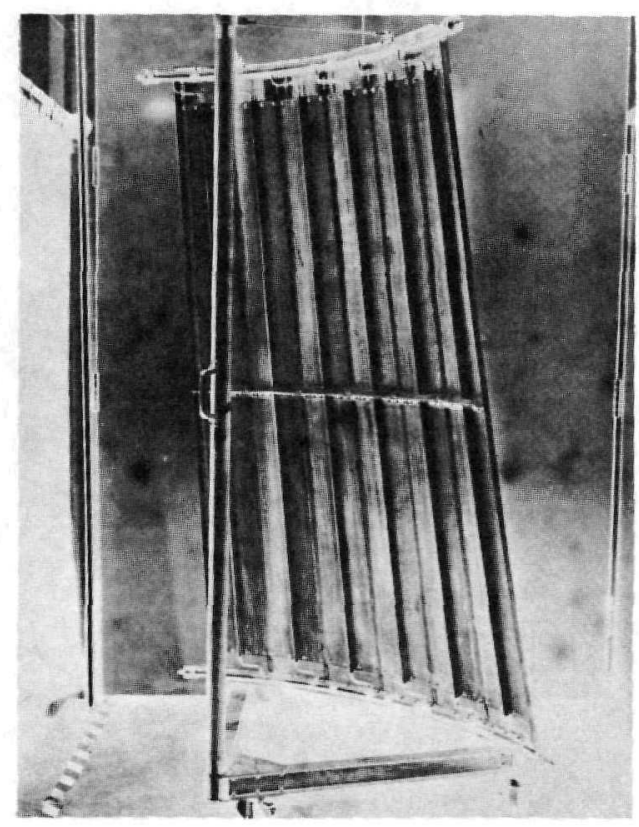

Figure 2-8 Radiator Panel Using Offset Fin-Tube Geometry 
SECTION 3.0

DESIGN REQUIREMENTS AND APPROACH

This section describes the design requirements and approach utilized in determining the Reference Design. Ground rules for the design were formulated by the USAF System Performance Objectives and the AEC Nuclear Safety Criteria. In addition, the SURVSATCOM Mission was assumed to be similar to DOD's LES 8 and LES 9 Mission with regard to launch vehicle, ascent trajectory and final orbit.

One of the main considerations in developing the Reference Design was to identify a design with low unit and development costs. This approach is outlined in Section 3.2. The approach used in the MB-ERTG Reference Design was to allow flexibility with regard to power level and fuel selection in order to assure low development costs. These aspects of the system are discussed below and in Section 4.0.

\subsection{GROUND RULES AND ASSUMPTIONS}

The ground rules used in this study are the USAF System Performance Objectives and AEC Nuclear Safety Criteria. These criteria are presented below.

A key assumption made during the study was to design the MB-ERTG system to accommodate either a plutonia or curia fueled heat source assembly (HSA). This assumption resulted from the uncertainty concerning the availability of $\mathrm{Cm}-244$. Therefore, the HSA concept was designed to utilize either a Pu-238 or $\mathrm{Cm}-244$ heat source. The interchangeability feature provided flexibility to the basic development program without incurring redundant or parallel efforts.

\subsubsection{USAF SYSTEM PERFORMANCE OBJECTIVES}

The USAF System Performance Objectives (USAF-SPO), shown in Table 1-1, were the main requirements and groundrules for the study. All system designs were determined primarily on the basis of the weight, envelope and cost limitations listed in the USAF-SPO.

\subsubsection{USAEC/SNS NUCLEAR SAFETY CRITERIA}

The USAEC/SNS Nuclear Safety Criteria is 1isted in Table 3-1. This criteria is directed towards maximizing the probability of radioisotope containment under normal and accident or abort conditions. The approach utilized in the design, ground handling, and testing of the heat source reflects the need for developing a cost effective system which meets the safety criteria.

\subsubsection{REFERENCE MISSION}

The SURVSATCOM Mission, for purposes of the MB-ERTG design and safety assessment, is assumed in this study to be similar to DOD's LES 8 and LES 9 missions with regard to launch vehicle, ascent trajectory, and final orbit. 


\begin{tabular}{|c|c|c|c|}
\hline \multirow[t]{2}{*}{ I. } & \multicolumn{3}{|l|}{ PURPOSE } \\
\hline & \multicolumn{3}{|c|}{$\begin{array}{l}\text { The purpose of these nuclear safety criteria is to provide guddance for contractor design studies and research and development activities in } \\
\text { support of economic radiolsotope power systems to be used on operational apaeecraft. }\end{array}$} \\
\hline II. & \multicolumn{3}{|l|}{ GENERAL SAFETY DESIGN OBJECTIVES } \\
\hline & \multirow{2}{*}{\multicolumn{3}{|c|}{ 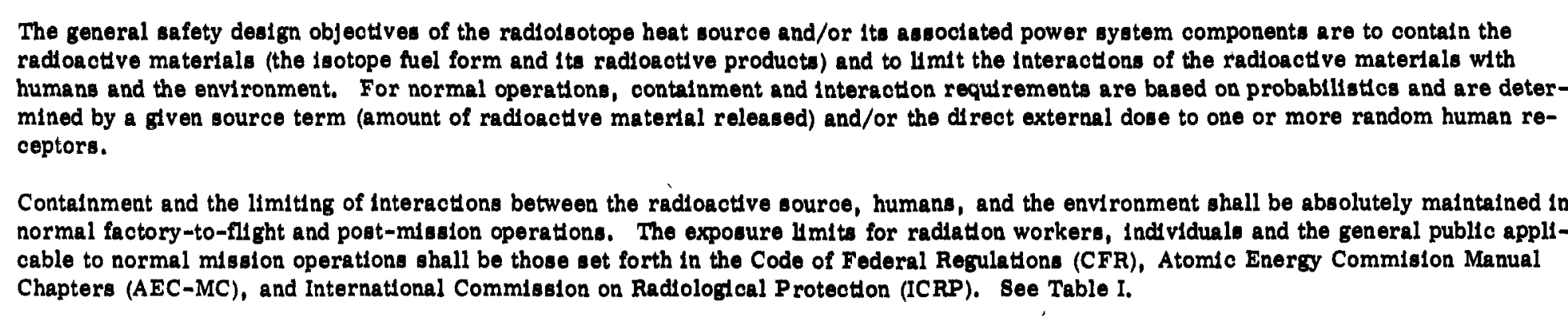 }} \\
\hline & & & \\
\hline \multicolumn{4}{|c|}{ Table I. Normal Mission Operattons Exposure Limita } \\
\hline & \multicolumn{3}{|l|}{ Indlviduals in Controlled Areas: } \\
\hline & Types of Exposure & Condition & Dose $(\mathrm{rem})$ \\
\hline & $\begin{array}{l}\text { Whole body, head and trunk, active blood-forming } \\
\text { organs, gonads, or lens of eye }\end{array}$ & $\begin{array}{l}\text { Accumulated dose } \\
\text { Calendar quarter }\end{array}$ & $\begin{array}{c}5(N-18)^{*} \\
3\end{array}$ \\
\hline & Skdn, thyroid, and bone & $\begin{array}{l}\text { Year } \\
\text { Calendar Quarter }\end{array}$ & $\begin{array}{l}30 \\
10\end{array}$ \\
\hline & Hands and forearms, feet and ankles & $\begin{array}{l}\text { Year } \\
\text { Calendar Quarter }\end{array}$ & $\begin{array}{l}75 \\
25\end{array}$ \\
\hline & Other organs & $\begin{array}{l}\text { Year } \\
\text { Calendar Quarter }\end{array}$ & $\begin{array}{r}15 \\
5\end{array}$ \\
\hline & \multirow{2}{*}{\multicolumn{3}{|c|}{$\begin{array}{l}\text { *Where N equals age in years at next birthday. } \\
\text { Individuals in Uncontrolled Areas: }\end{array}$}} \\
\hline & & & \\
\hline & Type of Exposure & $\begin{array}{l}\text { Annual dose (n } \mathrm{rem} \text { ) to crittical individuals } \\
\text { at points of maximum probable exposure }\end{array}$ & $\begin{array}{l}\text { Average annual dose (In rem to a sutt- } \\
\text { able sample of the exposed population }\end{array}$ \\
\hline & Whole body, gonads, or bone marrow & 0.5 & 0.17 \\
\hline & Other organs & 1.5 & 0.5 \\
\hline
\end{tabular}

In the event of random earth impact situations, the objective is to locate and recover or cause location and recovery of the heat source(s). Table II summarizes exposure 1 mits applicable to accident cases. For accident cases, the duration of the external dose period shall be the
time to discover, locate, or recover the fuel and the reference distance between the source and receptor shall be ten meters.

$$
\text { Table II. Acoldent Case Exposure Limits }
$$

External dose to whole body of Individuals in the population 5 rem/year*

Internal dose to lung, bone, liver or any critical organ of individuals in the population $\quad 15 \mathrm{rem} / \mathrm{year}$
*The duration of the external dose period shall be the time to discover, locate, or recover the fuel and the reference distance shall be ten
meters.

III. DEFINITIONS

Contalnment is defined as the retention of the radioactive material within one or more integral barriers of the heat source.

Limiting the interaction is defined as maintaining the exposure of humans both internal and external radiation doses from the fuel at or below

rv. The safety design criteria are first generalized and then criterla applicable to specifle mission phases are identified.

A. General Criteria

1. Duration of Containment

The heat source shall be designed to satisfy the containment requirement for ten half-lives of the fuel under normal sttuations.

2. Accident Condition Exposure Limits

For accident situation, it is permissible to use the probabilistic criteria identied below,

a. The total probabllity of releasing one millicurle of fuel and/or its daughter products or exposing one or more people to a direct external radiation dose exceeding the limits of Table II shall be less than $10^{-5}$ per flight, given the occurence of any accident. For source terms other than one millicurle, scaling the fuel release probability inversely-proportional to the source term shall be considered.

b. The probabilistic criteria of paragraph a. above shall be demonstrated at a reasonable confidence level ( $250 \%)$ by analysis and/or test.

3. Quality Control and Reliability

Heat sources shall be interchangeable so that test data will be applicable to all flight units and so heat source exchange can be accomplished up until the time of launch, if necessary.

The ability to verify containment, by means such as nondestructive testing of the heat source, shall be avallable untll the time of launch.

4. Criticality

Subcriticality of the fuel under all normal and accident conditions shall be assured.

B. Mission Phase Criteris

The specific criteria listed in the succeeding section shall be considered supplementary to the general criteria of Paragraph A. above.

1. Ground Handling, Transportation and Preflight Testing

All procedures shall be compatible with the radiation exposure limits set forth in AEC-MC-0524 and summarized in Table I. For hipping and handling the RTG or heat source, the shipping container must satisfy the requi rements of the Atomic Energy Commis ion, as set forth in ACE-MC-0529, and the Department of Transportation, as applicable, for any potential shipping modes.

The heat source shall be designed to satisfy the requirement of fuel contalnment during all ground handling, transportation and preflight testing operations. The accumulation of radioactive gases shall be compatible with the limits set forth in AEC-MC-0524.

2. Prelaunch and Launch

All prelaunch procedures shall be compattble with the radiation exposure limits summarized in Table I. For all potential prelaunch and launch single or sequential abort environmients (e.g., overpressure and Impulse, freball, shrapnel, impact, afterfire and total fuel release probability is consistent with that identified in Paragraph IV. A. 2. The heat source shall be designed to sattsfy those requirements until recovery is completed.

3. Suborbital

For normal operattion and all potential single or sequential suborbital or ascent aborts and their consequences, the heat source Paragraph IV A. A that the fuel release probability and external radiation exposure are consistent with those limits identified the fuel is burled and for water depths up to 600 feet. For those conditions which place the heat source in water at depths where recovery is not possible, the heat source shall be designed to contain the fuel for at least ten half-lives.

4. Orbital and Superorbital

During normal operation, the heat source shall be designed to satisfy the requirement of containing the fuel for ten half-lives in rder to facilitate potential space recovery. For those conditions which place the heat sourcel not possible, the heat source shall be designed to contain the fuel for at least ten half-lives.

For all potential single or sequential orbital and superorbital aborts and their consequences, the heat source shall be designed such that the fuel release probability and external radiation exposure are consistent with those limits identified in Paragraph IV. A. 2.
The heat source for water depths up to 600 feet. 
Blank Page 


\subsubsection{REFERENCE MISSION (continued)}

The spacecraft will be launched with one MB-ERTG by a Titan IIIC booster. The spacecraft will be placed in a $19,380 \mathrm{~nm}$ circular orbit inclined at 23.5 degrees. The launch is from ETR at an azimuth of 93 degrees from North. The spacecraft will first be placed into an 80 by $300 \mathrm{~nm}$ elliptical parking orbit inclined at 28.5 degrees and then transferred to the final orbit by a Hohmann transfer. A slight correction in orbit inclination will be made at apogee, just before circularization.

A simplified illustration of the sequence of events is shown in Figure 3-1. A ground trace of the instantaneous impact points for a launch from Cape Kennedy is shown in Figure 3-2.

The reference mission is divided into six distinct phases which cover all mission-related operations beginning with the ground handling and transit of the nuclear heat sources and ending with the successful attainment of orbit. Each phase is defined to include significant events in the mission.

\subsubsection{Phase 1 - Ground Handling and Transit}

This phase of the Mission begins with transportation of the heat source from the Oak Ridge National Laboratory to the launch facility and delivery of the power conversion system (PCS) to the launch facility by the systems contractor. A preliminary mating of the heat source with the PCS occurs in the MB-ERTG fueling facility to ensure compatibility.

\subsubsection{Phase 2-Prelaunch}

This covers the period of installation of the PCS on the spacecraft atop the launch vehicle on the launch pad. The heat source is then installed in the PCS by a remotely handled transfer assembly at the launch pad.

\subsubsection{Phase 3 - Launch}

This covers the period from ignition of the solid rocket motors and the point in time at which vehicle impact points reach the Cape Kennedy shoreline. The inclusive period is about 22 seconds. This phase was elected to include a11 launch aborts where the vehicle or its debris may fall onto the land area adjacent to the launch site.

\subsubsection{Phase 4 - Ascent}

This phase of the mission commences approximately 22 seconds after 1ift-off and ends at insertion of the spacecraft into the 80 by $300 \mathrm{~nm}$ parking orbit.

\section{Subphase 4A, Stage 0 Boost}

The Stage 0 solid rocket motors (SRM's) provide the initial thrust to lift the payload from the launch pad. These rockets will fire for approximately 121 seconds, at the end of which time the SRM is jettisoned. During this phase, booster and debris impact points occur in the ocean. 


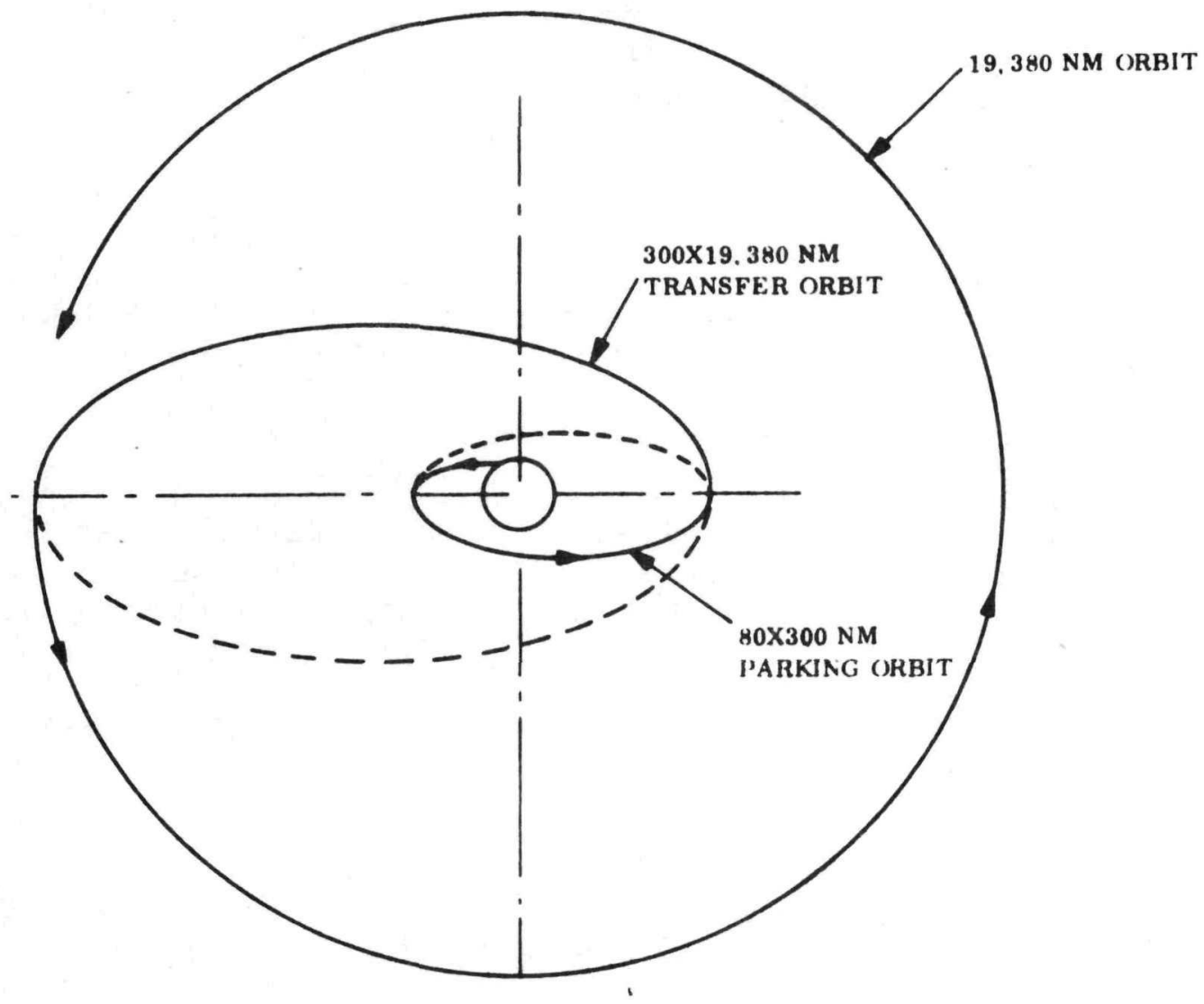

Figure 3-1. Launch Trajectories

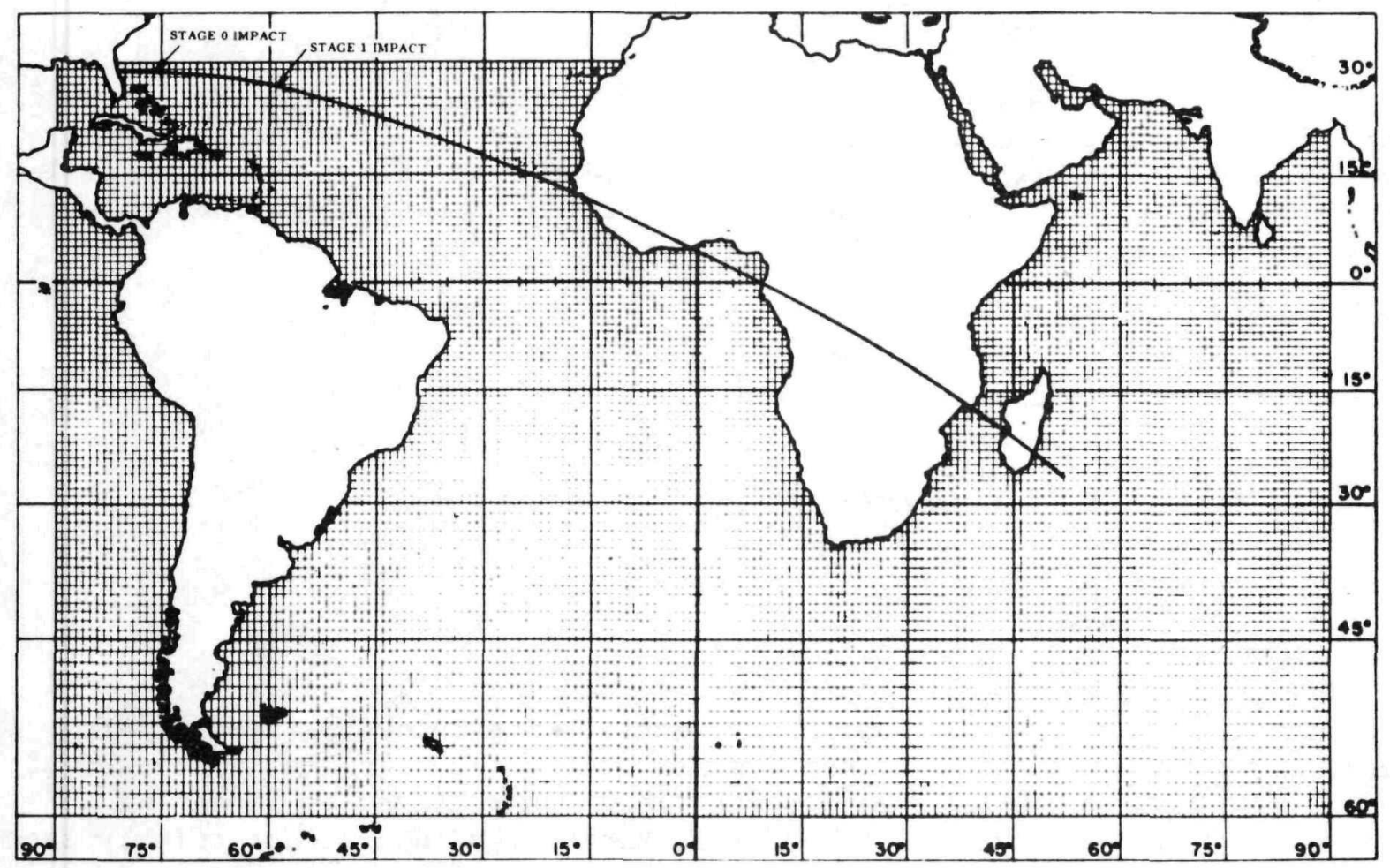

Figure 3-2. Reference Ascent Ground Trace of IIP's For a Cape Kennedy Launch 


\subsubsection{Phase 4-Ascent (continued)}

\section{Subphase 4B, Stage I Boost}

The Titan IIIC Stage I begins to thrust 12 seconds before SRM jettison. It provides a 137 second steady-state burn and then begins to tail-off. Stage I is jettisoned at about 258 seconds into the mission. During this phase, booster and debris impact points occur in deep ocean.

Subphase 4C, Stage II Boost

Stage II boost places the spacecraft into a 28.5 degree 80 by $300 \mathrm{~nm}$ parking orbit. Stage II burn time is about 208 seconds; engine cut-off occurs approximately 466 seconds into the mission, and injection into the parking orbit occurs at approximately 482 seconds. Stage II separation occurs prior to injection. During this subphase, the flight fairing is jettisoned into the ocean at approximately 270 seconds into the mission. Potential impact points for this subphase include the continent of Africa as well as deep ocean (See Figure 3-2).

\subsubsection{Phase 5 - Parking Orbit}

The transtage/spacecraft will coast in the parking orbit until optimum conditions exist for the orbit transfer maneuver (second equatorial crossing). Total time in the parking orbit will be about 849 seconds ( 14 minutes). During this period the MB-ERTG will be started up.

\subsubsection{Phase 6 - Orbit Transfer}

This phase begins with the first burn of the transtage at about 1331 seconds. Burn duration is 320 seconds, and the spacecraft is placed in an elliptical transfer orbit. At apogee $(19,380 \mathrm{~nm})$, a second burn of the transtage will simultaneously circularize the orbit at $19,380 \mathrm{~nm}$ and adjust to the proper orbit inclination.

\subsection{STUDY APPROACH}

This program was divided into 5 tasks:

- Conceptual Design

- Technology Assessment

- Parametric Analyses

o Reference Design

- Development Plan

The interrelationship between these tasks is shown in Figure 3-3. The conceptual design and technology assessment tasks provided a first order estimate of the 400 We MB-ERTG performance characteristics and an assessment of the potential to improve the design. This was achieved by designing a system with components based on available technology in order to quickly assess the difficulty of meeting the USAF-SPO. The technology assessment task reviewed the technology incorporated in the conceptual design to determine 


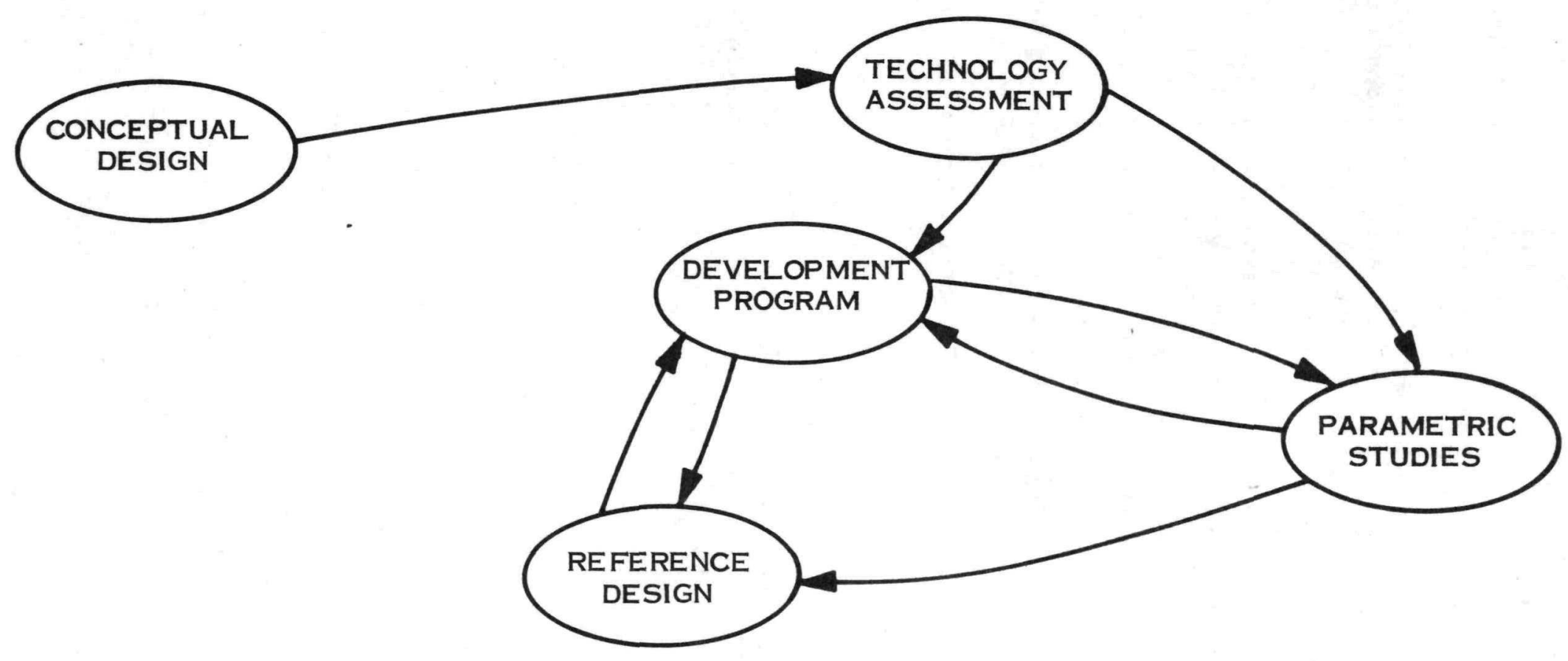




\subsection{STUDY APPROACH (continued)}

whether new or different technologies had the potential to improve the safety, weight or cost of the MB-ERTG at the 400 We level.

The three remaining tasks were performed in a parallel manner so as to produce a Reference Design which considered the effects of development and unit cost related factors as well as the USAF-SPO and AEC Nuclear Safety Criteria on the Reference Design.

The Parametric Analysis task quantitatively assessed the impact of introducing new technologies into the Conceptual Design. Included in this assessment was the effect on the development and unit costs. Typically a new technology would increase the program development costs while decreasing the MB-ERTG production unit costs; this cost trade-off was a major factor in the design selection process.

Therefore, the design of the Reference System was an iterative process resulting from the cost effectiveness objectives of the study.

The next two sections describe the results of the Conceptual Design and Technology Assessment tasks which formed the groundwork for the selection of the Reference Design.

\subsubsection{CONCEPTUAL DESIGN}

This section describes the cycle and component characteristics of the MB-ERTG Conceptual Design which was used as a means of characterizing a 400 We radioisotope Brayton power System. The design approach was to utilize technologies and, if possible, presently available component design concepts identified in previous programs.

Assumptions concerning the cycle conditions and component designs are listed below:

- Heat Source

- Multi-Hundred Watt (MHW) heat source concept. (See Figure 3-4).

- Heat Source Heat Exchanger (HSHX)

- Nb 103 construction

- cylindrical geometry, annular, finned flow passages.

- Insulation

- high temperature multi foil insulation

- 8 percent heat loss from HSA. 
- Emergency Cooling System

- variable conductance heat pipes.

- Mini-BRU

- $1600^{\circ} \mathrm{F}$ turbine inlet temperature

- single shaft turbine, Rice alternator and compressor supported on foil bearings.

\section{- Recuperator}

- Hastelloy X construction

- fin/plate counterflow design

- Radiator

- aluminum construction

- cylindrical design, offset fin/tube geometry

- sink temperature, $-70^{\circ} \mathrm{F}$

- micrometeoroid environment, NASA SP-8013

- probability of micrometeoroid survival, 0.99.

Cooling of the alternator was assumed to be accomplished by flowing the compressor discharge over the exterior of the alternator stator.

Bearings losses were calculated on the basis of the cavity pressure as shown in Figure 3-5. The curve in Figure 3-5 has the same slope as that defined for the $2 \mathrm{kWe}$ Mini-BRU studies. In order to compensate for the 400 We Mini-BRU characteristics the curve has been shifted to pass through the 60 watts at the 12 psia point.

\subsubsection{MB-ERTG Cycle Analysis and Design}

An envelope of system weight as a function of net cycle efficiency was defined by the Brayton Cycle Design computer code using the ranges of critical parameters listed below:

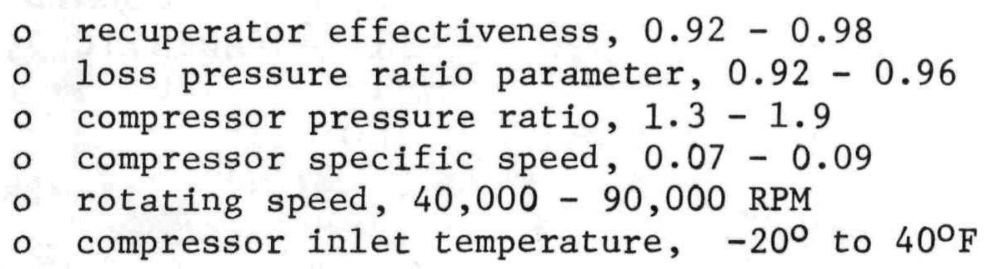




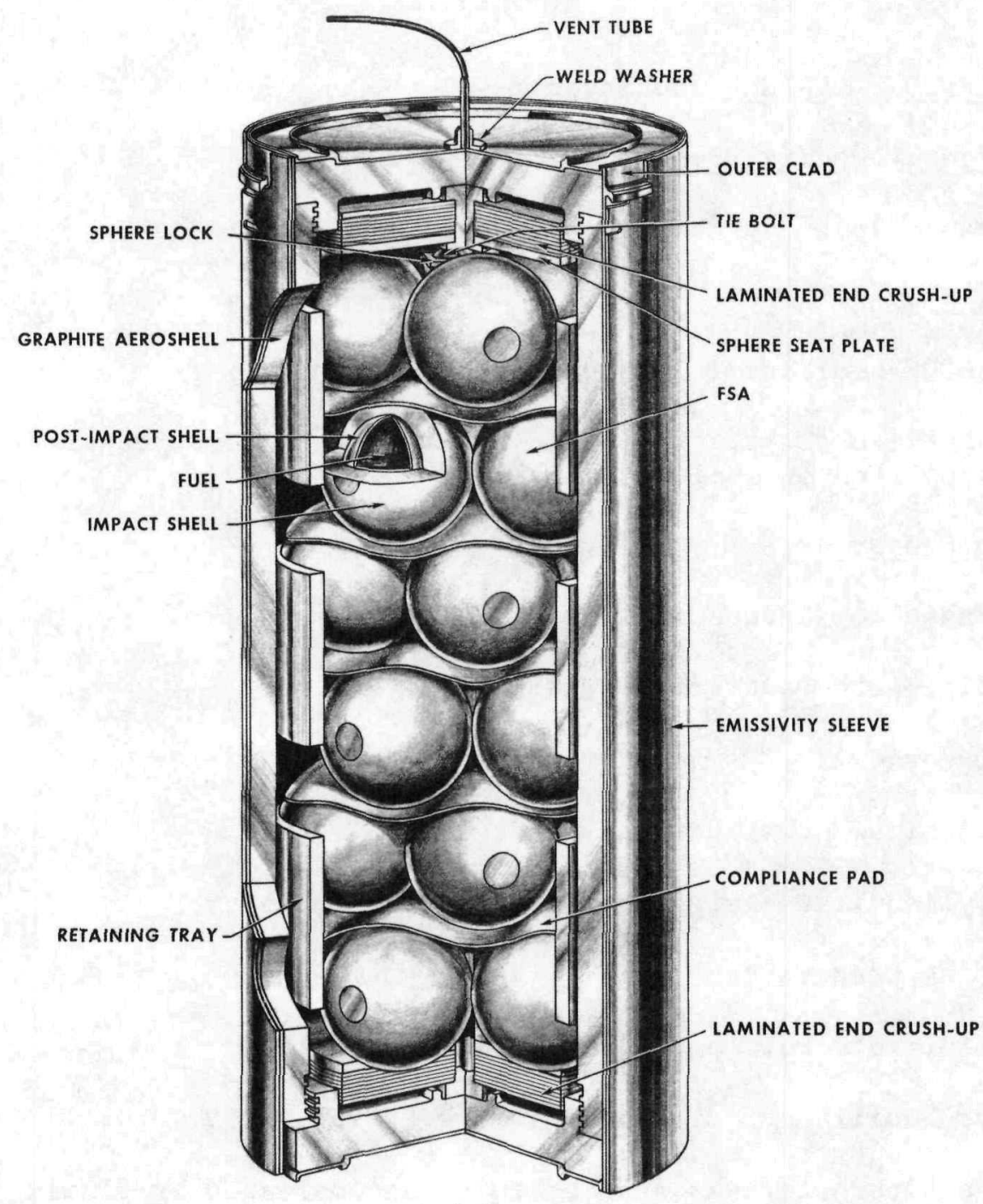

Figure 3-4. Multi-Hundred Watt Heat Source

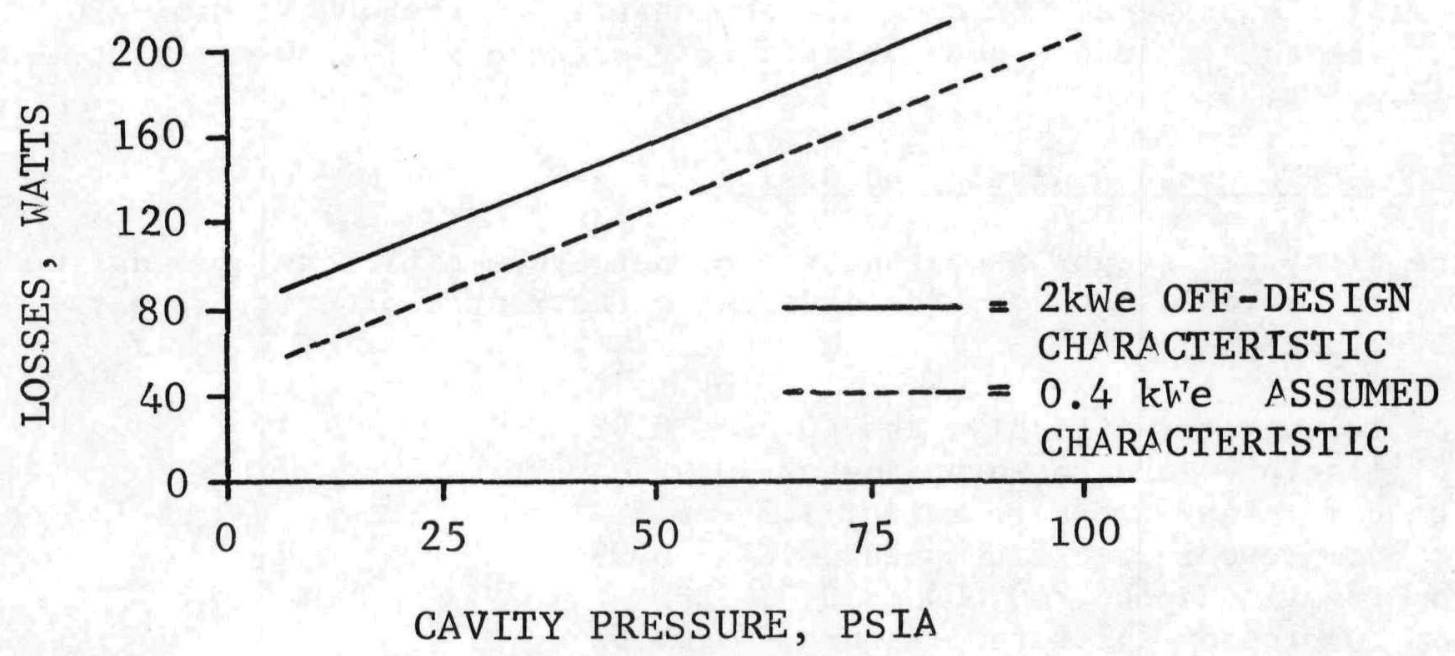

Figure 3-5. Foil Bearing Loss Estimate 


\subsubsection{MB-ERTG Cycle Analysis and Design (continued)}

Results obtained by this investigation are shown in the "shotgun plot" in Figure 3-6 where the hundreds of cycle designs generated are placed on a plot of specific weight versus net cycle efficiency.

The design point selected has an efficiency of 22 percent and a specific weight of 0.5 . This point was selected because it lay on the line formed by the locus of minimum weight systems and utilized a 1.6 inch diameter compressor wheel. Systems having lower weight required smaller compressor wheels whose fabricability had not been demonstrated.

The thermodynamic cycle conditions of the Conceptual Design are shown in Figure 3-7. These conditions are similar to those established for the Brayton system in past programs conducted by NASA-Lewis. Two parameters which show the greatest change from previous cycle optimizations are the compressor inlet temperature, $20^{\circ} \mathrm{F}$ and the mini-BRU speed, 80,000 RPM. The relatively low compressor inlet temperature results from the low sink temperature available in synchronous orbit. A higher RPM reflects the need to maintain a reasonable specific speed at the low flow rates inherent in the 400 We system. The combination of high speed, low pressure ratio and lower specific speeds provides a relatively high pressure system which minimizes the weight of the radiator and recuperator.

Summaries of the Conceptual Design MB-ERTG design conditions and weight are shown in Tables $3-2$ and 3-3, respectively. 
Table 3-2. Summary of Conceptual Design Conditions

Gross thermal power, w $(\mathrm{Pu} / \mathrm{Cm})$ $1890 / 2150$

Net electrical power, w 400

Cycle efficiency, percent

Net system efficiency, percent

Turbine inlet temperature, ${ }^{\circ} \mathrm{F}$ 1600

Compressor inlet temperature, ${ }^{\circ} \mathrm{F}$ 20

Turbine efficiency, percent 77

Turbine specific speed 0.062

Compressor efficiency, percent 72

Compressor specific speed 0.080

Compressor B width, inches

0.060

Compressor pressure ratio

1.6

Rotational speed, RPM 80,000

Total bearing losses, w 82

Loss pressure ratio 0.97

Alternator efficiency

0.88

Working fluid $\mathrm{He} / \mathrm{Xe}$

Molecular Weight 83.8

Flow rate, $1 \mathrm{~b} / \mathrm{sec}$ 0.090

Recuperator effectiveness 0.96

Radiator area, $\mathrm{ft}^{2}$ 55

Radiator fin thickness, inches

0.020

Tube inside diameter, inches

0.32 
Table 3.3 Conceptual Design Weight Summary

Heat Source Assembly

Combined Rotating Unit

Recuperator

Radiator

47

Electronics

10

Structural

10

Ducting

5

Insulation

Parasitic Load Resistor

Total System Weight

194 1bs 


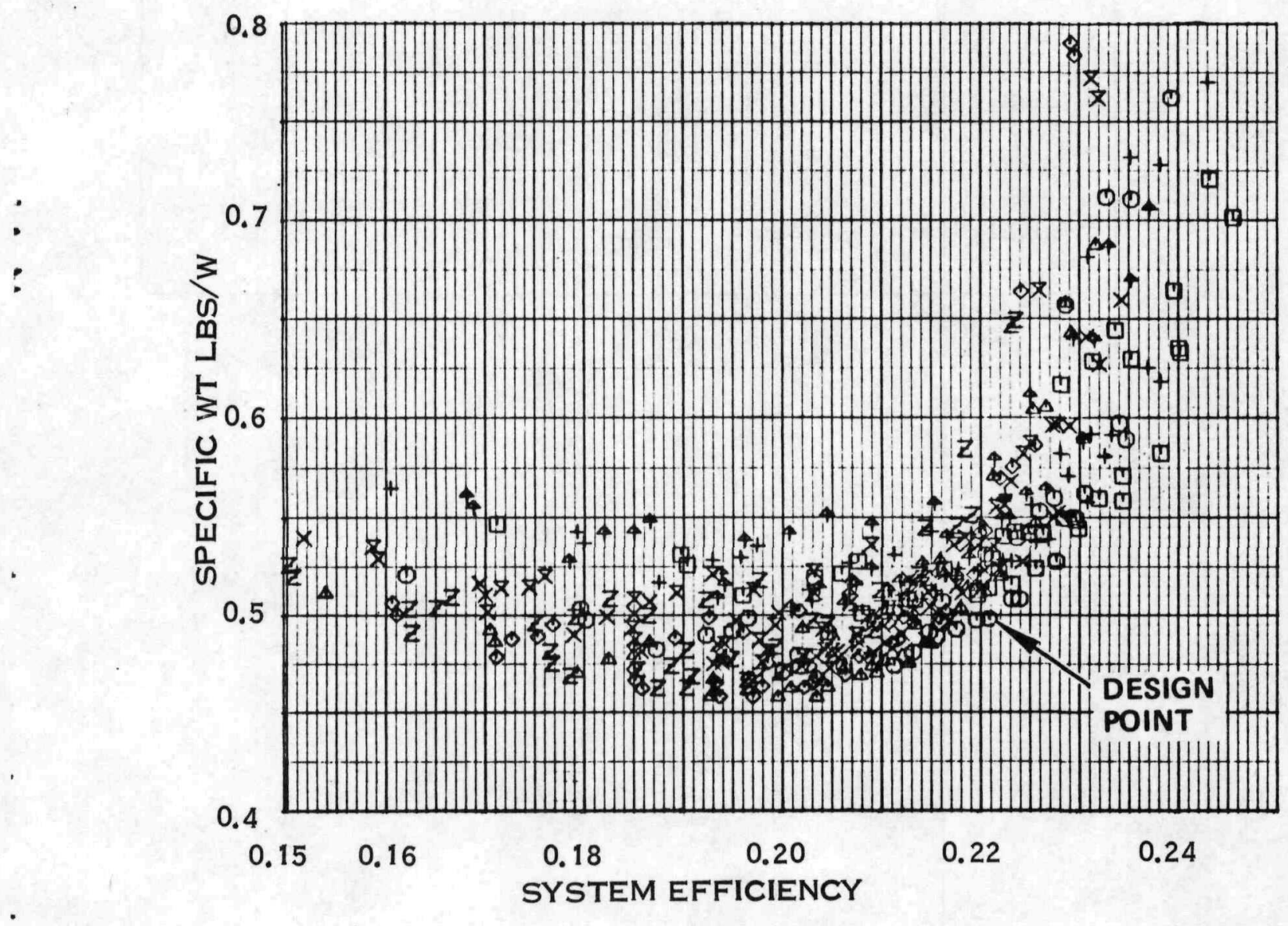

Figure 3-6. Conceptual Design Selection,

MB-ERTG Specific Weight Versus Efficiency 


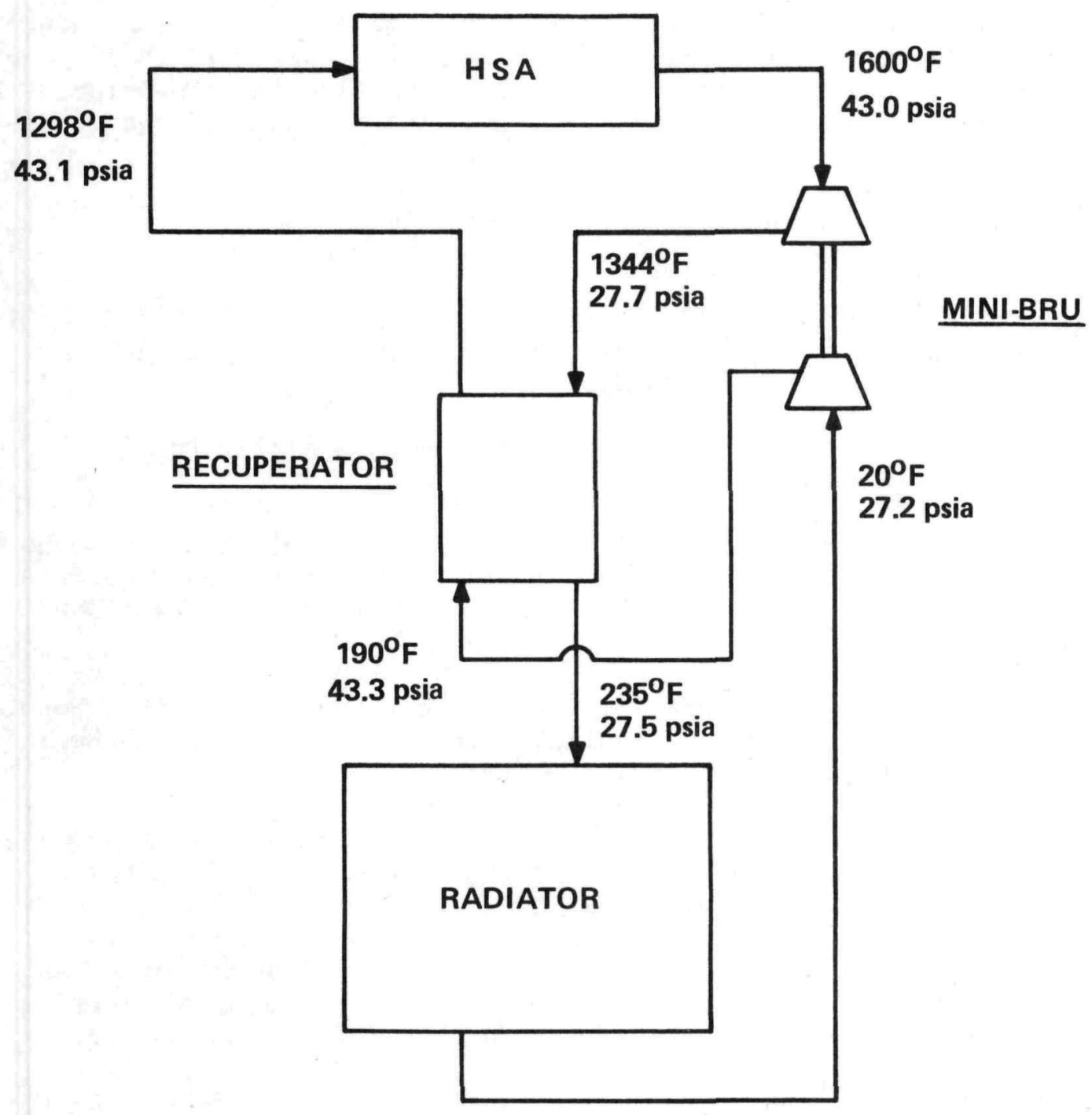

FLUID: $\mathrm{He} / \mathrm{Xe}(\mathrm{MW}=83.8)$

FLOW RATE: 0.09 LB/SEC

Figure 3-7. MB-ERTG Conceptual Design Cycle Conditions 


\subsubsection{Component Characteristics}

This section describes the components used in the MB-ERTG Conceptual Design. Heat Source

In order to provide a $1600^{\circ} \mathrm{F}$ turbine inlet temperature, a high temperature heat source is required. The Multi-Hundred Watt heat source which is under development by the AEC is compatible with the MB-ERTG design conditions. For the following reasons a version of the MHW heat source was utilized in developing the initial conceptual MB-ERTG design:

o The MHW Heat Source technology afforded an efficient means of estimating a heat source weight for the MB-ERTG System.

- A heat source utilizing the MHW Heat Source technology and meeting the safety and operational requirements of this program can be designed for the MB-ERTG System.

o The MHW Heat Source can be designed to accommodate either Pu-238 or a diluted $\mathrm{Cm}-244$ fuel.

The MHW heat source shown in Figure 3-4 consists of 24-100 watt Fuel Sphere Assemblies (FSA), which provide individual impact and post-impact containment. For the 400 We MB-ERTG the following changes to the MHW Heat Source were assumed:

o The number of FSA's was reduced from 24-100 watt spheres to 16 . For the Conceptual Design the fuel loading would be 118 and 134 watts per sphere for $\mathrm{Pu} \mathrm{O}_{2}$ and $\mathrm{Cm}_{2} \mathrm{O}_{3}$ fuels, respectively.

o The 8-pack subassembly used during the FSA loading procedure was eliminated since recent experience has shown it to be unnecessary. This change results in a 2 pound weight reduction.

o The outer iridium clad was eliminated for this application since its previous functions can be adequately performed by the heat source heat exchanger. A 7 pound weight reduction resulted from this design change.

The design changes listed above decreased the dimensions of the MHW heat source from a length of 16.68 to 12.12 inches and a diameter of 7.19 to 6.82 inches. The weight of the altered MHW heat source unit is estimated to be 26 pounds.

A thorough safety analysis of this modified MHW heat source is inappropriate for this portion of the study, however, from a qualitative standpoint the same level of safety associated with the MHW heat source design can be expected. In fact, since the ballistic coefficient of the heat source has been lowered from 41.4 to 34.9 and the MHW aeroshell and end crush-up thicknesses have been retained, a greater margin of reentry and impact safety can be accorded the modified design. As a result of previous work performed at General Electric the change in L/D from 2.32 to 1.77 is not expected to perturb the side-onstable reentry mode of the MHW heat source. 
Heat Source Heat Exchanger

The heat source heat exchanger (HSHX) transfers heat from the heat source to the He/Xe working fluid. Therefore, the basic requirement of the HSHX is to provide adequate heat transfer capability such that the fluid enters the turbine at the proper temperature. In addition, the HSHX must be designed to:

- Contain the He/Xe for a 5-year period

- Minimize the fluid pressure drop

- Allow for uniform fluid flow distribution

- Minimize heat losses from the HSA

- Minimize the overall weight of the HSA

The HSHX can be designed to accept heat from the isotope heat source by radiation across a gas filled gap, radiation across a vacuum, by direct conduction or through a contact conductance. Another possibility is for the working fluid to flow directly over the heat source surface and thus remove heat by direct convection. One of the attempts in this study is to minimize the heat source temperatures so as to reduce the potential for material compatibility problems. Therefore, radiation heat transfer was considered less attractive than the other modes available. The remaining approaches offer the opportunity to effectively transfer energy without incurring large temperature drops between the heat source and gas.

A conceptual illustration of the HSA showing the HSHX design is provided in Figure 3-8.

Insertion of the heat source into the heat exchanger is accomplished by placing a subcooled heat source into a heated HSHX, resulting in an interference fit at operational conditions. A Vac-Hyde coating on the niobium heat exchanger eliminates any compatibility problems between the heat source POCO graphite aeroshe11 and the niobium.

A compressive end fitting ensures that the heat source is maintained against the rear of the HSHX and eliminates any destructive vibrations which might otherwise occur during launch. The following HSHX design values were estimated to provide adequate heat transfer, pressure drop and structural

characteristics.

\author{
Outer Can Thickness \\ Inner Can Thickness \\ Fin Thickness \\ Fin Height \\ Channel Width
}
0.060 inches
0.015 inches
0.007 inches
0.250 inches
0.250 inches

The weight of the HSHX including manifolding was calculated to be approximately 20 pounds.

\section{Emergency Cooling System}

In the event that heat cannot be rejected from the MB-ERTG system the HSA will overtemperature. This condition could result in fuel release due to melting 


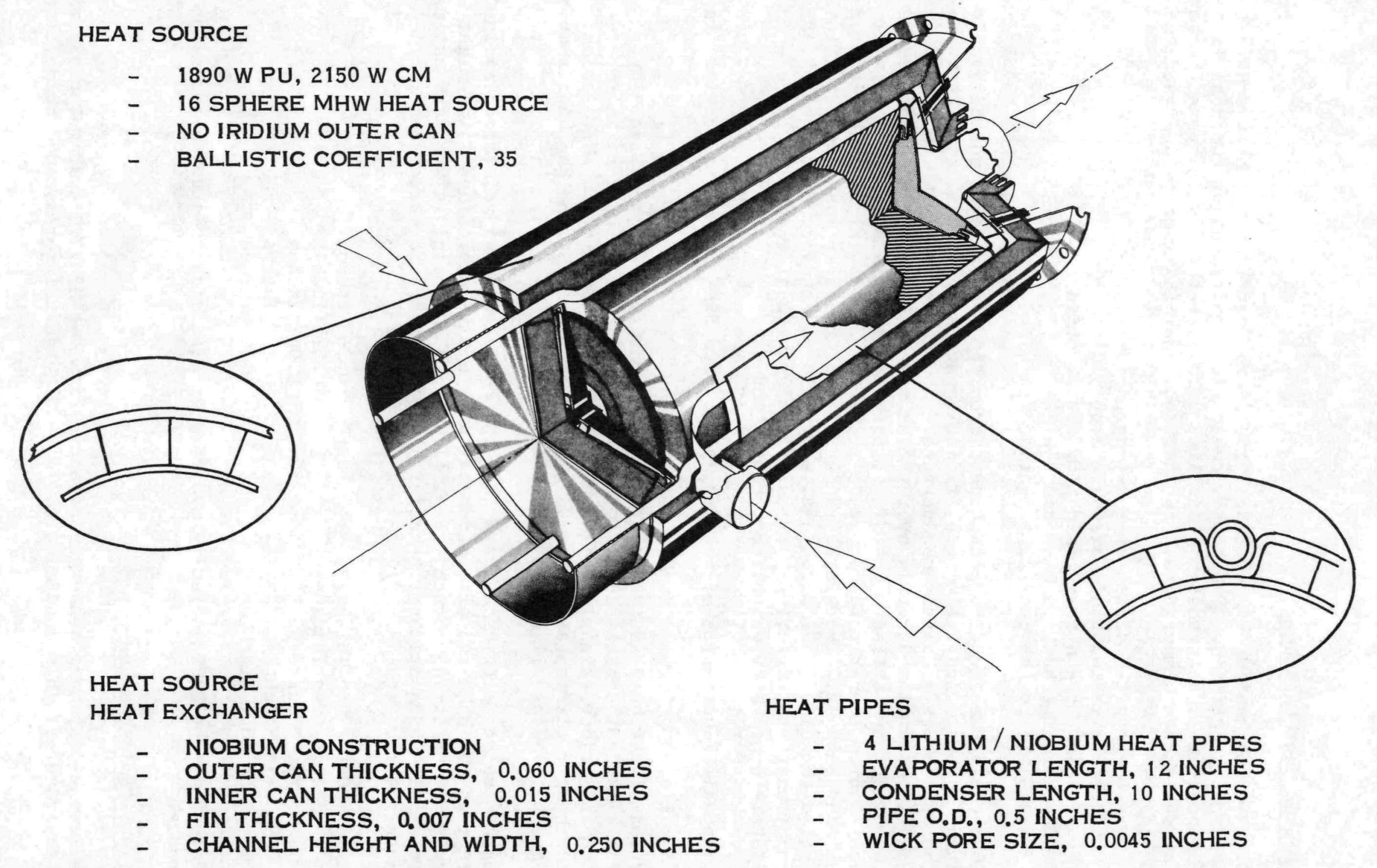


of the fuel containment material. The use of an emergency cooling system is designed to maintain the integrity of the HSA if such a situation occurs.

Three emergency cooling designs were considered for the MB-ERTG conceptual design: heat pipes, doors, and melting insulation. The melting insulation approach appeared to have the potential of offering high reliability and minimum weight; however, a preliminary investigation revealed that a significant development program would be required before this concept could be employed. It was decided to pursue this approach further in Task 2.0. Previous experience on NASA Contract NAS 3-16810 led to the conclusion that doors would be a high weight design approach and therefore undesirable for this application.

The use of variable conductance heat pipes was considered to be the least development cost approach towards providing emergency cooling capability. Using niobium as the heat pipe material, lithium working fluid, and argon as the control gas a passive, reliable and low weight emergency cooling system can be employed.

For a curium fueled system, where a 17.4 percent decrease in thermal power occurs over 5 years, the variable conductance heat pipes are also designed to power flatten the heat source.

Table 3-4 summarizes the heat pipe design characteristics; total weight for the heat pipe ECS is less than 1.0 pound.

Table 3-4. Heat Pipe Design Summary

\begin{tabular}{|c|c|c|}
\hline \multirow[b]{2}{*}{ PARAMETER } & \multicolumn{2}{|c|}{ MB-ERTG FUEL } \\
\hline & PU-238 & CM-244 \\
\hline Number of Heat pipes & 4 & 4 \\
\hline Evaporator length (le), in & 12. & 12. \\
\hline Condenser length (1c), in & 10. & 9.5 \\
\hline Pipe outer radius ( $r p$ ), in & 0.25 & 0.028 \\
\hline Wick outer radius (ri), in & 0.23 & 0.26 \\
\hline Vapor channel radius (rv), in & 0.21 & 0.21 \\
\hline Wick: & & \\
\hline $\begin{array}{l}2 \text { 1ayers of } 100 \text { mesh wire screen } \\
\text { porosity }=0.68\end{array}$ & & \\
\hline $\begin{array}{l}\text { minimum pore size, in } \\
\text { friction factor, ft }-2\end{array}$ & $\begin{array}{l}0.0045 \\
6.1 \times 10^{8}\end{array}$ & $\begin{array}{l}0.0045 \\
6.1 \times 10^{-8}\end{array}$ \\
\hline
\end{tabular}




\section{Turbine}

The turbine design utilizes a radial flow 1.9 inch wheel, 0.2 pounds in weight. Turbine characteristics were based on experience gained in previous hardware and design studies; Figure 3-9 illustrates the turbine performance of various machines as a function of specific speed. Adiabatic expansion efficiency of the Conceptual Design turbine is shown as 91 percent. In order to account for size and Reynolds' number effect the Conceptual Design turbine efficiency was conservatively estimated to be 77 percent. Of the 1410 watts delivered to the turbine shaft 774 watts are used in driving the compressor; a complete breakdown of the power split is shown in Figure 3-10. Salient features of the turbine design are: inlet temperature $-1600^{\circ} \mathrm{F}$, inlet pressure -43 psia, outlet pressure - 27.7 psia, flow rate - $0.088 \mathrm{lb} . / \mathrm{sec}$, specific speed - 0.061 , wheel diameter - 1.9 inches.

\section{Alternator}

The Rice type alternator selected for the Conceptual Design provides excellent voltage regulation capability by virtue of the use of external excitation, and has been proven as a means for motor starting the rotating group to selfsustaining speed. Efficient use of the bearing support structure as a return path for the magnetic flux minimizes the weight of this design. Overall efficiencies in excess of 85 percent at one $\mathrm{kW}$ can be expected. Figure 3-11 shows the typical construction details of the Rice alternator.

A computerized model design program and motor start program allows rapid optimization and evaluation of configuration variations. The alternator design program includes the following routines:

(a) Pole and flux collector geometry; stator geometry

(b) Pole leakage

(c) Rotor windage loss

(d) End bell design and leakage

(e) Control and series field design

(f) Pole head loss

(g) Eddy factor for stator windings

(h) Apparent power factor, a-c volts and amps, $d-c$ volts and amps, distortion factor, and rectifier losses for operation into a three-phase, fullwave rectifier load

(i) Iteration of stator turns to achieve specified commutation reactance.

The operation of the alternator design program is such that the initial or "design" load condition synthesizes a basic geometry. Then, when subsequent load conditions are applied, performance is calculated using the initial basic geometry. The basic geometry can readily be changed either by changing the initial "design" load data or by changing initial design parameters such as pole flux density, winding reactance, or an air gap dimension. The model makes it possible to rapidly compare many design variations while maintaining consistent values for flux densities, winding reactance, or geometric features as appropriate. 


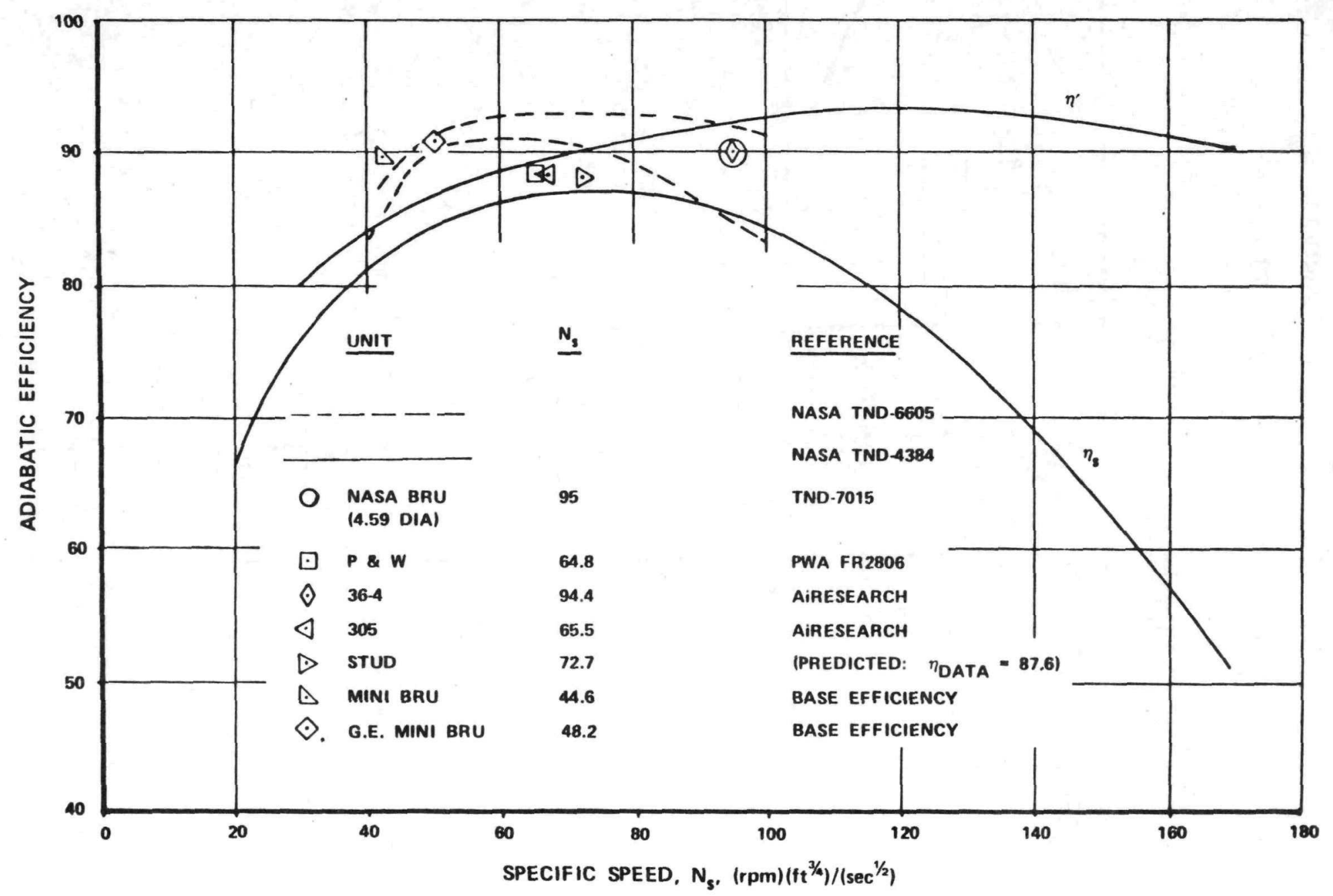




\section{FIGURE 3-10}

TURBINE SHAFT POWER BREAKDOWN

- ALL POWER SHOWN IN WATTS -

\section{ROTATING GROUP PACKAGE}

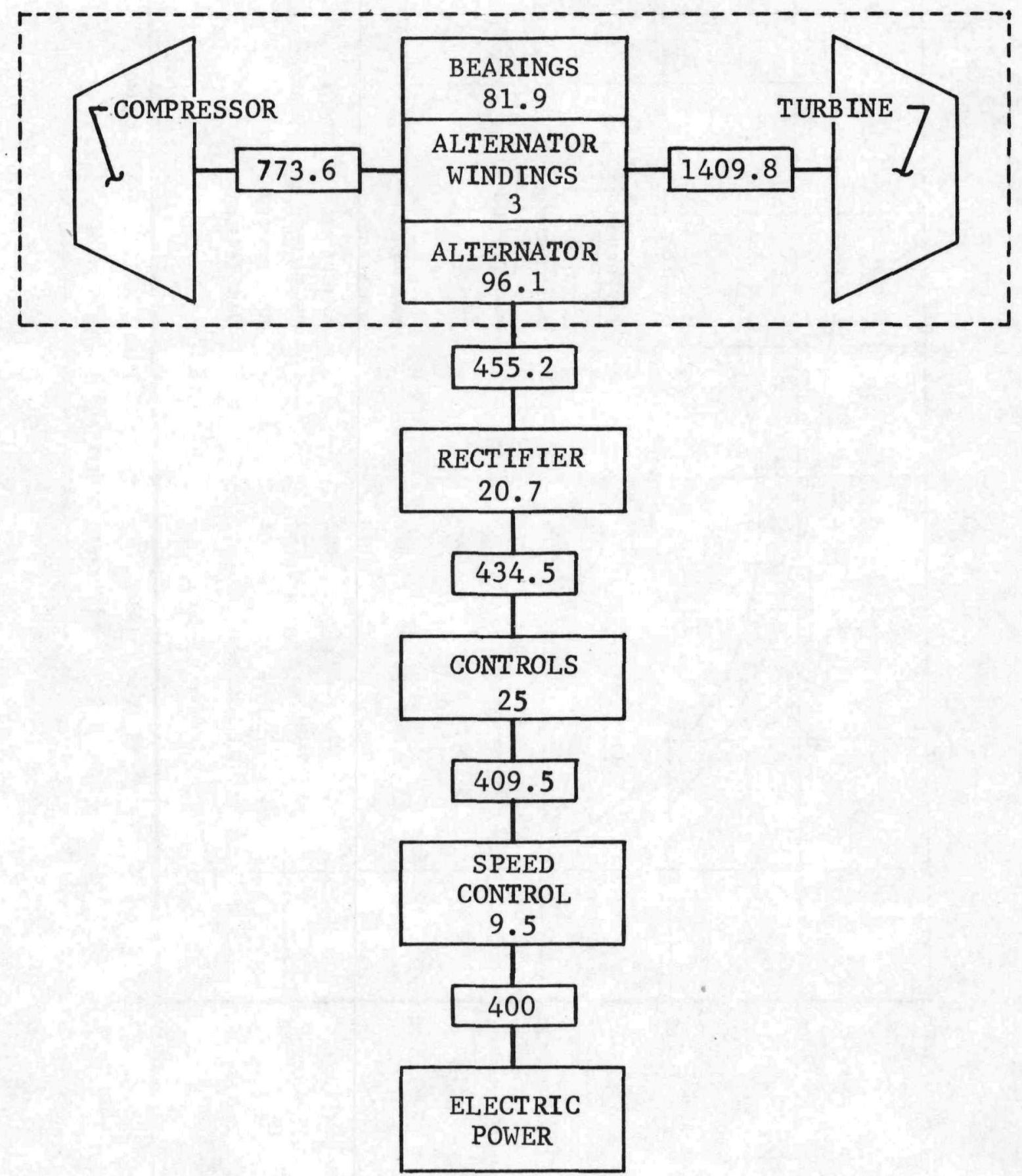




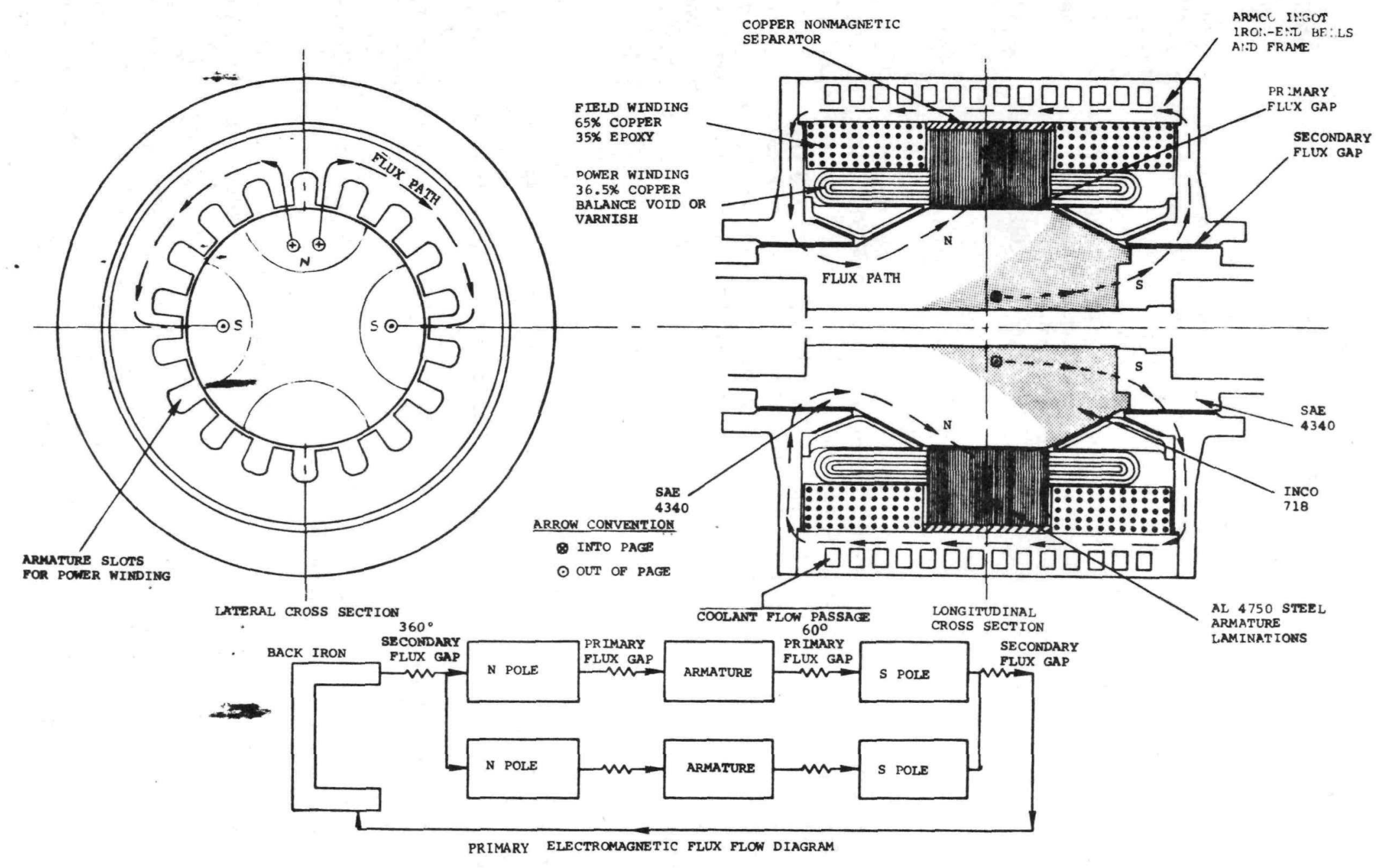

Figure 3-11. Typical 4 Pole Rice Alternator Design 


\section{Alternator (continued)}

Design characteristics of the three phase Rice alternator used in the MB-ERTG Conceptual Design are: efficiency - 88 percent, rotating speed 80,000 RPM, electromagnetic losses - 96 watts, rotor diameter - 1.0 inch.

\section{Compressor}

The compressor impeller design for the Conceptual Design is smaller than those previously considered. The diameter of the compressor wheel is 1.6 inches as compared to 2.2 inches for the NASA Mini-BRU and 4.2 inches for the $5 \mathrm{kWe}$ BRU compressor. Figure 3-12 illustrates the effect of compressor impeller design on efficiency; note that a substantial efficiency penalty has been taken for the Conceptual Design compressor. The salient compressor design conditions include: efficiency - 72 percent, inlet pressure - 27.2 psia, inlet temperature $-480^{\circ} \mathrm{F}$, pressure ratio -1.6 , flow rate $-0.90 \mathrm{lb} . / \mathrm{sec}$, specific speed -0.080 .

\section{$\underline{\text { Recuperator }}$}

The MB-ERTG Conceptual Design recuperator is a pure counterflow design as shown in Figure 3-13 constructed completely of Hastelloy-X. The fin construction is identical to the Mini-BRU unit designed for NASA Lewis under Contract NAS 3-16739. The design selected has an aspect ratio (height/width) of 0.7 to optimize the weight split between headers and solid spacer bars . This unit was designed for an effectiveness of 0.96 and a total pressure drop of 1.5 percent resulting in high cycle efficiency and near minimum weight. The Reference Design recuperator has the 20 percent conductance margin and 20 percent pressure drop margin used in the previous Mini-BRU study. Table 3-5 summarizes the pertinent recuperator geometry.

\section{Controls}

Controls for the system provide two functions - start-up and load control; voltage control may also be provided if the inherent regulation is inadequate. Figures 3-14 and 3-15 illustrate the proposed control system and logic network.

A single start system is simply implemented when complimented with a speed regulated load control. A start is effected by accelerating the rotating group to self-sustaining speed. The unit then bootstraps to rated speed at which point the load contactor closes and the speed control regulates a parasitic load to maintain rated speed.

Acceleration of the rotating group will be effected by electrically motoring the alternator. A check valve located between the recuperator and compressor ensures proper flow direction of the working fluid.

Load control consists of inhibiting the load contactor from closing until the unit achieves 95 percent speed and applying parasitic load for speed control. A speed controller parasitic load was selected due to its inherent system simplicity. By maintaining a constant speed with the essentially constant heat source, voltage regulation of a few percent can be attained. 


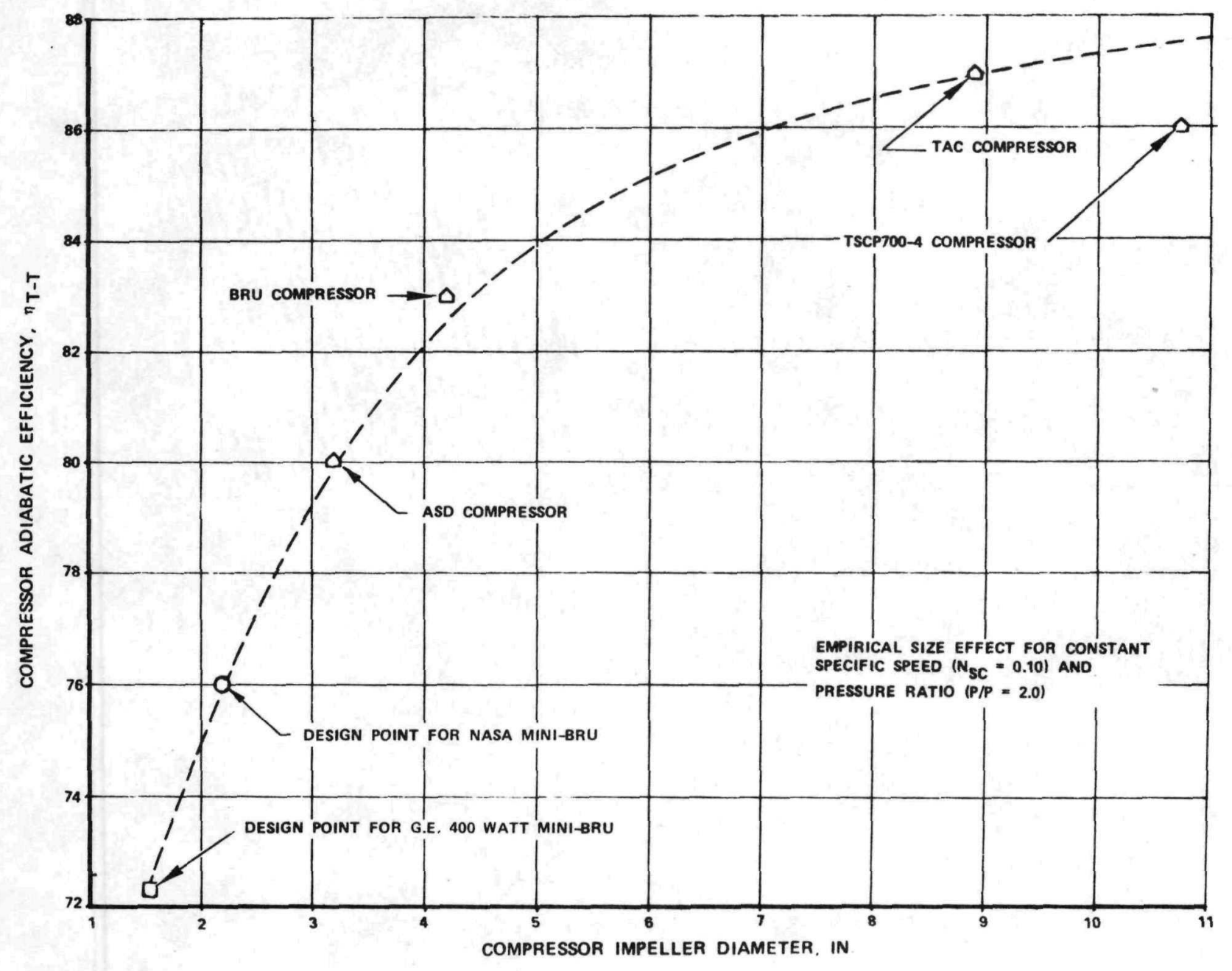

Figure 3-12. Effect of Compressor Size on Efficiency 


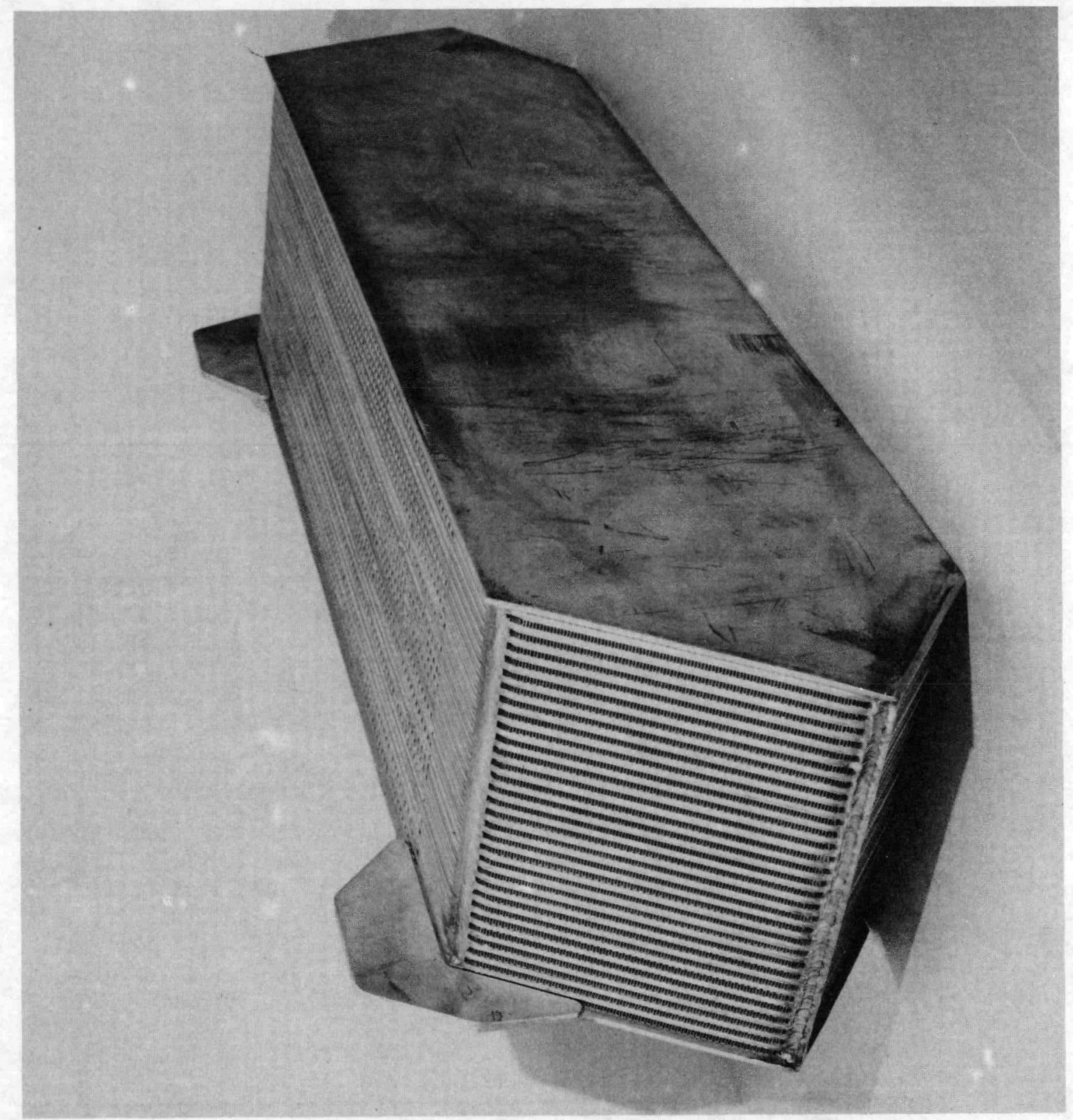


Table 3-5

MB-ERTG Conceptual Design Recuperator Characteristics

Weight, 1b

Width, in.

5.62

Height, in .

3.79

Core length, in.

16.3

Overall length, in.

21.2

Splitter plate thickness, in.

0.008

Side plate thickness, in.

0.100

Wrap up thickness, in.

0.060

Low pressure side

Splitter plate spacing, in.

0.101

Fin thickness, in.

0.004

Fin length, in.

0.100

Number of fins per in.

20

High pressure side

Splitter plate spacing, in.

0.101

Fin thickness, in.

0.004

Fin length, in.

0.100

Number of fins per in.

20

Total fractional pressure drop

0.015 


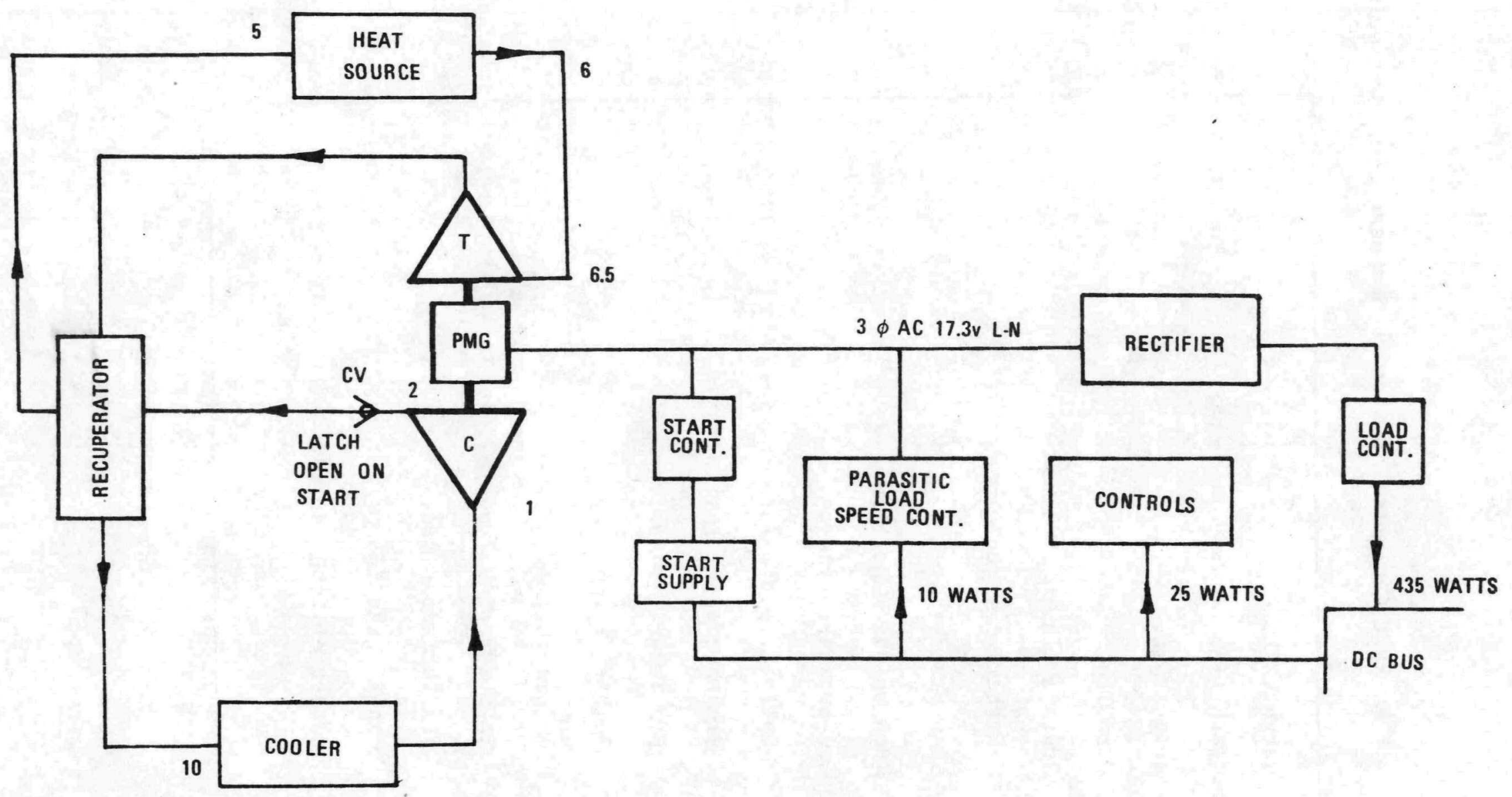




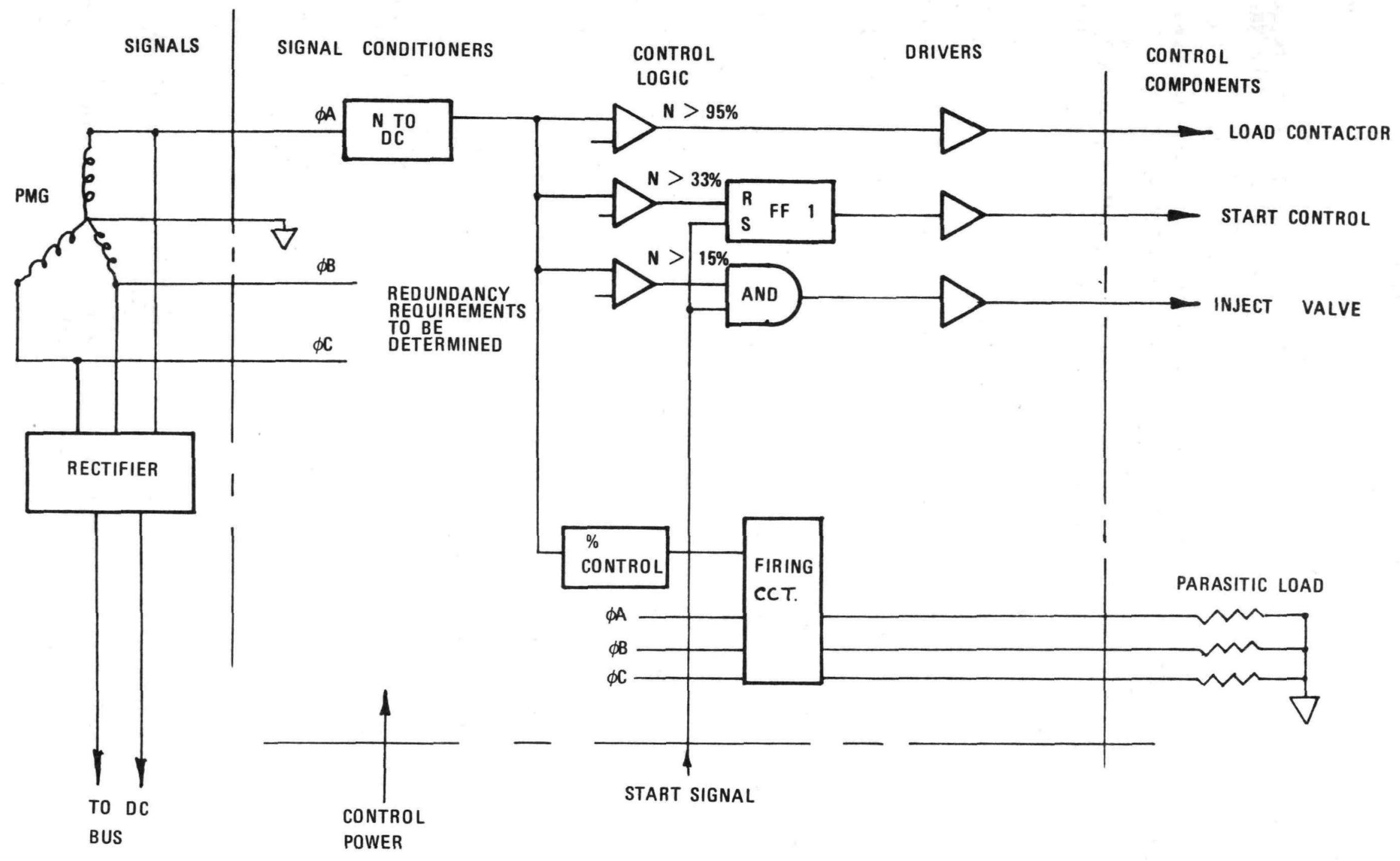

Figure 3-15. Basic Control Logic Network 
Controls (continued)

The speed control consists of a speed error amplifier and saturable reactor controlled SCR firing circuits. A similar system designed for the NASA is described in NASA CR 72564.

Once the detailed control, protection and monitoring requirements are fully defined, implementation is quickly achieved with proven, high reliability, standardized circuitry. These circuits were developed for the Brayton Control System (NASA Report CR 72697), industrial applications and open cycle systems. The circuits are divided into three groups on a functional basis.

(a) Signal Conditioning

(1) Thermocouples - adjustable gain and offset

(2) Frequency (speed) - adjustable gain, no roll off at overspeed

(3) AC Voltage $-0.2 \mathrm{v} p-\mathrm{p}$ and up (may be used with C.T. for current analog)

(4) Three-phase power (any wave shape)

(5) Discrete receivers

(6) Contact interface

(7) Analog receivers

(b) Logic and Analog Operation*

(1) Comparators - high or low

(2) Comparators with alarms

(3) Analog selectors

(4) Timers

(5) Proportional with integral

(c) Drivers

(1) Digital (2 amp)

(2) Digital (10 amp)

(3) Proportional

(4) Buffers

Logic unique to the system, when fully defined, is readily implemented with integrated circuits on printed circuit boards. 
Figures 3-16 and 3-17 illustrate the use of these standard circuits for control. The basic control circuit shows analog signals being received from remote signal conditioners by analog receivers (for noise immunity), then utilized by the comparators and operational devices to provide the desired output to the receiver/driver.

Reliability objectives are readily achieved by using variations of the basic configurations such as shown in Figure 3-16. Three duplicate (tridundant) transducers and signal conditioners provide 0-5 vdc analog signals to two analog selector boards. These boards include majority voting circuitry to select an output. (Disagreement of any of the three signals results in an alarm). Parallel logic circuits provide complimentary signals to the driver; non-complimentary commands result in an alarm and no change of state.

Actual implementation of the various techniques is accomplished during detail design in a manner that assures fail-safe operation.

Override logic in the receiver greatly improves flexibility in implementing special control functions, such as emergency shutdowns, load shedding or external computer system control.

Figure 3-17 illustrates various configurations of receiver/drivers to implement various preferred failure modes. 


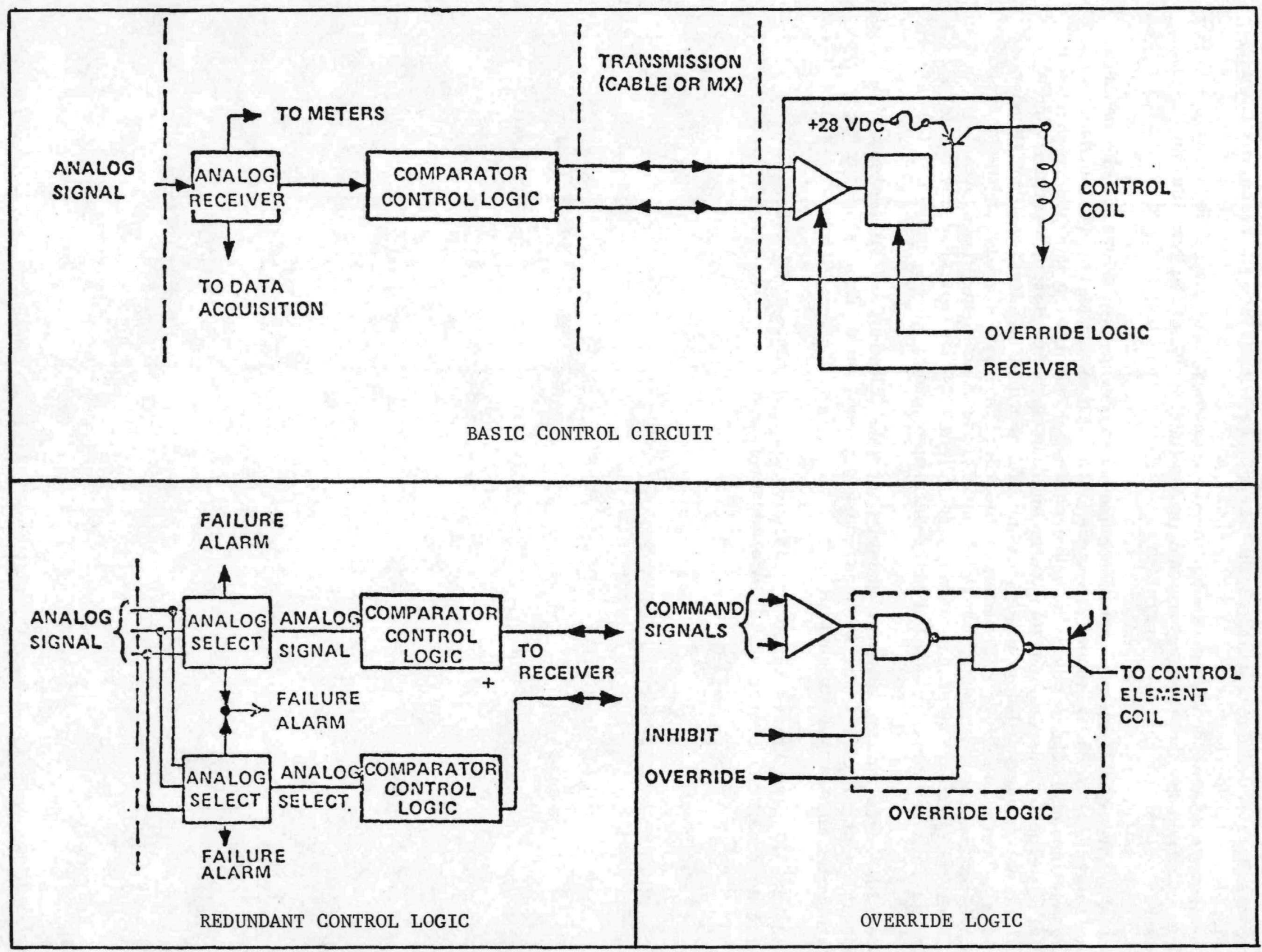




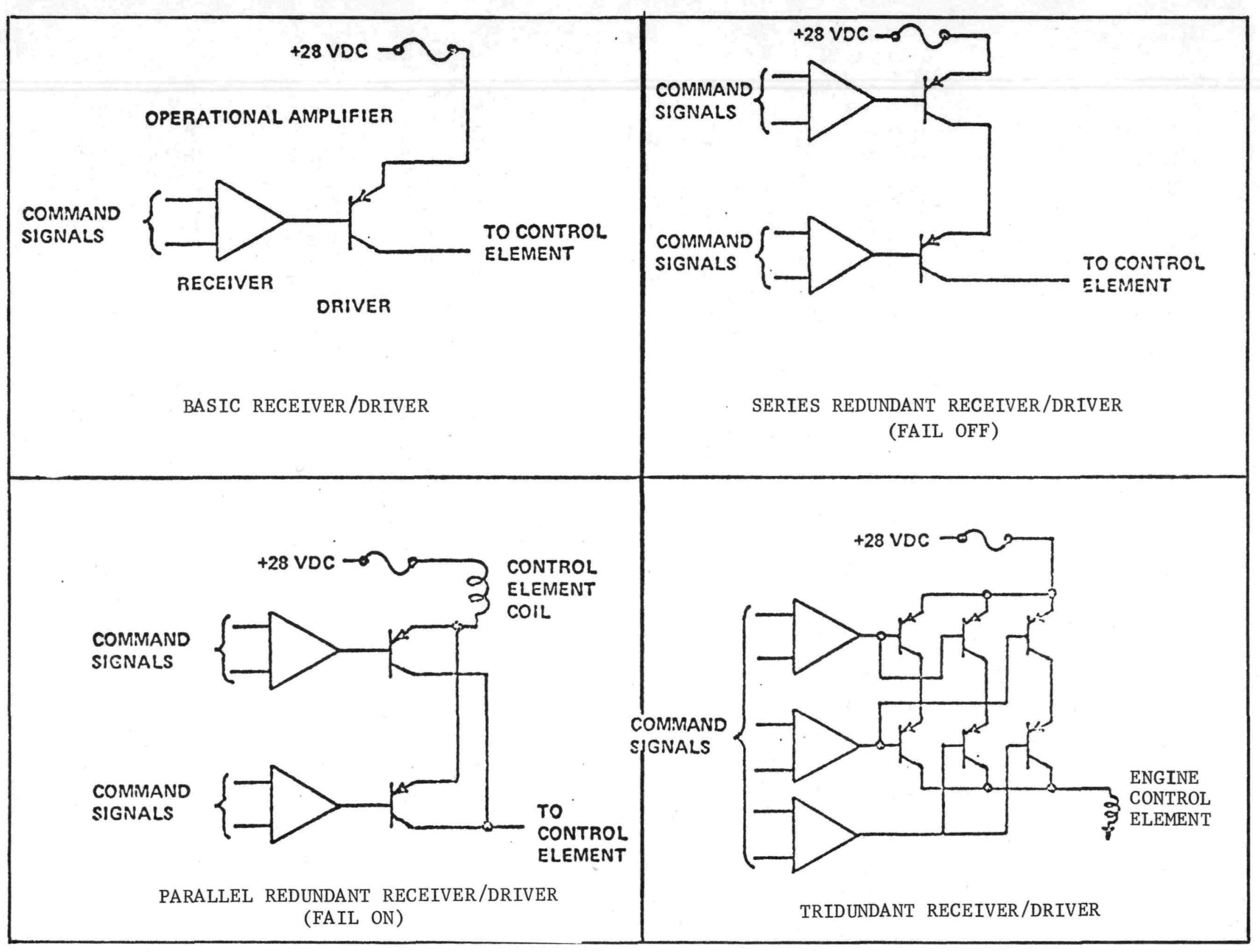




\section{$\underline{\text { Radiator }}$}

The design and performance of the radiator is important to the overall cost, weight, reliability and arrangement of the power system. The factors determining the design encompasses a broad range of disciplines and include the following :

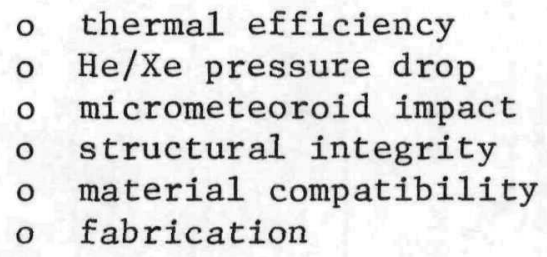

Past studies by the General Electric Company have considered both flat panel and cylindrical radiators. This work has indicated that although flat panel radiators are more thermally efficient, the reduced micrometeoroid armor requirements and structural capability of the cylindrical configuration makes this design the preferred choice. Another characteristic of the cylindrical radiator is the fact that it integrates in a more compact manner with the remainder of the power system.

This investigation showed the cylindrical radiator to be superior to the flat panel due to the restricted dimensions of the power system. Assuming the optimistic values listed below the minimum radiator area required is $30.5 \mathrm{ft}^{2}$.

$$
\begin{aligned}
& \text { heat } \text { rejection }=1200 \text { watts } \\
& \text { fin efficiency }=0.85 \\
& \text { emissivity } \quad=0.85 \\
& \text { sink temperature }=-460^{\circ} \mathrm{F} \\
& \text { radiator effective temperature }=115^{\circ} \mathrm{F}
\end{aligned}
$$

This area exceeds the maximum permissible without allowing for the geometric and heat transfer interactions with the remainder of the spacecraft and power system. An illustration, Figure 3-18, of a flat panel MB-ERTG, developed during previous investigations demonstrates the tendency towards a relatively large power system envelope with this concept.

In light of the factors discussed, a cylindrical radiator was selected as the configuration for the Task 1.0 conceptual design. This geometry has been shown to provide: excellent micrometeoroid protection due to the fin "bumper" effect, good heat transfer from the tube to the fin and a sound structural member capable of supporting substantial launch loads.

The radiator sink temperature used in this study assumed an equatorial synchronous orbit, a "hardened" coating with an $\alpha / e$ of $0.23 / 0.85$ (EOM) and a cylindrical radiator oriented with its axis pointed towards the center of the Earth. The maximum sink temperature was calculated to be $-70^{\circ} \mathrm{F}$. Assuming that the Sun flux is distributed uniformly over the surface of the radiator. This maximum sink temperature condition occurs twice in the orbit when the axis of the radiator is normal to the Sun's rays. 


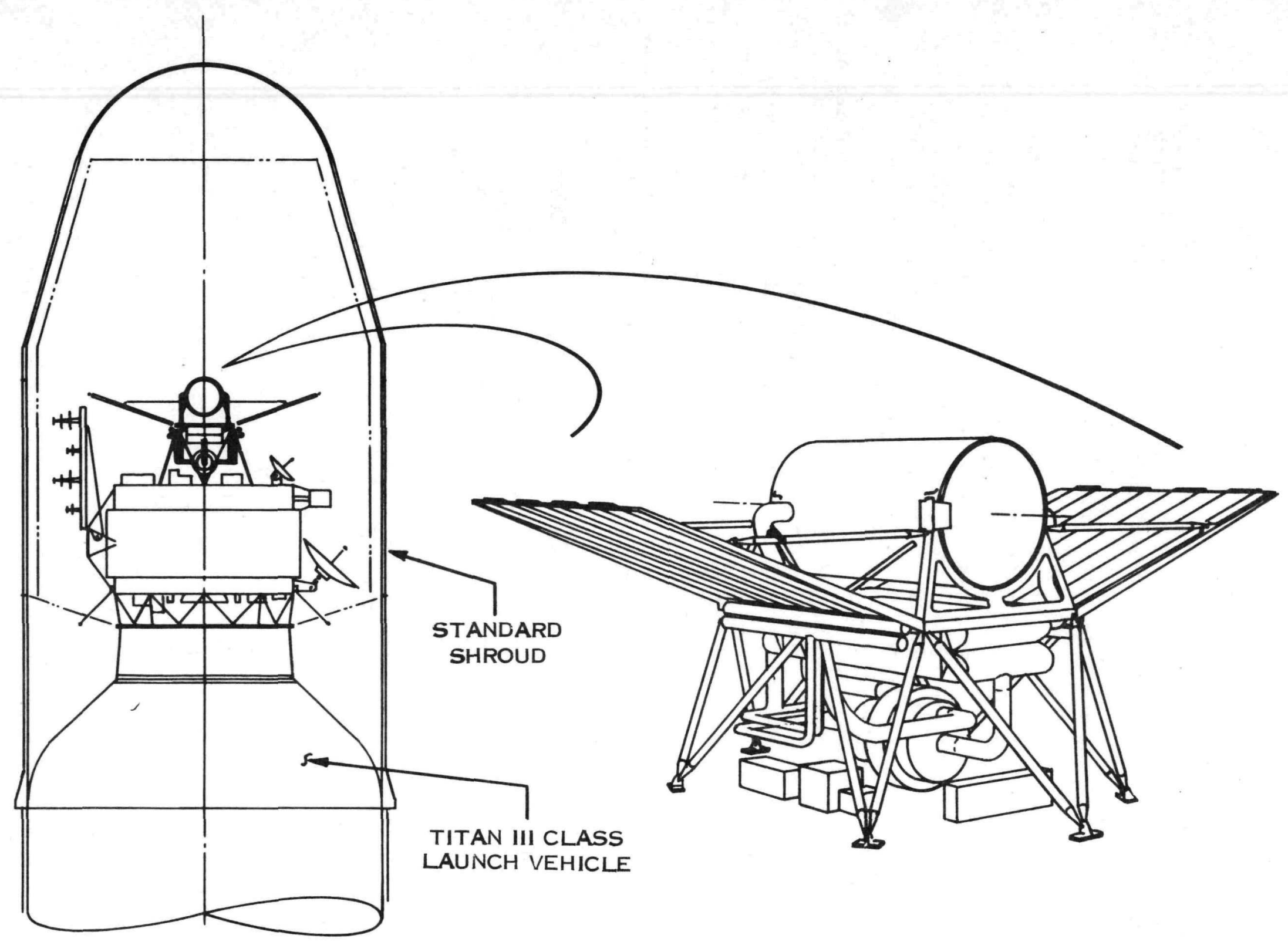




\section{$\underline{\text { Radiator (continued) }}$}

The possibility of a micrometeoroid damage to the radiator loop has a substantial effect upon the design of the radiator. In order to limit the probability of penetration, weight optimization of the radiator design results in smaller tube diameters, fewer tubes and larger tube thicknesses than would be desirable from other system considerations.

Several difficulties are apparent in the selection of a design criterion to minimize the probability of meteoroid penetration. The data obtained from satellite experiments by various impact sensors and of indirect measurements from zodiacal light and radar photographic observation of meteors show various discrepancies. Secondly, simulation of the available data by hypervelocity impact tests is impossible due to the inability of experimenters to duplicate observed meteoroid velocities. Meteoroid velocities are reported to average 17 to $20 \mathrm{~km} / \mathrm{sec}$ while projectile velocities in the order of only $8 \mathrm{~km} / \mathrm{sec}$ can be achieved in the laboratory. The third problem becomes one of interpreting and modeling the observed meteoroid flux and hypervelocity impact data into an analytical expression which can be used for a reliable radiator design. The sporadic nature of meteoroid events, the uncertainty involved in the hypervelocity impact testing and the variation of damage mode with respect to tube and tube liner materials and thicknesses combine to further complicate the situation.

The damage criteria generally used and widely accepted for calculating meteoroid armor protection requirements is that proposed by Loeffler, et al

(Reference 3.1-1) where:

$$
t_{a}=\operatorname{ar}\left(\frac{\rho_{m p}}{\rho_{t}}\right)^{1 / 2}\left(\frac{v_{m p}}{c_{t}}\right)^{2 / 3}\left(\frac{6}{\pi \rho_{m p}}\right)^{1 / 3}\left[\frac{\alpha A_{v} \tau}{-\log _{e} P_{N D}}\right]^{1 / 3 \beta}\left(\frac{1}{\beta+1}\right)^{1 / 3 \beta}
$$

where

$$
\begin{aligned}
t_{a} & =\text { required armor thickness } \\
\boldsymbol{\gamma} & =\text { damage thickness factor } \\
\boldsymbol{\rho}_{\mathrm{mp}} & =\text { materials cratering coefficient } \\
\boldsymbol{\rho}_{\mathrm{t}} & =\text { armor material density } \\
\mathrm{V}_{\mathrm{mp}} & =\text { meteoroid velocity }(25 \mathrm{~km} / \mathrm{sec}) \\
\mathrm{C}_{\mathrm{t}} & =\text { sonic velocity in armor } \\
\mathrm{A}_{\mathrm{V}} & =\text { vulnerable area } \\
\boldsymbol{\gamma} & =\text { mission time }
\end{aligned}
$$




$$
\begin{aligned}
\alpha & =10^{-14.41} \frac{\mathrm{gm}^{1.22}}{\mathrm{~m}^{2}-\mathrm{sec}} \\
\beta & =1.22 \\
\mathrm{P}_{\mathrm{ND}} & =\text { design probability of no critical damage }
\end{aligned}
$$

The constant a and $\gamma$ vary from material to material and with damage mode. A recent study, Reference 3.1-2, determined the cratering coefficient for several materials as a function of temperature according to the following relationships.

$$
\gamma=\gamma_{R}\left(\frac{T}{T_{R}}\right)^{1 / 6}
$$

where:

$$
\begin{aligned}
& \boldsymbol{Y}_{\mathrm{R}}=\text { room temperature cratering coefficient, } 2.19 \\
& \mathrm{~T}_{\mathrm{R}}=\text { room temperature (absolute) } \\
& \mathrm{T}=\text { target temperature (absolute) }
\end{aligned}
$$

Design of the radiator was performed by means of the General Electric SPARTAN III radiator computer code. This code considers all of the important factors necessary to provide a realistic radiator design including the effects of heat transfer, fluid flow, micrometeoroid protection, manufacturing limitations and power system interactions.

Due to its low density, high thermal conductivity and ability to be easily fabricated aluminum is an excellent radiator material in the temperature range of interest, $0^{\circ}-300^{\circ} \mathrm{F}$. In addition, the high ratio of elastic modulus to density makes aluminum a good material for micrometeoroid protection. Therefore, a series of computer runs were made to calculate the weight, area and design characteristics of the radiator for the MB-ERTG cycle characteristics.

The following is a list of the inputs and outputs used by the SPARTAN III code in performing the design analysis:

\section{INPUT}

- Thermal Requirements

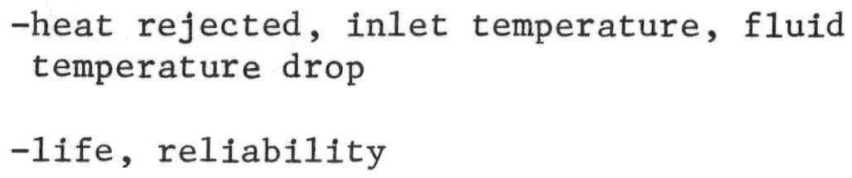

-life, reliability

- Mission Requirements

- Environmental Factors

-Meteoroid size, density, flux, incident heat fluxes, view factors 
$\underline{\text { Radiator }}$ (continued)

\section{INPUT}

o Physical Property Data

-densities, Youngs' Moduli, viscosities, conductivities, etc.

- Configuration

-different fin tube designs, various header, and feed line designs

- Geometric Factors

-numbers of panels, tubes, tube spacing fin thickness, etc.

o Criteria for

-pressure drop, heat transfer, meteoroid armor and bumper effects

\section{OUTPUT}

- Flow Characteristics

-velocities, Reynolds number, pressure drop, pump work

- Temperature Characteristics

-header and tube temperatures, fin temperatures and efficiencies, sink temperature

o Weights

-fins, tubes, headers, liner, armor, fluid, etc.

- Geometry

-projected radiator area, armor thickness, vulnerable area, tube length

The results obtained from the SPARTAN III computer program are shown in Figure 3-19. A major consideration in the radiator design is the fluid pressure drop. A high fluid pressure drop produces light weight radiator designs since smaller tubes requiring less armor can be employed. However, a high radiator $\Delta P$ results in an increase in the compressor pressure ratio and a loss in overall system efficiency. For the Task 1.0 Conceptual Design a radiator having a micrometeoroid survival probability of 0.99 was used. The design of the radiator fin-tube geometry is shown in Figure 3-20; total radiator area was calculated to be $48 \mathrm{ft}^{2}$.

\subsubsection{TECHNOLOGY ASSESSMENT}

This task involved reviewing the Conceptual Design to assess whether new or different technologies could be utilized to improve the performance of the MB-ERTG. The following sections list the technology options for each of the components; these options were evaluated in the Parametric Analysis task which is discussed in Section 4.1.

\subsubsection{Heat Source}

Since the MHW heat source is being developed for the LES 8 and 9 Mission, 


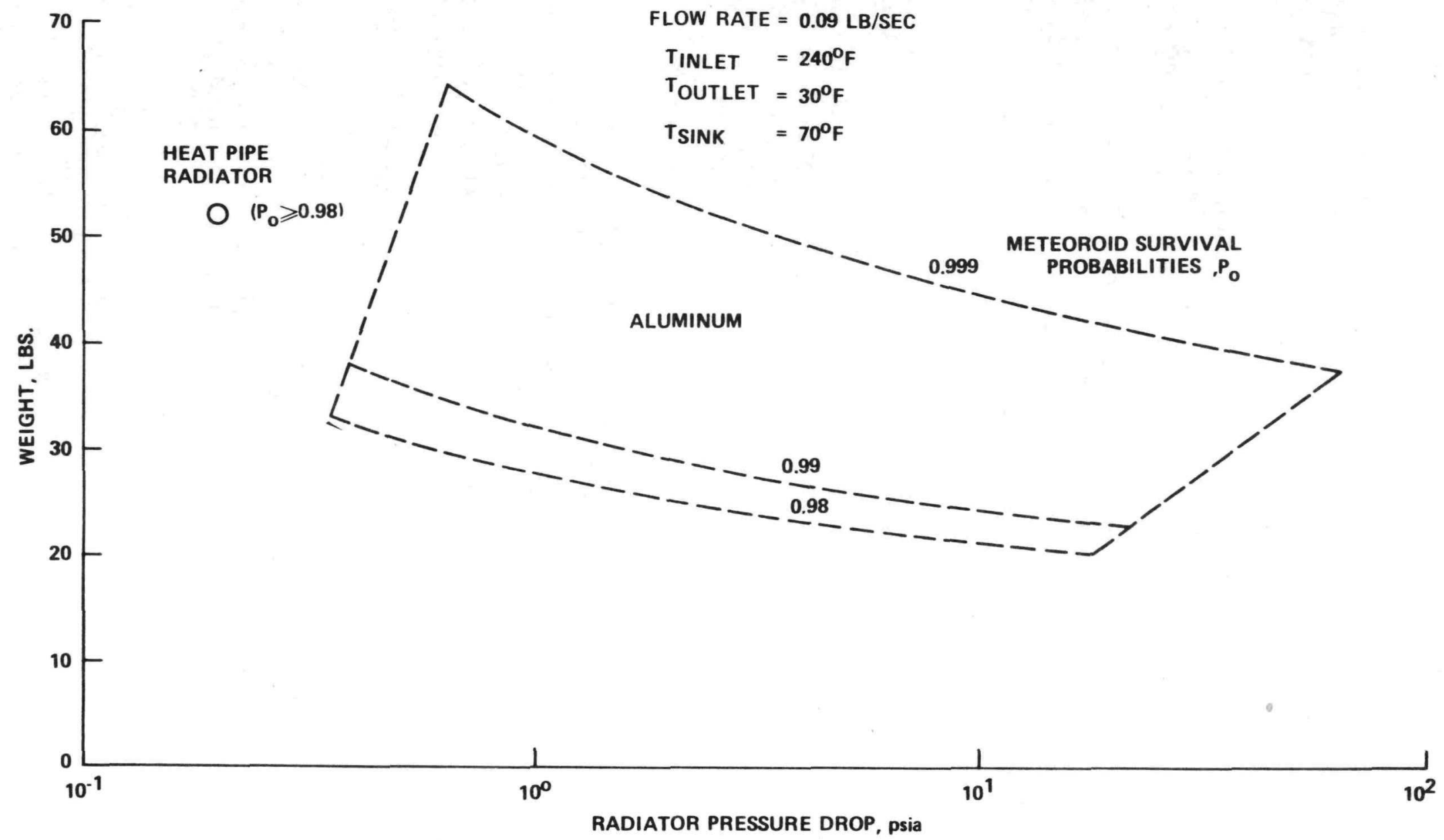

Figure 3-19. Effect of Fluid Pressure Drop on Radiator Weight 


\subsubsection{Heat Source (continued)}

utilization of this heat source concept could result in lower development costs than alternative approaches. However, for the reasons listed below it was decided that an assessment of alternative heat source designs should be undertaken.

- The Conceptual Design heat source does not take advantage of the high power density of $\mathrm{Cm}-244$ and therefore suffers a weight disadvantage as compared to a heat source designed specifically for $\mathrm{Cm}_{2} \mathrm{O}_{3}$ fuel.

- The MHW FSA's as presented in the Conceptual Design heat source have 135 watts of $\mathrm{Cm}_{2} \mathrm{O}_{3}$ fuel each. Post-impact temperature for the FSA's would exceed the oxidation temperature limit for iridium under certain conditions. While the fuel loading per sphere could be reduced by increasing the number of spheres from 16 to 20 , an additional weight penalty would be incurred.

- Although development costs for the Conceptual Design heat source would be low, unit fabrication costs were expected to be relatively high due to the use of iridium as the fuel clad.

Table 3-6 lists various materials which were examined as possible encapsulation candidates. The materials in this table were examined with regard to their potential to produce a simple, low cost heat source. Section 4.1.1 discusses the relative merits of the candidate liner materials.

\subsubsection{Heat Source Heat Exchanger}

The principal feature of the heat exchanger which was assessed during this task was the manner in which heat was transferred from the heat source to the HSHX. Figure 3-21 illustrates three concepts which were considered: (a) penetration of the heat source with He/Xe coolant channels; (b) contact conductance between aeroshell and HSHX; and (c) radiation gap between aeroshe11 and HSHX. Each of these options was evaluated with respect to reducing the heat source weight, improving the safety of the system and/or reducing ground handling costs.

\subsubsection{Emergency Cooling System}

The Emergency Cooling System (ECS) identified in the conceptual design consisted of 4 variable conductance, lithium heat pipes. Another technique to provide emergency cooling is the use of an insulation system which melts if the HSA is overtemperature. The potential advantages of a melting insulation system are:

- Eliminate an additional component from the HSA (heat pipes)

o Eliminate the heat leak associated with the heat pipes when they are not in use

- Increase safety of system by providing an inherently more reliable ECS approach and by removing the presence of alkali metals from the HSA region. 
Figure 3-20.

Conceptual Design Radiator Fin-Tube Geometry

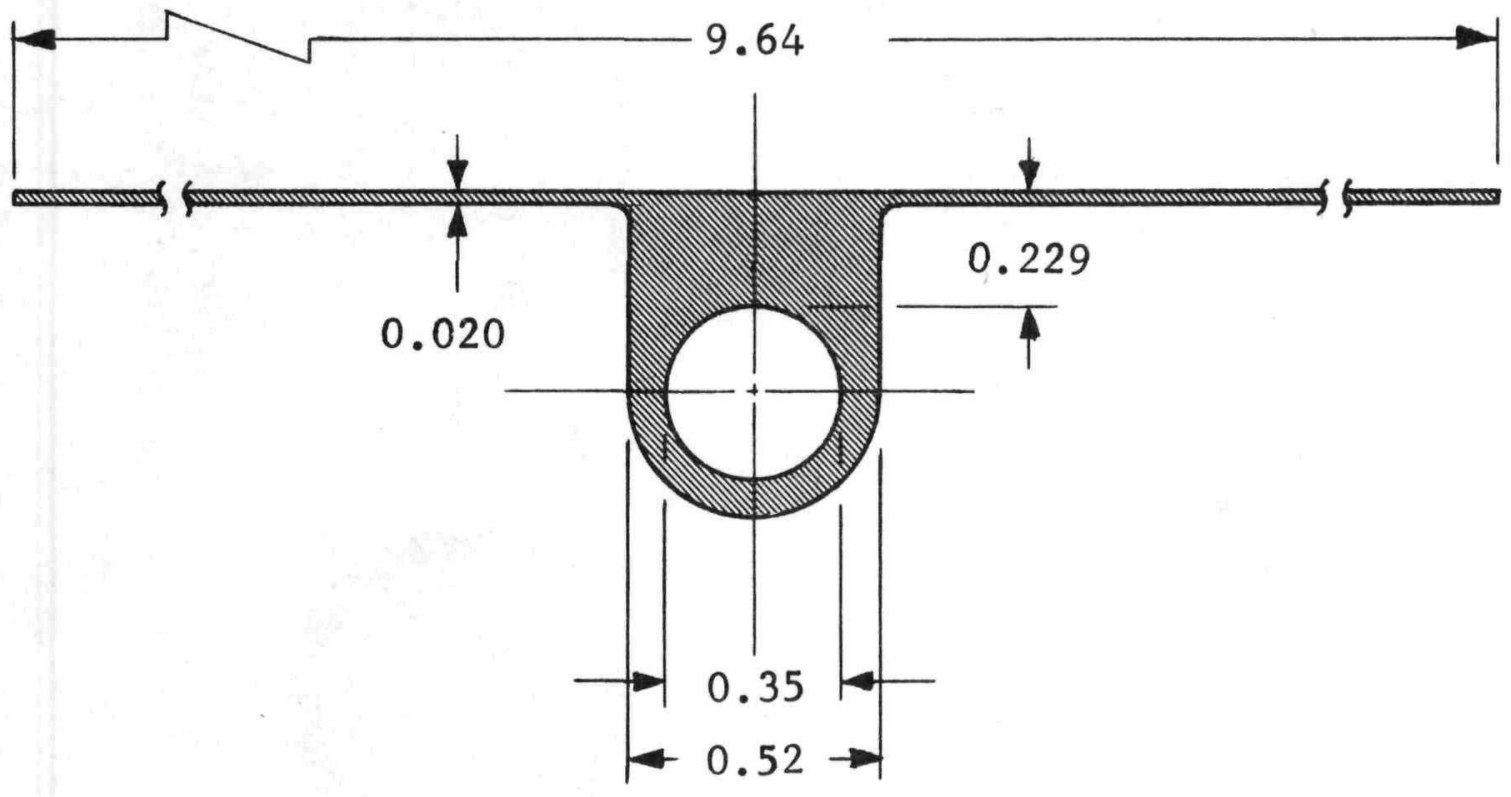

Table 3-6. Candidate Fuel Liner Materials

Super Alloys

Refractories

Refractory

Oxides

(Ceramics)

Noble Metals
Haynes - 25, Hastelloy C

Niobium, Molybdenum, Tungsten, Tantalum, Rhenium and Alloys

Beryllia, Hafnia, Thoria, Zirconia, Yttria, Samaria, Gadolina, Magnesia, Alumina

Ruthenium, Rhodium, Palladium, Osmium, Iridium, Platinum and Alloys 
B

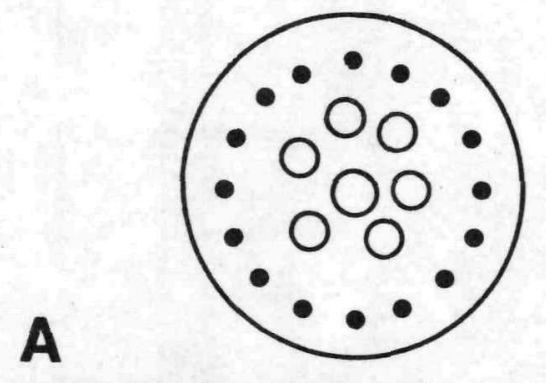

DIRECT COOLED (HEAT SOURCE PENETRATED)

- LIGHTWEIGHT

- SEPARATION OF VENT GASES FROM WORKING FLUID DIFFICULT

- COMPLEX MANIFOLDING

- RE-ENTRY MAY BE DIFFICULT TO ASSESS

- GROUND HANDLING DIFFICULT
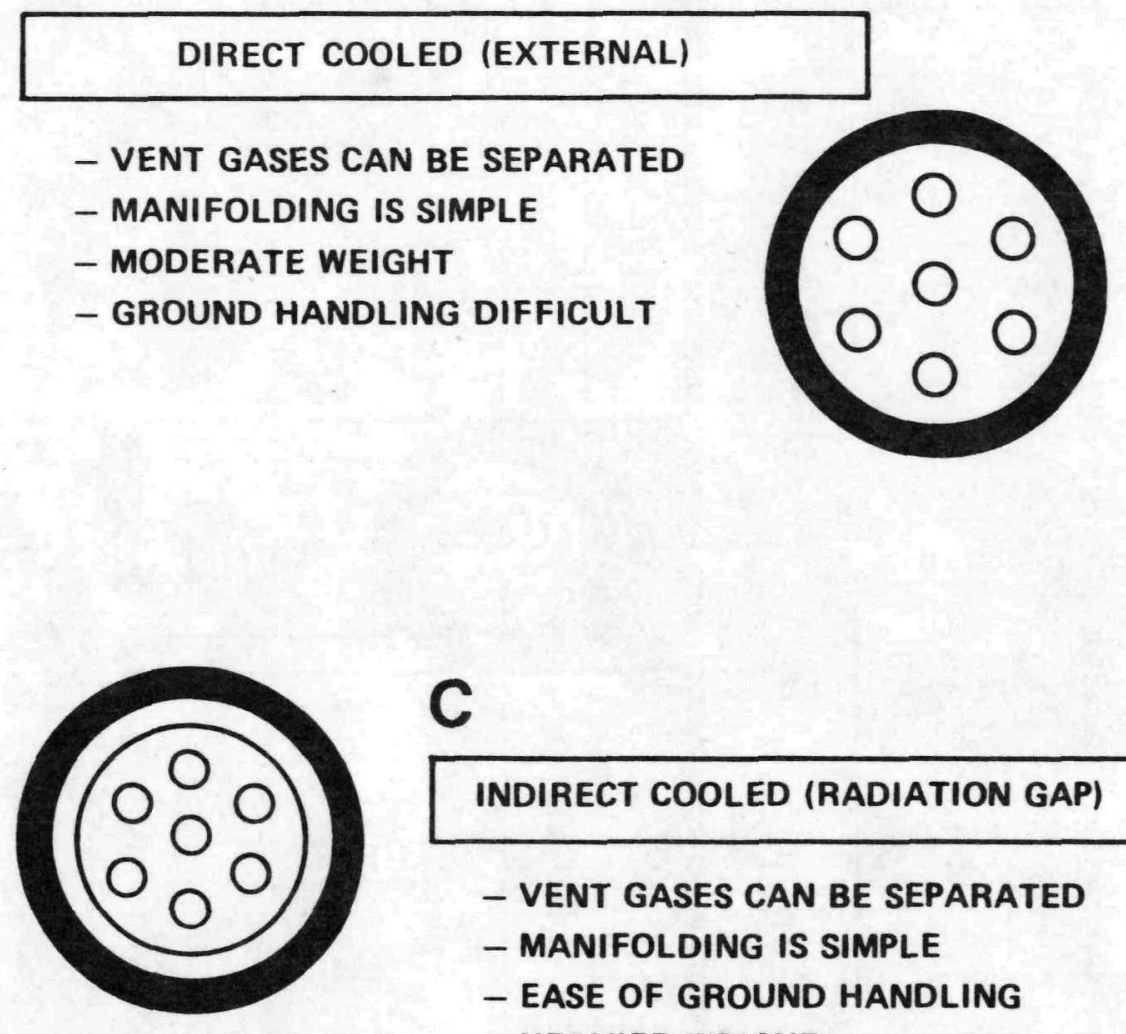

C INDIRECT COOLED (RADIATION GAP)

- VENT GASES CAN BE SEPARATED

- MANIFOLDING IS SIMPLE

- EASE OF GROUND HANDLING

- HEAVIER WEIGHT

- HIGHER HEAT LEAK

- LARGER $\triangle T$ T BETWEEN HS \& HSHX 


\subsubsection{Turbine}

The $1600^{\circ} \mathrm{F}$ turbine inlet temperature level had been set in previous studies as a result of maximum allowable heat source temperatures. However, the Conceptual Design HSA did not indicate any temperature limitations were being reached. The technology improvement considered for this component is an increase in the turbine inlet temperature. Increasing the turbine inlet temperature would increase the Carnot efficiency of the system with a potential increase in the net system efficiency.

\subsubsection{Alternator}

A Rice alternator was used in the Conceptual Design based on the experience NASA-Lewis and the AiResearch Company have with this concept. At the 400 We power level, however, the permanent magnet alternator may offer higher efficiency and lower weight.

Two aspects of the permanent magnet alternator must be carefully evaluated before it can be utilized in the Reference Design: (1) voltage regulation characteristics and (2) motor start capability.

The PM alternator consists of a rotor and stator assembly. Both radial gap and axial gap machines have been built. The use of rare-earth-cobalt permanent magnets provides the maximum energy for a given volume, providing nearly a 2:1 increase relative to previously available materials. Figure 3-22 shows a typical PM machine.

Because the PMA has a relatively constant magnetic field, voltage is load sensitive. Depending upon regulation requirements and load range, the inherent regulation can in some cases eliminate the need for a voltage regulator. Where tight voltage regulation is required, additional means of regulating voltage may be necessary.

\subsubsection{Bearings}

The journal and thrust bearing design utilized in the Conceptual Design were self-acting foil gas bearings. At the 400 we output power the bearing losses amounted to 80 watts or 20 percent of the output power. Therefore, a decision was made to analyze the use of pad bearings for the Reference Design.

\subsubsection{Recuperator}

The recuperator can comprise the heaviest weight component in high efficiency Brayton systems. Therefore, several heat exchanger concepts were identified which had the potential to maintain a high effectiveness while reducing the recuperator weight. The concepts which were factored into the Parametric Analysis are:

(1) Bi-metallic recuperator - Hastelloy $\mathrm{X}$ fins at the hot end and titanium at the cold end

(2) Higher density Hastelloy $\mathrm{X}$ fins

(3) Ceramic recuperator design 

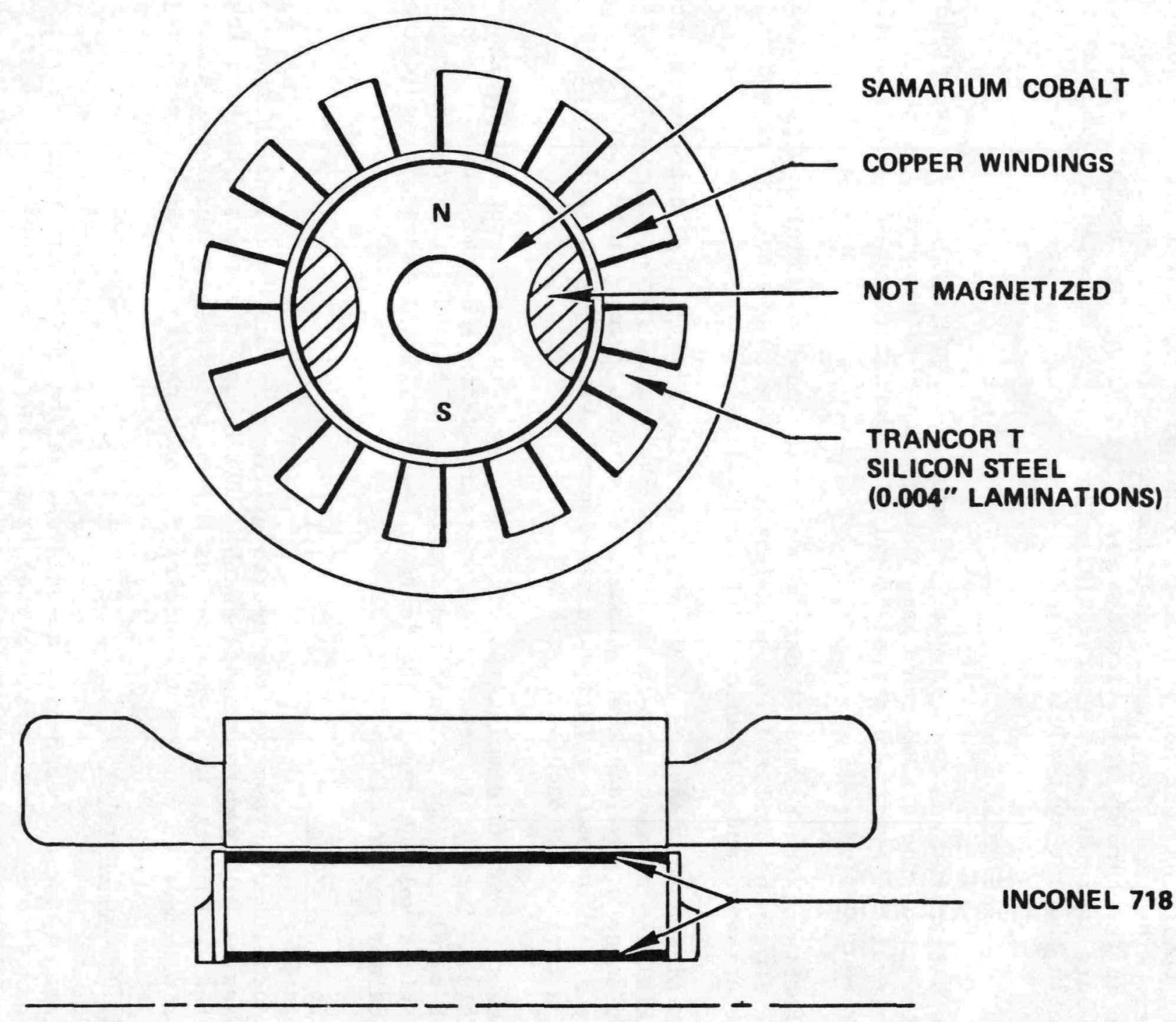


\section{$\underline{\text { Radiator }}$}

The Conceptual Design employed a cylindrical load bearing aluminum radiator as the heat rejection system. A higher cost but potentially lighter weight system could be provided by a beryllium radiator. From a performance standpoint beryllium is an outstanding radiator material choice due to its high thermal conductivity, low density and high ratio of elastic modulus to density. Consequently, it was decided to evaluate beryllium radiators for use in the Reference Design. 
SECTION 4.0

REFERENCE DESIGN SELECTION

This section describes the work leading to the selection of the Reference Design. Included in the following sections is a description of the parametric analyses which resulted in the various component concept selections, the cycle optimization leading to the Reference Design, Pu-238 fueled system options and a summary of the Reference Design component characteristics. Features of the Reference Design were selected on the basis of minimizing the overall program cost within the framework of the USAF-SPO and AEC Nuclear Safety Criteria.

Design of the HSA allows either a curia or plutonia heat source to be utilized without causing serious changes to the remainder of the program. The rotating unit, referred to as the "flexible BRU", has a variable power capability, thereby, eliminating the possibility of redirecting the Mini-BRU development in the event of a change in power leve1. An improved recuperator design, already under development by NASA-Lewis and AiResearch is also identified for use in the MB-ERTG. Although heavier than a beryllium radiator, an aluminum radiator was judged to be more cost effective in a curia fueled system.

\subsection{COMPONENT SELECTION}

Subsequent to the development of the Conceptual Design and the technology review of that system, a quantitative assessment of design alternatives was made where possible, in order to provide a basis for the Reference Design component concept selection. Since the cost of developing the technologies and producing the components entered into the decision making process a development plan was formulated and utilized in conjunction with the parametric evaluation. Figure 4-1 illustrates the development plan assumed; a detailed presentation of the development program is presented in Section 8.0. For purposes of the parametric evaluation the development program can be though of a 3 part program: technology development, prototype system development and flight unit production.

The following sections discuss the parametric work performed and the decisions made in selecting component concepts for the Reference Design.

\subsubsection{HEAT SOURCE SELECTION}

The heat source presented in the MB-ERTG Conceptual Design incorporated a 16 sphere MHW heat source design using either $\mathrm{PuO}_{2}$ or a diluted $\mathrm{Cm}_{2} \mathrm{O}_{3}$ fuel. Use of this concept, however, does not take advantage of the lower weights

achievable with a $\mathrm{Cm}_{2} \mathrm{O}_{3}$ fuel having a power density of $23 \mathrm{~W} / \mathrm{cc}$. Incorporation of the pure $\mathrm{Cm}_{2} \mathrm{O}_{3}$ fuel in a MHW FSA would result in excessive operational fuel temperatures and post-impact temperatures.

Evaluations by the ORNL estimated the unit cost of fabricating the Conceptual Design heat source to be $\$ 131 \mathrm{~K}$. Piece parts for the MHW heat source on a production basis are an additional $\$ 200 \mathrm{~K}$ (without the iridium outer can). 


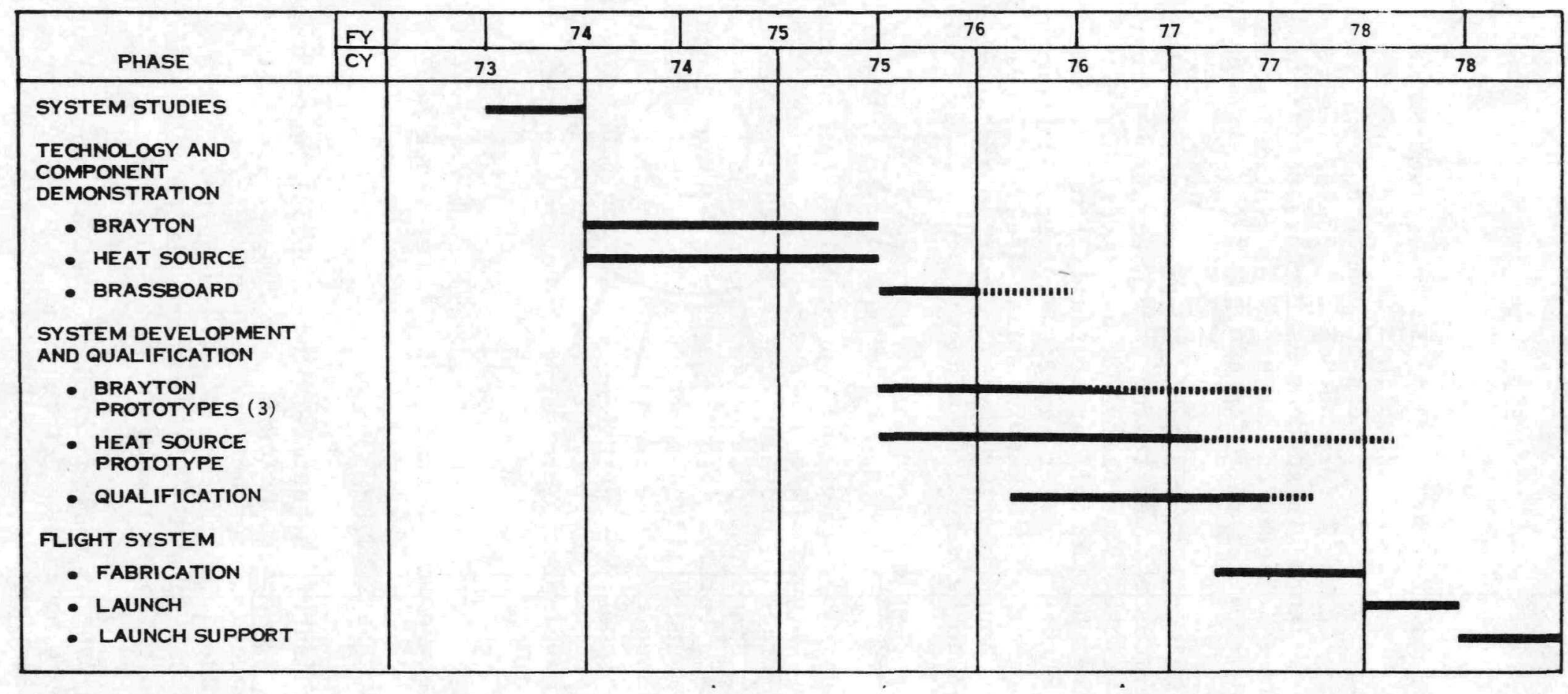




\subsubsection{HEAT SOURCE SELECTION (continued)}

Therefore, it was decided to investigate the potential for decreasing the unit cost and weight of the Conceptual Design Heat Source.

Since a major intent of this investigation was to identify a heat source with low unit and development costs a simple, uncomplicated design approach was required.

Figure 4-2 illustrates the candidate classes of fuel cladding materials and their various characteristics. Since the turbine inlet temperature is $1600^{\circ} \mathrm{F}\left(871^{\circ} \mathrm{C}\right)$, heat source temperatures will be in excess of $2012^{\circ} \mathrm{F}\left(1100^{\circ} \mathrm{C}\right)$ due to the temperature drops induced between the heat source and the heat source heat exchanger.

The superalloys are not an attractive class of materials for this application since they are incompatible with both the fuel and graphite at $1100^{\circ} \mathrm{C}$. In addition, the impact capability of the superalloys at these temperatures is minimal. The superalloys were discarded from further consideration.

The refractory metals did not appear to offer the potential for a simple heat source design due to their incompatibility with graphite and susceptibility to post-impact oxidation. In fact, because of the high power density of the Cm-244 it is difficult to maintain post-impact temperatures at levels far above the oxidation thresholds of the refractories.

The refractory oxides were judged to have the potential to offer a simple, low cost, low weight heat source design. At the $1100^{\circ} \mathrm{C}$ temperature level several of the ceramics may offer good compatibility with both curia, plutonia and graphite. Post impact containment for the ceramics is excellent due to the basic inertness of this class of material. The ceramics are inexpensive, can be co-pressed with the fuel to provide a monolithic structure and will vent helium through its natural structure.

Decontamination of the ceramic clad will be more difficult than for metallic materials, however, several promising techniques to provide adequate decontamination have been identified. These techniques include abrading the finished material or flame spraying with a thin metallic film.

Tests conducted in the past (see Section 6.0) by General Electric have demonstrated that the ceramic can be protected with modest thicknesses of thornel fiber to withstand impacts greater than $300 \mathrm{fps}$.

The noble metals are another class of materials which can be applied to the MB-ERTG heat source. Iridium is one of the noble metals. Since this family of metals does not offer the low unit cost potential of a ceramic liner and is inferior as a post-impact containment material for curia it was decided to focus on the ceramics and utilize the noble metals/MHW technology as a back-up approach . 


\begin{tabular}{|c|c|c|c|c|c|c|c|c|}
\hline \multirow[b]{2}{*}{$\begin{array}{l}\text { CLASS OF } \\
\text { MATERIALS }\end{array}$} & \multicolumn{2}{|c|}{ COMPATABILITY } & \multirow{2}{*}{$\begin{array}{l}\text { POST-IMPACT } \\
\text { CONTAINMENT } \\
\text { @ } 500^{\circ} \mathrm{C}\end{array}$} & \multirow[b]{2}{*}{$\begin{array}{l}\text { LOW COST } \\
\text { POTENTIAL }\end{array}$} & \multirow{2}{*}{$\begin{array}{l}\text { IMPACT } \\
\text { CAPABILITY } \\
@ 1100 \mathrm{C}\end{array}$} & \multirow[b]{2}{*}{$\begin{array}{c}\text { VENTING } \\
\text { CAPABILITY }\end{array}$} & \multirow[b]{2}{*}{$\begin{array}{c}\text { EASE OF } \\
\text { FABRICATION }\end{array}$} & \multirow[b]{2}{*}{$\begin{array}{l}\text { ABILITY TO BE } \\
\text { DECONTAMINATED }\end{array}$} \\
\hline & $\begin{array}{l}\text { FUEL } \\
@ 1100{ }^{\circ} \mathrm{C}\end{array}$ & $\begin{array}{l}\text { GRAPHIJE } \\
\text { @ } 1100 \mathrm{C}\end{array}$ & & & & & & \\
\hline $\begin{array}{l}\text { SUPER ALLOYS- } \\
\text { HAYNES - } 25 \text {, } \\
\text { HASTELLOY C }\end{array}$ & NO & NO & YES & YES & NO & YES & YES & YES \\
\hline $\begin{array}{l}\text { REFRACTORIES - } \\
\text { NIOBIUM, MOLYBDENUM, } \\
\text { TUNGSTEN, TANTALUM, } \\
\text { RHENIUM AND ALLOYS }\end{array}$ & YES* & NO & NO & YES & YES & YES & $\begin{array}{l}\text { YES } \\
\text { Nb, Ta }\end{array}$ & YES \\
\hline $\begin{array}{l}\text { REFRACTORY } \\
\text { OXIDES (CERAMICS)- } \\
\text { BERYLLIA, HAFNIA, } \\
\text { THORIA, ZIRCONIA, } \\
\text { YTTRIA, SAMARIA, } \\
\text { GADOL INIA, MAGNESIA } \\
\text { ALUMINA }\end{array}$ & $\begin{array}{l}\mathrm{YES}_{2}, \mathrm{ZrO}_{2} \\
\mathrm{ThO}_{2}, \mathrm{MgO}\end{array}$ & $\begin{array}{l}\mathrm{YES} \\
\mathrm{HfO}_{2}, \mathrm{ThO}_{2} \\
\mathrm{ZrO}_{2} \mathrm{BeO}\end{array}$ & YES & YES & YES & YES & YES & YES** \\
\hline $\begin{array}{l}\text { NOBLE METALS - } \\
\text { RUTHENIUM, RHODIUM, } \\
\text { PALLADIUM, OSMIUM, } \\
\text { IRIDIUM, PLATINUM } \\
\text { AND ALLOYS }\end{array}$ & $\begin{array}{l}\text { YES } \\
\text { Ir, Rh, } \\
\mathrm{Pt}_{3} \text { Ir, } \\
\text { Pt-Rh-W }\end{array}$ & $\begin{array}{l}\text { YES } \\
\text { Ir, Ru, Os }\end{array}$ & $\begin{array}{l}\text { YES } \\
\text { Rh, Pa, Ir, } \\
\text { Pt }\end{array}$ & NO & $\begin{array}{c}\text { YES } \\
\mathrm{Rh}, \mathrm{Pa}, \mathrm{Ir} \text {, } \\
\mathrm{Pt}\end{array}$ & YES & $\begin{array}{l}\text { YES } \\
\text { Pt }\end{array}$ & YES \\
\hline
\end{tabular}

- Nb \& Ta INCOMPATIBLE WITH PUO 2 " DEVELOPMENT PROGRAM REQUIRED 


\subsubsection{Ceramic Clad Heat Source Design Approach}

Two basic decisions were made early in the evaluation of ceramic clad heat source concepts: utilization of cylindrical fuel elements and a low terminal velocity heat source configuration.

The high power density of $\mathrm{Cm}-244$ makes it necessary to maintain a small dimension in the direction of heat transfer in order to avoid elevated temperatures during operation and post-impact. Figure 4-3 and 4-4 show the temperature drops across spheres and cylinders, respectively, for $\mathrm{Cm}-244$. The selection of spheres for this application would result in 15 to 30 individual fuel bodies in order to maintain reasonable temperatures drops across the fuel which preclude melting and potential swelling. Cylinders were chosen as the fuel geometry because of the design flexibility offered in terms of:

- minimizing the number of individual fuel elements

o providing a more volumetric efficient packaging geometry.

The second important aspect of the design was to configure the heat source in a low terminal velocity geometry. Figure 4-5 illustrates the terminal velocity of cylindrical and rectangular prism geometries as a function of their weight to area ratio; Figure 4-6 provides the same information for flat plates and discs. For all geometries it is apparent that W/A must be kept below the 30-40 $1 \mathrm{~b} / \mathrm{ft}^{2}$ range if terminal velocities less than $200 \mathrm{fps}$ are to be achieved.

Three candidate concepts, shown in Figure 4-7 were selected which utilized cylindrical fuel elements in a low W/A heat source geometry. The annular heat source design pictured in Figure 4-7aconsists of cylindrical fuel elements within an annular shaped crush-up body and aeroshell. Also shown is a cylindrical heat exchanger around the heat source. Configuration (b) is similar to (a) in that the cylindrical fuel elements are placed within a crush-up structure and aeroshell, but in a rectangular shape. In this case a heat exchanger with flow passages on the two faces of the heat source is shown. The third concept is similar to the Plutonium Aero-Disc (PAD) approach which has been studied by the Los Alamos Scientific Laboratory and NASA-AMES. As shown in Figure 4-7c, the fuel cylinders have been reduced to discs. Each of the discs have their own impact protection; five are then placed within an aeroshell structure. A total of six of these assemblies is shown attached to the heat exchanger plate.

Each of the geometries discussed above were evaluated parametrically to identify a weight optimum design consistent with a terminal velocity characteristic less than $200 \mathrm{fps}$. Results of the parametric evaluation are summarized in Table 4-1 for plutonia and curia fueled heat source assemblies. The lightest weight heat source assembly is offered by the rectangular prism design; this concept also has terminal velocities well below 200 fps for both fuel options.

\subsubsection{HEAT SOURCE HEAT EXCHANGER SELECTION}

Brayton system heat source heat exchangers have been under study by the General Electric Company for NASA-Lewis under contract NAS 3-16810. This work has identified $\mathrm{Nb} 103$ as the material most attractive for this application due 


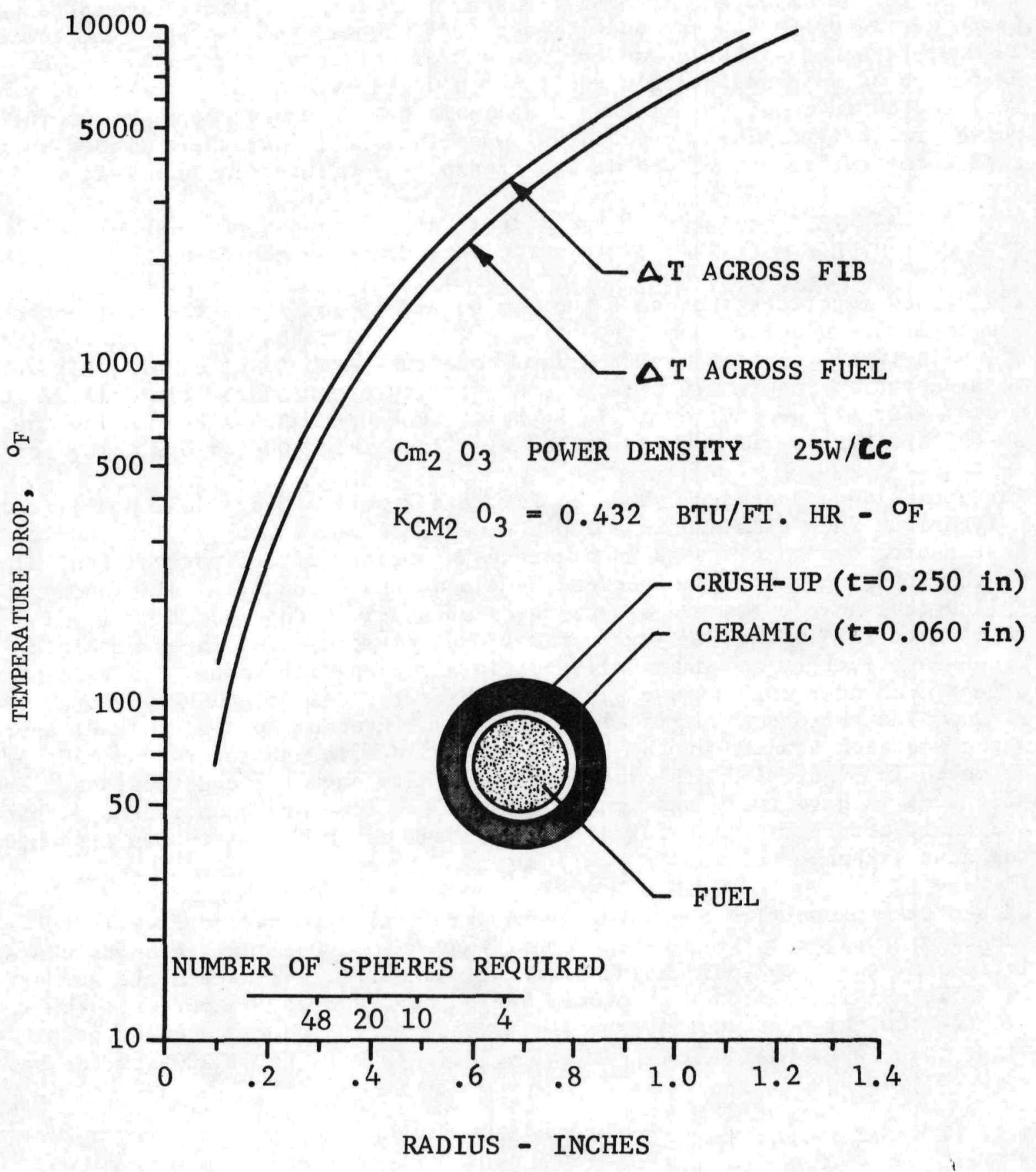

Figure 4-3. Temperature Drop Across a Ceramic Clad, Spherical Cm-244 Fuel Body 


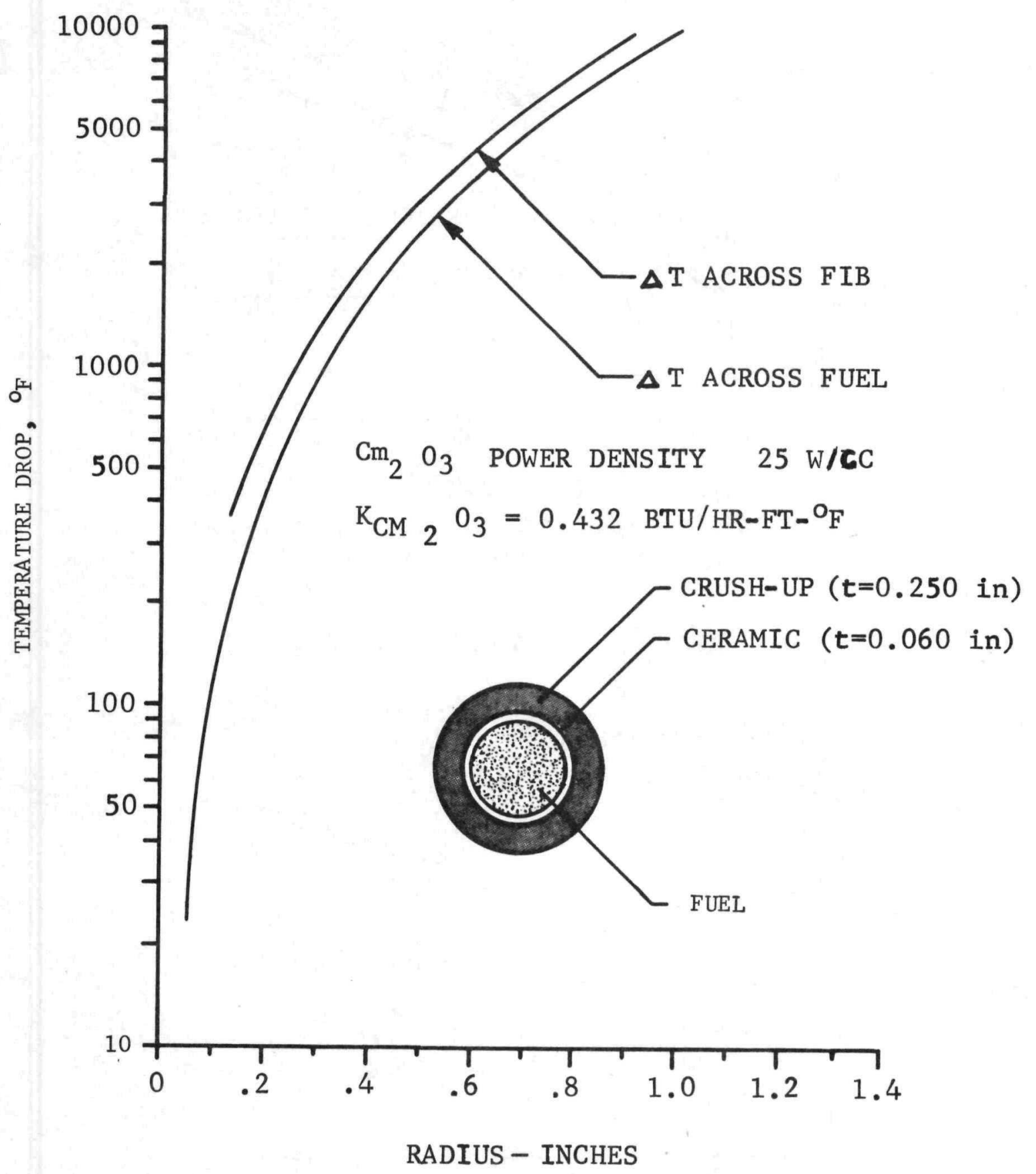

Figure 4-4. Temperature Drop Across a Ceramic Clad, Cylindrical Cm-244 Fue1 Impact Body 


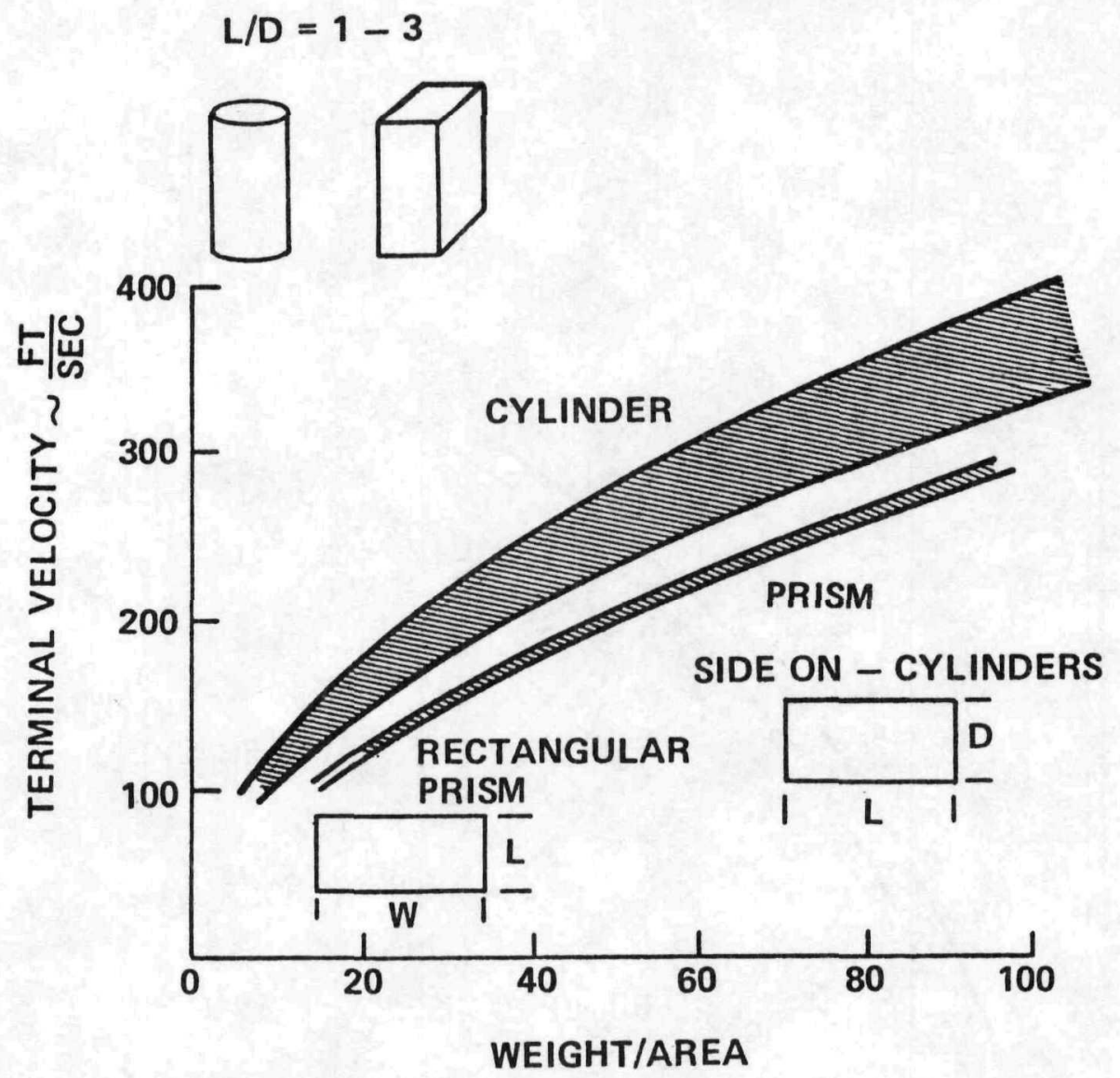

Figure 4-5. Effect of Geometry and Weight-to-Area Ratio on Terminal Velocity

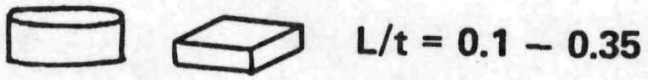

FLAT PLATE, $L / t=0.35$

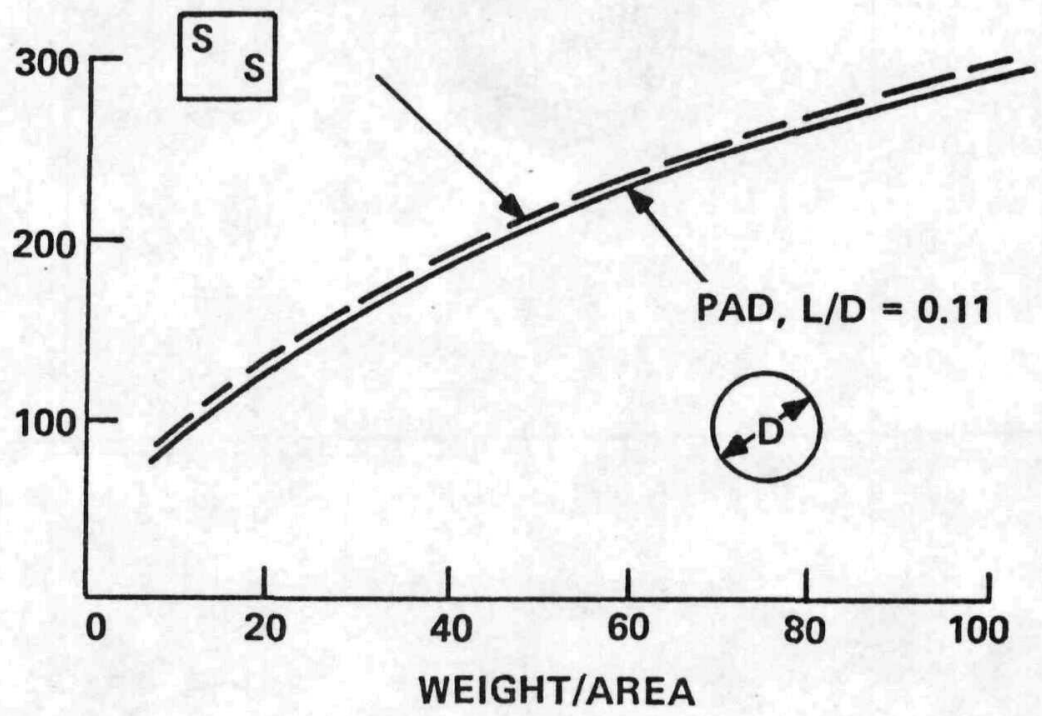

Figure 4-6. Effect of Weight-to-Area Ratio on Terminal Velocity for Flat Plates and Discs 


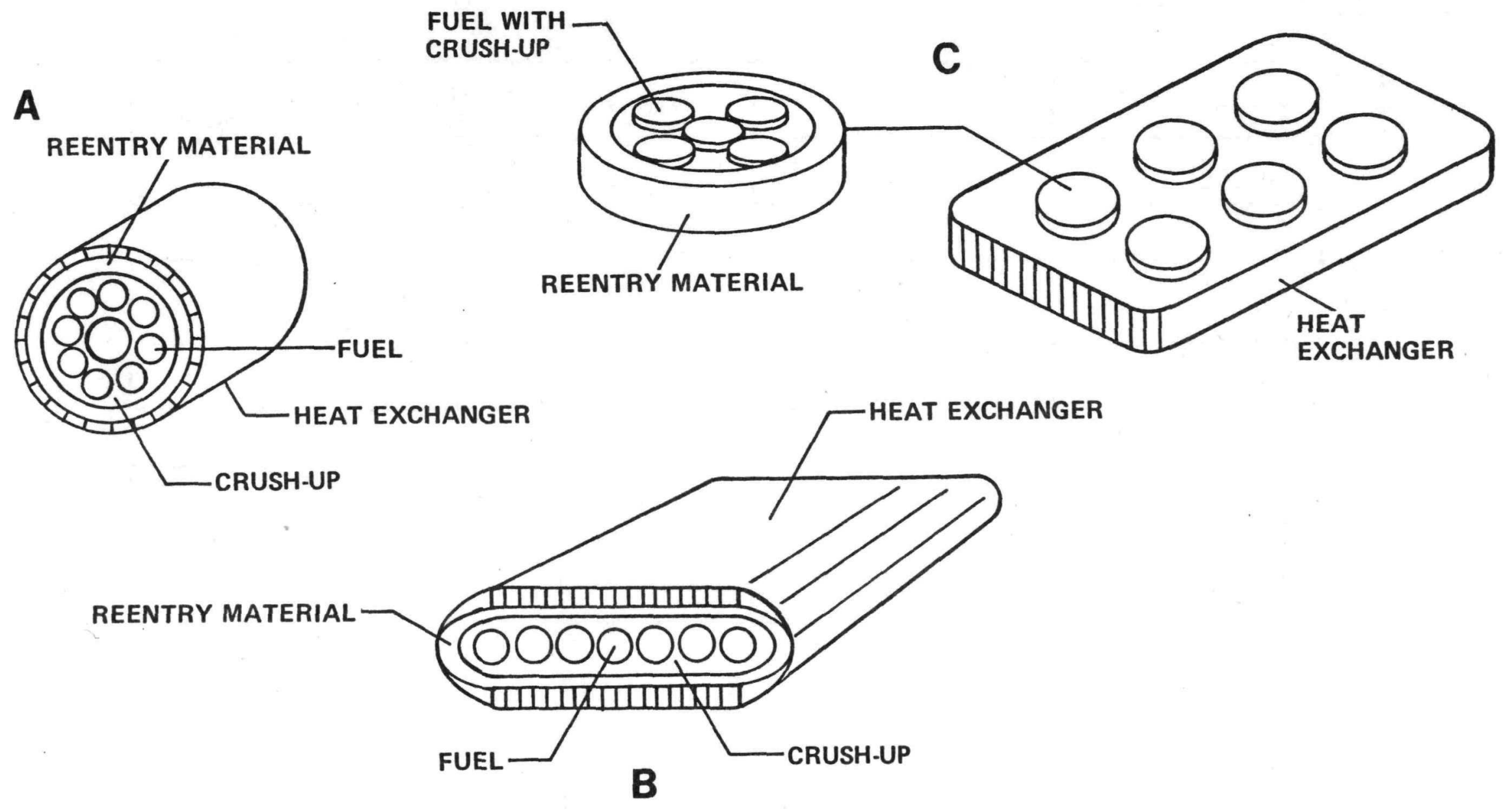




\begin{tabular}{|c|c|c|c|}
\multicolumn{2}{c}{} & $\begin{array}{c}\text { ESTIMATED } \\
\text { WEIGHT, } \\
\text { LBS }\end{array}$ & $\begin{array}{c}\text { TERMINAL } \\
\text { VELOCITY, } \\
\text { FI/ SEC }\end{array}$ \\
\hline \multirow{3}{*}{ CYLINDRICAL } & $\mathrm{PuO}_{2}$ & 37 & $180-190$ \\
\cline { 2 - 4 } & $\mathrm{Cm}_{2} \mathrm{O}_{3}$ & 20 & $135-140$ \\
\hline \multirow{3}{*}{ FLAT PRISM } & $\mathrm{PuO}_{2}$ & 28 & $145-155$ \\
\cline { 2 - 4 } & $\mathrm{Cm}_{2} \mathrm{O}_{3}$ & 15 & $125-135$ \\
\hline \multirow{2}{*}{ PAD } & $\mathrm{PuO}_{2}$ & 41 & $135-145$ \\
\cline { 2 - 4 } & $\mathrm{Cm}_{2} \mathrm{O}_{3}$ & 25 & $120-125$ \\
\hline
\end{tabular}

*HEAT SOURCE PLUS HEAT EXCHANGER - DOES NOT INCLUDE INSULATION 


\subsubsection{HEAT SOURCE HEAT EXCHANGER SELECTION (continued)}

to its relatively high strength and creep resistance in this temperature range. A comparison of material properties for $\mathrm{Nb} 103, \mathrm{~T}-111$ and Ta-10W is shown in Table 4-2.

The design work performed in the NASA study established the need for finned flow passages; fabrication techniques to provide this design feature have been identified.

The major factor in determining the HSHX design approach previously discussed in Section 3.2.2.2, is the use of $\mathrm{Cm}-244$ fuel. In order to minimize ground handling costs of the curia fueled MB-ERTG it is desirable to install the heat source in the HSHX when the MB-ERTG is attached to the spacecraft on the launch pad. Therefore, it was decided to design the HSA with a radiation gap between the heat source and the HSHX to allow for ease of heat source installation.

The basic HSHX design concept selected for the Reference Design is pictured in Figure 4-8. The rectangular design consists of an inner can which forms a central cavity for the heat source. At the top and bottom of the HSHX are finned flow passages; at each end of the HSHX are the headers for the working fluid. Bulkheads located in the headers protect the integrity of the HSHX from thermal stresses and internal pressure.

\subsubsection{EMERGENCY COOLING SYSTEM SELECTION}

The melting insulation concept was chosen as the ECS for the Reference Design MB-ERTG .

A drawback of the ECS used in the Conceptual Design is the fact that the heat pipes introduce a significant thermal leak into the HSA design. This characteristic increases the fuel inventory and cost. In the case of a Pu-238 fueled HSA the estimated heat loss from the 4 heat pipes, 120 watts, translates into a $\$ 75 \mathrm{~K}$ increase in the MB-ERTG unit cost. Over the anticipated 20 units, a $\$ 1.5$ million cost increase results.

A melting insulation concept has the potential to eliminate the thermal leak associated with the ECS. Initial estimates of the melting insulation development costs were significantly less than the projected increase in the $\mathrm{PuO}_{2}$ fuel costs. Therefore, the feasibility of the melting insulation concept was evaluated.

Figure 4-9 illustrates the time associated with melting through a blanket of a copper foil-refrasil quartz fiber paper insulation. As shown in the illustration, heat from the heat source was input to one side of the 0.7 inch insulation system. The first insulation layer melts in about 5 seconds and the entire system melts in less than 5 minutes. Estimated heat source temperatures were well below any critical limitations during the transient. 
Table 4-2. Properties of Candidate HSHX Materials

TEMPERATURE $1255^{\circ} \mathrm{K}\left(1800^{\circ} \mathrm{F}\right)$

\begin{tabular}{|c|c|c|c|c|c|c|c|c|c|c|}
\hline \multirow{2}{*}{\begin{tabular}{|l} 
CHARACTERI STIC \\
MATERI AL
\end{tabular}} & \multicolumn{2}{|c|}{ DENSITY } & \multicolumn{2}{|c|}{$\begin{array}{l}\text { TENSILE } \\
\text { STRENGTH }\end{array}$} & \multicolumn{2}{|c|}{$\begin{array}{c}\text { YIELD } \\
\text { STRENGTH } \\
\end{array}$} & \multicolumn{2}{|c|}{$\begin{array}{r}1 \% \text { CREEP } \\
(40,000 \mathrm{HR})\end{array}$} & \multicolumn{2}{|c|}{$\begin{array}{l}\text { COEFFICIENT } \\
\text { OF EXPANSION } \\
\end{array}$} \\
\hline & $L B / F T^{3}$ & $\mathrm{GM} \mathrm{CM}^{3}$ & KSI & $10^{3} \mathrm{~N} / \mathrm{CM}^{2}$ & KSI & $10^{3} \mathrm{NCM}^{2}$ & KSI & $10^{3} \mathrm{~N} / \mathrm{CM}^{2}$ & $10^{-6}$ IN. IN. ${ }^{\circ} \mathrm{F}$ & $10^{-6} \mathrm{~cm} / \mathrm{CM}^{\circ} \mathrm{C}$ \\
\hline NB- 103 & 552.5 & 8.85 & 35.0 & 24.0 & 21.0 & 14.5 & 1.8 & 1.24 & 4.3 & 7.75 \\
\hline$T-111$ & 1048.8 & 16.8 & 55.0 & 38.0 & 35.0 & 24.0 & 10.0 & 6.9 & 3.5 & 6.3 \\
\hline TA-10W & 1055.1 & 16.9 & 70.0 & 48.5 & 38.0 & 26.2 & 15.0 & 10.3 & 3.0 & 5.4 \\
\hline
\end{tabular}




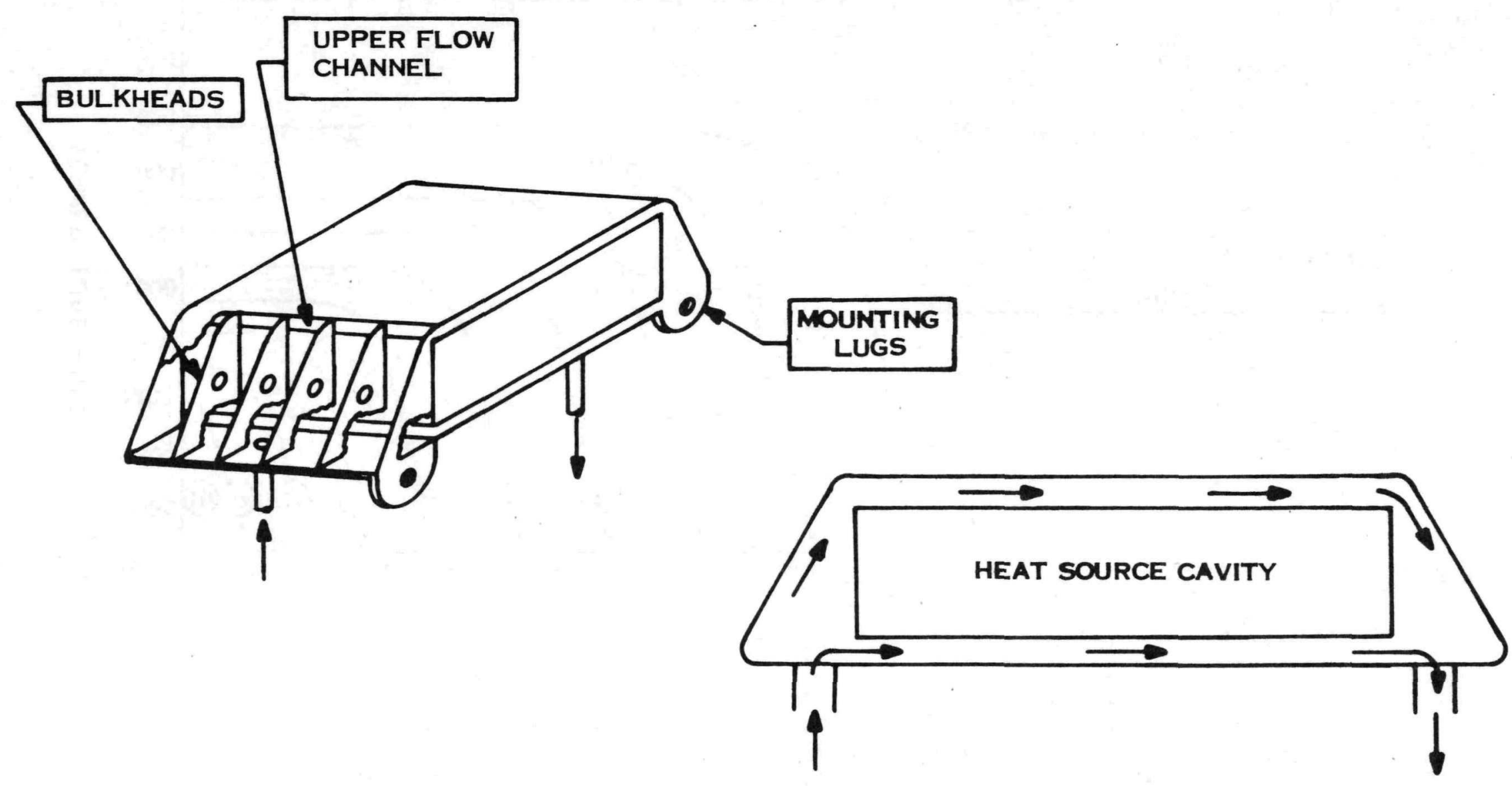




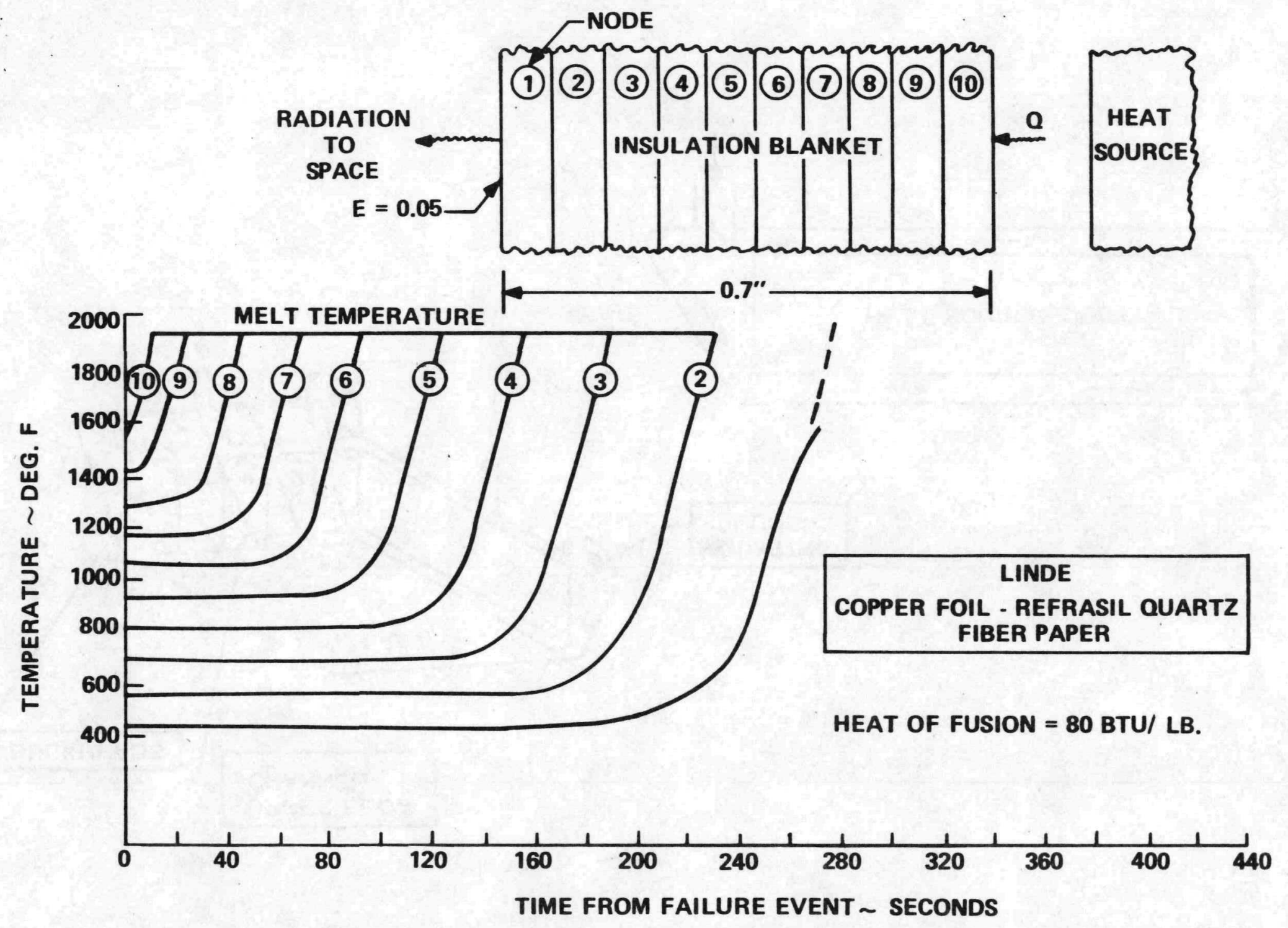




\subsubsection{MINI-BRU SELECTION}

A rotating unit using a Rice alternator was chosen for use in the Reference Design.

The Conceptual Design also incorporated a mini-BRU utilizing a Rice alternator, however, at the 400 We power level a permanent magnet alternator could offer higher efficiencies. Therefore, the PMA concept was evaluated as a means of increasing the mini-BRU alternator efficiency. The conclusion was that the Conceptual Design alternator efficiency could be increased from 88 percent to 93 percent by substituting the PMA for the Rice alternator concept. Table 4-3 lists the principal features of a 400 We mini-BRU with a PMA. The effect of the PMA on the Conceptual Design is to increase the cycle efficiency by 2 percentage points. This results in a fuel savings of approximately 150 watts or $\$ 1.9$ million of $\mathrm{PuO}_{2}$ and $\$ 0.3$ million of $\mathrm{Cm}_{2} \mathrm{O}_{3}$ for 20 MB-ERTG units.

Although the potential for considerable fuel cost savings can be attributed to the use of the PMA, the concept was not pursued further due to a fundamental change in the Development Plan. At the outset of this study, the $400 \mathrm{We}$ power level was considered to be firm, however, as the study progressed it became apparent that a reasonable probability existed for an increased power level requirement.

Development of a mini-BRU with a fixed power level in Phase 2 is expected to take 18 months to complete. If the DOD Requirement Letter were to indicate a significantly higher power level requirement (for example, $1000 \mathrm{We}$ ) Phase 3 could be delayed by as much as 18 months due to the need for re-developing the mini-BRU. The impact on total program development costs would easily exceed the potential fuel savings indicated; Phase 2 development costs for the miniBRU is estimated to be $\$ 1.3$ million (see Section 8.2 ).

A decision was made to select the mini-BRU using an oversized Rice alternator for the Reference Design. This concept would provide a machine with the capability to operate at relatively high alternator efficiencies over a broad power range (see Figure 5-2). Therefore, Phase 2 could proceed with development of the "flexible BRU" for an intended use in a 400 We system. If a change in the power level is indicated in Phase 3, the flexible BRU can be used in systems having a power output in the 400 We to 3000 We range. A summary of the design features of the flexible BRU is shown in Table 4-4.

\subsubsection{RECUPERATOR SELECTION}

The recuperator design concept used in the Reference System is the fin-plate design presented in the Conceptual Design.

The Conceptual Design recuperator is made completely from Hastelloy-X; the fin construction is identical to that developed by AiResearch and NASA-Lewis under NAS 3-16739.

Potential methods of reducing the recuperator weight were listed in Section 3.2.2.7. A summary of the candidate recuperator concepts advantages and disadvantages is shown in Table 4-5. 
Table 4-4.

Flexible BRU Performance Summary

Table 4-3.

400 We PMA BRU Performance Summary

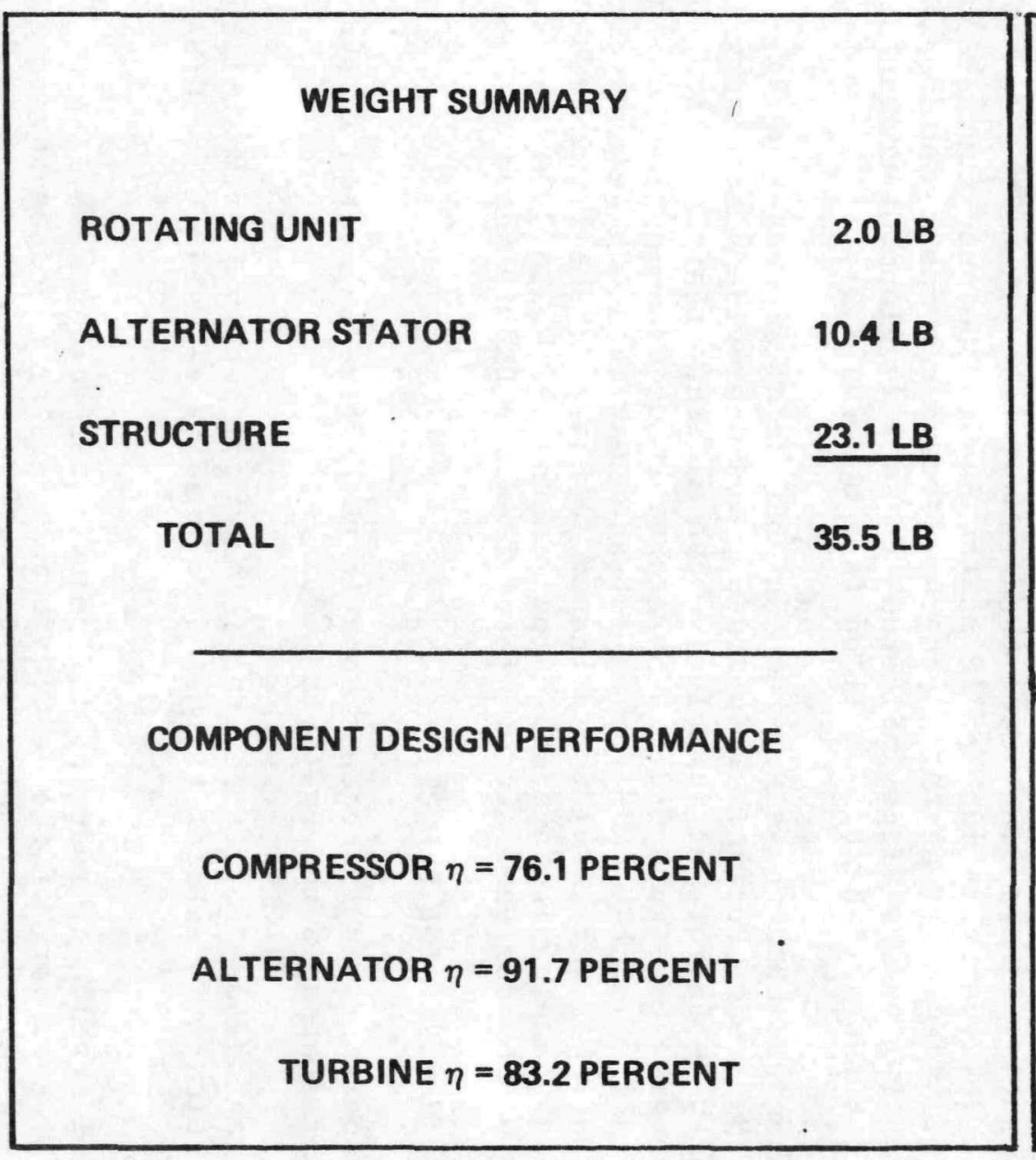

\section{WEIGHT SUMMARY}

ROTATING UNIT

$1.0 \mathrm{LB}$

ALTERNATOR STATOR

2.0 LB

STRUCTURE

16.3 LB

TOTAL

19.3 LB

COMPONENT DESIGN PERFORMANCE

COMPRESSOR $\eta=72.1$ PERCENT

ALTERNATOR $\eta=93.3$ PERCENT

TURBINE $\eta=76.4$ PERCENT 
Table 4-5. Candidate Recuperator Concepts

\begin{tabular}{|c|l|l|}
\hline CONCEPT & ADVANTAGES & \multicolumn{1}{|c|}{ DISADVANTAGES } \\
\hline Hastelloy X & Simplicity, State of Art & Fairly Heavy \\
\hline $\begin{array}{c}\text { Hastelloy X (Hot End) } \\
\text { plus }\end{array}$ & 10 percent lighter & $\begin{array}{l}\text { Complex, difficult to } \\
\text { fabricate, thermal } \\
\text { problems }\end{array}$ \\
\hline $\begin{array}{l}\text { Higher Density } \\
\text { Hastelloy-X Fins }\end{array}$ & 10 percent lighter & Requires development \\
\hline Ceramic & $\begin{array}{l}\text { Up to } 40 \text { percent lighter, } \\
\text { capable of } 3000^{\circ} \text { inlet } \\
\text { temperature }\end{array}$ & $\begin{array}{l}\text { Requires extensive } \\
\text { development }\end{array}$ \\
\hline
\end{tabular}




\subsubsection{RECUPERATOR SELECTION (continued)}

The ceramic recuperator has the greatest weight savings potential of the concepts considered, however, development of this concept is still in the formative stages. A judgement was made that development of the ceramic recuperator would require time and monies inconsistent with the expected time frame and cost objectives of the SURVSATCOM application.

The bimetallic Hastelloy-X/titanium concept yields a four-pound reduction in the recuperator weight. This comparatively small effect must be traded-off against the cost of developing a sophisticated piece of hardware with potentially more thermal stress considerations than the existing design. The small weight advantage does not justify selection of the bimetallic concept.

Use of a higher density fin design could also result in a recuperator weight reduction. This concept has the potential to decrease the recuperator weight by ten percent. At the present time, however, successful development of a fin die is in question. Therefore, this approach will be considered in future studies but will not be incorporated into the Reference Design.

\subsubsection{RADIATOR SELECTION}

The Reference Design employed a cylindrical aluminum radiator with an offset fin-tube geometry. This concept was selected as a result of years of study and fabrication experience with this design approach. The cylindrical configuration provides an excellent load bearing structure which is easily integrated with the spacecraft. The high thermal conductivity, high ratio of elastic modulus to density, availability and fabricability makes aluminum a technically attractive and cost effective material choice.

Beryllium is a material which has received considerable attention in the past for use as a space radiator. Beryllium combines the attractive properties of aluminum with an even lower material density which suggests a potential weight saving with this material.

Parametric studies performed with the SPARTAN III computer code confirmed the weight attractiveness of the beryllium approach; these results are shown in Figure 4-10. At meteoroid survival probabilities of 0.98 the beryllium radiator introduces a 30 to 50 percent savings in weight over the aluminum concept. At higher meteoroid survival probabilities, the effect was even more apparent; at this design condition, 0.99 probability of non-puncture, weight savings of $60-75$ percent are realizable.

The effect of the beryllium radiator on the MB-ERTG Conceptual Design, with a turbine inlet of temperature of $1700^{\circ} \mathrm{F}$, was evaluated. A comparison between the aluminum and beryllium systems with $\mathrm{PuO}_{2}$ fuel is shown in Section 4.2.3. The effect of the beryllium radiator on the system results in trading off radiator weight for recuperator weight and thereby increasing the recuperator effectiveness and system efficiency'.

The cost impact of increasing the system efficiency is dependent upon the fuel cost. Figure 4-11 summarizes the beryllium/aluminum radiator trade-off for $\mathrm{Pu}-238$ and $\mathrm{Cm}-244$ fueled production units. 


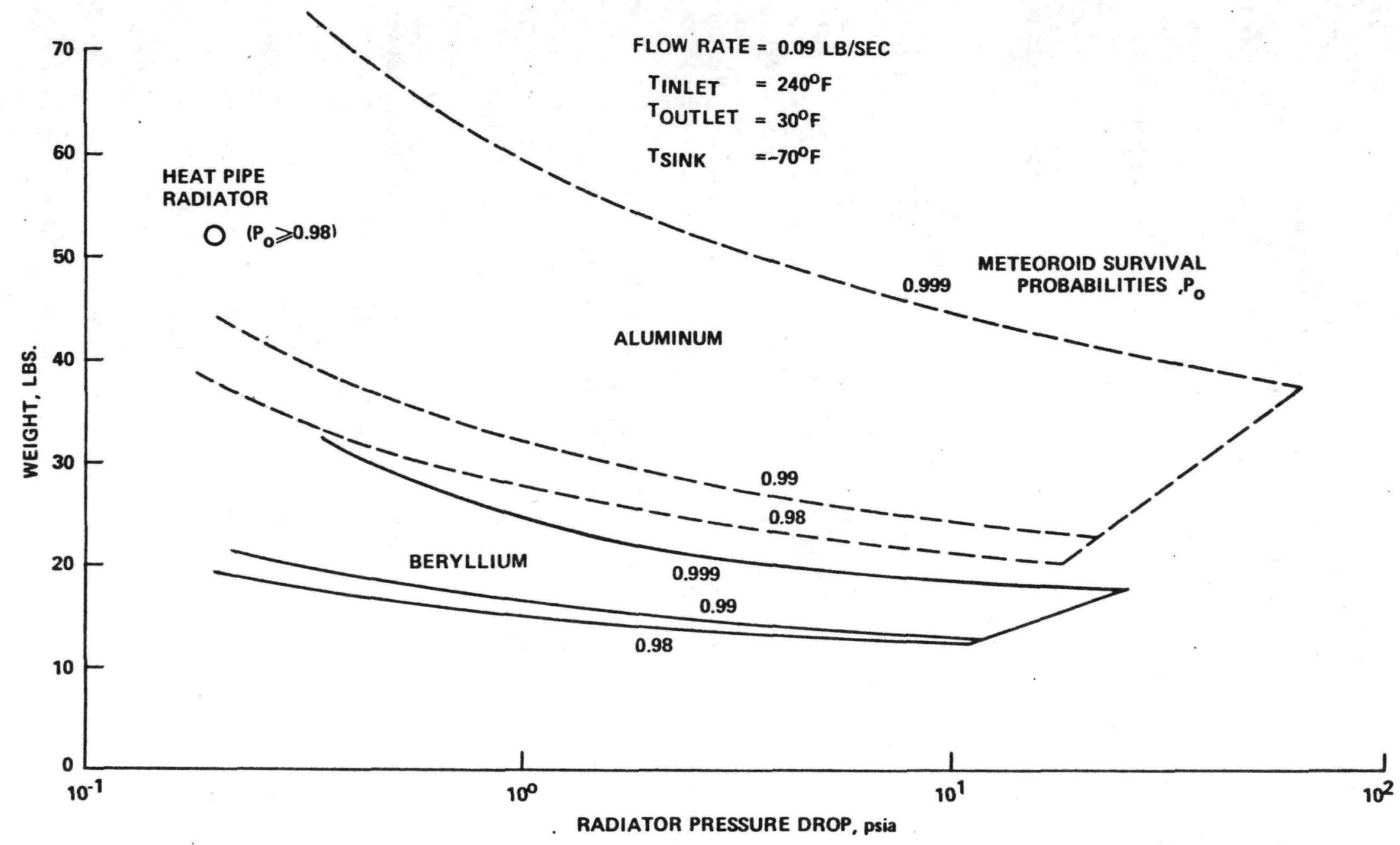

Figure 4-10. Comparison of Radiator Weights as a Function of Pressure Drop and Meteoroid Survival Probability 


\subsubsection{RADIATOR SELECTION (continued)}

The cost increment for using a beryllium as compared to an aluminum radiator is shown as "net excess beryllium radiator cost" in Figure 4-11, as a function of the number of production units. Before one unit is built this figure is estimated to be $\$ 241 \mathrm{~K}$ as a result of increased radiator fabrication costs in Phases 2, 3 and 4. Assuming Pu-238, the savings in fuel is estimated to be approximately $\$ 80 \mathrm{~K}$ per unit. Therefore, it becomes cost effective to use a beryllium radiator with a Pu-238 fueled system after five systems have been built.

In the case of a $\mathrm{Cm}-244$ fueled system, the estimated fuel cost savings of $\$ 10 \mathrm{~K}$ per unit does not match the additional $\$ 15 \mathrm{~K}$ per unit for the beryllium radiator.

\subsection{MB-ERTG SYSTEMS DESCRIPTIONS}

This section presents a description of the Reference Design which features a curia fueled HSA, flexible BRU and aluminum radiator. Options to this design are also discussed; these include systems with a fixed power BRU, plutonia fueled systems and a plutonia fueled system with a beryllium radiator.

The Reference Design presented offers the mission planner considerable flexibility with regard to final power level selection, fuel selection and system characteristics. The incorporation of a "flexible BRU", a long lead development item, into the Reference Design allows a cost effective development program to be initiated prior to a final power level selection. Due to the high efficiency of the MB-ERTG the USAF cost objectives can be met with either a $\mathrm{Pu}-238$ or $\mathrm{Cm}-244$ fuel. Therefore, the HSA conceptual design can accommodate a $\mathrm{Pu}-238$ or $\mathrm{Cm}-244$ fueled heat source; either HSA is interchangeable with the remainder of the system. Another aspect of flexibility is that weight can be traded-off against efficiency to provide systems with either very low weight or very high efficiencies.

\subsubsection{REFERENCE DESIGN DESCRIPTION}

The Reference Design was selected from the MB-ERTG Design Optimization Computer Code which plots the locus of minimum weight systems as a function of system efficiency. The component concepts assumed for this are:

Heat Source - ceramic clad; flat prism design

HSHX - Nb construction, single pass, double passage concept

BRU - Rice alternator, foil bearing design, $1700^{\circ} \mathrm{F}$ turbine inlet temperature

Recuperator - Haynes 188 or Hastelloy-X, double containment concept

Radiator - aluminum construction, cylindrical, load bearing design

Results of the cycle optimization are shown in Figure 4-12. The point 


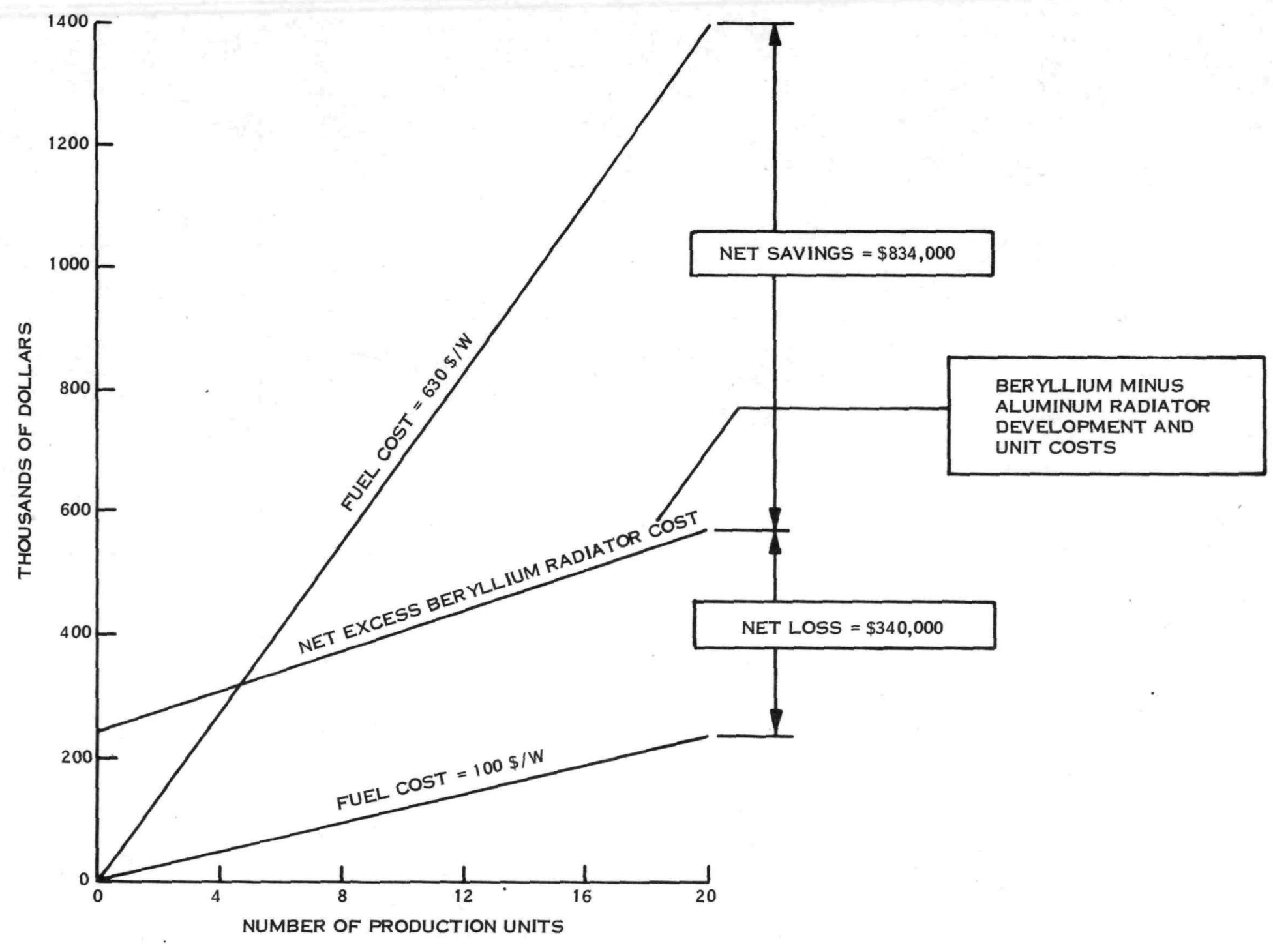




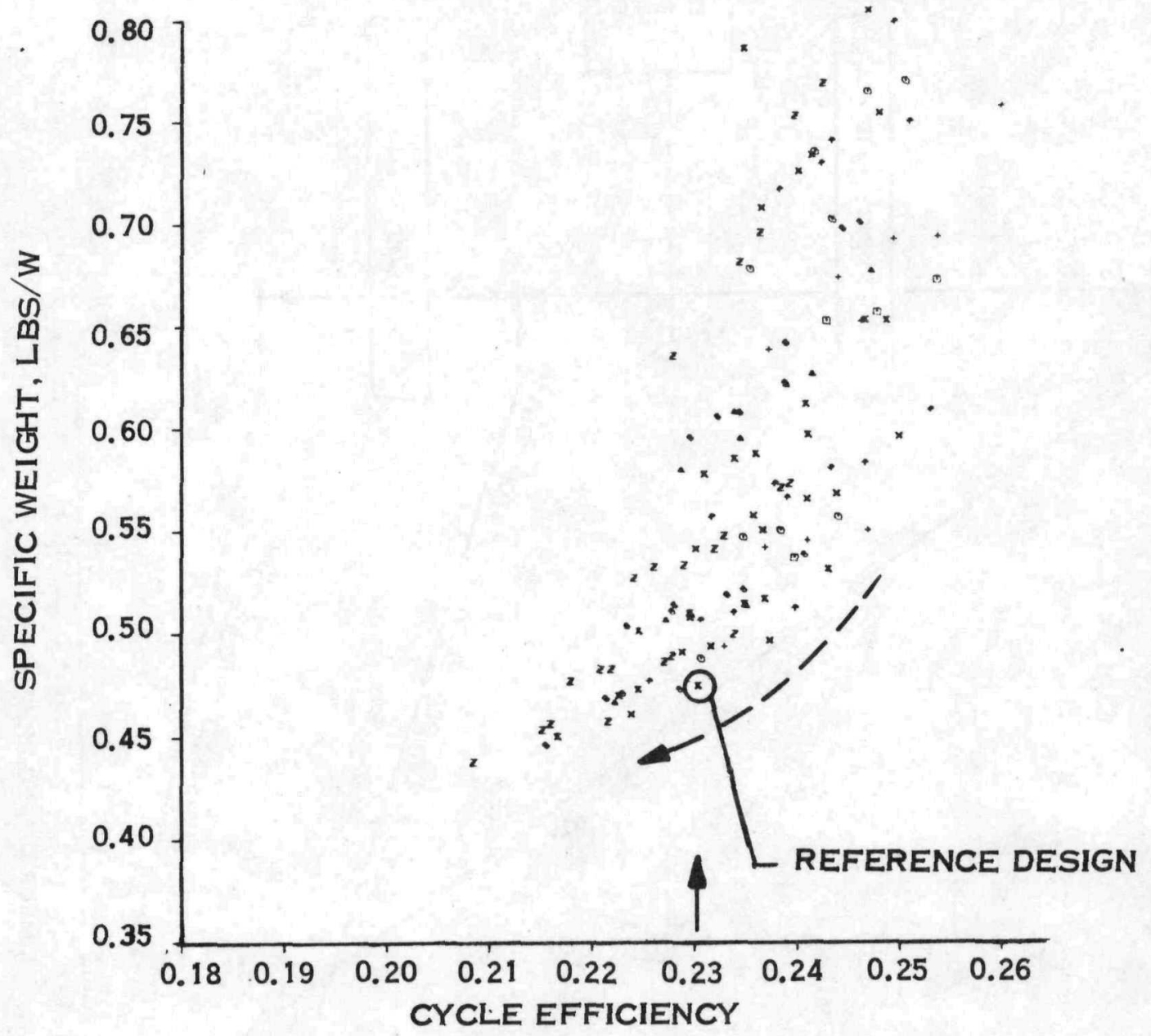

Figure 4-12. MB-ERTG 400 We Reference System Design Optimization 


\subsubsection{REFERENCE DESIGN DESCRIPTION (continued)}

selected allows the MB-ERTG to meet the USAF system weight objectives even when the spacecraft shield weight is included and provides a 23 percent system efficiency. Overall system weight could be reduced further by accepting a lower system efficiency.

Cycle conditions at end of mission are illustrated in Figure 4-13. Turbine inlet temperature and radiator outlet temperature have been raised $90^{\circ} \mathrm{F}\left(50^{\circ} \mathrm{C}\right)$ and $40^{\circ} \mathrm{F}\left(22^{\circ} \mathrm{C}\right)$, respectively, from that of the Conceptual Design. Table 4-6 lists the principal system characteristics of the Reference System. Turbine and compressor efficiencies are higher than that quoted in the Conceptual Design due to the larger wheel diameters on the flexible BRU. This is offset, however, by a lower alternator efficiency at the 400 We power level. Component characteristics are covered in Section 4.3.

In the Reference Design 92 percent of the radioisotope heat is assumed to be transferred to the working fluid throughout the mission. As a result of the radioisotope decay there is an 18 percent change in the heat entering the Brayton loop from beginning to end of mission. The variable heat input or "power flattening problem" is solved by adjusting the mini-BRU RPM so as to change the flow rate and heat transferred in the HSHX during the mission. At BOM the BRU RPM is calculated to be 58,000 RPM; this decreased to 52,000 RPM at EOM. In order to reject the additional heat at BOM the radiator exit temperature is about $20^{\circ} \mathrm{F}$ higher and the turbine inlet temperature is $15^{\circ} \mathrm{F}$ higher at BOM.

Total weight for the Reference Design MB-ERTG is 186 pounds; in addition a neutron shield is required to meet the USAF 5 year maximum neutron dose level of 1012 nvt. The lithium hydride shield thickness is $10 \mathrm{Cm}$ and adds 14 pounds to the system weight.

A breakdown of the component weights is provided in Table 4-7. The calculated HSA weight includes the heat source, HSHX and melting insulation weight. Weights for the mini-BRU and recuperator also result from detailed calculations. The radiator weight was determined from the General Electric SPARTAN III Radiator Code. The electronics and controls weight includes 5 pounds for the parasitic load resistors and 4 pounds for controls. A detailed calculation for the control weight was not performed.

The insulation weight 1 isted in Table 4-7 refers to insulation around the recuperator and ducting. Ducting and structural weights resulted from calculations performed in conjunction with the Reference Design layout, shown in Figure 2-1, and typical Tital III C launch conditions.

The MB-ERTG configuration shown in Figure 2-1 is determined primarily from the cylindrical radiator configuration. The HSA is situated at the top of the cylinder in order to minimize heat leaks into the spacecraft and to provide accessibility to the heat source. Parasitic load resistors are aside of the HSA. The neutron shield has been placed immediately to the rear of the HSA so as to minimize its size. The mini-BRU is shown beneath the shield; note that the rotor of the mini-BRU is oriented horizontally in order to eliminate 


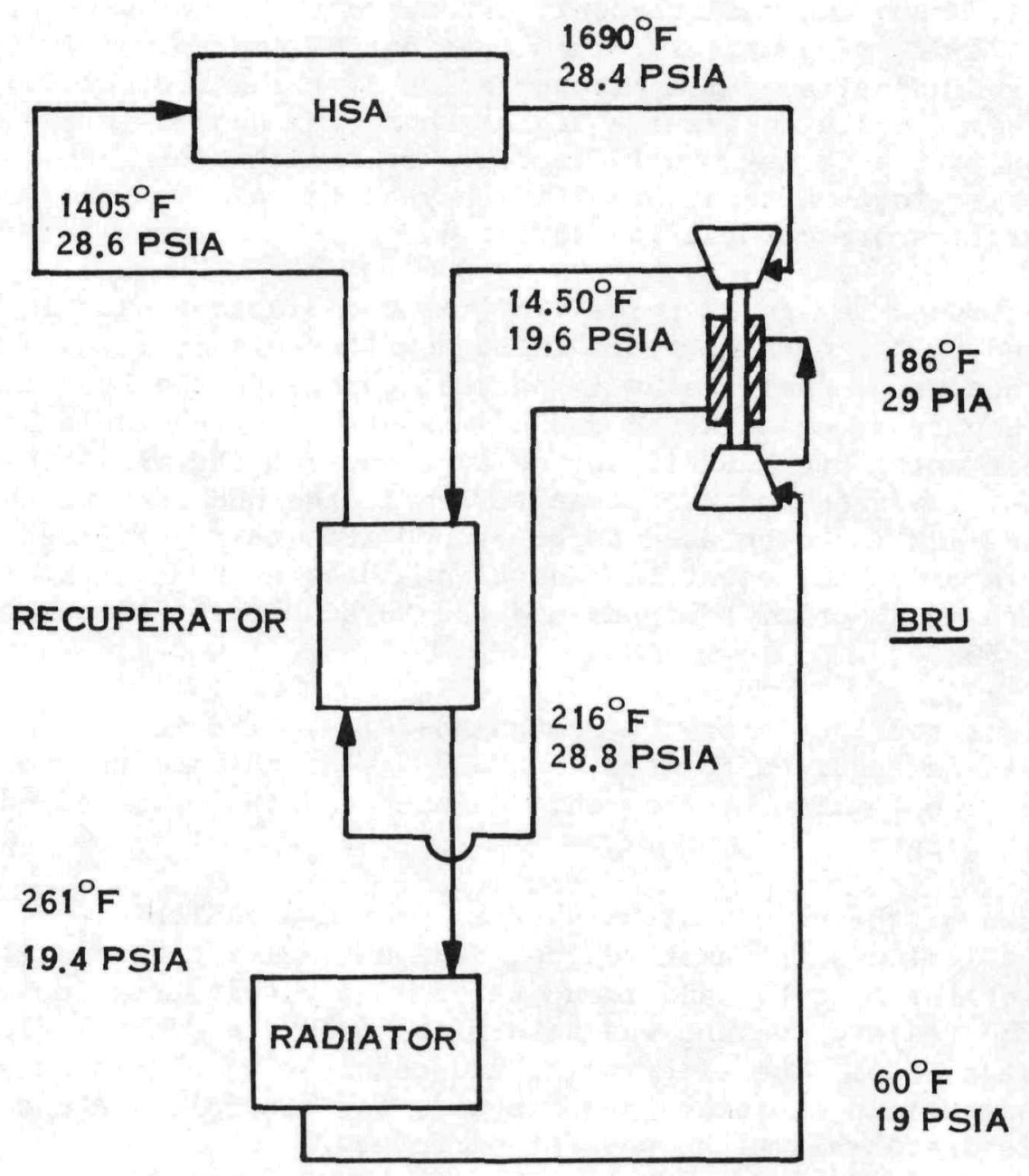

END OF MISSION CONDITIONS

Figure 4-13. Reference Design Cycle Conditions 
Table 4-6.

Principal Reference Design Characteristics

\begin{tabular}{|lc|}
\hline \multicolumn{1}{|c|}{ REFERENCE DESIGN } & \multicolumn{1}{c|}{ HE/XE } \\
FLUID & 0.073 \\
FLOW RATE, LB/SEC & 52,000 \\
BRU RPIM & 79 \\
TURBINE EFFICIENCY, $\%$ & 2.2 \\
TURBIINE WHEEL DIAMETER & 75 \\
COMPRESSOR EFFICIENCY, $\%$ & 1.8 \\
COMPRESSOR WHEEL DIAMETER & 1.5 \\
COMPRESSOR PRESSURE RATIO & 455.2 \\
ALTERNATOR OUTPUT, W & 55.2 \\
CONTROL POWER, W & 86 \\
ALTERNATOR EFFICIENCY, \% & 76 \\
BEARING LOSS, W & 19 \\
WINDAGE LOSS, W & \\
RECUPERATOR EFFECTIVENESS & \\
\hline
\end{tabular}

Table 4-7.

Reference Design MB-ERTG Weight Summary

\begin{tabular}{|l|c|}
\hline \multicolumn{1}{|c|}{ COMPONENT } & $\begin{array}{c}\text { REFERENCE } \\
\text { DESIGN }\end{array}$ \\
\hline HEAT SOURCE ASSEMELY & 21 LBS \\
BRU & 35 \\
RECUPERATOR & 46 \\
RADIATOR & 47 \\
ELECTRONICS AND CONIKOLS & 9 \\
INSULATION & 6 \\
DUCTING & 5 \\
STRUCTURAL & 17 \\
\hline SYSTEM WEIGHT & 186 \\
SHIELD VEIGHT & 14 \\
\hline \multicolumn{1}{|c|}{ TOTALS } & 200 LBS \\
\hline
\end{tabular}




\subsubsection{REFERENCE DESIGN DESCRIPTION (continued)}

cross-coupling torques with the spacecraft. The recuperator, a major weight component has been placed under the mini-BRU to lower the system center-ofgravity. System controls are mounted from a support cone at the bottom of the radiator and receive radiation protection from the lighium hydride shield.

\subsubsection{We MB-ERTG DESIGN}

The Reference Design uses a mini-Bru with an oversized Rice alternator which enables it to provide power outputs in the 3000 We range when coupled with the proper system. An investigation was performed to evaluate the penalty of providing this design flexibility. A cycle optimization was performed to establish the weight and efficiency of the MB-ERTG with the same design characteristics; except a smaller mini-BRU having a permanent magnet generator was substituted for the flexible BRU. The resulting design has a system weight of 188 pounds and a net system efficiency of 25 percent. The weight saved by using the PMA BRU was traded-off for additional recuperator weight, thereby increasing the cycle efficiency. Therefore, by making this substitution a 2 percent increase in efficiency can be realized for no increase in total system weight. A weight breakdown of the 400 We design is given in Table 4-8.

Table 4-8. MB-ERTG 400 We Design Weight Summary

\begin{tabular}{|lc|}
\hline \multicolumn{1}{|c|}{ COMPONENT } & WEIGHT \\
\hline Heat Source Assembly & 19 lbs \\
BRU & 19 \\
Recuperator & 67 \\
Radiator & 45 \\
Electronics and Controls & 9 \\
Insulation & 7 \\
Ducting & 5 \\
Structural & 17 \\
\hline System Weight & 188 \\
Shield Weight & 14 \\
\hline Totals & 202 lbs \\
\hline
\end{tabular}




\subsubsection{Pu-238 FUELED MB-ERTG'S}

Although the emphasis of this study has been placed on curia fueled heat sources, due to the potential delay in $\mathrm{Cm}-244$ availability, plutonia fueled systems were also investigated. The ceramic clad heat source is adaptable to either curia or plutonia fueled systems, as is the overall HSA design. Furthermore, since the MB-ERTG power flattening approach is to allow the excess heat to enter the system (see Section 4.2.1), a plutonia fueled HSA can be substituted directly for a curia fueled HSA.

Direct substitution of a plutonia fueled HSA in the Reference Design yields a system having a total weight of $207 \mathrm{lbs}$ and an efficiency of 23 percent. Removal of the neutron shield would be the only other change to the system. The increase in the system weight is due to the lower power density of the $\mathrm{Pu}-238$ fuel which results in a larger HSA design.

Since the plutonia fuel is considered to be more expensive than curia fuel, $\$ 630 /$ watt compared to $\$ 100 /$ watt, it is desirable to increase the MB-ERTG efficiency within the weight envelope. The use of a beryllium radiator is recommended to increase the efficiency of plutonia fueled MB-ERTG's. Substitution of beryllium for aluminum results in a 21 pound weight savings. Consequently, the recuperator weight and effectiveness can be increased to result in an overall system efficiency increase.

Table 4-9 summarizes the two $\mathrm{PuO}_{2}$ systems discussed. The optimized system contains a beryllium radiator as well as an optimized mini-BRU using a PMA. The optimized mini-BRU also increases the efficiency and reduces the weight of the plutonia fueled Reference Design.

The $\mathrm{PuO}_{2}$ inventory for the optimized system is only $1550 \mathrm{~W}$ with a system weight of 193 pounds. Unit cost of the system is $\$ 1.51$ million. Therefore, the MB-ERTG can be designed to meet the USAF-SPO using a plutonia fueled HSA.

\subsection{REFERENCE DESIGN COMPONENT CHARACTERISTICS}

This section presents a description of the components which comprise the Reference Design. Component design assumptions, characteristics and weights are presented. The Reference Design control system is identical to that reviewed in Section 3.2.1.2 for the Conceptual Design and is not repeated here.

\subsubsection{REFERENCE HEAT SOURCE DESIGN}

The Reference Heat Source is a thoria clad design having 9-244 watt curia fueled FIB's. Figure 4-14 illustrates the heat source geometry.

Total weight of the heat source is 8.6 pounds. The aeroshell is sized to withstand a face-on or edge-on reentry; 0.20 and 0.50 inches of POCO graphite are shown on the faces and edges, respectively, of the heat source. The aeroshell impact core assembly acts as a thermal barrier to the FIB during a potential reentry and also provides additional clad impact protection. Each FIB has 0.225 inches of thornel-50 on the sides of the cylinder and 0.240 inches 


\begin{tabular}{|l|l|}
\hline \multicolumn{2}{|l|}{\begin{tabular}{|l|}
\hline \multicolumn{2}{|l|}{$\begin{array}{l}\text { REFERENCE MB-ERTG DESIGN } \\
\text { USING AU-238 HSA }\end{array}$} \\
BRU CAPABILITY
\end{tabular}} \\
FUEL, PU $0_{2}$ & $1810 \mathrm{~W}$ \\
FUEL CLAD & CERAMIC \\
RADIATOR MATERIAL & ALUMINUM \\
TOTAL SYSTEM WEIGHT, LBS & 207 \\
NET SYSTEM EFFICIENCY, PERCENT & 23.0 \\
UNIT COST & $\$ 1,670 \mathrm{~K}$ \\
\hline SUBSYSTEM WEIGHTS & \\
\hline HEAT SOURCE ASSEMBLY & 42 \\
BRAYTON ROTATING UNIT & 35 \\
RECUPERATOR & 46 \\
RADIATOR & 47 \\
SHIELD & 0.0 \\
ELECTRONICS AND CONTROLS & 9 \\
INSULATION & 6 \\
DUCTING & 5 \\
STRUCTURAL & 17 \\
\hline
\end{tabular}

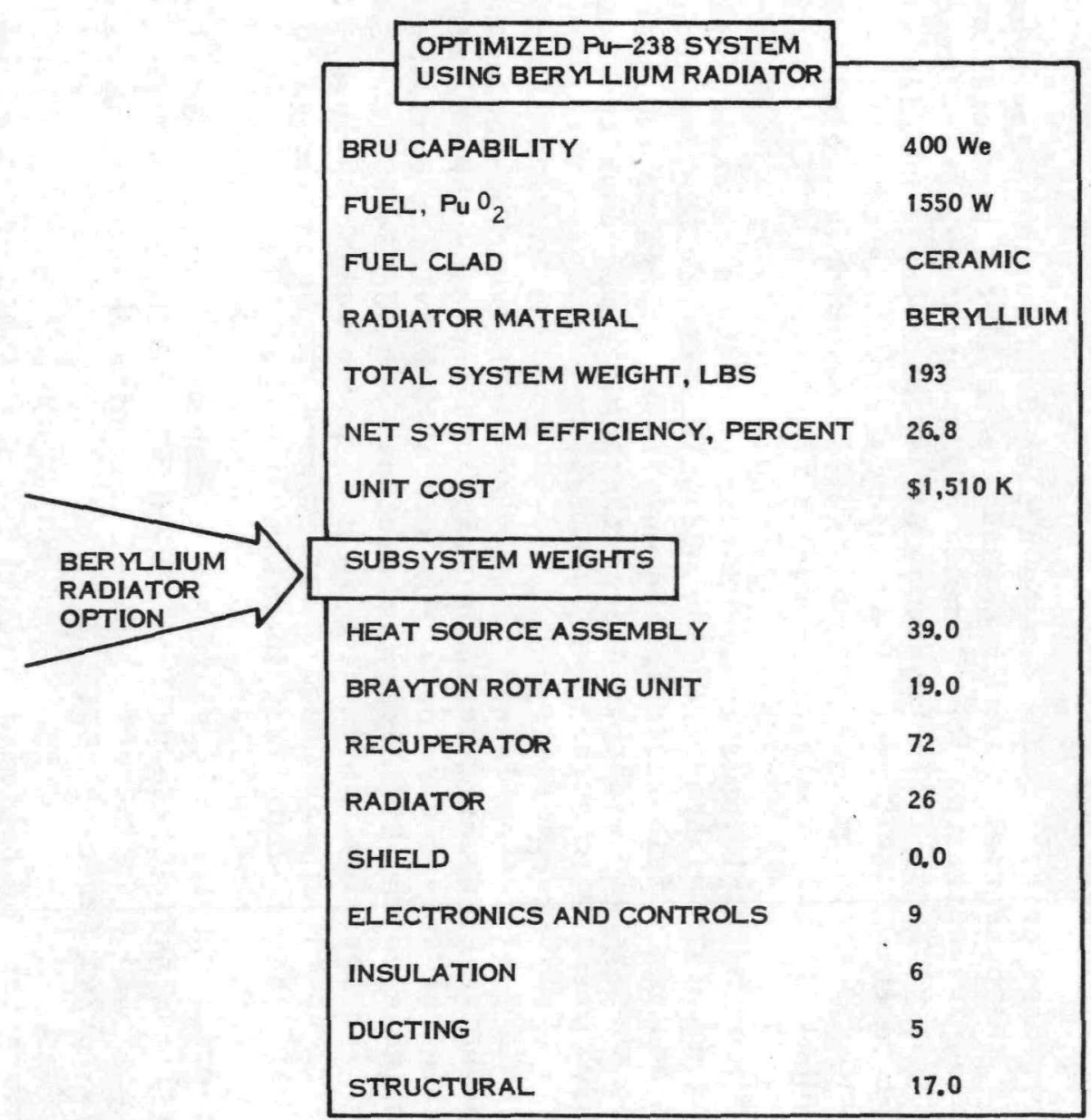




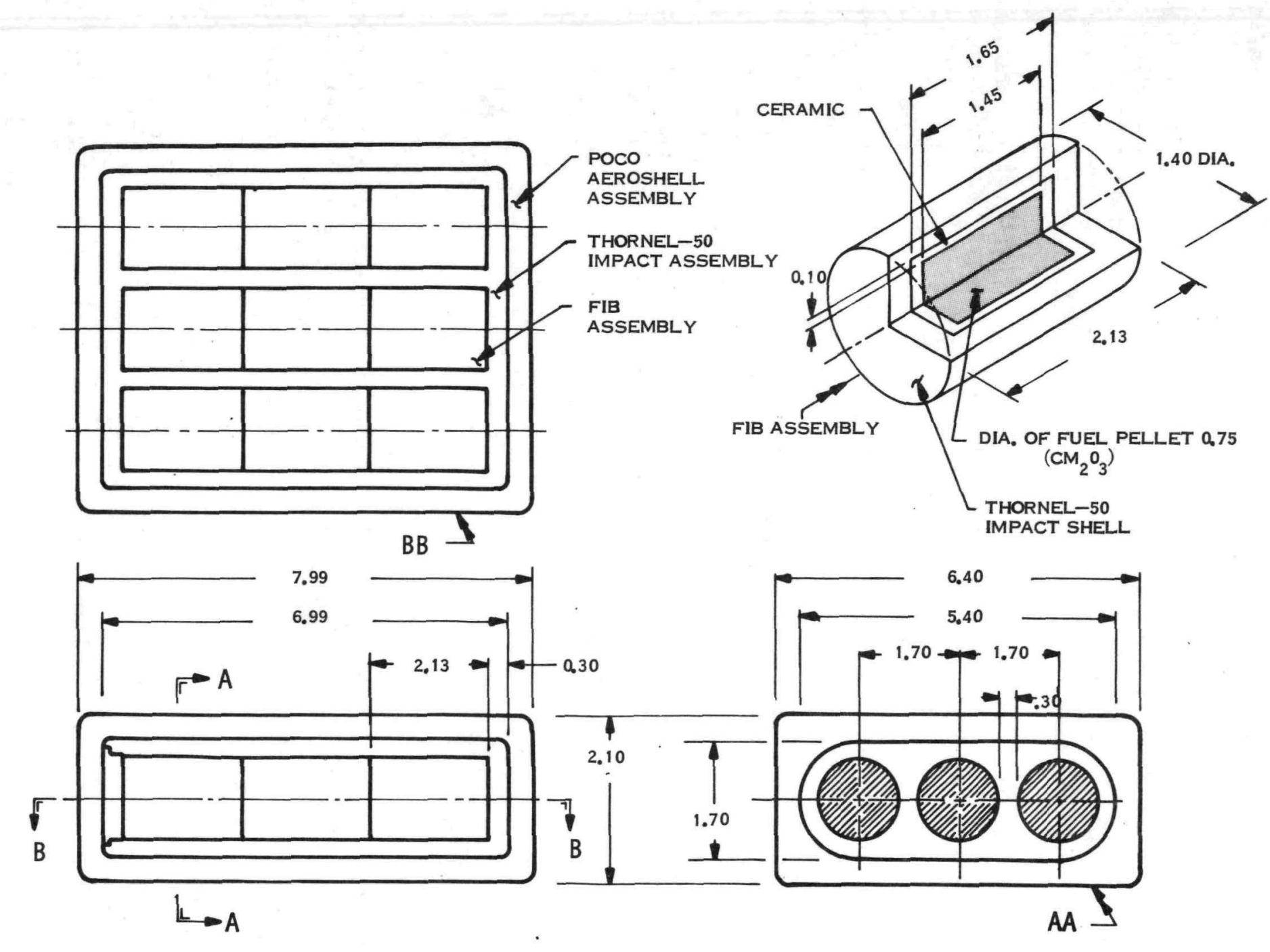




\subsubsection{REFERENCE HEAT SOURCE DESIGN (continued)}

on the ends. This design gives the FIB individual impact protection at the heat source terminal velocity of $<180 \mathrm{fps}$. Calculated impact capability of the overall heat source is $283 \mathrm{fps}$ for a flat impact and $225 \mathrm{fps}$ for an end-on impact.

Thoria was selected as the ceramic clad based on its known compatibility with plutonia and graphite at $1100^{\circ} \mathrm{C}$ and its acceptable impact performance. A final determination of the ceramic clad material would be made during the heat source technology effort in Phase 2 of the development program. Zirconia is another ceramic which shows promise as a clad material.

FIB impact protection requirements were based on the ability of the ceramics to survive the initial impact transient shock wave stress. The shock wave stress is principally dependent on the material impedances of the graphite/ ceramic media and the surface on which the body impacts.

The shock wave pressure (compressive stress) in the graphite may be expressed in terms of impact velocity $\left(\mathrm{V}_{\mathrm{I}}\right)$.

$$
p\left(\sigma_{c}\right)=\frac{I_{0} V_{I}}{1+I_{0} / I_{G}}
$$

where subscripts $O$ and $G$ represent the graphite and granite media, and I the material impedance. The material impedance is expressed as follows:

$$
I=\rho C
$$

where

$$
\begin{aligned}
& \rho=\text { mass density } \\
& C=(E / \rho)^{1 / 2} \text { or speed of shock wave in media. }
\end{aligned}
$$

It can be shown that the shock wave stress transmitted between the graphite and ceramic is amplified by a factor of 1.8 due to the impedance mismatch at the boundary between the two materials. Using the material properties given in Tables 4-10 and 4-11, the resulting compressive stress in the ceramic is predicted as

$$
\begin{aligned}
& \sigma_{C}=60 \mathrm{v}_{\mathrm{I}} \quad \text { (granite surface) } \\
& \sigma_{C}=65 \mathrm{v}_{\mathrm{I}} \quad \text { (rigid surface) }
\end{aligned}
$$

During impact a transient tensile wave stress is generated on the cylindrical surface which may be approximated by

$$
\sigma_{T}=P(1-E / 3 G)
$$


TABLE 4-10 CERAMIC MATERIAL PROPERTIES

\begin{tabular}{|c|c|c|c|c|c|c|c|c|c|c|c|c|}
\hline \multirow[b]{2}{*}{ CERAMIC } & \multicolumn{4}{|c|}{$\mathrm{T}=1000^{\circ} \mathrm{F}$} & \multicolumn{4}{|c|}{$\mathrm{T}=1500 \circ \mathrm{F}$} & \multicolumn{4}{|c|}{$\mathrm{T}=2200^{\circ} \mathrm{F}$} \\
\hline & $\mathrm{F}_{\mathrm{TU}}$ & $\mathrm{F}_{\mathrm{CU}}$ & $E^{*}$ & G & $\mathrm{F}_{\mathrm{TU}}$ & $\mathrm{F}_{\mathrm{CU}}$ & $\mathrm{E}$ & G & $\mathrm{F}_{\mathrm{TU}}$ & $\mathrm{F}_{\mathrm{CU}}$ & $\bar{E}$ & G \\
\hline BERYLLIA & 10.5 & 70 & 79.0 & 29.5 & 8.0 & 50 & 72.5 & 23.0 & 1.5 & 26 & 41.0 & 15.4 \\
\hline Z IRCONIA & 17.5 & 224 & 38.0 & 20.0 & 16.5 & 208 & 35.0 & 18.5 & 12.5 & 110 & 32.0 & 15.0 \\
\hline THORIA & 12.5 & 98 & 33.5 & 12.5 & 10.5 & 66 & 32.5 & 10.5 & 4.0 & 24 & 20.0 & 7.5 \\
\hline & KSI & $\mathrm{KSI}$ & $10^{6} \mathrm{PSI}$ & $10^{6} \mathrm{PSI}$ & $\mathrm{KSI}$ & KS I & $10^{6} \mathrm{PSI}$ & $10^{6} \mathrm{PSI}$ & KSI & KSI & $10^{6} \mathrm{PSI}$ & $10^{6} \mathrm{PSI}$ \\
\hline
\end{tabular}

E* represents estimated sonic modulus ( 1.85 times elastic modulus). 
TABLE 4-11 MATERIAL IMPEDANCE

\begin{tabular}{|c|c|c|c|c|c|c|c|c|c|c|}
\hline \multirow[b]{2}{*}{ MATERIAL } & \multirow[b]{2}{*}{$\frac{\mathrm{LB}-\mathrm{SEC}^{2}}{\mathrm{FT}^{4}}$} & \multicolumn{3}{|c|}{$\mathrm{T}=1000^{\circ} \mathrm{F}$} & \multicolumn{3}{|c|}{$\mathrm{T}=1500^{\circ} \mathrm{F}$} & \multicolumn{3}{|c|}{$T=2200^{\circ} \mathrm{F}$} \\
\hline & & $10^{6}$ PSI & FPS & $\frac{\mathrm{I}}{\mathrm{LB}-\mathrm{SEC}}$ & $\frac{E}{106^{\mathrm{E}}}$ & $\begin{array}{c}\text { C } \\
\text { FPS }\end{array}$ & $\begin{array}{c}I \\
\frac{L B-S E C}{I N^{2}-F T}\end{array}$ & $\frac{E}{106^{\mathrm{PSI}}}$ & $\begin{array}{c}\text { C } \\
\text { FPS }\end{array}$ & $\frac{L B-S E C}{I N^{2}-F T}$ \\
\hline BERYLLIA & 6.8 & 79.0 & 40800 & 1930 & 72.5 & 39000 & 1850 & 41 & 29400 & 1390 \\
\hline ZIRCONIA & 10.2 & 38.0 & 23200 & 1650 & 35.0 & 22200 & & 32 & 21200 & \\
\hline THORIA & 17.8 & 33.5 & 16500 & 2040 & 32.5 & 16200 & 1480 & 20 & 12800 & 1580 \\
\hline TH-50 GRAPHITE & 2.32 & .08 & 700 & 36 & \multirow{2}{*}{\multicolumn{6}{|c|}{$\begin{aligned} & E_{\text {Graphite }}- \text { Based on Secant Modulus From } \\
& \text { Compression Test PIR }-4068\end{aligned}$}} \\
\hline GRANITE & 2.70 & 7.0 & 19300 & 362 & & & & & & \\
\hline
\end{tabular}




\subsubsection{REFERENCE HEAT SOURCE DESIGN (continued)}

For analysis purposes, rigidity and properties of the fuel are assumed equivalent to the ceramic since little data is available to evaluate this more precisely.

Figure 4-15 presents predicted impact capability as a function of temperature for the various ceramics evaluated. A design factor of safety of 1.25 and 1.5 is carried for compression and tension, respectively to account for uncertainties in the material characteristics and transient wave stresses.

Figure 4-16 illustrates the steady state operational temperatures through a center section of the heat source. The critical temperature from a materials compatibility viewpoint occurs at the fuel/thoria interface; at the heat source midplane this temperature is approximately $2530^{\circ} \mathrm{F}\left(1388^{\circ} \mathrm{C}\right)$. If the compatibility studies being performed at ORNL indicate that this level is unacceptable, temperatures can be lowered by reducing the fuel element diameter from the 0.75 inches shown.

\subsubsection{Plutonia Fueled Heat Source Design}

Figure 4-17 illustrates a plutonia fueled, thoria clad heat source. This design is larger than the curia heat source and weighs 24.7 pounds. Total fuel loading is 1550 watts.

The same assumptions and design techniques were used for the $\mathrm{PuO}_{2}$ heat source as for the Reference Design. The lower power density of the plutonia allows a larger diameter fuel element to be used, 1.50 inches, without causing excessive operational temperatures. The operational temperature distribution is shown in Figure 4-18. Impact protection requirements were based on a calculated terminal velocity of $180 \mathrm{fps}$.

\subsubsection{HEAT SOURCE HEAT EXCHANGER}

The heat source heat exchanger design characteristics are shown in Figure 4-19. Niobium ( $\mathrm{Nb} 103$ or $\mathrm{NblZr}$ ) is selected as the primary HSHX material to withstand operational pressures and thermal stresses. A creep limit of 1 percent in 5 years was chosen in establishing fundamental structural requirements.

The He/Xe working fluid flows into the header at one end of the HSHX; the gas distributes itself along the header and flows down the upper and lower finned passages to the exit header. The heat source is situated in the cavity between the flow passages as pictured in Figure 4-19. A preload is applied to the heat source to resist dynamic launch loads by means of the side access covers. Eight corner fittings which support the heat source contain graphite compliance pads to maintain a $50 \mathrm{~g}$ preload and absorb dynamic oscillations. It is assumed that installation of the heat source occurs at a maximum of 50 hours prior to 1 aunch.

The design characteristics and weight breakdown for the HSHX are shown in Tables 4-12 and 4-13, respectively. The weight for the Reference Design HSHX is 10.25 pounds including insulation. A weight breakdown for a plutonia fueled HSHX, based on the same design concept is also shown in Table 4-13. 


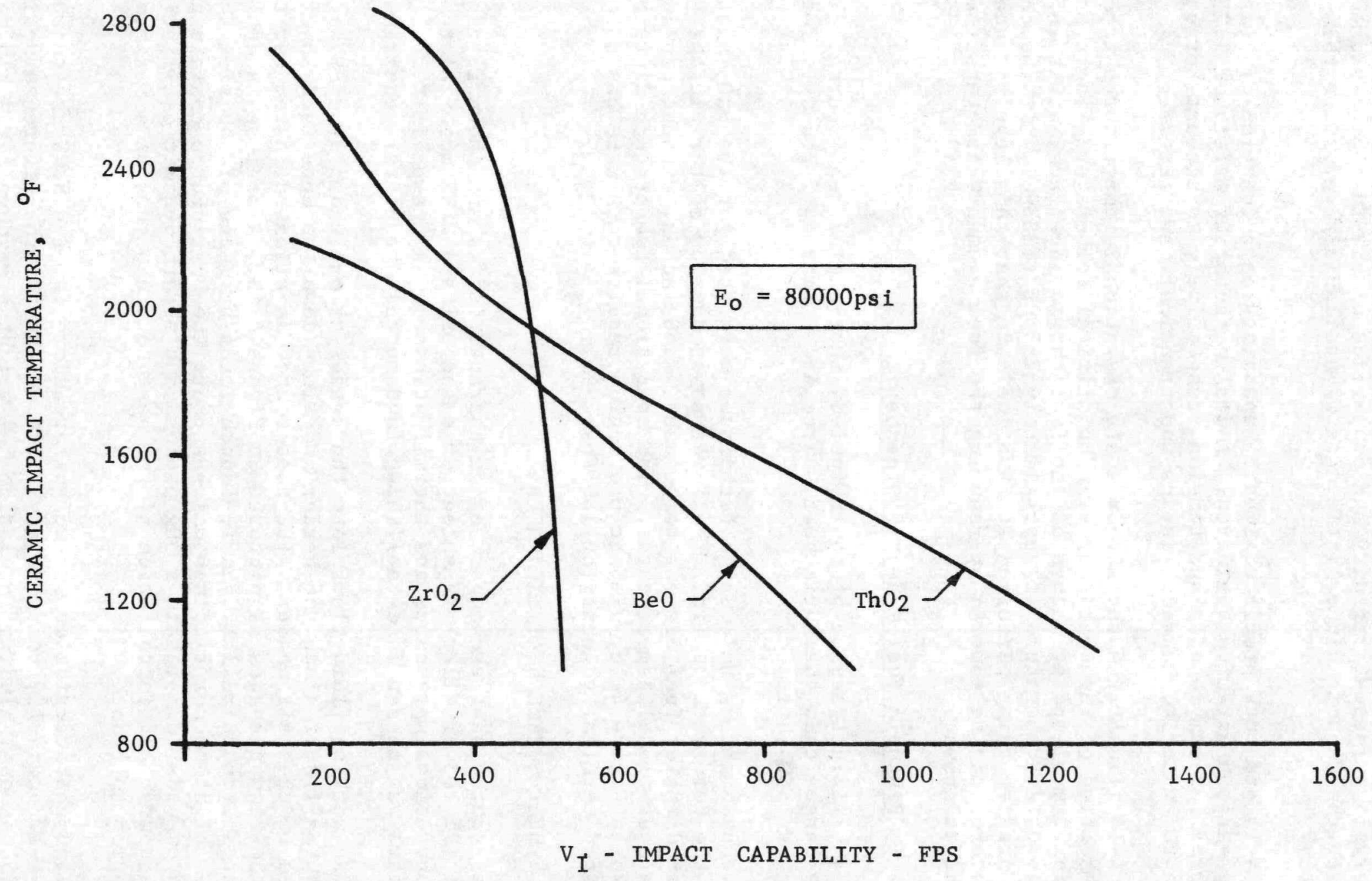

Figure 4-15. F1B Impact Capability for Various Ceramics 


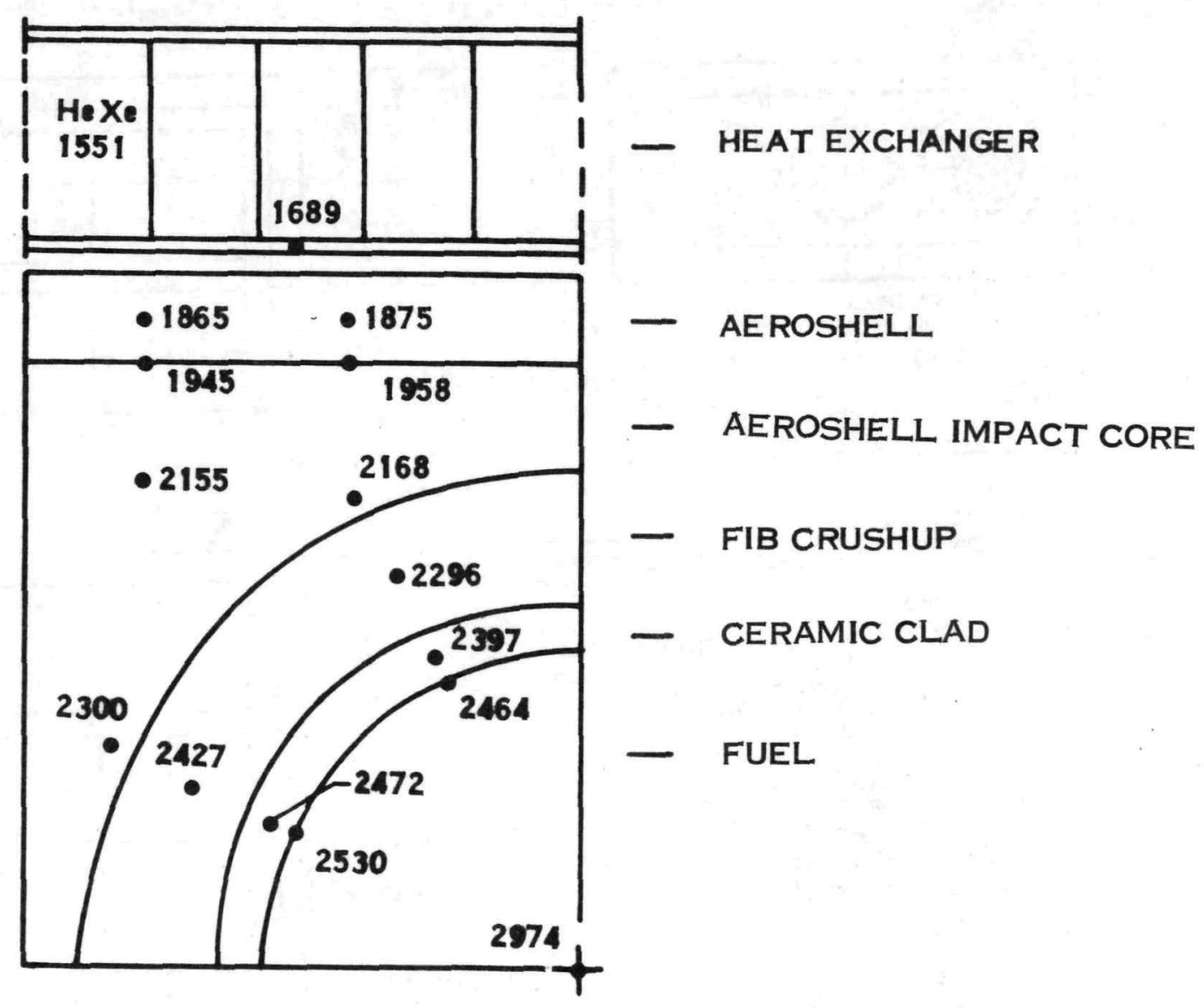

- All temperatures, ${ }^{\circ} \mathrm{F}$ 

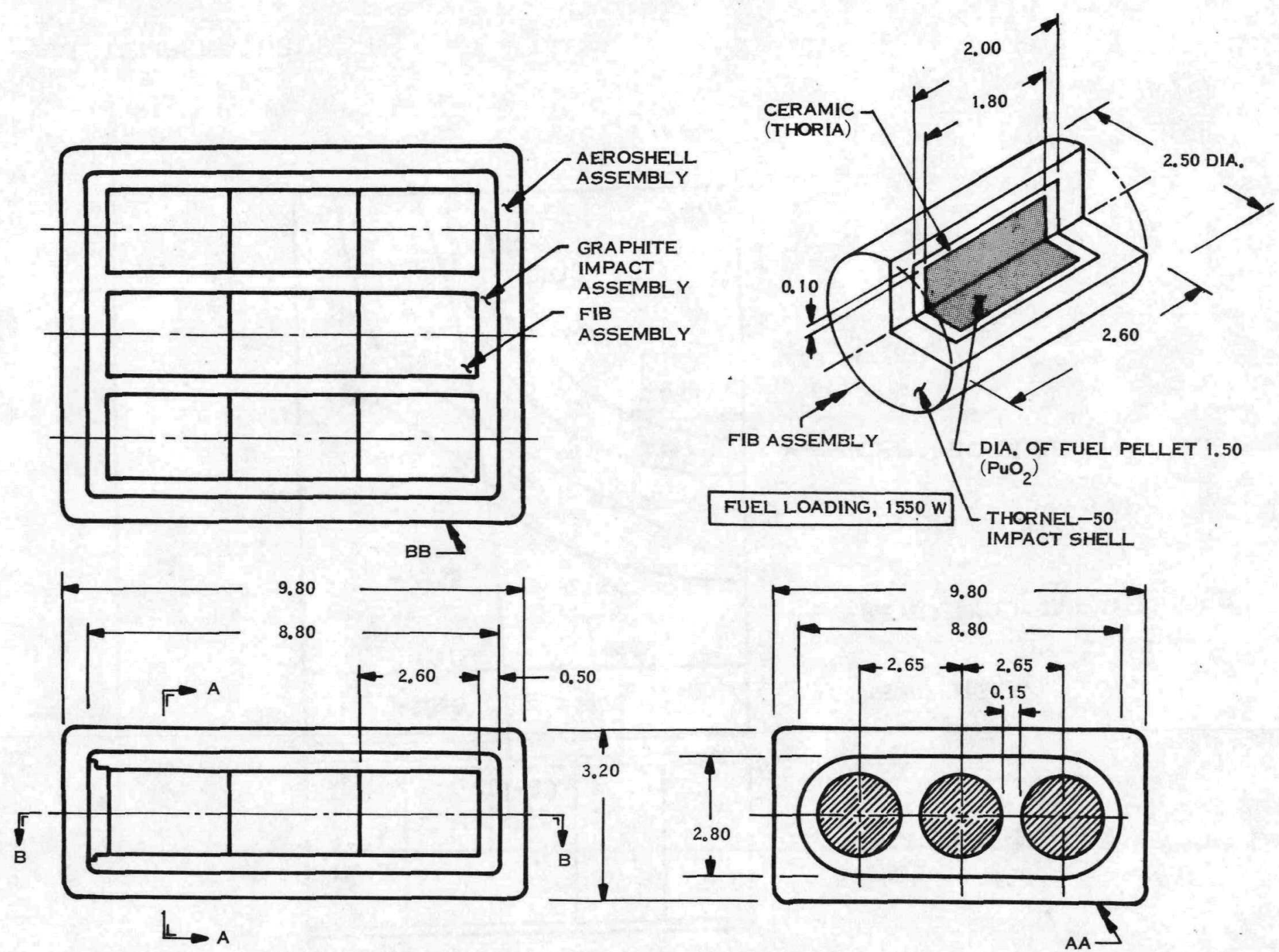


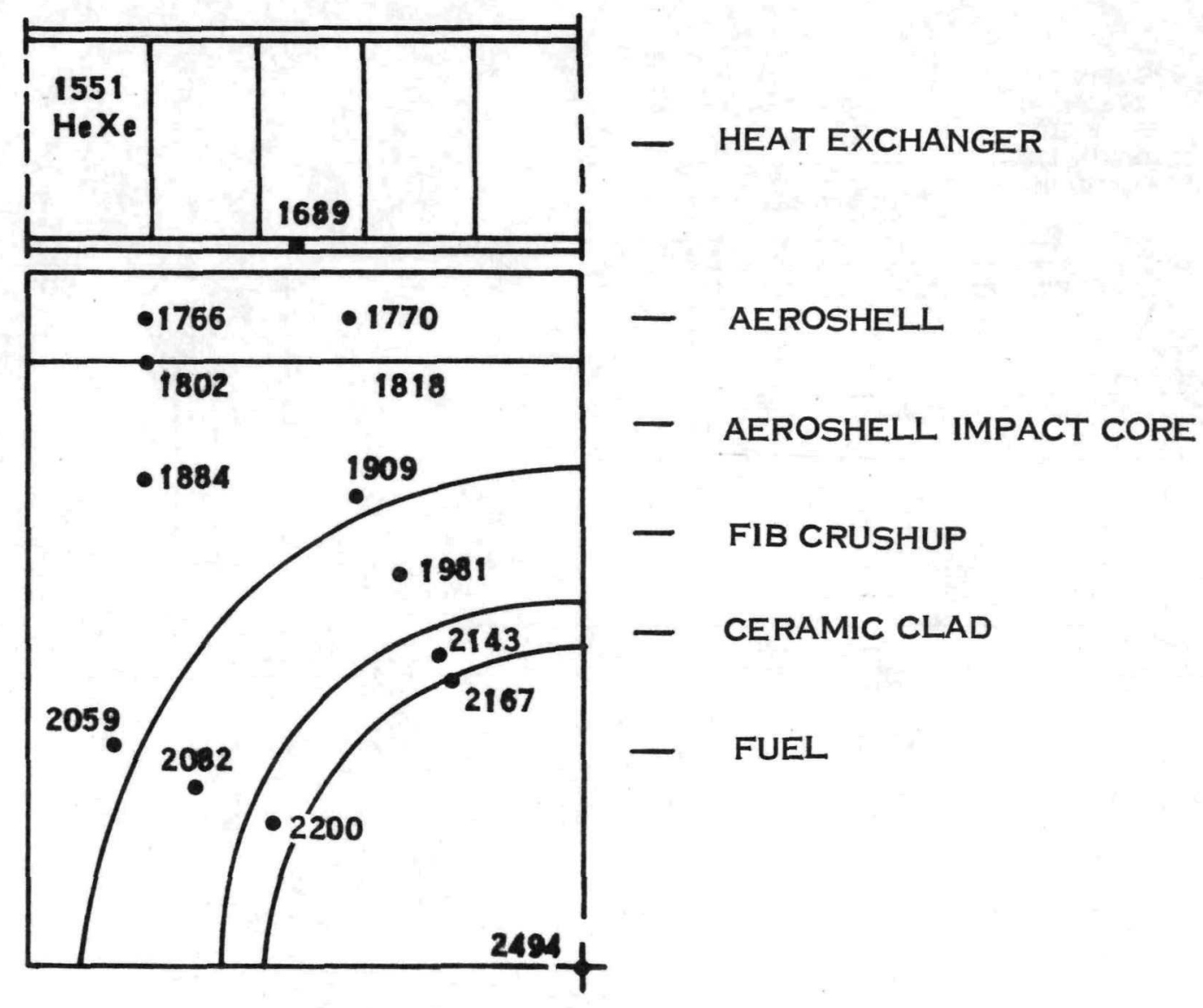




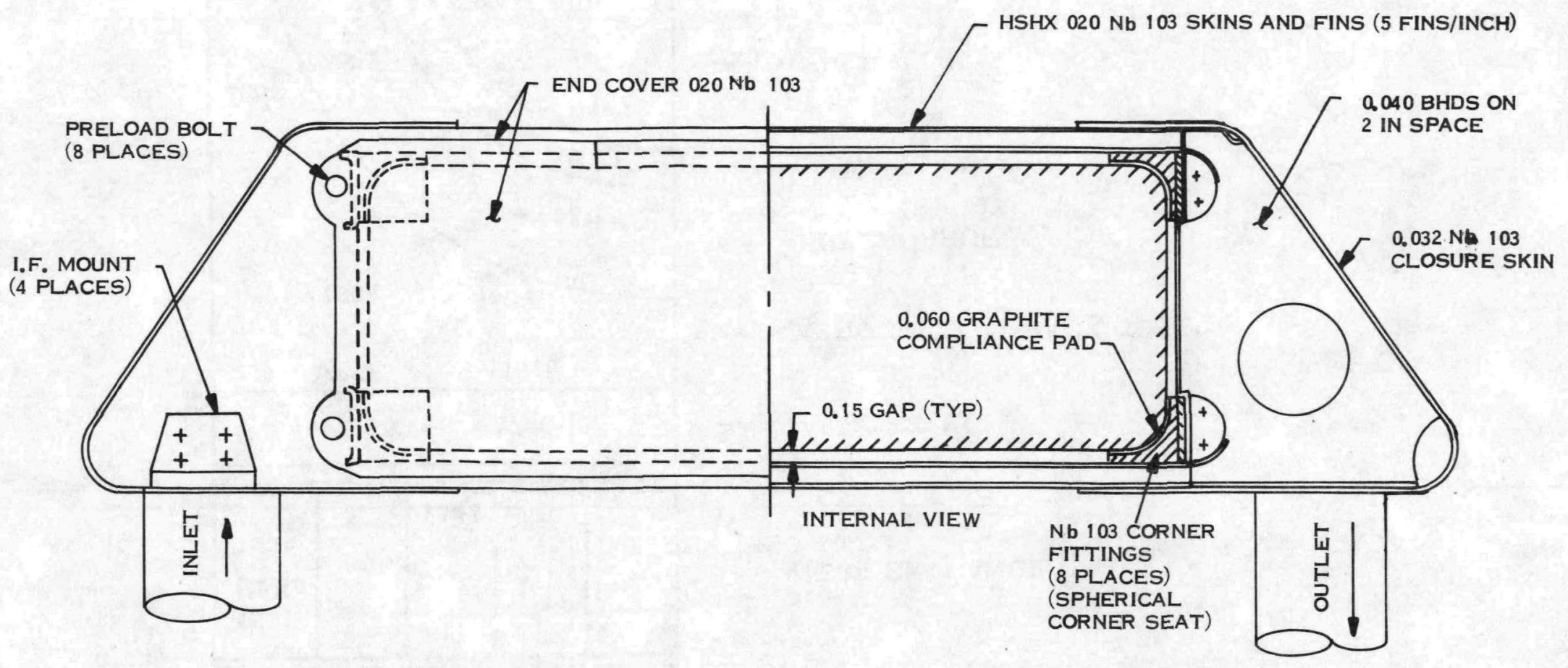

Figure 4.19 Heat Source Heat Exchanger Design 
Table 4-12. HSHX Design Characteristics

\begin{tabular}{|c|c|c|c|c|c|}
\hline \multicolumn{6}{|c|}{ STRUCTURAL REQUIREMENTS } \\
\hline \multirow{2}{*}{\multicolumn{2}{|c|}{$\begin{array}{l}\text { - INTERNAL WEB } \\
\text { HSHX SKINS } \\
\text { HSHX FINS } \\
\text { END COVER } \\
\text { SIDE ACCESS COVER } \\
\text { BULKHEADS } \\
\text { I.F. FTGS. } \\
\text { - PRELOAD STRINGER } \\
\text { - BOLTS }\end{array}$}} & \multirow{2}{*}{$\begin{array}{l}.020 \mathrm{Nb} 103 \\
.020 \mathrm{Nb} 103 \\
.020 \mathrm{Nb} 103 \\
.020 \mathrm{Nb} 103 \\
.020 \mathrm{Nb} 103 \\
.032 \mathrm{NJ} 103 \\
.125 \mathrm{Nb} 103 \\
.064 \mathrm{Nb} 103 \\
.25 \mathrm{Nb} 103\end{array}$} & & $\mathrm{Cm}_{2} \mathrm{O}_{3}$ & $\mathrm{PuO}_{2}$ \\
\hline & & & $\begin{array}{l}\text { SKINS (2) } \\
\text { END COVER (2) } \\
\text { BULKHEADS (12) } \\
\text { SIDE ACCESS COVER (2) } \\
\text { PRELOAD STRINGER (4) } \\
\text { INTERFACE FTGS. (4) } \\
\text { INTERNAL WEB (2) } \\
\text { INSULATION } \\
\text { MISC. HDWR. }\end{array}$ & $\begin{array}{l}2.10 \\
1.20 \\
0.95 \\
2.70 \\
0.55 \\
0.20 \\
0.30 \\
1.85 \\
0.40\end{array}$ & $\begin{array}{l}3.80 \\
1.45 \\
1.15 \\
2.90 \\
0.85 \\
0.30 \\
0.40 \\
2.90 \\
0.50\end{array}$ \\
\hline $\begin{array}{l}\bullet \text { REQUIREMENT } \\
\text { INSTALLATION }\end{array}$ & & $\begin{array}{l}2000 \text { LB. } \\
3500\end{array}$ & TOTAL & 10.25 & 14.25 \\
\hline $\begin{array}{l}- \text { LAUNCH } \\
\text { ORBIT } \\
\text { OREEP RATE }\end{array}$ & & $\begin{array}{l}2500 \\
\text { NONE } \\
.00156 \% / \mathrm{HR}_{\circ}\end{array}$ & & . & \\
\hline HSHX OPERATING STRESS & & 2070 PSI & & & \\
\hline $\begin{array}{l}\text { - PRESSURE } \\
\text { - THERMAL }\end{array}$ & $\begin{array}{r}(320) \\
(1750)\end{array}$ & & & & \\
\hline $\begin{array}{c}- \text { CREEP LIMIT } \\
1 \% \\
2 \%\end{array}$ & $\left(40000 \mathrm{HR}_{\bullet}\right)$ & $\begin{array}{l}1800^{\circ} \mathrm{F} \\
2500^{\circ} \mathrm{F}\end{array}$ & & & \\
\hline
\end{tabular}




\subsubsection{HEAT SOURCE ASSEMBLY INSULATION SYSTEM}

A nickel multifoil HSA insulation is used in the Reference Design due to its stable operation in vacuum at $900^{\circ} \mathrm{C}$. In addition, this insulation system provides emergency cooling capability as discussed in Section 6.2 .

Total heat loss through the insulation system is calculated to be 120 watts; additional edge losses of 50 watts is anticipated. Figure 4-20 illustrates the operational temperature gradient through the Reference Design insulation system.

The multifoil insulation concept consists of many layers of thin metal foils separated from one another by high purity refractory oxide particles such as zirconia. The layers of metal foil, which typically are a quarter of a mil to one mil thick, act as thermal radiation barriers. The oxide particles prevent adjacent foils from coming in contact with one another forming a metal-tometal conduction path. The oxide particles are a few microns in diameter and are sprayed onto one side of each foil. The particle coatings are relatively sparse, and the low thermal conductivities of the oxides plus the high contact resistances between particles and foil minimize the conduction component of the total heat transfer through the insulation.

Typical performance curve for vacuum operation is shown in Figure 4-21 where the heat flow through the insulation system is shown as a function of hot side temperature. The cold side temperature during these tests was on the order of $50^{\circ} \mathrm{C}$. Since multifoil systems are primarily radiation barriers, heat flows at various hot and cold side temperatures can best be determined by using the effective emissivity of the system rather than the effective conductivity. The effective emissivity of the $\mathrm{Ni}-\mathrm{ZrO}_{2}$ system in Figure 4-21 was determined to be approximately 0.008 . The effective emissivity is approximately proportional to the number of layers in the system.

The insulation stack-up is typically around $4 \mathrm{mils} /$ layer, so the 35 foil Reference Design system would be 0.14 " thick.

\subsubsection{MINI-BRU}

The mini-BRU design incorporates a radial inflow turbine, Rice alternator and centrifugal compressor wheel mounted on a single shaft and supported on selfacting gas foil bearings. Due to use of an oversized alternator and other features the mini-BRU can be utilized in MB-ERTG systems with as much as a 3000 We capability.

Figure 4-22 illustrates the mini-BRU or flexible BRU (referring to power level capability) design. Weight of the machine is 35.5 pounds. The efficiencies of the flexible BRU turbine, alternator and compressor at the 400 We operating condition are 79,86 and 75 percent respectively. Turbine and compressor characteristics at the 1200 We design point and 400 We operating point are listed in Tables 4-14, and 4-15, respectively. The alternator efficiency characteristic as a function of power level is shown in Figure 5-2.

Two hydrodynamic foil bearings and a bidirectional thrust bearing is incorporated in the mini-BRU design. Assumed bearing losses for the Reference Design 
CLAD

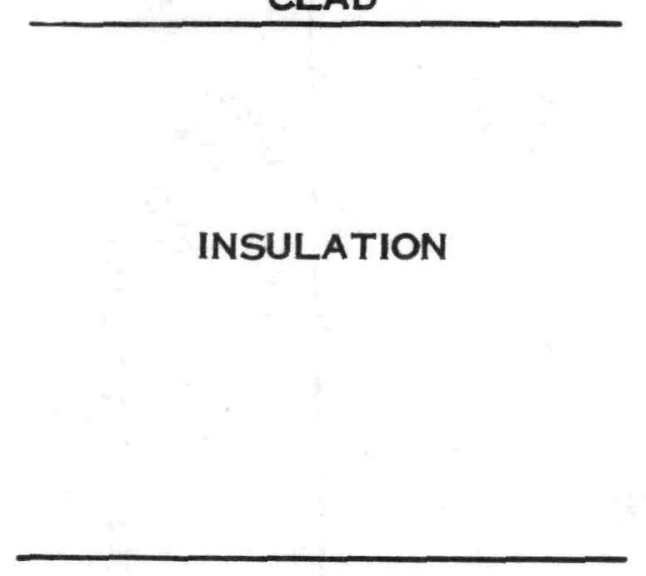

HEAT EXCHANGER

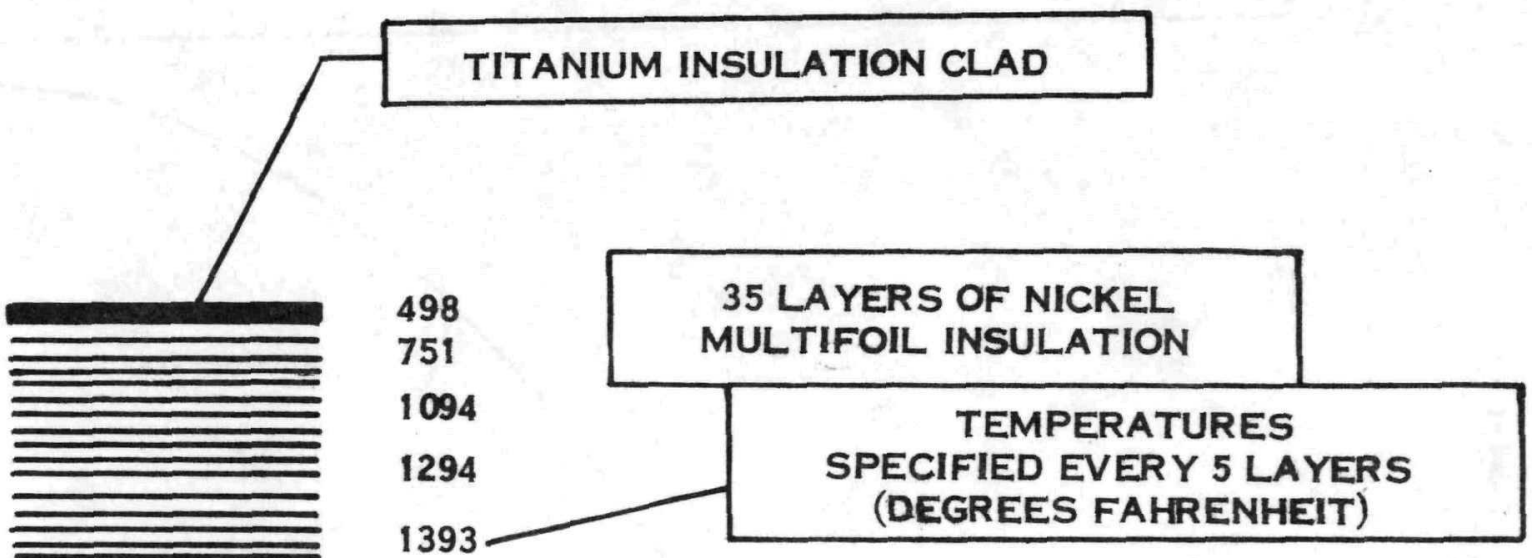

1474

1547

1612

1672

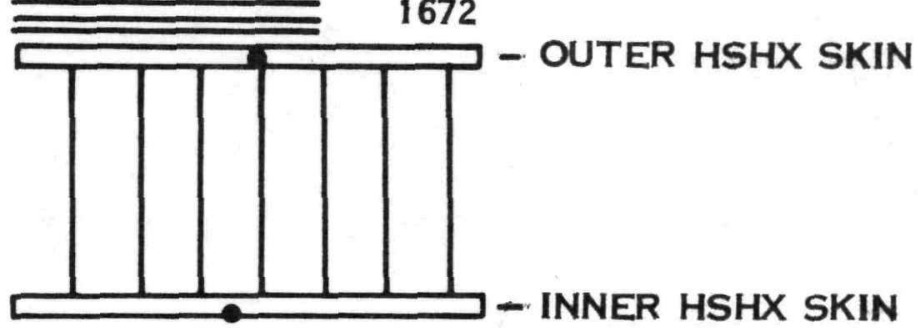




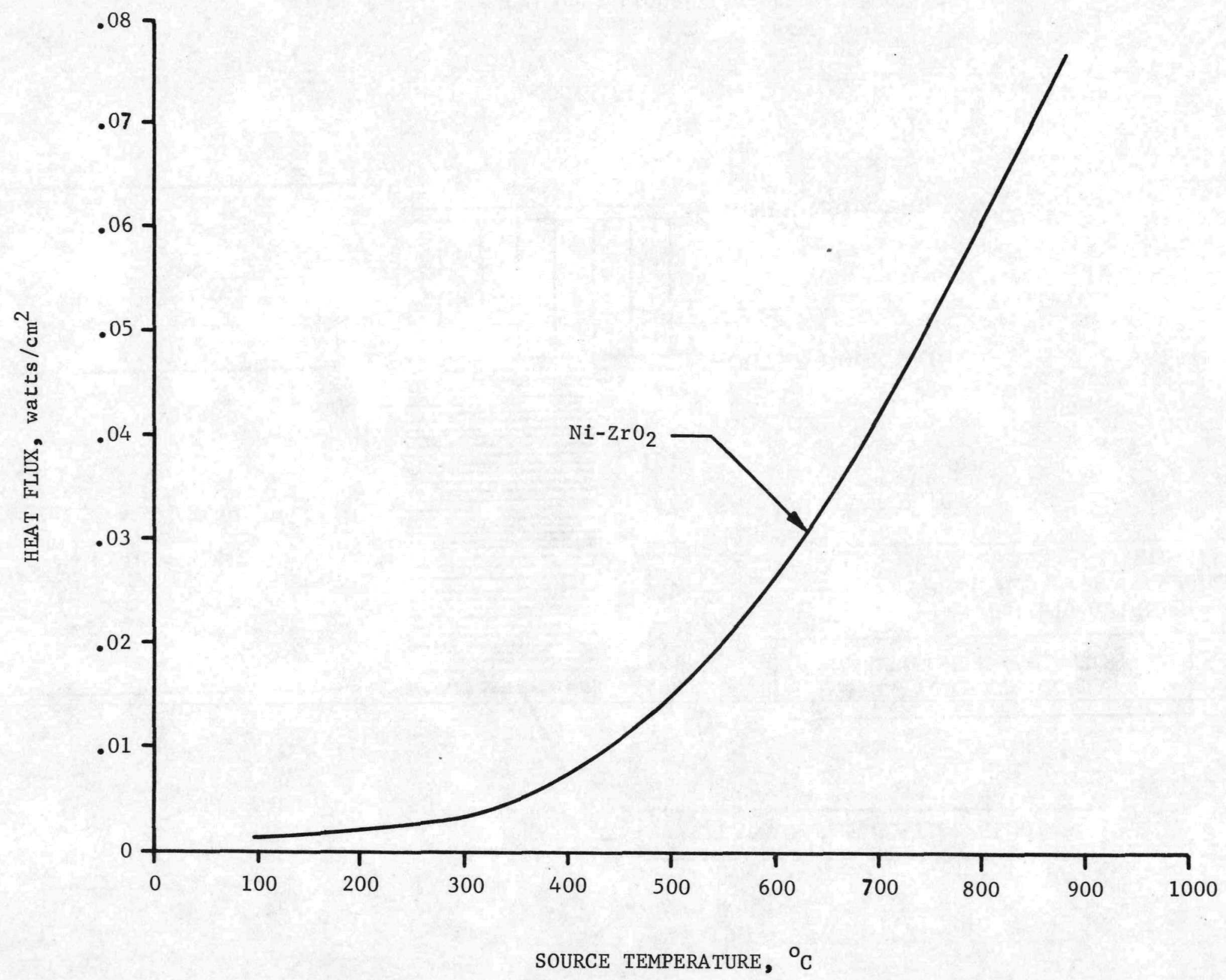

Figure 4-21. Heat Flux Versus Hot Side Temperature for Nickel Multi-Foil Insulation 


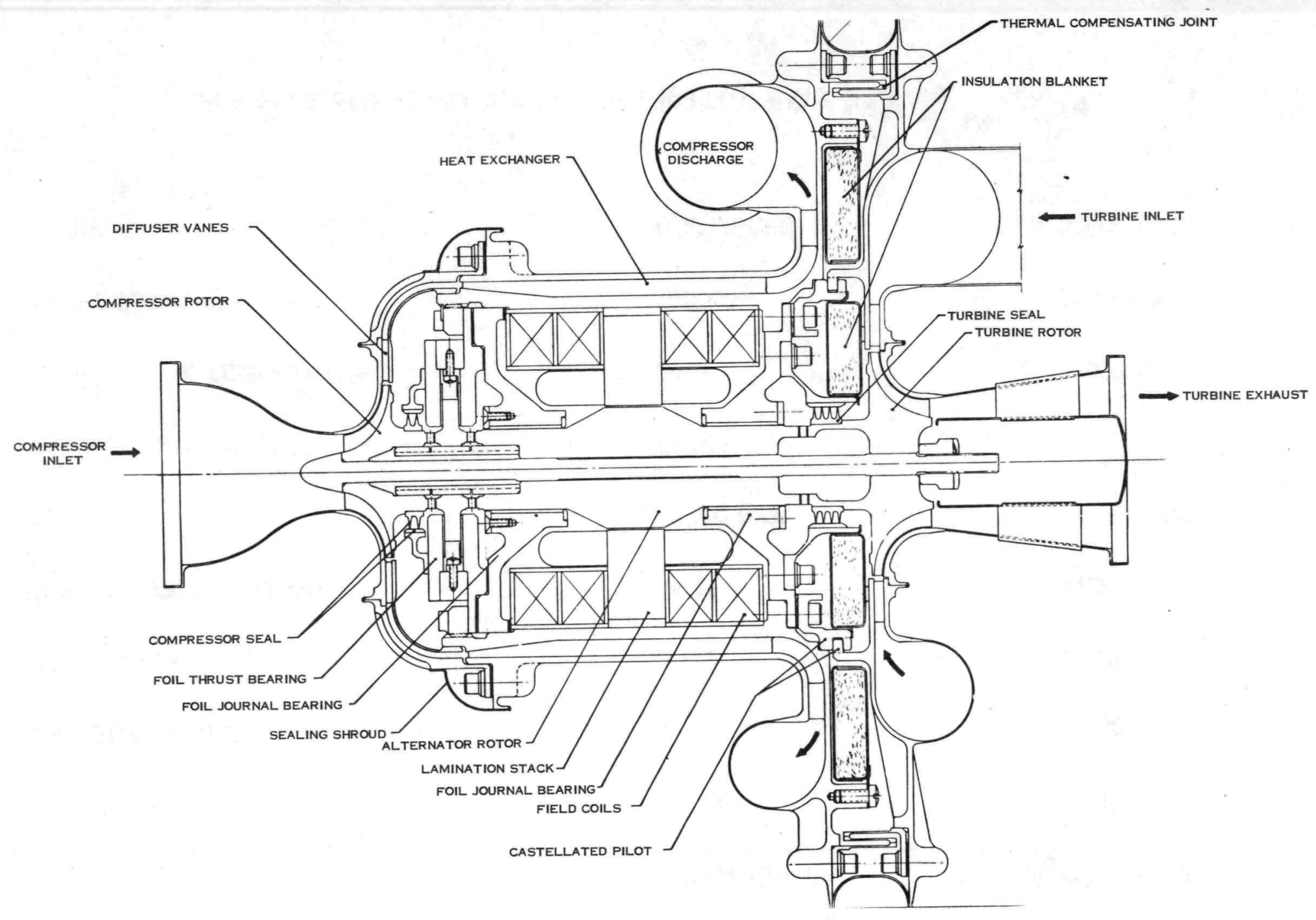




\begin{tabular}{|c|c|c|}
\hline & DESIGN POINT & $400 \mathrm{~W}_{\mathrm{e}}$ OPERATING POINT \\
\hline DIAMETER & 2.8 IN. & $2.8 \mathrm{IN}$. \\
\hline PRESSURE RATIO & 1.47 & 1.452 \\
\hline EFFICIENCY & 0.832 & 0.802 \\
\hline SPECIFIC SPEED (MEAN) & $44.3^{*}$ & $44.0^{*}$ \\
\hline SPEED & 52,000 RPM & 52,000 RPM \\
\hline REYNOLDS NUMBER $(\dot{\omega} / \mu r)$ & 64,500 & 16,200 \\
\hline INLET TOTAL TEMPERATURE & $2060^{\circ} \mathrm{R}$ & $2150^{\circ} \mathrm{R}$ \\
\hline INLET TOTAL PRESSURE & 105 PSIA & 28.4 PSIA \\
\hline FLOW & $0.35 \mathrm{LB} / \mathrm{SEC}$ & 0.091 LB/SEC \\
\hline \multicolumn{3}{|c|}{ * SPECIFIC SPEED $=($ RPM $) \times(\text { VOLUMETRIC FLOW RATE })^{1 / 2} \times\left(\frac{T R}{P R}\right)^{1 / 4} /(\Delta h)^{3 / 4}$} \\
\hline
\end{tabular}


Table 4-15. Flexible BRU Compressor Design Summary

\begin{tabular}{|c|c|c|}
\hline & DESIGN POINT & $400 \mathrm{~W}_{\mathrm{e}}$ OPERATING POINT \\
\hline DIAMETER & $2.2 \mathrm{IN}$. & $2.2 \mathrm{iN}$. \\
\hline PRESSURE RATIO & 1.5 & 1.53 \\
\hline EFFICIENCY & 0.761 & 0.757 \\
\hline SPECIFIC SPEED (MEAN) & 44.3* & 47.1* \\
\hline SPEED & $52,000 \mathrm{RPM}$ & $52,000 \mathrm{RPM}$ \\
\hline REYNOLDS NUMBER $\left(\rho_{1} \mathrm{U}_{2} \mathrm{D}_{2} / \mu_{1}\right)$ & $5.68 \times 10^{6}$ & $1.7 \times 10^{6}$ \\
\hline FLOW & $0.357 \mathrm{LB} / \mathrm{SEC}$ & $0.093 \mathrm{LB} / \mathrm{SEC}$ \\
\hline CORRECTED FLOW & 0.0756 LB/SEC & 0.072 LB/SEC \\
\hline INLET TOTAL PRESSURE & 70.8 PSIA & 19.0 PSIA \\
\hline INLET TOTAL TEMPERATURE & $536^{\circ} \mathrm{R}$ & $520^{\circ} \mathrm{R}$ \\
\hline \multicolumn{3}{|c|}{${ }^{*}$ SPECIFIC SPEED $=($ RPM $) \times(\text { VOLUMETRIC FLOW RATE })^{1 / 2} \times\left(\frac{P \mathrm{P}}{\mathrm{TR}}\right)^{1 / 4} /(\Delta h)^{3 / 4}$} \\
\hline
\end{tabular}




\subsubsection{MINI-BRU (continued)}

were 76 watts. A more detailed analysis, performed subsequent to formulation of the Reference Design, indicated that a 10-15 watt reduction in the bearing losses could be achieved; this would increase the system efficiency 0.6 percent.

A number of different materials are used in the mini-BRU. The turbine scroll, which is the highest temperature part in the BRU, will be manufactured from the same refractory material as the HSHX, $\mathrm{Nb} 103$ or $\mathrm{Nb} 1 \mathrm{Zr}$. Other parts of the mini-BRU will utilize the following materials: turbine wheel-INCONEL 713LC, compressor whee1 17455, rotor-INCONEL 713LC, magnetic portion of rotor HP 9-4-20, alternator windings-copper, housing - 34755 .

\subsubsection{RECUPERATOR}

The Reference Design recuperator is a high effectiveness heat exchanger, $\epsilon=0.96$, having a total weight of 46 pounds. Both Haynes-188 and Hastelloy$\mathrm{X}$ were considered as materials of construction. Previously build recuperators have used Hastelloy- $X$ in systems having a $1600^{\circ} \mathrm{F}$ turbine inlet temperature. The increase in the turbine inlet temperature to $1690^{\circ} \mathrm{F}$, and resulting recuperator inlet temperature of $1450^{\circ} \mathrm{F}$, suggested the consideration of other materials.

Figure 4-23 shows the yield strength and creep rupture strength in 50,000 hours for Haynes -188 and Hastelloy-X as a function of temperature. At the recuperator inlet temperature Haynes-188 shows a 50\% higher allowable creep rupture stress, therefore, it was selected as the Reference Design recuperator material.

The recuperator design used in the Reference Design MB-ERTG will incorporate the advanced design concepts developed by AiResearch and NASA-Lewis under NAS 3-15347.

These concepts were evolved from in-house work directed toward development of advanced gas turbine engine recuperators and incorporated the following design improvements :

- Reduced thermal lag between bar and plate

- Increased thermal flexibility of bars

o Elimination of welding over braze joints

- Provision for double containment

o Reduced production costs

The concept developed for the advanced recuperator is illustrated in Figure 4-24. A stamping process folds the tube sheets in such a manner that, when stacked up, they form the gas manifolds. This eliminates the requirement to weld pans to the heat exchanger core.

An approach to providing double containment, developed for this concept, is shown in Figure 4-25. A flexible seal plate is welded to the outer top and bottom plates of the recuperator, providing another level of containment of the gas. The flexible seal plate is supported by a series of rings or bands wrapped around the heat exchanger. 


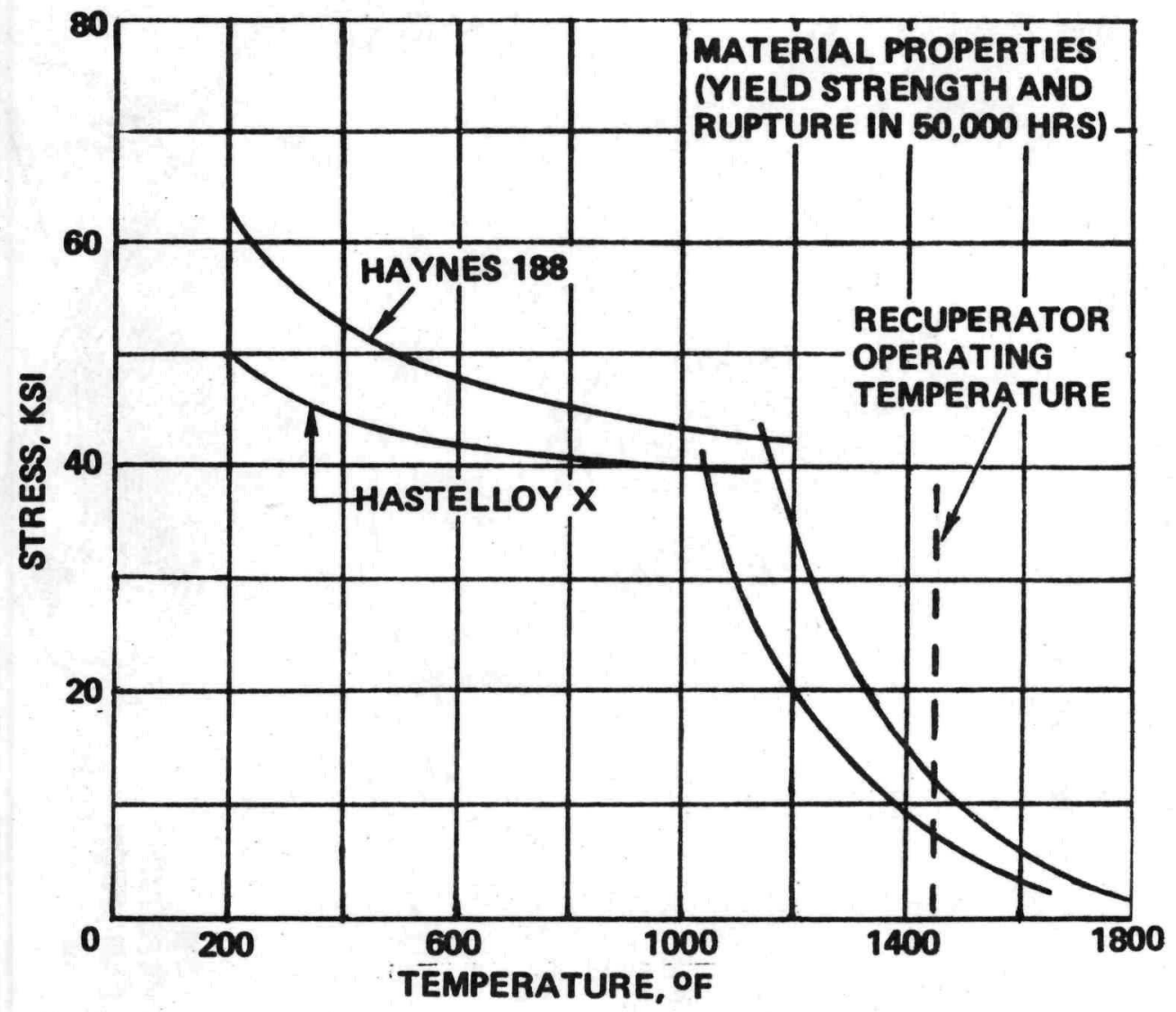

Figure 4-23. Comparison of Haynes-188 and Hastelloy-X Structural Properties 


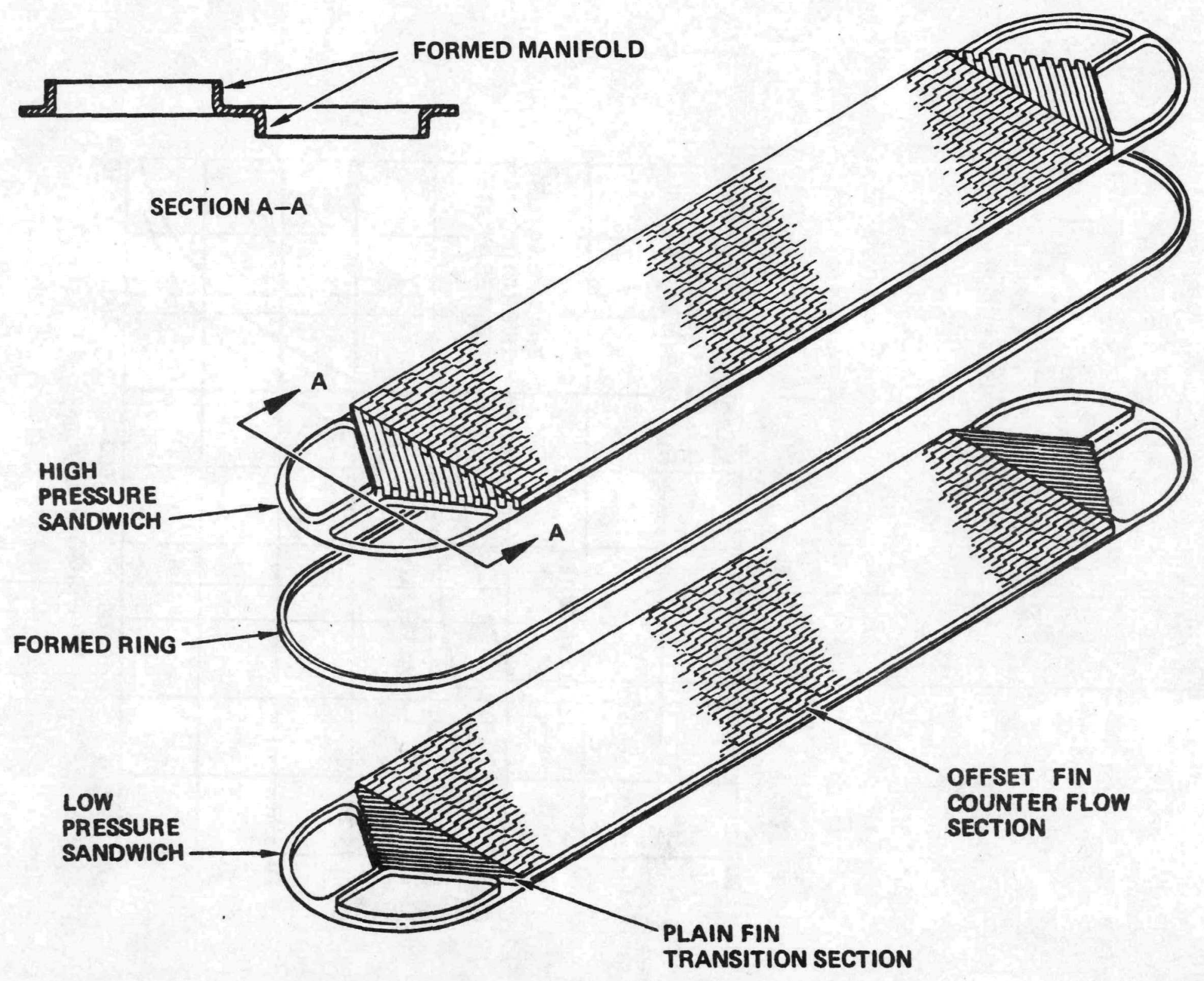




\subsubsection{RECUPERATOR (continued)}

Evaluation of initial fabrication samples based on the improved recuperator design lend support to the expectation of a successful development.

\section{PRESSURE}

Figure 4-25. Double Fluid Containment Recuperator Design Concept

\subsubsection{REFERENCE RADIATOR DESIGN}

The reference radiator design concept was the same as that used in the MB-ERTG Conceptual Design. Total weight of the aluminum radiator, including a radiation hardened coating was 47 pounds; a weight breakdown is provided in Table 4-16. Required radiator area of $48 \mathrm{ft}^{2}$ was based on a $390^{\circ} \mathrm{R}$ sink temperature.

The design characteristics of the radiator are listed in Table 4-17. Meteoroid armor requirements was based on a 0.99 probability of no puncture; meteoroid protection requirements were based on criteria presented in Section 3.2.1.2. 
Table 4-16. Radiator Weight Breakdown

\begin{tabular}{|lr|}
\hline Headers & 5.0 \\
Tubes & 20.8 \\
Fins & 13.4 \\
Fluid & 0.1 \\
Coating & 6.0 \\
Pigtails & 1.5 \\
Total Weight, LBS & 46.8 \\
\hline
\end{tabular}

Table 4-17. Radiator Design Characteristics

Fluid Inlet Temperature, ${ }^{\circ} \mathrm{F} \quad 261$

Fluid Outlet Temperature, ${ }^{\circ} \mathrm{F} \quad 60$

Fluid Flow Rate, $1 \mathrm{~b} / \mathrm{sec} \quad 0.073$

Total Fluid Pressure Drop, $1 \mathrm{~b} / \mathrm{in}^{2} \quad 0.36$

Fluid Reynolds Number $\quad 20,500$

Tube Inside Diameter, inches $\quad 0.35$

$\begin{array}{ll}\text { Number of Tubes } & 14\end{array}$

$\begin{array}{ll}\text { Armor Thickness, inches } & 0.19\end{array}$

$\begin{array}{ll}\text { Fin Length, inches } & 3.7\end{array}$

$\begin{array}{ll}\text { Fin Efficiency } & 0.85\end{array}$ 
SECTION 5.0

\section{MB-ERTG GROWTH CHARACTERISTICS}

During the course of this study it became apparent that power levels higher than 400 We may be of interest for the SURVSATCOM Application. Therefore, a general investigation of the MB-ERTG performance characteristics in the 4003500 We power range was made. A specific design point at 3300 We was also investigated in some detail

The results of this investigation, which are presented in subsequent sections, showed a marked performance increase at higher power levels.

\subsection{MB-ERTG 400-3300 We PERFORMANCE EVALUATION}

A parametric study was performed to see the effect of power level on the MB-ERTG specific power (watts/1b) and efficiency. The results of this analysis is shown in Figure 5-1. At the 400 We level, system efficiencies between 22 and 25 percent are achievable; at the 3000 We level the efficiency increases to 35 percent. The reason for the increase in efficiency at the higher power level is due to the following factors:

- higher turbomachinery efficiencies

o increased alternator efficiency

- reduction in bearing and parasitic losses to output power

In the 400 We MB-ERTG, turbomachinery efficiencies are relatively low since the leakage flow around the wheel clearances comprise a substantial fraction of the total flow. The fraction of leakage to total flow rate can be reduced for larger machines; therefore, higher aerodynamic efficiencies can be obtained at $3000 \mathrm{We}$.

The Rice alternator used in the Reference Design has an efficiency of 86 percent, however, at the 1300 We power level its efficiency peaks rises above 91 percent as shown in Figure 5-2. As power needs continue to increase the alternator may be redesigned to provide efficiencies above 91 percent into the 3000 We region.

The third effect mentioned is the reduction in bearing power and parasitic losses as a function of output power. For the Reference Design the ratio of bearing losses to power output is 0.205 and the ratio of windage and control power losses to power output is 0.15 . These ratios are substantially less at the 3000 We leve1.

Figure 5-1 also shows a dramatic increase in the MB-ERTG specific power with increasing power level. This characteristic is due to both the increase in system efficiency and the less than proportional increase in component weights with increases in power level. A major reason for the latter effect is that while the system power level increases, all flow passage sizes remain relatively constant since the pressure level can be increased. Note that Figure 5-1 presents this relationship for optimized systems as well as for systems using the flexible BRU. 


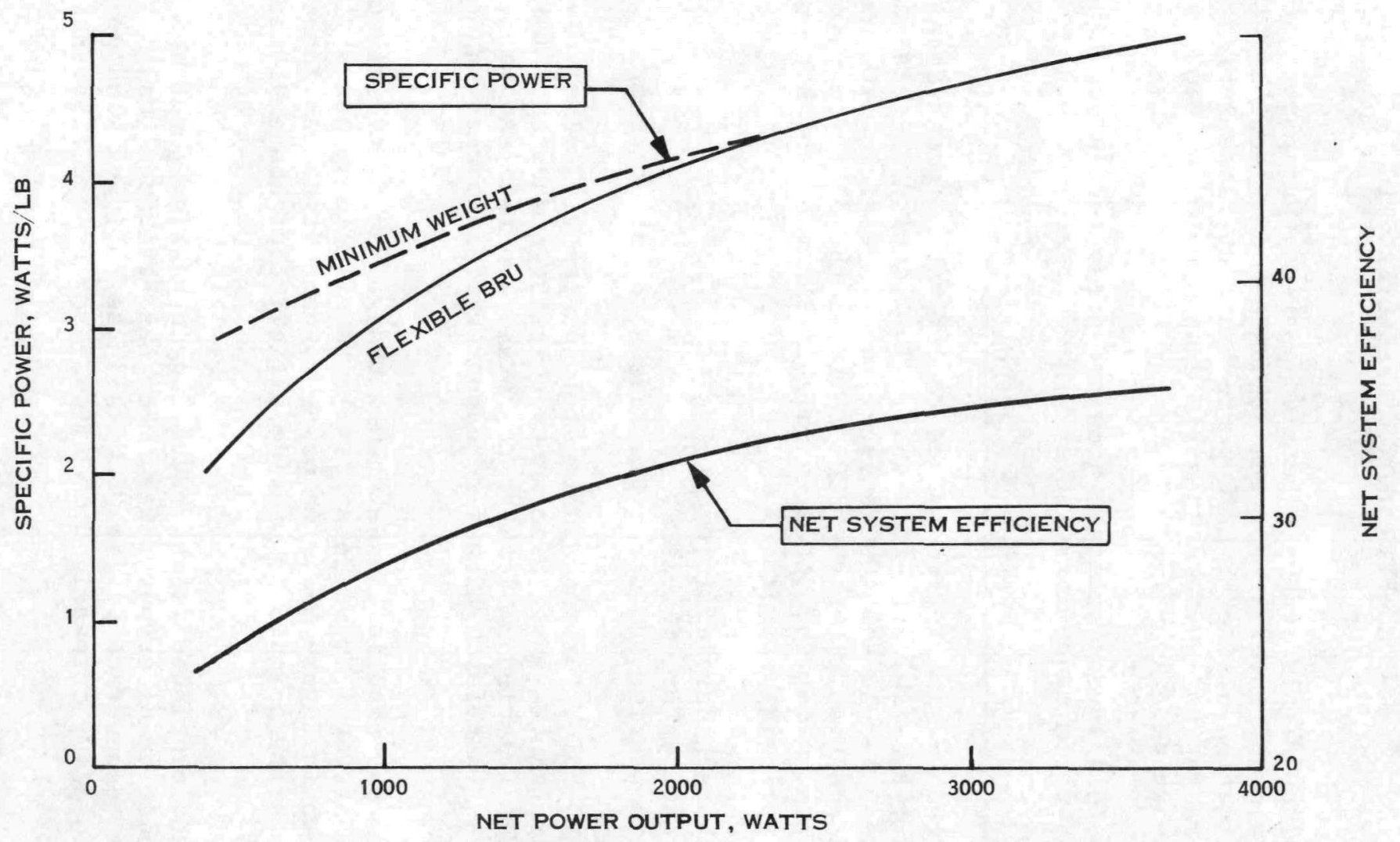




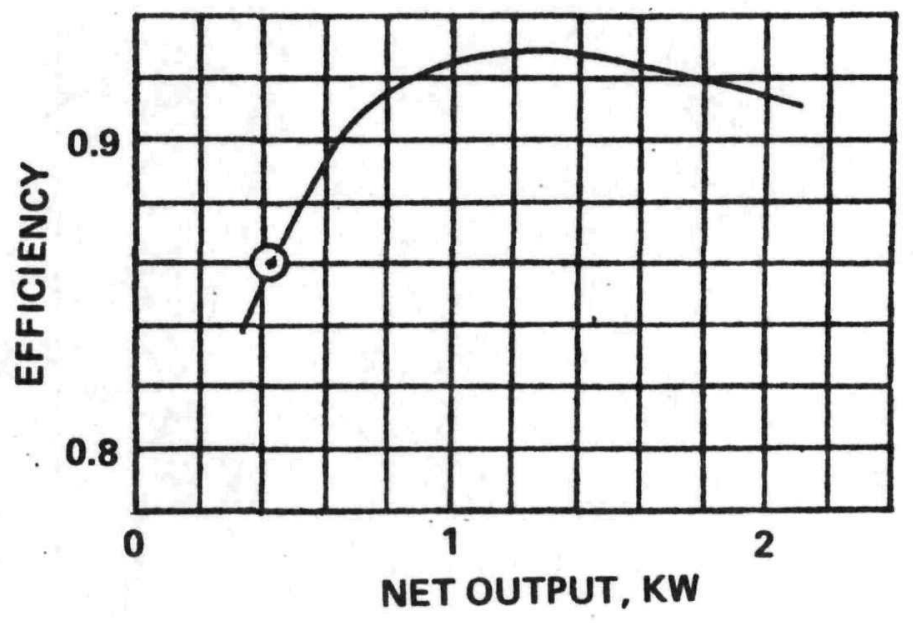

Figure 5-2. Effect of Power Level on Flexible BRU Alternator Efficiency

\section{$5.2 \quad 3.3 \mathrm{kWe}$ DESIGN POINT}

A single design point was investigated to assess specific MB-ERTG characteristics at the 3000 We level. The exact electrical power output was determined by assuming the use of $4 \mathrm{MHW}$ heat sources which provided a thermal power of $9600 \mathrm{~W}$. All other components in the system were assumed to be a single unit design. This analysis assumed a 10 percent heat loss from the 4 heat source assemblies.

First a series of design cases were run to establish the minimum weight envelope as shown in Figure 5-3. Due to the insensitivity of specific weight with power level over a large region, it was possible to select a 34 percent efficient case without imposing a system weight penalty.

A weight summary of the design point is provided in Table 5-1. Weight estimates for the heat source assembly reflect a design concept identical to the Conceptual Design HSA excepting that 24 FSA's are used instead of 16 per heat source. Estimates were made for ducting, insulation, structural, controls and parasitic load resistor weights; the sum of these weights is 16 percent of the total system weight. All other component weights were based on design calculations. Total system weight is $683 \mathrm{lbs}$. which yields a specific power of 4.8 watts/1b. 


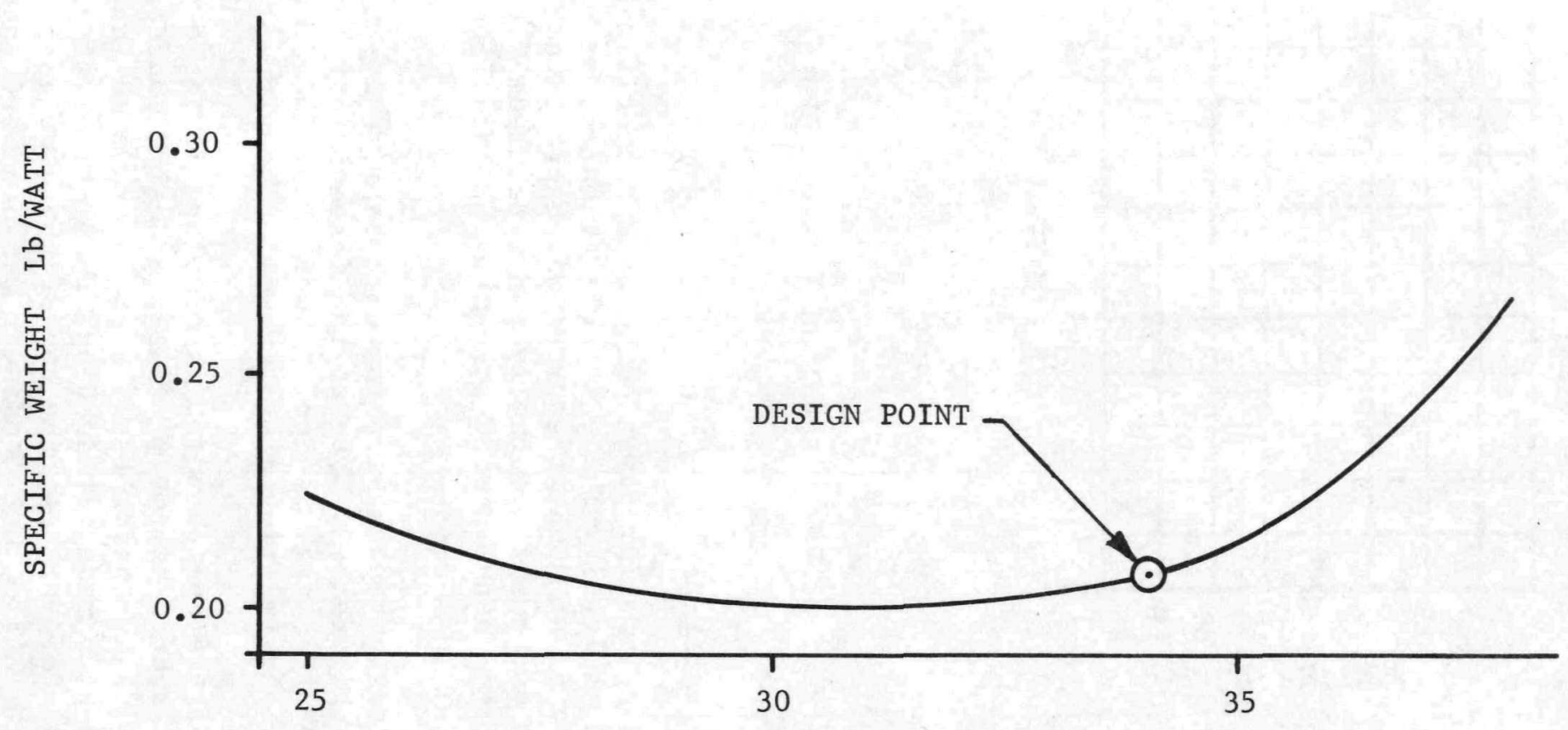

NET CYCLE EFFICIENCY, PERCENT 
Table 5-1. 3300 We MB-ERTG Weight Summary

\begin{tabular}{|lc|}
\hline BRU & 39 \\
Recuperator & 94 \\
Radiator & 182 \\
Ducts & 12 \\
Heat Source Assembly (4) & 255 \\
Brayton Cycle Insulation & 42 \\
Structure & 30 \\
Controls & 10 \\
Parasitic Load Resistor & 20 \\
Total Weight, lbs & 683 \\
Cycle Efficiency & .3401 \\
Specific Power, Watts/1bs & 4.8 \\
Net Output, kWe & 3.27 \\
\hline
\end{tabular}




\section{$5.2 \quad 3.3 \mathrm{KWe}$ DESIGN POINT}

A diagram of the cycle with temperature and pressure conditions is shown in Figure 5-4. Other characteristics of the 3300 We system are shown in Table 5-2. Referring to the discussion in paragraph 5.1, it is interesting to see the ratios of bearing losses to power output and control power and windage to power output have been reduced to 0.047 and 0.11 , respectively. In addition, turbine, alternator and compressor efficiencies are significantly higher as compared to the Reference Design.

Table 5-2. 3300 We MB-ERTG Component Design Summary

\section{COMPRESSOR}

Flow Rate, $1 \mathrm{~b} / \mathrm{sec}$

0.372

Inlet Pressure, psia

49.0

Inlet Temperature, ${ }^{\circ} \mathrm{R}$ 480

Pressure Ratio

1.73

Specific Speed

0.08

Efficiency

0.766

Diameter, in.

2.22

B-Width, in.

0.092

TURBINE

Flow Rate, $1 b / \mathrm{sec}$

0.365

Inlet Pressure, psia

83.6

Inlet Temperature, ${ }^{\circ} \mathrm{F}$

1710

Pressure Ratio

1.669

Efficiency

0.83

Diameter, in.

2.88 
Table 5-2. 3300 We MB-ERTG Component Design Summary (continued)

\section{ROTATING GROUP}

Speed, RPM

60,000

Weight, 1bs 3

Windage, watts

111

Bearing Loss, watts

Rice Alternator Efficiency

Gross Output, KW

Controls \& Parasitics, Watts

Net Output KW

Lost Pressure Ratio Parameter (B)

HEAT SOURCE HEAT EXCHANGER

Inlet Pressure, psia

83.8

Inlet Temperature, ${ }^{\circ} \mathrm{F}$

Flow Rate, $1 \mathrm{bs} / \mathrm{sec}$

RECUPERATOR

Effectiveness

Overall Length, in.

24.5

Pressure Drop, percent

L.P. In1et Temperature, ${ }^{\circ} F$

RADIATOR

Area, $\mathrm{Ft}^{2}$

Length, ft

8

Inlet Temperature, ${ }^{\circ} \mathrm{F}$

Pressure Drop, percent 


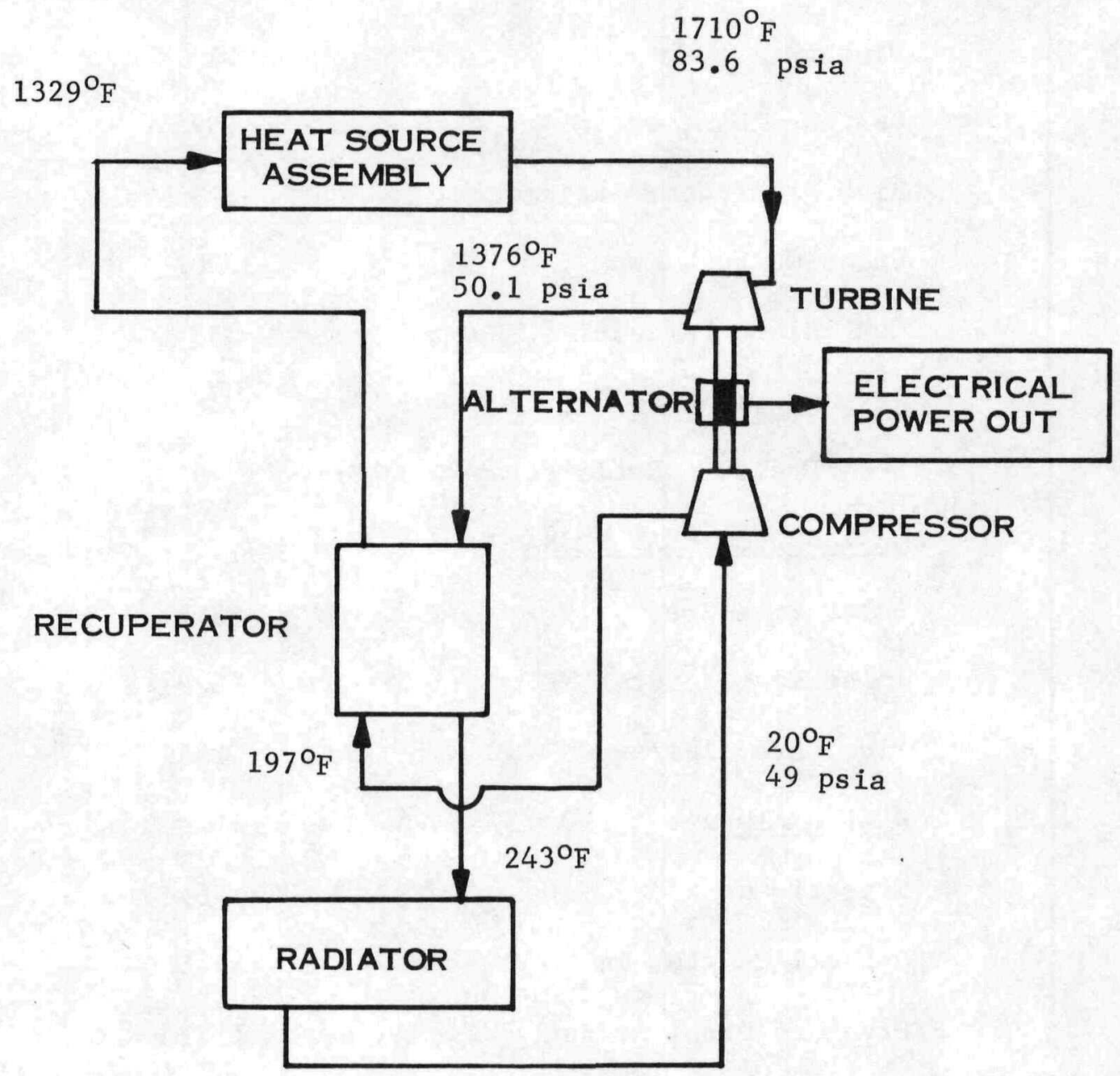

Figure 5-4. 3300 We MB-ERTG

Cycle Conditions 
SECTION 6.0

REFERENCE DESIGN NUCLEAR SAFETY ASSESSMENT

This section presents the potential nuclear accidents associated with the use of the MB-ERTG for the SURVSATCOM Mission and an evaluation of the heat source response to that accident. Section 6.1 discusses the on-pad cooling system designed to protect the heat source during on-pad operations and Section 6.2 presents the emergency cooling system which maintains the integrity of the heat source when the MB-ERTG ceases to operate. Sections 6.3, 6.4 and 6.5 discuss possible accidents which may occur during transportation and various stages of the launch operation.

\subsection{ON-PAD COOLING SYSTEM}

As discussed in Section 3.1.3 the heat source is installed in the MB-ERTG after the MB-ERTG has been attached to the spacecraft. A schematic representation of this procedure is shown in Figure 6-1. In the illustration, insertion of the curium heat source into the HSA is made through an access panel in the shroud. By making the installation the last procedure, nuclear shielding considerations for ground personnel are minimized. Since the radiation levels associated with a plutonium heat source are much less, installation of the heat source into the MB-ERTG could be made in the assembly building.

Once the heat source has been installed, the graphite aeroshe11 and the niobium heat exchanger must be kept from oxidizing. This can be done by either lowering the material temperatures below their oxidation limits or by providing an inert gas atmosphere. The approach used in the Reference Design is to impose an inert atmosphere around the HSA which prevents oxidation. As an additional benefit the inert gas thermally short circuits the multifoil insulation and lowers the temperature of the heat source substantially below its operational temperature.

Figure 6-2 illustrates the on-pad cooling concept. Inert gas is transferred into the HSA by means of a quick-disconnect fitting attached to the outer insulation clad. The gas flows slowly through the insulation system, through the slotted end plate in the HSHX and into the cavity between the HSHX and the aeroshe11. Oxygen is prevented from getting into the system by maintaining a positive argon pressure within the HSA.

Figure 6-3 shows the temperature distribution through a center slice of the HSA for steady state conditions on-the-pad. This temperature profile assumes convective cooling on the HSA exterior sufficient to maintain a $350^{\circ} \mathrm{F}$ surface temperature. Prior to start-up, the argon gas must be removed from the HSA to permit the attainment of operational temperatures. In the present concept the argon inlet tube is disconnected immediately prior to launch. The rate at which the HSA heats up is a function of how rapidly the gas is removed from the system. Assuming immediate expulsion of the gas, a minimum of 100 minutes are available before start-up need be effected. The estimated temperature transient is shown in Figure 6-4. 


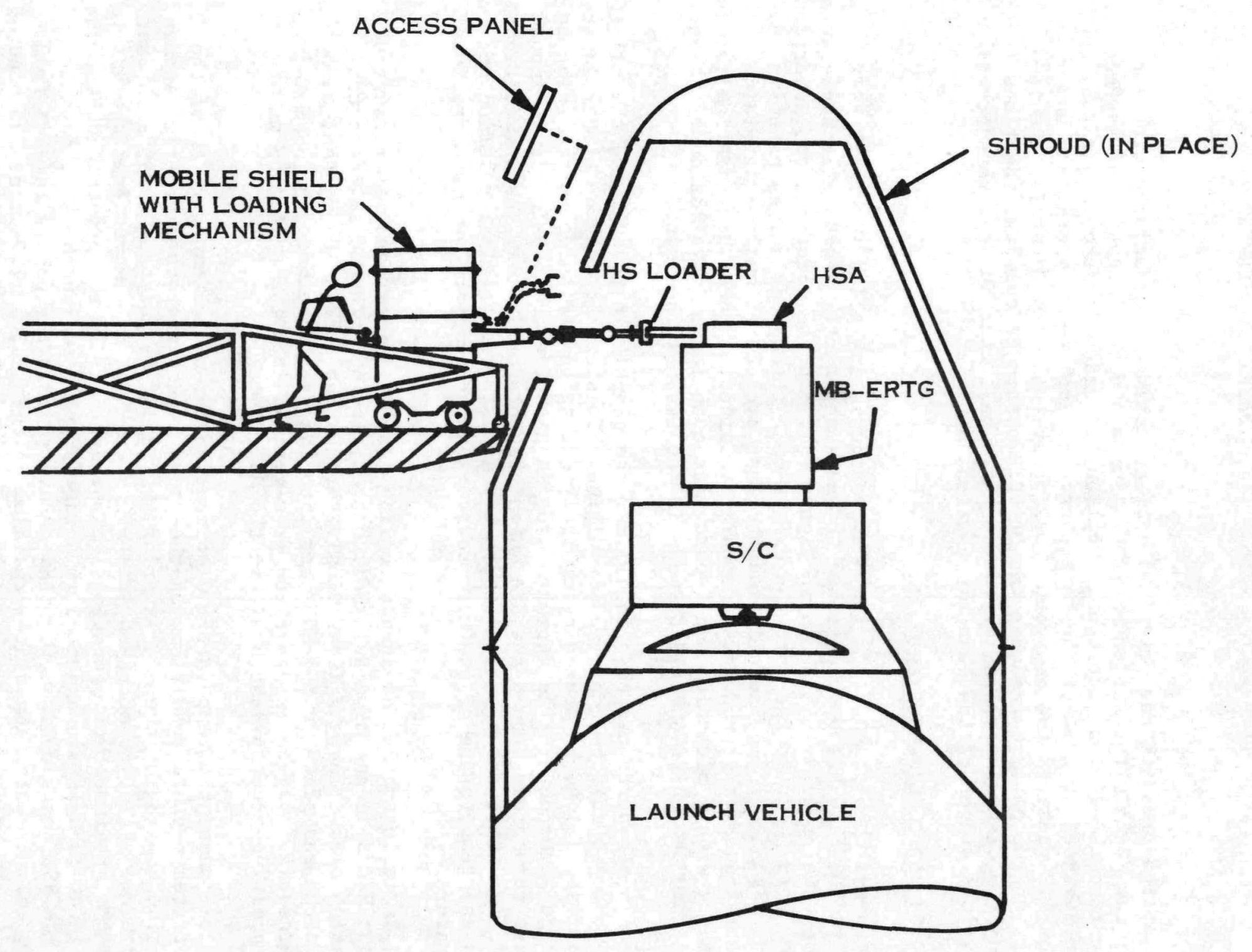




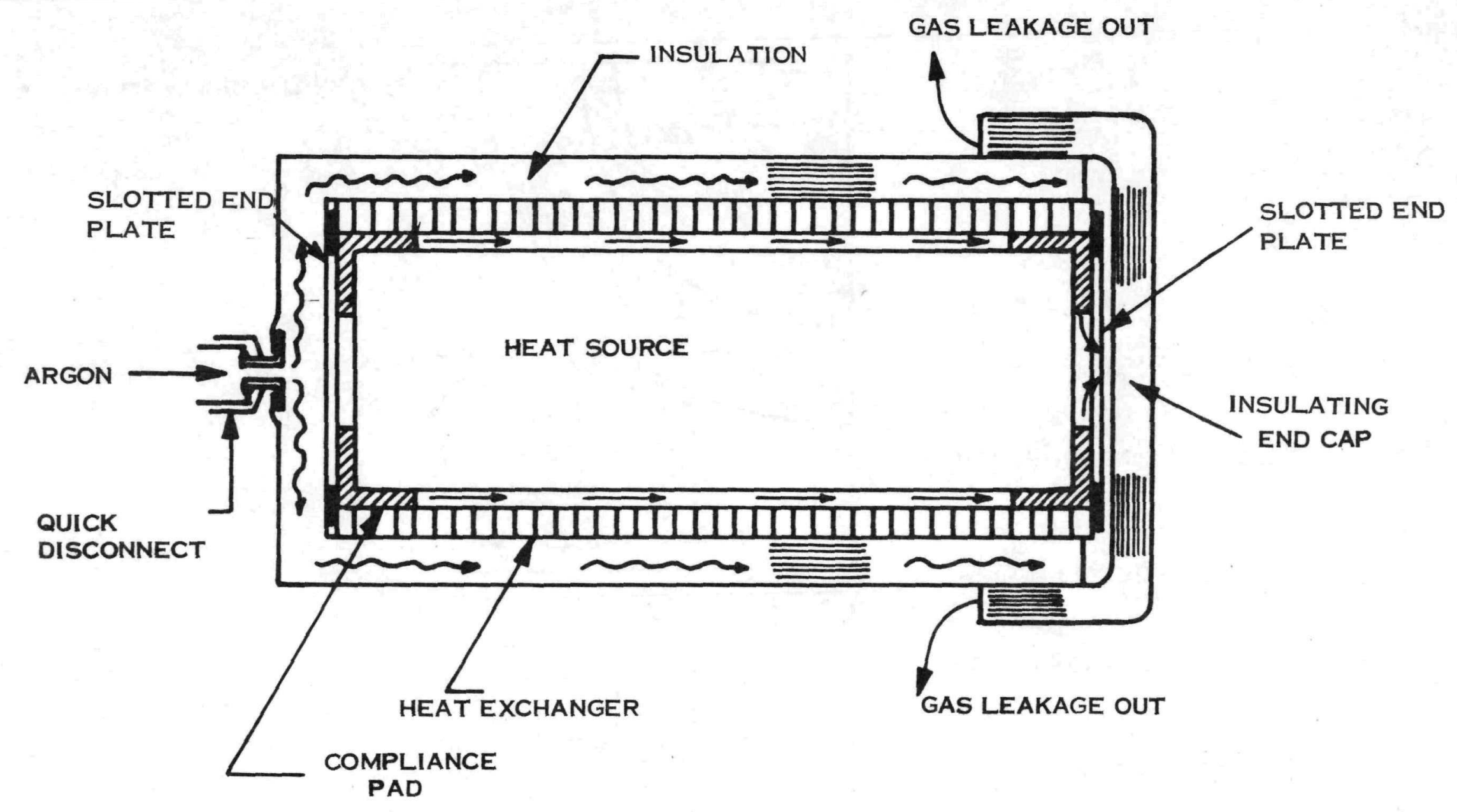


OUTER FOIL $\quad 350^{\circ} \mathrm{F}$

- $\quad$ all temperatures, ${ }^{\circ} \mathrm{F}$
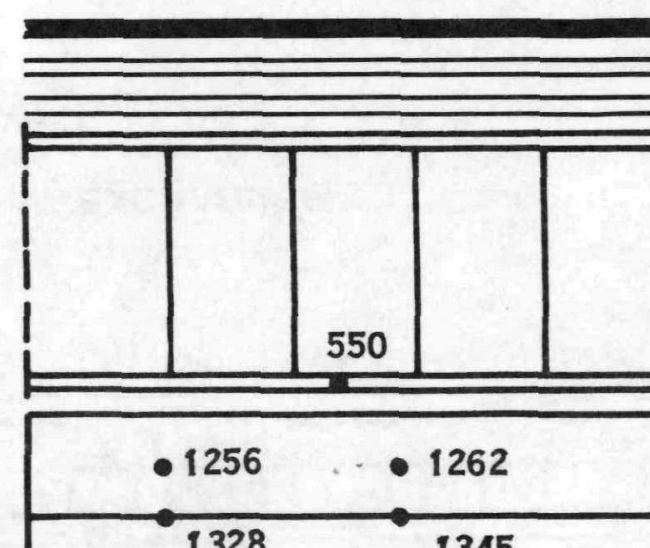

$\bullet 1256$

1328

1345

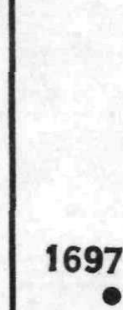

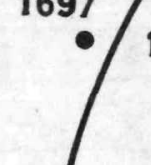

- 1539

1555

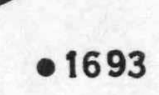

(7794

1794

1861

.
- ARGON FILLED INEULATION

- HEAT EXCHANGER

- ARGON FILLED GAP

- Aeroshell

- AEROSHELL IMPACT CORE

- FIB CRUSHUP

- ceramic clad

- FUEL 


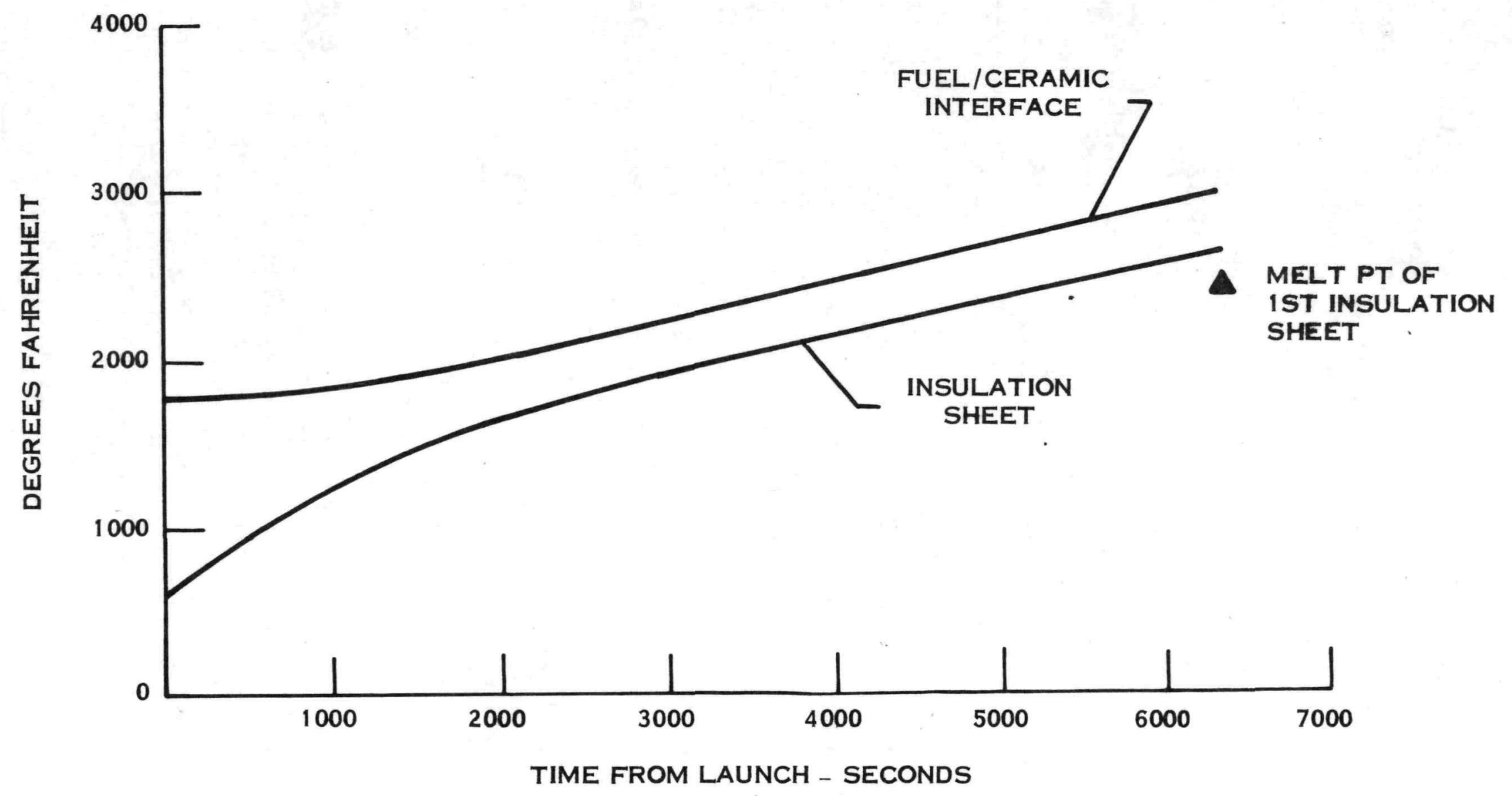




\subsection{ON-PAD COOLING SYSTEM (continued)}

One design alternative to the above concept is to provide a sealed HSA which retains the inert gas until a pressure release device is actuated. This concept would require a more expensive development program, however, greater operational flexibility would be gained. A final selection of the on-pad cooling design may depend upon other factors such as the choice of fuel and type of insulation system.

\subsection{EMERGENCY COOLING SYSTEM}

Unlike static RTG's, dynamic nuclear power systems are designed to retain the thermal energy within the HSA. The only mode of heat removal in the basic system is by the flow of working fluid through the HSHX. The emergency cooling system,(ECS) is designed to prevent meltdown of the heat source after the MBERTG ceases to function.

Three emergency cooling concepts were considered for the Reference Design; as discussed in Section 3.2.2 the melting insulation approach was determined to be the most reliable as well as cost effective. Two types of melting insulation systems were evaluated: two layer systems which utilize a metal foil and a separator material and secondly, high density foil systems which have an oxide layer to prevent conduction between foils.

The high density foil systems were judged to be more attractive for this application due to the lighter weight afforded by this design. A second advantage of this type of insulation system is that it is $1 / 3$ to $1 / 6$ the thickness of the two layer system. This feature allows the inert gas to more effectively thermally short circuit the insulation during the on-pad cooling operation, thus providing lower on-pad HSA temperatures.

Several different materials were evaluated for the melting insulation system; these included:

$$
\begin{aligned}
& \text { copper, m.p }=1982^{\circ} \mathrm{F}\left(1083^{\circ} \mathrm{C}\right) \\
& \text { gold, m.p. }=1946^{\circ} \mathrm{F}\left(1063^{\circ} \mathrm{C}\right) \\
& \text { nickel, m.p. }=2615^{\circ} \mathrm{F}\left(1435^{\circ} \mathrm{C}\right) \\
& \text { t titanium, m.p. }=3273^{\circ} \mathrm{F}\left(1800^{\circ} \mathrm{C}\right)
\end{aligned}
$$

Conversations with the Thermo Electron Corporation indicated that the above materials could be used with a flame sprayed coating of zirconia or thoria. The HSA working fluid exit temperature at BOM is $1705^{\circ} \mathrm{F}$ with the exterior of the HSHX at about $1800^{\circ} \mathrm{F}$. In order to minimize the melt through time and thereby, limit the heat source temperature rise, a material with a melting point close to the HSHX normal operating temperature would be selected. However, continued investigation revealed that for this type of insulation system serious performance degradation occurs when the material is near its melt point. Therefore, copper and gold were not considered further and nickel was selected for the melting insulation system. 


\subsection{EMERGENCY COOLING SYSTEM}

Another consideration in selecting nickel is its compatibility with the graphite aeroshell and HSHX. Compatibility with the aeroshell is important since a reentry capability must be maintained subsequent to a loss of cooling event.

Figure 6-5 shows the temperature distribution through the insulation system at the center section of the HSA. Heat loss through the HSA is calculated to be 120 watts, an additional 50 watts is estimated to leak as a result of edge losses.

The heat source temperature transient during a loss of cooling is shown in Figure 6-6. The maximum heat source temperature is conservatively calculated to be $3750^{\circ} \mathrm{F} 5000$ seconds after the event. This temperature is below the melting point of $\mathrm{Cm}_{2} \mathrm{O}_{3}, 4082^{\circ} \mathrm{F}$. Maximum thoria clad/fuel interface temperature is $3100^{\circ} \mathrm{F}$ which also occurs 5000 seconds after the event. Similarly, this temperature is well below $5610^{\circ} \mathrm{F}$, the melting point of thoria. Therefore, the ECS is shown to maintain the integrity of the heat source.

\section{$6.3 \quad$ POTENTIAL ACCIDENTS AND ABORTS}

The preliminary safety assessment presented in these sections is based to a large extent on results generated in the conduct of the MHW RTG Program. MHW ground operations (for the LES $8 / 9$ mission) are considered to be typical and applicable to the SURVSATCOM type of mission. Since the launch vehcile is identical for both missions, analyses performed for the MHW/LES mission have been used for direct comparison in the SURVSATCOM application.

The methodology employed is essentially the same as that used in the SNAP-27 and the MHW safety analyses. This approach consists of the following steps as applied to the MB-ERTG assessment.

1. Review all ground handling operations and all mission phases to identify the potential accidents and aborts

2. Define and characterize the induced environments to which the heat source can be exposed as a result of the accidents/aborts

3. Analyze the response of the radioisotope heat source to the induced environments in order to assess its safety capability

4. Identify those instances that potentially can lead to release of and/or exposure to radioactive material and assess the nature of the releases/exposures

5. Determine the consequences to the biosphere of the potential releases of the radioactive fuel.

For purposes of convenience and because of the similarity to the LES $8 / 9$ mission, the SURVSATCOM type mission and ground operations have been divided into the phases identified in Table 6-1. Table 6-2 lists the potential accidents and aborts that have been identified for the various operations and mission phases. The aborts related to the launch vehicle are based on recent studies by Martin-Marietta Corporation for the Air Force in support of the 


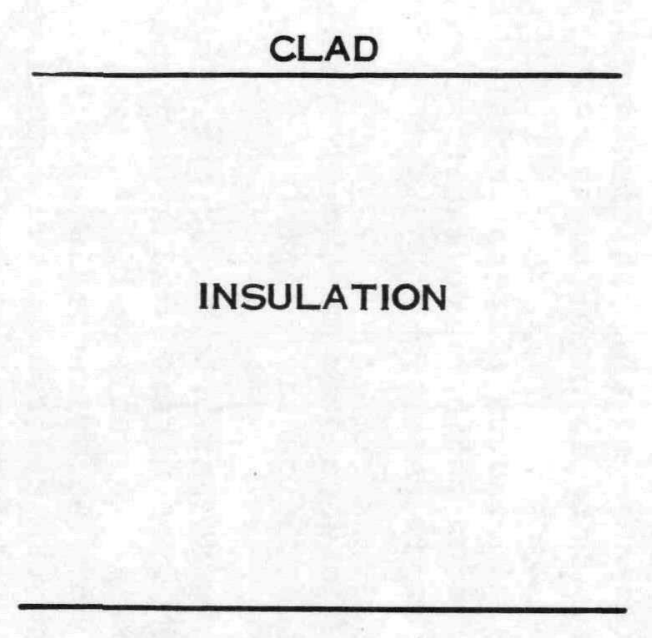

HEAT

EXCHANGER

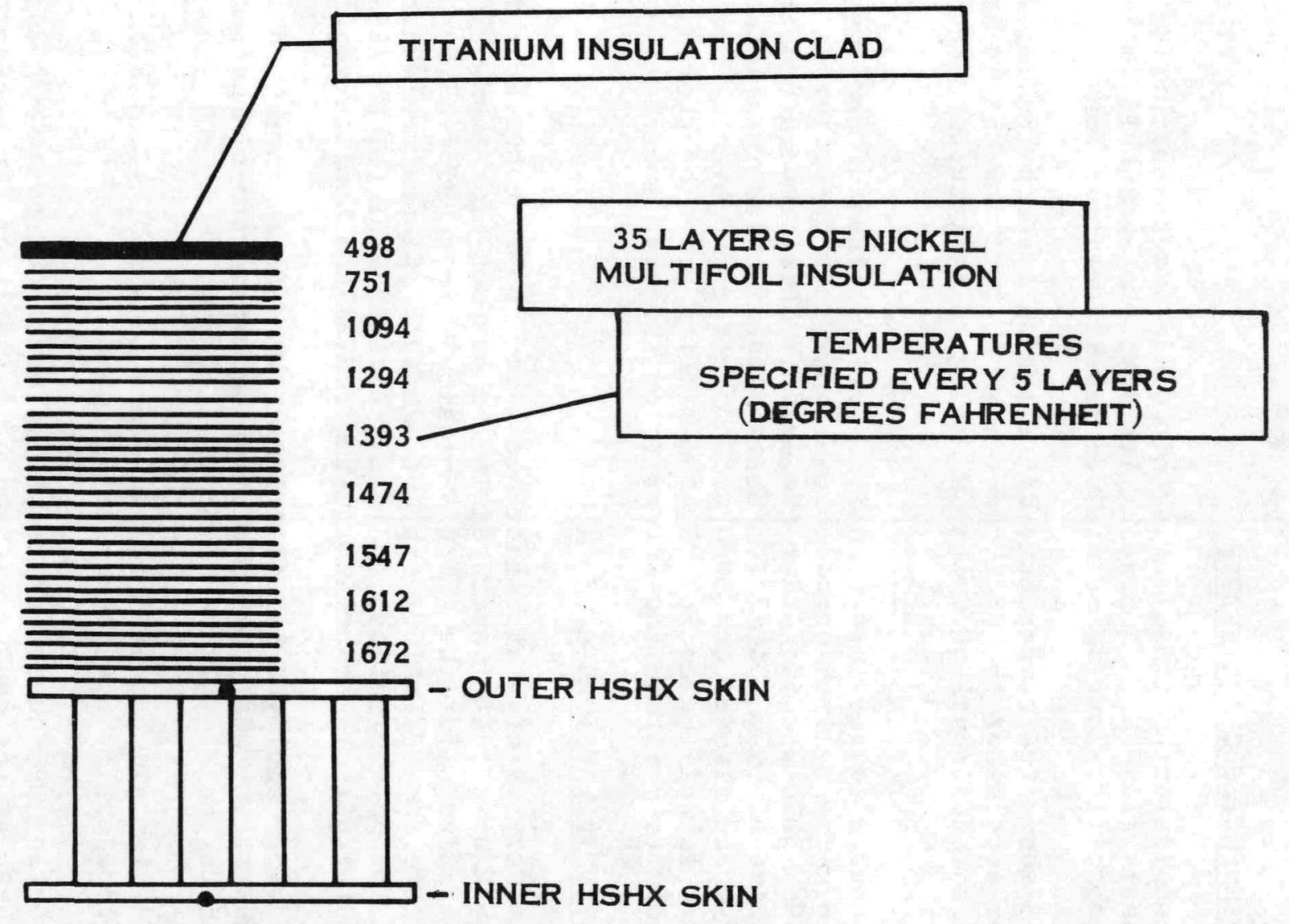

Figure 6-5. Typical Operational Temperature Profile Through Heat Source Assembly Insulation 


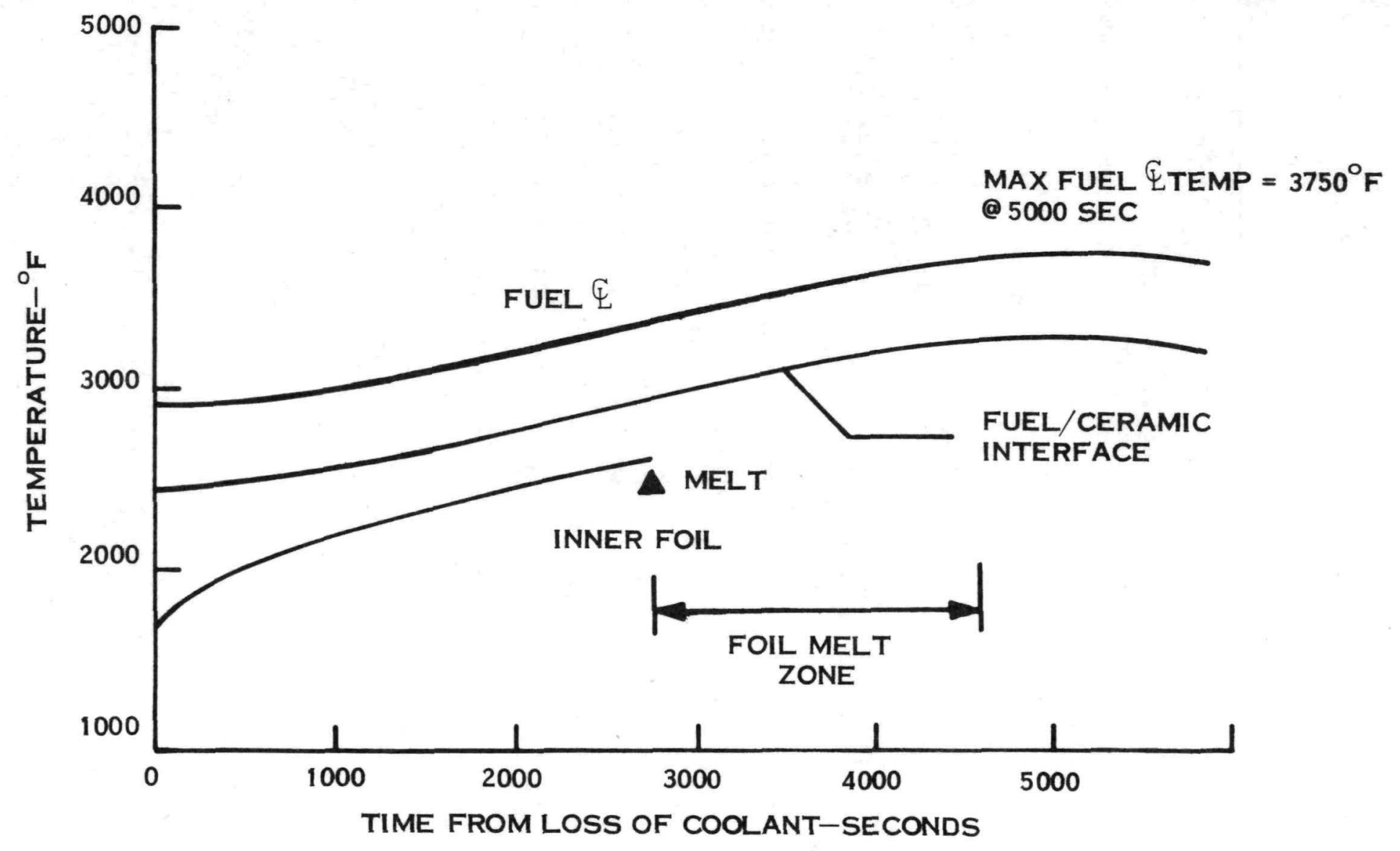


Table 6-1. Ground Operations and Mission Phases

G1 - Transportation

Fueling Agency to GE

GE to Test Sites to GE

GE to Launch Site

G2 - Ground Handling

$\mathrm{GE}$

Test Sites

Launch Site

1 - Prelaunch Phase

(Vehicle fueling to launch)

2 - Launch Phase

(Lift-off to clearing launch tower)

3 - Ascent Phase

(Clear launch tower to park orbit acquisition)

4 - Park Orbit Phase

(Coast - low Earth orbit)

5 - Transfer Orbit Phase

(Transtage first burn and coast)

6 - Orbit Injection Phase

(Transtage second burn - to synchronous orbit) 
Table 6-2. Potential Accidents and Mission Aborts

G1

Transportation

Collisions with other vehicles

Collisions with stationary objects

Overturns

Others

G2

Ground Hand 1ing

Dropping the heat source

Impact on the heat source by falling objects

Collisions during intraplant transfers

Fire/explosion

1

Prelaunch Phase

Launch vehicle structural failure

Explosion and fire due to propellant leakage

Inadvertent destruct of the launch vehicle

Loss of cooling to the heat source heat exchanger

2

Launch Phase

Launch vehicle structiral failure

Explosion and fire due to propellant leakage

Inadvertent destruct of the launch vehicle

Loss of cooling to the heat source heat exchanger

One engine (Stage 0) misfire

Snag of launch tower during liftoff

Ascent Phase

Premature shutdown of an engine or stage

Guidance error

Explosion and fire due to propellant leakage

Structural failure of launch vehicle

Inadvertent destruct of launch vehicle

Loss of cooling to the heat source heat exchanger

Powered impact of launch vehicle - target reference error

4

Park Orbit Phase

Failure to fire transtage for first burn

5

Transfer Orbit Phase

Guidance error

Premature first burn of transtage engines

Premature shutdown of transtage engines

Burn to depletion of propellants (long burn)

Late firing of transtage engines

6

Injection Phase

Failure to fire transtage for second burn

Premature second burn of transtage engines

Guidance error

Premature shutdown of transtage engines

Burn to depletion of propellants (including reserves)

Late firing of transtage engines 


\subsection{POTENTIAL ACCIDENTS AND ABORTS (continued)}

studies by Martin-Marietta Corporation for the Air Force in support of the safety analyses for the LES/MHW mission. These studies include failure modes that can occur in the four staging configurations of the Titan III $C$ as a function of mission phase. Individual component and system failures are selected that will result in gross malfunctioning of the vehicle such that the nominal mission cannot be completed. The entries in Table 6-2 reflect the results of those malfunctions.

\subsection{DEFINITION OF ENVIRONMENTS}

The occurrence of the accidents and malfunctions previously listed produce or induce environments that are potentially damaging to the physical integrity of the heat source. Since a major part of a nuclear safety study is to analyze the capability of the radioisotope heat source to survive the potentially hazardous environments, the necessity arises to characterize the environments that can exist. This has been done for the MHW safety study, and the results being directly applicable to the SURVSATCOM type of mission, will be discussed briefly in succeeding paragraphs. However, the detailed derivations of these environments will not be presented since they are available in the MHW safety reports and related documents.

Table 6-3 is a summary of the potential environments for all ground and mission accidents and malfunctions. The environments are grouped by mission and ground handling phases.

Environments shown for transportation operations are typical of potential collisions between vehicles and for collisions with stationary objects. The explosion environment is applicable to vehicles carrying dangerous materials.

Ground handling accident environments are representative of mishaps that can occur during intraplant transfers and storage of the heat sources. Also included are the potential conditions associated with handling the heat sources such as dropping and being hit by dropped objects.

The prelaunch phase environments are related to the characteristics of the propellants used in the several states of the launch vehicle with the vehicle undergoing a catastrophic accident. Typical explosion yields are a few tenths of a percent with upper limits around one percent for either range safety destruct or self destruct of the vehicle. Figures $6-7$ and $6-8$ show curves of static overpressure and static impulse as a function of distance from a typical explosion center in the transtage; parametric values of yield are shown also. With values of yield less than one percent, static overpressures will be below 50 psi for any location of the spacecraft. Equivalent static pressure impulses will be less than 0.5 psi-sec. as seen from Figure 6-8. Curves of fireball temperatures and heat fluxes are shown on Figure 6-9 for the 1iquid propellant loading (approximately 350,000 1bs) for the Titan III C. (The 1973 model is currently believed to be more representative). Thus, temperatures are seen to vary from around $4900^{\circ} \mathrm{F}\left(2704^{\circ} \mathrm{C}\right)$ to $2600^{\circ} \mathrm{F}\left(1426^{\circ} \mathrm{C}\right)$ over the 7.5 sec. period of duration for the fireball. Afterfire temperatures are seen to be in the range of $1900^{\circ} \mathrm{F}\left(1037^{\circ} \mathrm{C}\right)$. The impact velocity shown ( $\leq 95 \mathrm{fps}$ ) is representative of the free fall velocity from the top of the launch vehicle. 
Table 6-3. Definition of Potential Environments

Transportation

Impact

Explosion

Fire

Water Inmersion

Ground Handling

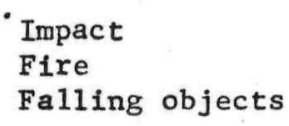

Prelaunch Phase

Explosion

Firebal1

Impact

Afterfire

Launch Phase

Explosion

Firebal1 - Liquid Propellant Impact

Solid Propellant Fire

Afterfire - Liquid Propellant

$\leq 190 \mathrm{fps}$

100 's of PSI

$\leq 2000 \circ \mathrm{F}, \leq 30 \mathrm{~min}$.

$\leq 95 \mathrm{fps}$

$\leq 2000^{\circ} \mathrm{F}$, $\leq 30 \mathrm{~min}$.

$\leq 50$ psi static overpressure

$\leq 0.5$ psi-sec. static impulse

$\leq 7.5 \mathrm{sec} .,<5000^{\circ} \mathrm{F}$ decreasing

$\leq 95 \mathrm{fps}$

$\leq 2000^{\circ} \mathrm{F}$, $\leq 30 \mathrm{~min}$.

$$
\begin{aligned}
& \leq 50 \mathrm{psi} \text { static overpressure } \\
& \leq 0.5 \mathrm{psi-sec} \text { static impulse } \\
& \leq 7.5 \mathrm{sec}, \quad<5000^{\circ} \mathrm{F} \text { decreasing } \\
& \leq 140 \mathrm{fps} \\
& \approx 4200^{\circ} \mathrm{F}, \leq 10 \mathrm{~min} . \\
& \leq 2000^{\circ} \mathrm{F}, \leq 30 \mathrm{~min} .
\end{aligned}
$$

\section{Ascent Phase}

Explosion

Firestream

Impact

Solid Propellant Fire

Sensible Re-entry

Water immersion
Less severe than on pad values

$>1000 \mathrm{fps}$ if destruct system fails

$\approx 4200 \mathrm{OF}$, < $10 \mathrm{~min}$.

$<25,000$ fps (ballistic) 
Table 6-3. Definition of Potential Environments (continued)

Park Orbit Phase

$\begin{array}{ll}\text { Re-entry } & 25,700 \mathrm{fps}, \approx 0^{\circ} \\ \text { Impact } & \text { Land, water } \\ & <180 \mathrm{fps} \\ \text { Buria1 } & \text { soft soils }\end{array}$

Transfer Orbit Phase (transtage first burn)

$\begin{array}{ll}\text { Re-entry } & 13,500-36,800 \text { fps } \\ \text { Impact } & 0.4-38^{\circ} \\ & \text { Land, water } \\ \text { Burial } & <180 \mathrm{fps} \\ & \text { soft soils }\end{array}$

Orbit Injection Phase (transtage second burn)

Re-entry

Impact

DutLaí
$28,900-36,400$ fps

$0.4-890$

Land, water

$<180$ fps

sott soils 


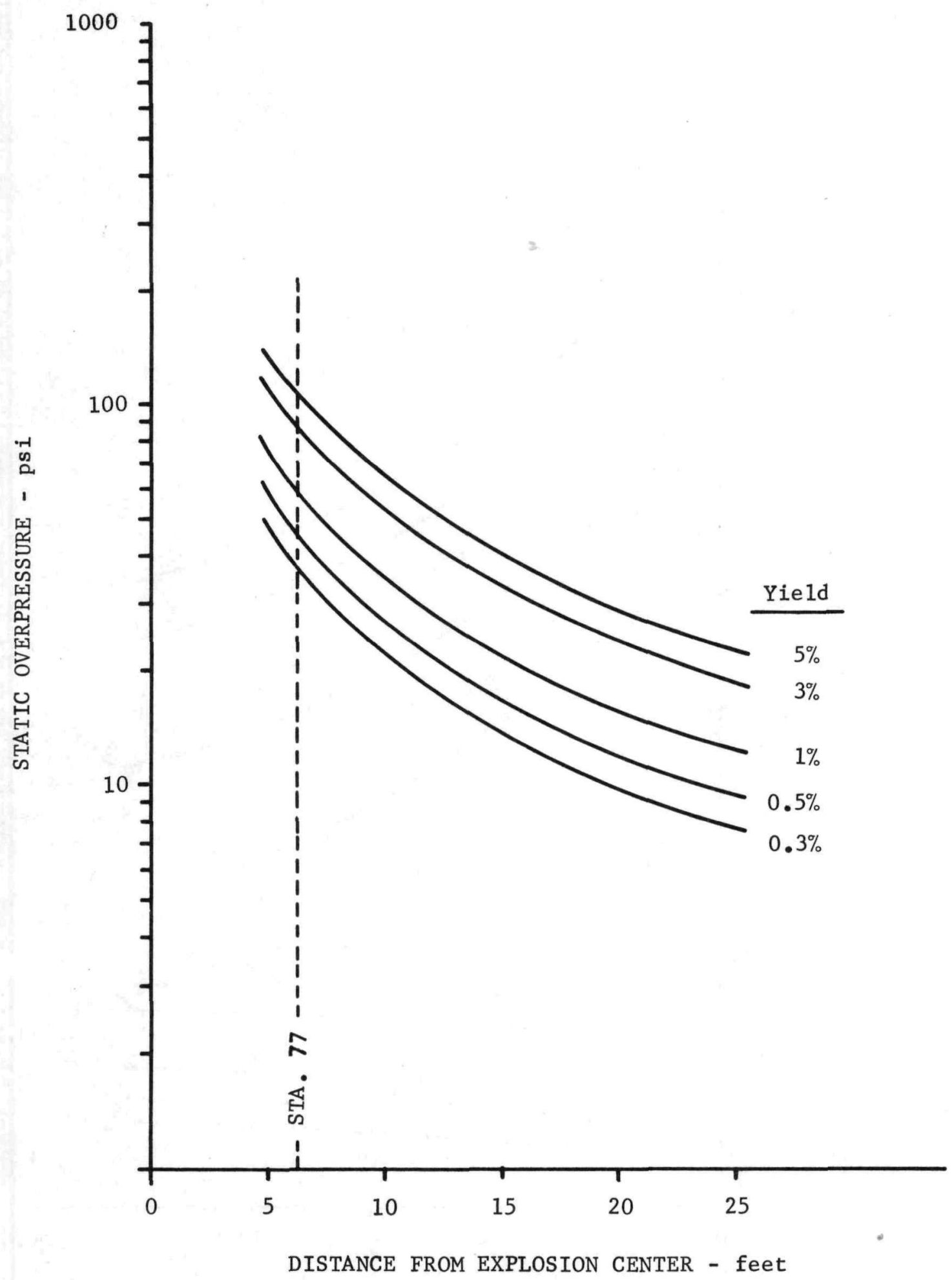

Figure 6-7. Static Overpressure as a Function of Distance From Explosion Center in the Transtage 


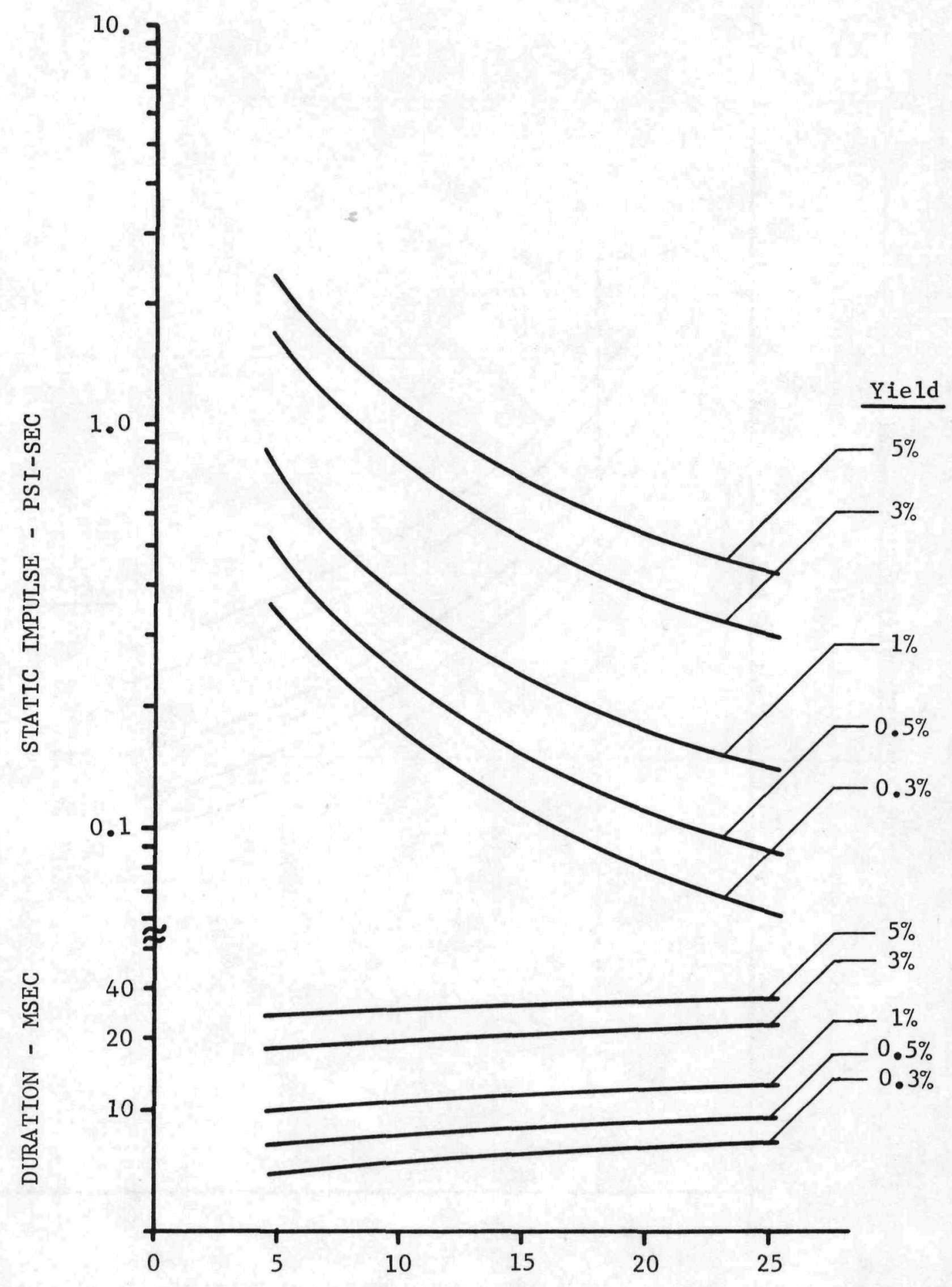

DISTANCE FROM EXPLOSION CENTER-Feet

Figure 6-8. Static Impulse as a Function of Distance From Explosion Center in the Transtage 


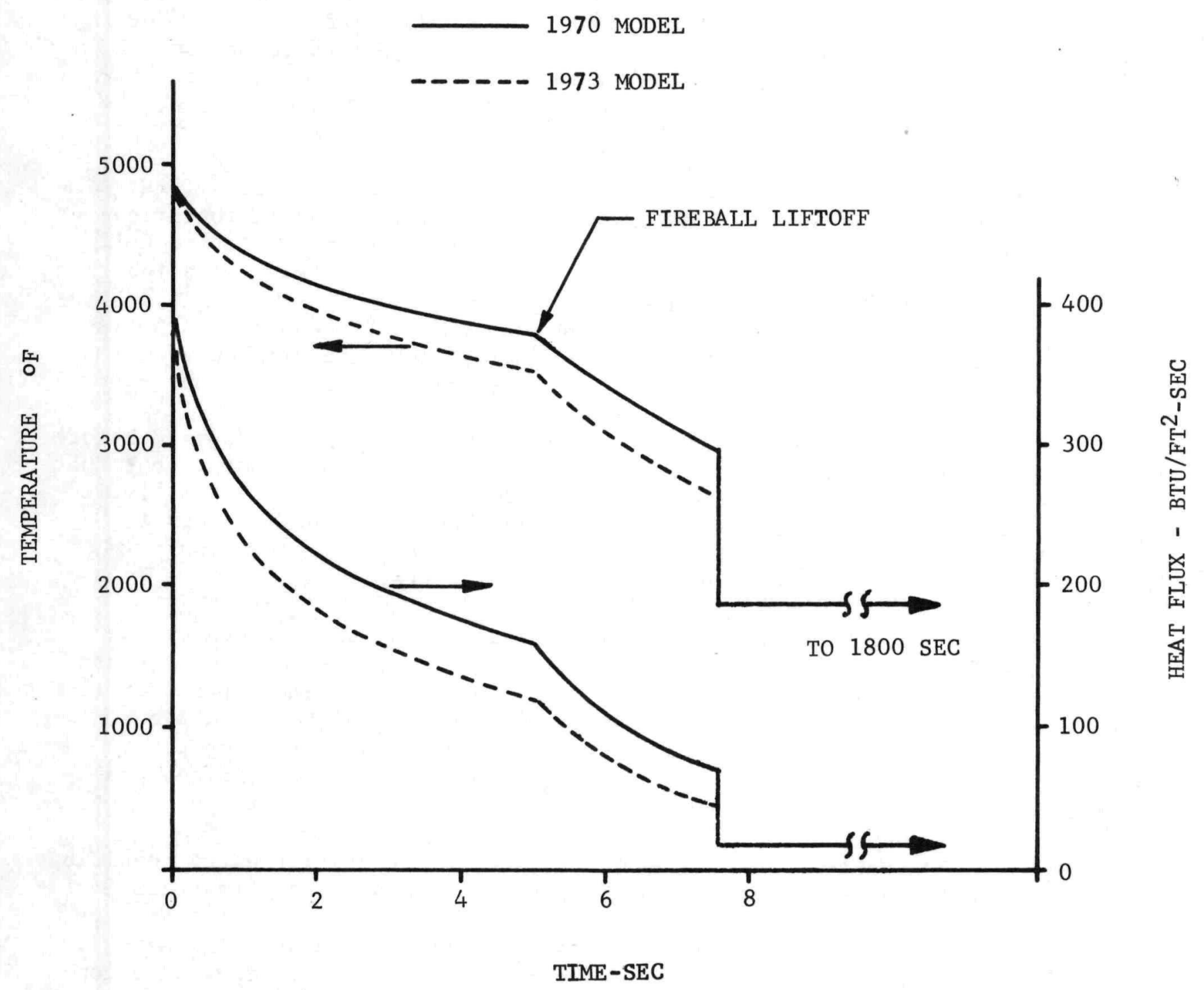

Figure 6-9. Fireball Temperatures and Heat Flux as a Function of Time for TITAN III C 


\subsection{DEFINITION OF ENVIRONMENTS (continued)}

There is no environment shown for the solid propellant since the Stage 0 engines would not have been ignited during this phase. Energy produced in combustion of the liquid propellant (as in the fireball and afterfire) is not sufficient to ignite the solids.

Launch phase accidents result in much the same environments as those for the prelaunch phase as shown in Table 6-3. In addition, the solid propellant fire must be included. Figure 6-10 shows temperature and heat flux as a function of duration of burn. This figure is applicable to the situation in which the object to be analyzed is initially in contact with the surface of the burning propellant. Recession of the burning surface as the propellant is consumed then accounts for the decrease in temperature and heat flux with time. For those cases in which the object stays in contact with the burning face, the temperature would remain steady at the $4250^{\circ} \mathrm{F}\left(2343^{\circ} \mathrm{C}\right)$ level.

During the ascent phase, the environments associated with explosion (and firestream) are less severe than those on pad due to atmospheric conditions of lowered pressure and density. This is illustrated in Figures 6-11 and 6-12 which show static overpressure and static impulse, respectively, as a function of time after liftoff. The duration associated with the burning of solid propellant pieces (after falling to the ground) will also be lessened with time because of consumption of the propellant and more extensive breakup upon impact as the solid engines or their remains fall from higher elevations.

The attainment of altitudes of 200,000 to 400,000 feet will be required before the MB-ERTG can experience sensible reentry heating should an abort occur that prevents attainment of the parking orbit. These reentries will be ballistic in nature and will involve velocities less than those for the park orbit $(\approx 25,000 \mathrm{fps})$. Aborts occurring in this phase, of course, will result in impact in ocean areas in the greater majority of cases.

After altitudes of 100,000 feet or higher are attained, the effects of explosion and fire are essentially non-existent, and so these environments are no longer applicable. Effectively, the environments that remain for the parking orbit and later phases are associated with the reentry conditions that can result from aborts due to transtage malfunctions. The reentry environments are followed by Earth impact (except for those conditions producing escape from the Earth's gravity) and post impact environments.

The Air Force has undertaken studies to define the potential reentry conditions that can exist as a result of the possible malfunctions in the transtage for the LES 8, 9/MHW mission. Only accidents related to firing of the transtage engines will cause reentry as opposed to nominal firing conditions leading to accomplishing the total mission. The several modes of failure that were considered in the study included velocity magnitude errors (long burns, short burns, failures to burn) errors in the true anomaly (position in orbit) at which the burn occurs (early burns, late burns), and spatial misalignment of the velocity addition vector (leading or misorientation errors). These failure modes were treated both singly and in combinations. The results have been presented in the form of velocity-flight path angle $(V, \gamma)$ envelopes at the 400,000 foot altitude or initial reentry point. The results of those studies 


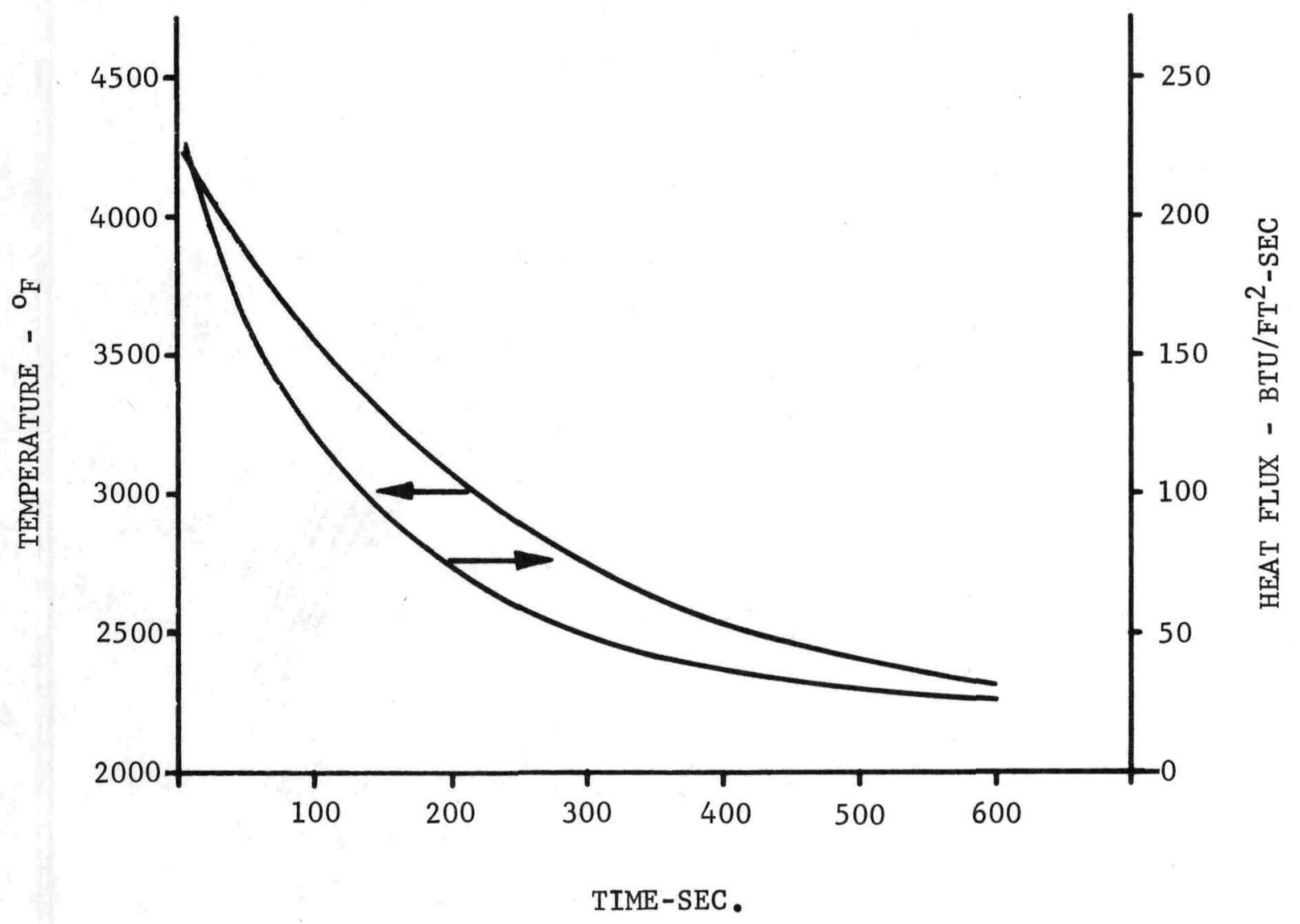

Figure 6-10. Solid Fire Model TITAN III C Vehicle 


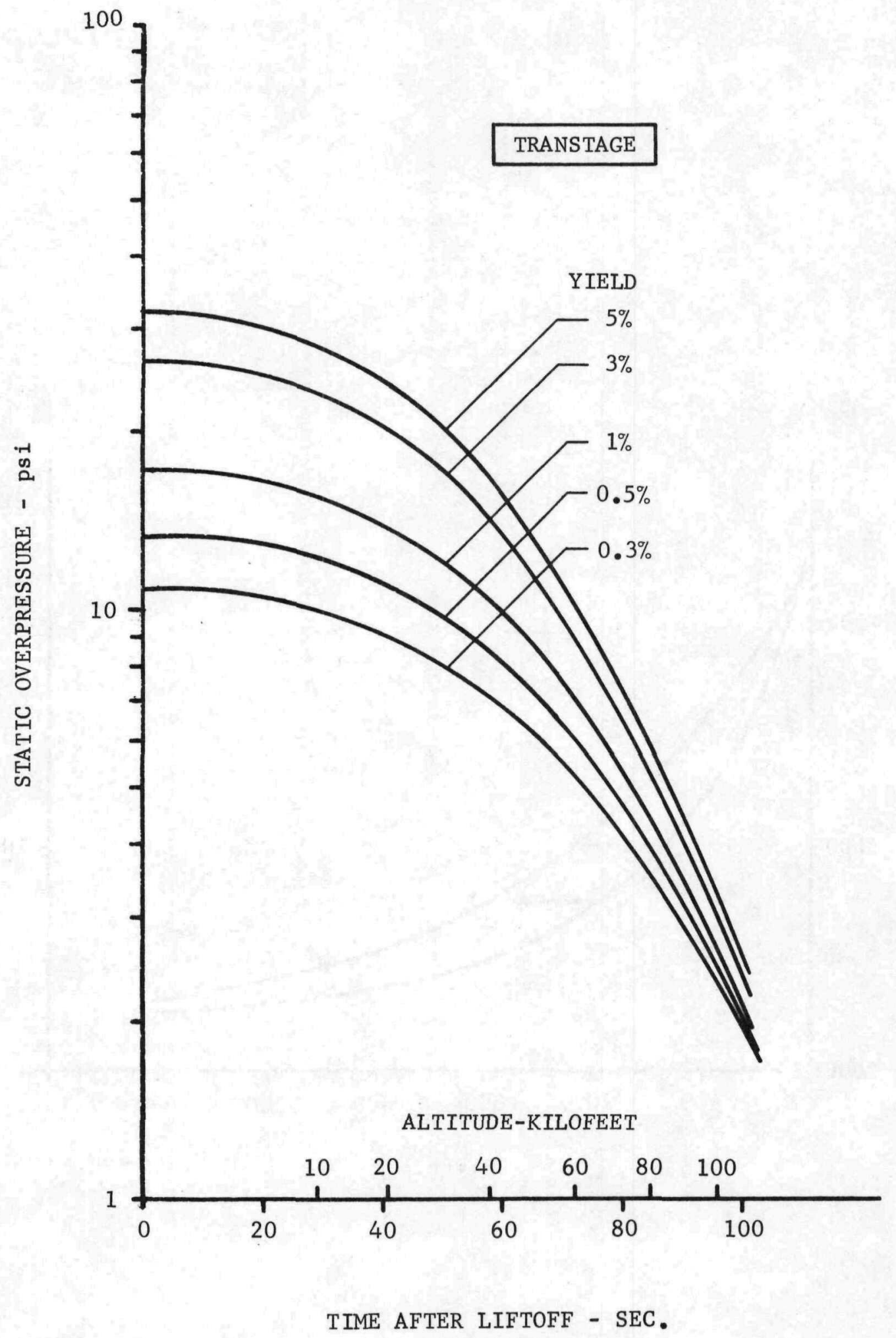

Figure 6-11. Static Overpressure versus

Time After Liftoff 


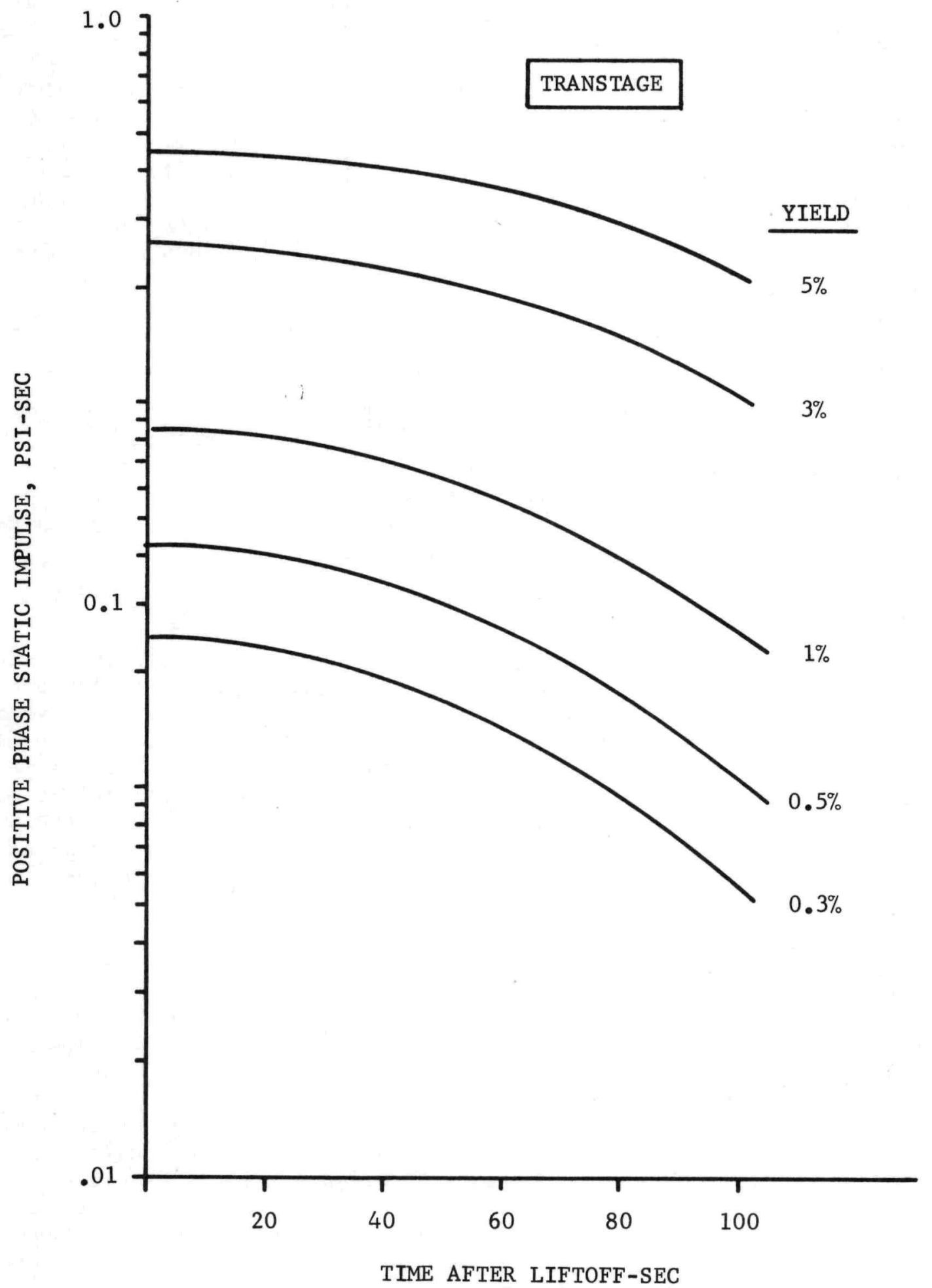

Figure 6-12. Static Impulse versus

Time After Liftoff 


\subsection{DEFINITION OF ENVIRONMENTS (continued)}

are summarized in Table 6-3 for the park orbit, transfer orbit and orbit injection phases. Entries shown represent the range of conditions possible. However, the ranges for velocity and path angle do not necessarily coincide. For example, in the transfer orbit, phase, the $0.4^{\circ}$ path angle and the 13,500 fps velocity represent only the lower values of the ranges for the given quantities. The $0.4^{\circ}$ angle and 13,500 fps velocity are not a consistent set of conditions. Neither are the 36,800 fps velocity and the $38^{\circ}$ angle consistent at the upper ends of the ranges.

The impact velocities given in Table 6-3 were calculated for the curia fueled heat source utilized in the Reference Design.

\subsection{RESPONSE OF HEAT SOURCE TO ENVIRONMENTS}

This section summarizes the expected response of the Reference Design heat source to the accident and abort environments previously identified by Mission Phase. Sections $6.5 .1,6.5 .2$ and 6.5 .3 present the analyses performed for various reentry, impact and post-impact conditions.

\section{Transportation Operations}

Operations involving transportation of the radioactive heat source between 1ocations will involve the use of a shipping cask designed to meet AEC requirements for credible and hypothetical accident situations. The cask must be shown, either by analyses or tests, to be capable of surviving these accidents without releasing its radioactive contents and without reducing the effectiveness of its radiation shielding. The use of such a cask will preclude direct exposure of the heat source to the accident generated environments shown in Table 6-3. Consequently, the secondary effects of the given environments, those effects seen by the heat source, will be negligible. In effect, the shipping cask will act as a barrier to the direct environments.

\section{Ground Handling Operations}

The shipping cask used for transportation of the heat source will also be used for storage of the source when it is not being tested or readied for the mission. Thus, the heat source will be protected from the more severe environments for a major fraction of time at the various locations. Exposure of the heat source to fire should present no problem since the temperatures involved are less than or equal to those experienced during normal operation. Dropping the heat source from the minimal heights involved in ground handling should also present no problem since the heat source is designed to withstand impacts at terminal velocity on granite without release of the radioactive fuel. Operational procedures, restrictions, and facility design will preclude the presence of heavy equipment that can fall onto the heat source when it is removed from the shipping cask. Crushing of the fueled heat source, therefore, will not occur. 


\section{PreLaunch Phase}

Prior to loading of propellants onto the launch vehicle, the heat source is assumed to have been installed into the mini-Brayton heat exchanger in preparation for the launch. In this configuration, the heat source will be protected from the initial effects of the launch pad accident environments. Effectively, the heat exchanger will act as a barrier to the environments of fireball and blast shock. The low overpressures expected from an explosion are not expected to result in release of the heat source from the heat exchanger. Because of this, the heat source will be further protected from the effects of impact in the launch pad area, and it is expected to exist essentially intact after the impact. Afterfire temperatures associated with burning of propellant pools around the pad area will also be equal to or less than those of the heat source during normal operation. In summary, the prelaunch phase accident environments are not expected to result in potential fuel releases.

\section{Launch Phase}

Accident environments for this phase of the mission are essentially the same as those for the prelaunch phase; the main difference is that the fire associated with burning of the solid propellant must be considered. Excluding the latter environment will result in the response of the heat source being the same as for the prelaunch phase. The end result therefore is an intact heat source due to the protection afforded by the heat source heat exchanger. This configuration and condition of the heat source will insure that the ceramic fuel clad will not be breached by exposure of the heat source to the solid propellant fire. Calculations performed for the LES/MHW design under essentially the same conditions have shown that the temperature of the fuel sphere containers (called Post Impact Containment Shells or PICS in the MHW design) will not exceed $3230^{\circ} \mathrm{F}\left(1778^{\circ} \mathrm{C}\right)$ for a 10 minute duration fire. This is based on the heat source being in contact with the burning surface of the propellant over the duration of a 10 minute fire. For the Reference Design the thoria can provide containment at temperatures up to $5610^{\circ} \mathrm{F}$. Since the solid propellant fire temperature is $4200^{\circ} \mathrm{F}$, fuel release will not occur.

\section{Ascent Phase}

During the ascent phase, the initial environments accompanying a catastrophic abort of the launch vehicle have been shown to be less severe than those on pad. For this reason, the explosion and fire are not expected to produce any damage to the heat source. On the other hand, the possibility of the launch vehicle undergoing powered impact on land at velocities considerably higher than the terminal velocity of the heat source becomes finite, although small. This event would occur only in the instance of failure of the Command Shutdown and Destruct System (CSDS). Should impact occur at velocities on the order of $1000 \mathrm{fps}$ or higher, breach of a number of the individual fuel containers is likely to occur - a probability of occurrence on the order of $10^{-7}$ is estimated for this accident. A factor that would tend to lessen the severity of the failures is that the impact medium would most likely be yielding based on the physical location involved (launch vicinity or neighboring areas). Also, the 


\subsection{RESPONSE OF HEAT SOURCE TO ENVIRONMENTS (continued)}

\section{Ascent Phase (continued)}

heat source would be protected additionally by the presence of the heat exchanger.

Sensible reentry will not be experienced by the heat source during the ascent phase until altitudes of around 200,000 feet or higher are reached. After these altitudes are attained, the other environments (e.g., explosion, firestream, solid propellant fire) are no longer applicable. The minimal reentry heating that can be experienced by the heat source prior to attainment of the park orbit does not present any problem, and the heat source will impact with the aeroshell intact.

In summary, the only accident that can result in potential release of the radioactive fuel is a powered impact of the launch vehicle. In addition, impact of the heat source into water must be investigated to determine whether thermal shock is a problem for the ceramic clad. Since the graphite cover would tend to insulate the ceramic from the water temperature, fracture of the clad may be improbable. Any fissure would be expected to result in a limited release.

\section{Park Orbit Phase}

Reentry of the Mini-Brayton power system with the SURVSATCOM spacecraft would occur with an initial velocity equal to the low Earth orbit velocity (around $25,700 \mathrm{fps})$. The heat source is designed to be intact at impact. For the design case, (free heat source at 400,000 feet - not attainable under actual conditions), calculations show that the maximum aeroshell temperature would be $4000^{\circ} \mathrm{F}$. The maximum fuel sphere containment shell would be $2780^{\circ} \mathrm{F}$. Actual conditions for the heat source within the power system would be expected to result in less severe conditions; thus, the orbital decay reentry would not result in damage to the heat source other than for partial ablation of the aeroshel1.

Impact of the heat source at its terminal velocity would not be expected to breach the fuel clad containers. The individual FIBS are designed to survive an impact of $180 \mathrm{fps}$; additional safety margin is provided by the aeroshell impact core and the partially ablated aeroshell.

Post-impact containment of the curia is not expected to be a problem since the thoria does not oxidize. Situations where post-impact temperatures $>1300^{\circ} \mathrm{C}$ are present at the fuel/clad interface could result in diffusion between the two materials. Temperatures of this magnitude will only occur in burial or partial burial situations. This aspect of the design must be thoroughly evaluated with regard to potential temperature levels, diffusion rates and the potential hazard.

\section{Transfer Orbit Phase}

Reentry conditions resulting from malfunctions and aborts occurring during this phase of the mission can be more severe than those during the park orbit phase. Considerations of fuel clad containment shell failures in burial are the same as those for the park orbit phase. 


\subsection{RESPONSE OF HEAT SOURCE TO ENVIRONMENTS (continued) \\ Orbit Injection Phase}

The range of reentry conditions for malfunctions during this phase are somewhat more severe than those for the transfer orbit phase because of the larger reentry path angles possible (up to $89^{\circ}$ ). Reentries at these greater path angles generally induce high thermal stress levels in the aeroshell. This aspect of maximum $\gamma$ reentries was not assessed in this study for the Reference Design heat source. Calculations of the design case (free heat source at 400,000) for the LES/MHW heat source under the reentry conditions at these large angles indicate vanishing margins of safety in the aeroshell at the juncture between the end and cylindrical members. However, the actual mission configuration and reentry response of the total system, taking into account the effects of the spacecraft, result in only minimal stress levels in the aeroshell. A similar situation would be expected to exist for the MB-ERTG system. The response of the heat source to impact and burial would be the same as discussed for the park orbit phase.

\subsubsection{REENTRY ANALYSIS}

To evaluate the reentry the-mal performance of the heat source, a 70 node model of a center-section was implemented for use on the THT-D thermal response computer code. The aeroshell contained 36 nodes, 6 in-depth and 6 lateral nodes, while the remaining nodes were devoted to the internals. Radiant interchange was present in all of the gaps. The aeroshell/impact core gap, as well as the impact core/FIB gap, had a thermal contact conductance (h) of $100 \mathrm{BTU} / \mathrm{Hr}-\mathrm{Ft}-{ }^{\circ} \mathrm{F}$ to account for the decelerating contact force. The crushup/clad gap had an " $h$ " value of $350 \mathrm{BTU} / \mathrm{Hr}-\mathrm{Ft}-0$ due to differential thermal expansion. The fuel and clad, however, are integrally bonded in the copressing process incorporating no thermal resistance at the bond.

The prism heat source reentered with its flat face directly and stably opposed to the flow vector. This orientation was chosen for analysis because test data indicates this for the hypersonic regime (Reference 6.5-1). A conservative ballistic coefficient $(\boldsymbol{\beta})$ of 20 psf was calculated to incorporate an appropriate safety margin in the trajectory and heating calculations. The continuum drag coefficient $\left(C_{D}\right)$ used for the calculation of was 1.62

(Reference 6.5-2). The trajectory was calculated using the DYNMASS computer code and was put into the ABTON code to generate the heating history. The appropriate heating for the center-section of a flat prism was applied utilizing heating factors obtained from Reference 6.5-3.

Two worst case reentry analyses were performed to provide an initial assessment of the rectangular prism heat source temperature response. Both analyses indicated that fuel/clad interface temperatures remained at moderate levels.

A steep angle reentry case was evaluated with initial conditions of $\gamma=-90^{\circ}$ and velocity, Vo $=36,000 \mathrm{fps}$. The altitude and the heating rate on the heat source as a function of time is shown in Figure 6-13. Total time to reach 100,000 feet is 8 seconds at which point peak heating is experienced. Figure 6-14 illustrates the temperature response versus time for the front face of the aeroshell, back face of the aeroshell and the front face of the aeroshell impact 


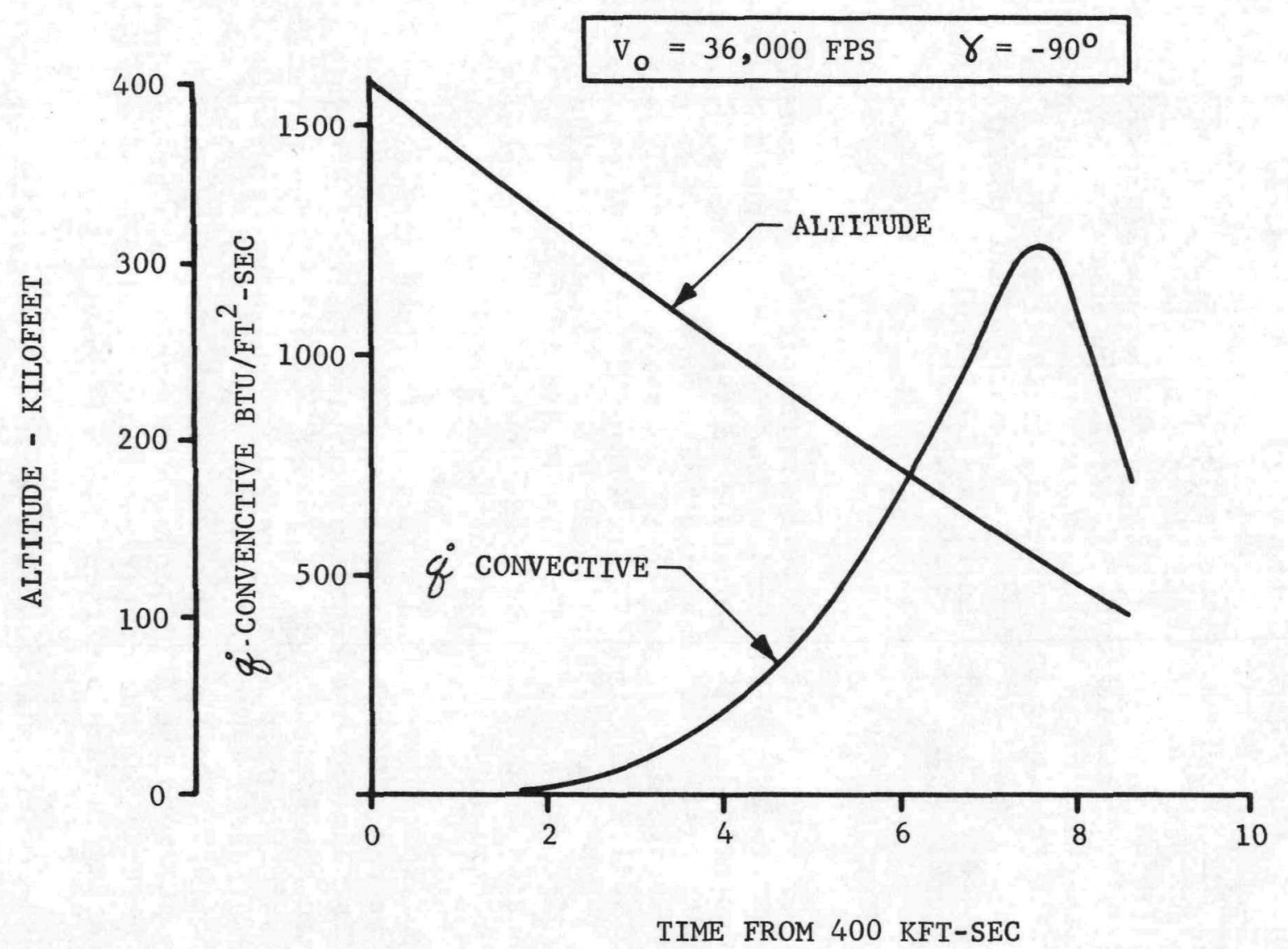

Figure 6-13. Steep Angle Reentry Heating Profile 


$$
\gamma=-90^{0} V_{0}=36,000 \text { FPS }
$$

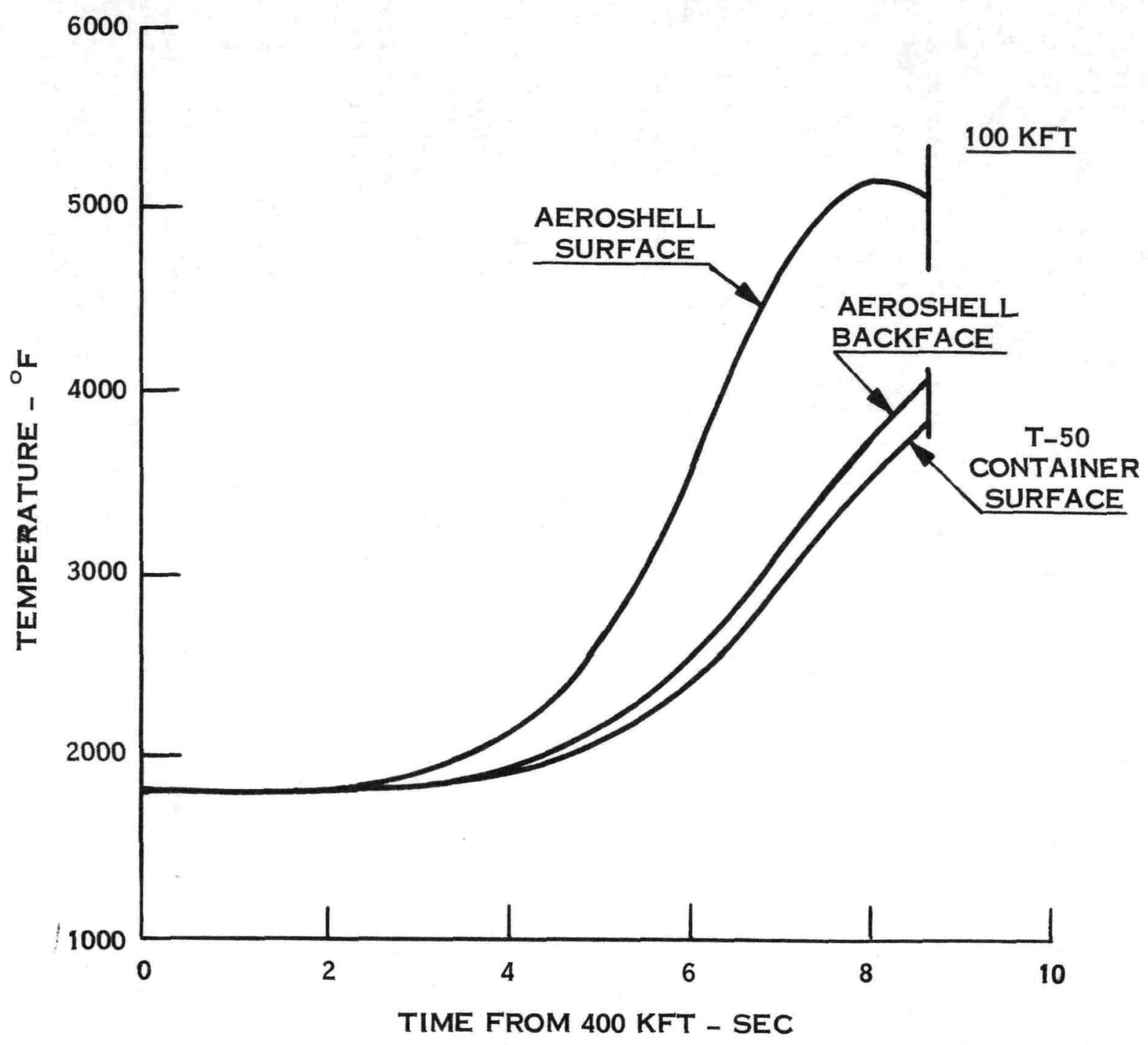




\subsubsection{REENTRY ANALYSIS (continued)}

core. No temperature change was experienced at the fuel/clad interface. The computer analysis was stopped after 8.5 seconds; at this point the outer aeroshel1 face temperature is starting to drop as will the backface and aeroshell impact core temperatures.

An important aspect of the steep angle reentry analysis which was not evaluated is the effect of thermal stresses on the integrity of the aeroshe11. This aspect of the evaluation must be covered in detail in subsequent studies in order to establish the viability of the heat source concept.

The second reentry analysis performed was a minimum $\gamma$ reentry where initial values of $\gamma=-5^{\circ}$ and $V o=36,000 \mathrm{fps}$ were used. This analysis indicated that the rectangular heat source would survive such a reentry without experiencing unacceptable temperatures. Figure 6-15 illustrates altitude and heating rates during the reentry as a function of time. The temperature response, Figure 6-16, shows the effect of the characteristic double pulse heating for a minimum $\gamma$ reentry. The fuel/clad interface temperature rises moderately above operational temperatures of $2400^{\circ} \mathrm{F}$ to $2700^{\circ} \mathrm{F}$ for a short duration. At impact, the temperature of the fuel/clad interface will be well below its operational temperature level due to the cooling experienced in the final reentry stages. A thorough evaluation of the fuel/clad interface temperatures at impact is warranted due to the sensitivity of the thoria properties with temperature.

\subsubsection{IMPACT ANALYSES}

Response of the heat source to impact constitutes one of the primary concerns in the ability to design an attractive curia fueled heat source with a ceramic clad. Therefore, considerable effort was made to perform a meaningful evaluation of the impact protection requirements for the ceramic clad design. The analytical results, coupled with tests performed in previous programs, indicate that a low weight heat source can be designed which will survive reentry impact.

The Reference Design heat source is designed such that each FIB has enough protection to survive impact. The protection system, consisting of a Thornel50 crushable graphite $(1.2 \mathrm{gm} / \mathrm{cc})$ is sized for a minimum impact velocity design margin of $25 \%$ to account for uncertainties in predicted terminal velocities and material properties. Temperatures of the fuel and thoria liner at the time of impact are assumed to be equal to operational temperatures. Preliminary calculations show that impact temperatures will be lower than operational thereby, increasing the safety margin further.

Survival of the thoria liner is highly dependent on the shock wave propagation as influenced by properties of the Thorne1-50 cover. Figure 6-17 presents the thoria ceramic impact capability for the Reference Design as a function of temperature and cover modulus, Eo. Even with a cover modulus of 300,000 psi, the maximum anticipated, the FIB would be able to survive the predicted 180 fps impact. Figure 6-18 shows the expected impact capability of the Reference Design FIB assuming an Eo of $100,000 \mathrm{psi}$. At $2500^{\circ} \mathrm{F}$ the impact capability is 220 fps. 


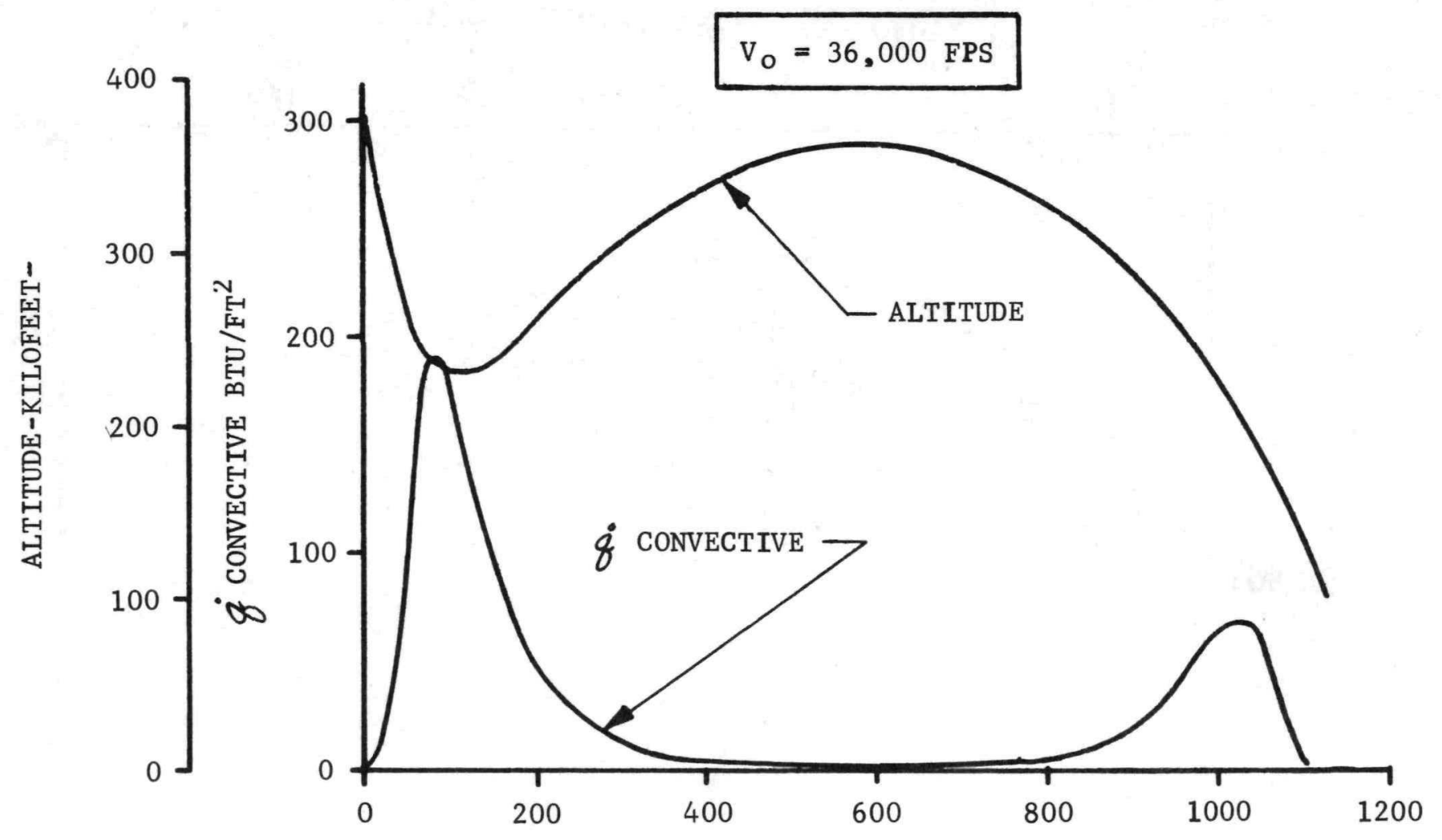

TIME FROM 400 KFT-SEC. 


$$
\gamma_{0}=-50 \quad V_{0}=36,000 \text { FPS }
$$

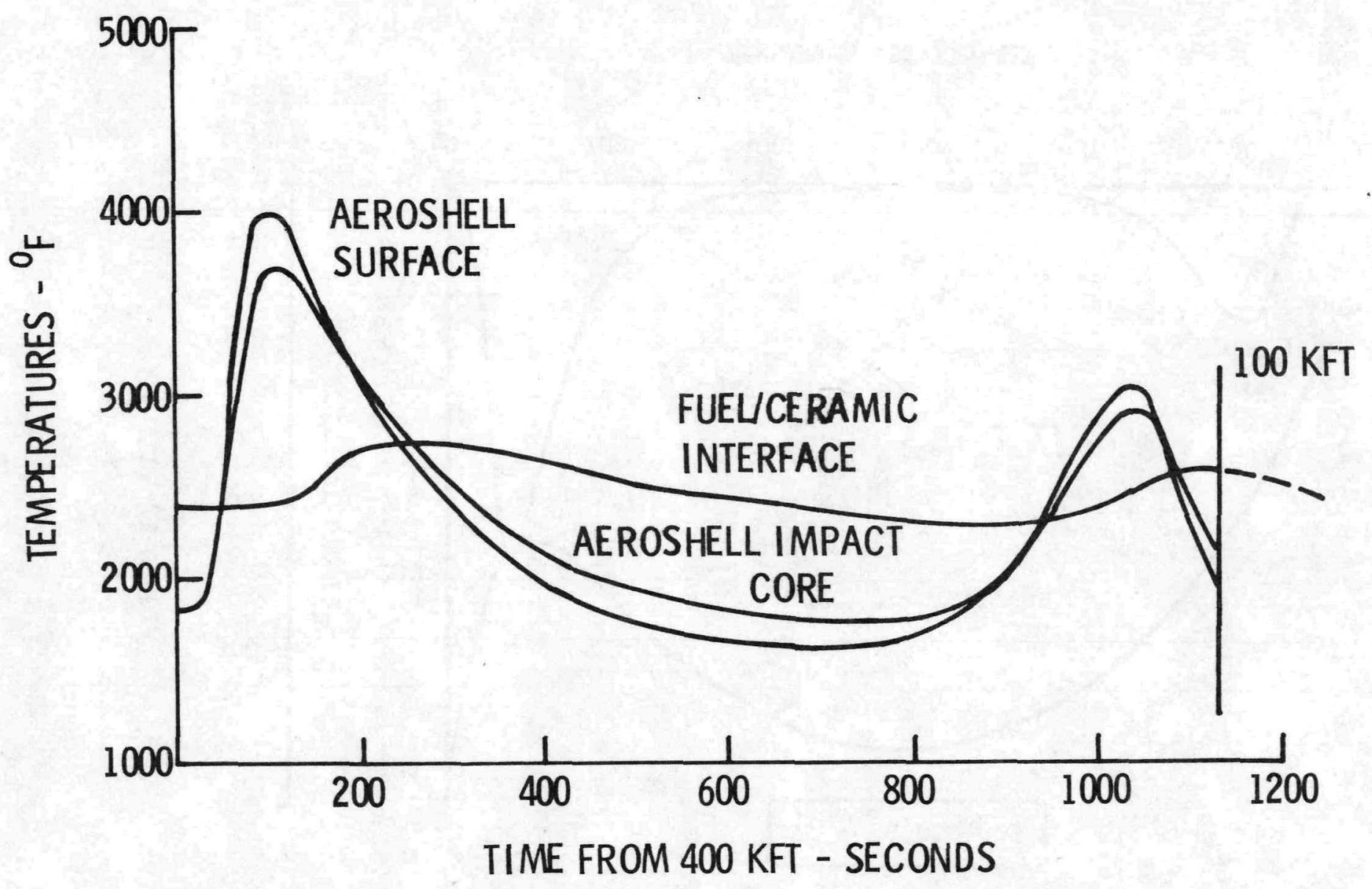



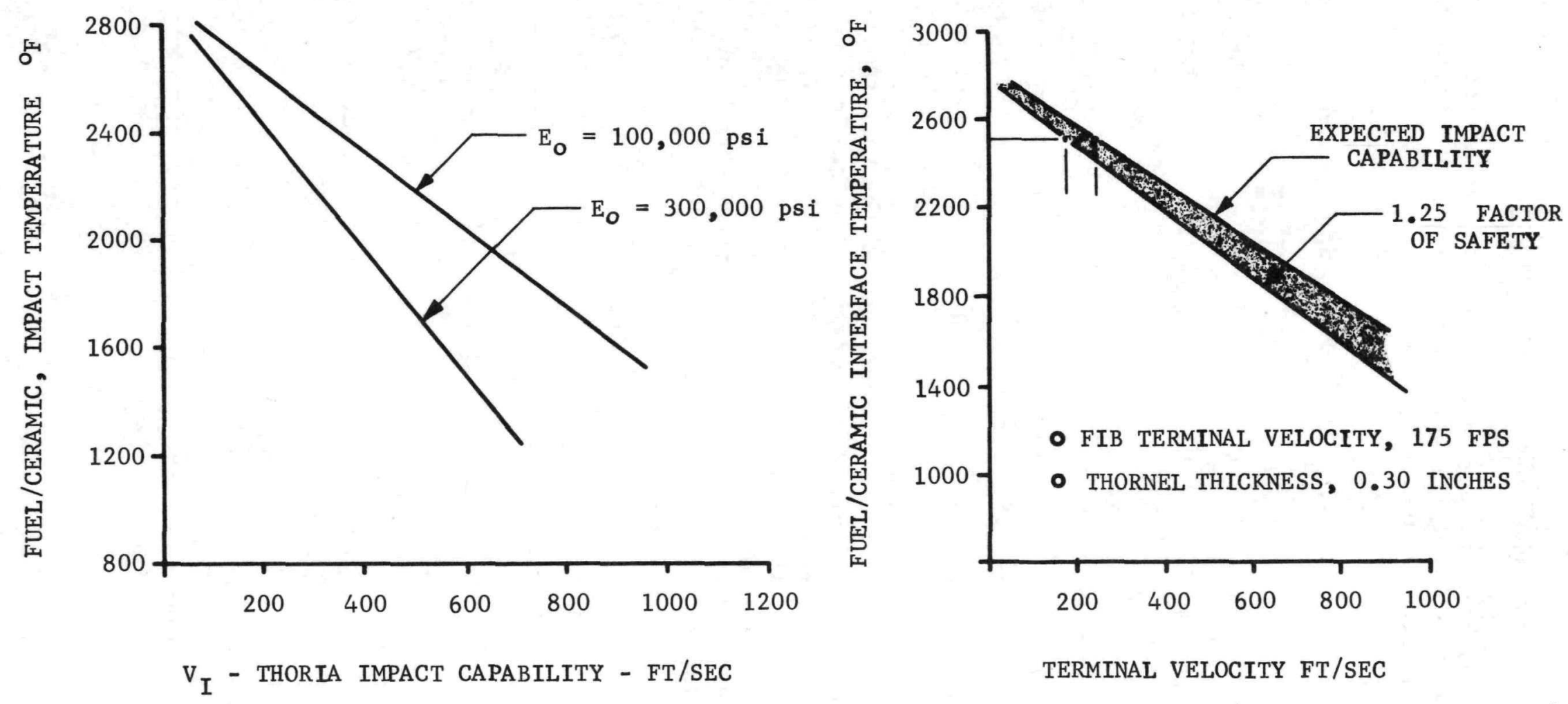


\subsubsection{IMPACT ANALYSES (continued)}

The heat source assembly will give added impact protection to the thoria clad. Table 6-4 summarizes the Reference Design heat source impact capability for an end-on and flat impact.

Table 6-4. Heat Source Impact Capability

\begin{tabular}{|c|c|c|}
\hline ITEM & FLAT & END-ON \\
\hline FIB & 220 & 220 \\
HSA & 283 & 225 \\
\hline
\end{tabular}

Added thickness of the impact aeroshell core at the end of the heat source would increase the capability further.

Impact tests of solid thoria spheres lend support that the Reference Design FIBS will survive impact without a release of fuel. Table 6-5 summarizes the results of bare ball and protected ball tests. These test results reveal two important facts: first, the temperature of the bare thoria balls had a great effect on their capability to survive impact and secondly, the impact capability of the system at $2500^{\circ} \mathrm{F}$ impacts is provided almost wholly by the Thorne1-50 material. This implies that the results of the solid thoria sphere impacts are valid for the copressed fuel/clad concept in the Reference Design. A list of individual tests conducted by General Electric on thoria spheres in the initial stages of the MHW Program are presented in Table 6-6. Figure 6-19 illustrates one ball, impacted twice at $330 \mathrm{fps}$ at $2500^{\circ} \mathrm{F}$.

Table 6-5. Summary of Thoria Sphere Impact Tests

\begin{tabular}{|l|l|}
\hline SPECIMEN & TEST RESULT \\
\hline Bare Bal1, & Max Pass, 138 fps \\
Room Temp & Min Fail, 158 fps \\
Bare Bal1, & Max Pass, 16 fps \\
$2500^{\circ} \mathrm{F}$ & Min Fail, 31 fps \\
Protected Bal1 & Max Pass, 338 fps \\
0.5 inch T-50, & Min Fail, 270 fps \\
\hline $2500^{\circ} \mathrm{F}$ & \\
\hline
\end{tabular}


TABLE 6-6

THORIA BALL IMPACT DATA

\begin{tabular}{|c|c|c|c|c|c|c|c|c|}
\hline $\begin{array}{l}\text { SPECIMEN } \\
\text { NUMBER }\end{array}$ & $\begin{array}{l}\text { BARE BALL } \\
\text { DIAM, IN }\end{array}$ & $\begin{array}{l}\text { IMPACT COVER } \\
\text { THICK., IN }\end{array}$ & $\begin{array}{l}\text { WEIGHT } \\
\text { GMS }\end{array}$ & $\begin{array}{l}\text { THORIA } \\
\% \text { TD }\end{array}$ & $\begin{array}{l}\text { IMPACT } \\
\text { VELOCITY,FES }\end{array}$ & $\begin{array}{l}\text { IMPACT } \\
\text { ENERGY } \\
\text { FT. LBS } \\
\end{array}$ & PASS & FAIL \\
\hline 1 & 1.25 & $\begin{array}{l}0.25 \\
\text { Infiltrated } \\
\text { Thorne1 }\end{array}$ & 201 & 98.2 & 297 & 606 & $\mathrm{X}$ & \\
\hline 2 & 1.50 & $\begin{array}{l}0.50 \\
\text { Infiltrated } \\
\text { Thorne1 } \\
\text { (Sp1it Seam) }\end{array}$ & 254 & $98,0$. & 291 & 736 & & $\mathrm{x}$ \\
\hline 3 & 1.50 & $\begin{array}{l}0.50 \\
\text { Pyrocarb } 406\end{array}$ & 513 & 98.5 & 291 & 1488 & & $\bar{x}$ \\
\hline 4. & 1.60 & $\begin{array}{l}0.50 \\
\text { T-50 Contin \& } \\
\text { Infiltrated }\end{array}$ & 540 & 98 & 315 & 1833 & $\bar{X}$ & \\
\hline 5 & 1.60 & $\begin{array}{l}0.50 \\
\text { T-50 Contin \& } \\
\text { Infiltrated }\end{array}$ & 478 & 83.6 & 311 & 1581 & $x$ & \\
\hline 6 & 1.52 & $\begin{array}{l}0.50 \\
\text { T-50 Infilt. } \\
\text { Polar Plug }\end{array}$ & 408 & 98 & 281 & 1100 & & $X$ \\
\hline 7 & 1.47 & $\begin{array}{l}0.50 \\
\text { T-50 Cóntinuous } \\
\text { \&Lig. Impreg. }\end{array}$ & 381 & 98.4 & 332 & 1435 & $\mathrm{X}$ & \\
\hline 8 & $1: 47$ & $\begin{array}{l}0.20 \\
\text { T-50 Cloth } \\
\text { Re Impreg. }\end{array}$ & 377 & 98.6 & 309 & 1232 & & $\mathrm{X}$ \\
\hline$\overline{9}$ & 1.60 & $\begin{array}{l}0.50 \\
\mathrm{~T}-50 \text { CONT } \\
\text { INE. \& PLUG }\end{array}$ & 436 & 81.6 & 310 & 1627 & $\mathrm{X}$ & \\
\hline 10 & 1.60 & $\begin{array}{l}0.375 \\
\text { T-50 Cont. } \\
\text { Doub1e Inf1 } \\
\text { and Polar P1ug }\end{array}$ & 430 & 80.7 & 311 & 1415 & & $\bar{x}$ \\
\hline
\end{tabular}




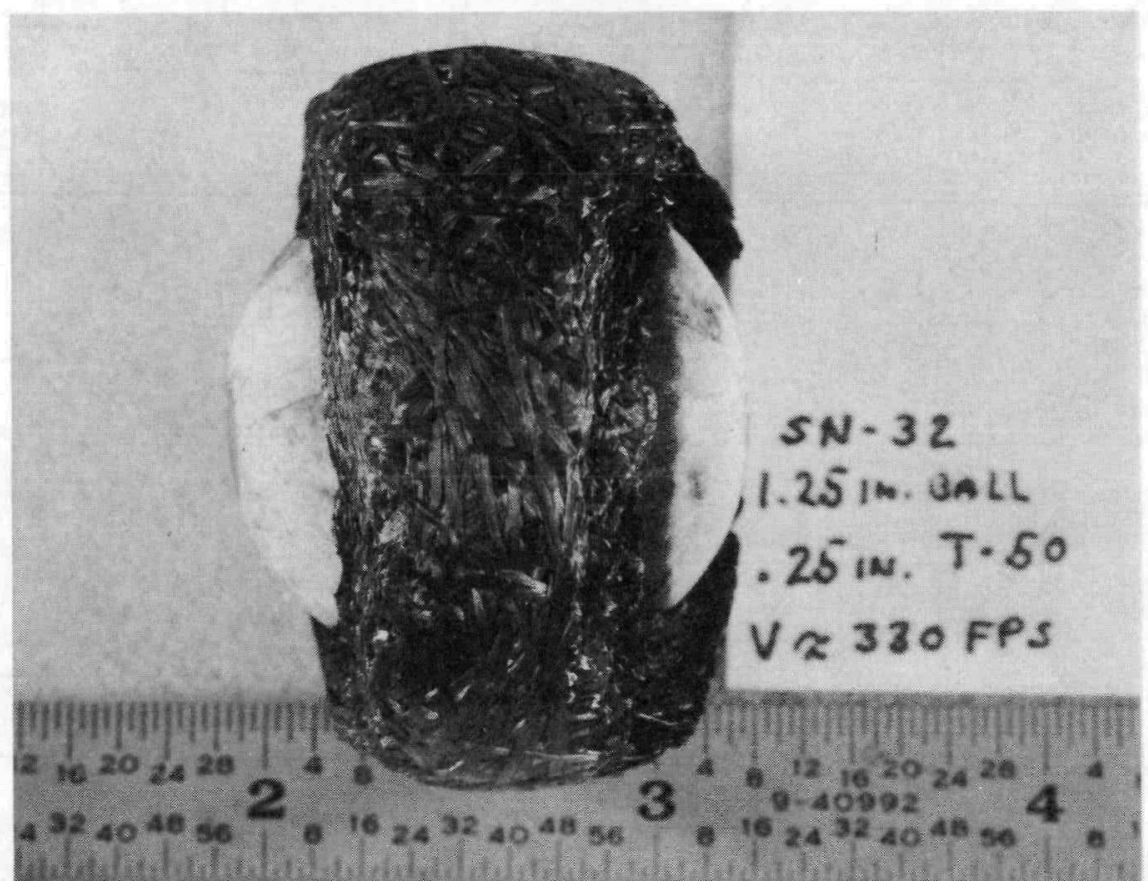




\subsubsection{POST-IMPACT BEHAVIOR}

A major feature of the thoria clad fuel design is the chemical inertness of the ceramic in air. The thoria clad is expected to maintain its integrity in air up to its melting point of $3100^{\circ} \mathrm{C}$; therefore, the Reference Design heat source should provide exceptional post-impact containment safety. Figure 6-20 illustrates post-impact containment temperatures for both a $\mathrm{PuO}_{2}$ and $\mathrm{Cm}_{2} \mathrm{O}_{3}$ fueled FIB resting on the ground surface. Clad/fuel interface temperatures for this situation are $1573^{\circ} \mathrm{F}$ and $1033^{\circ} \mathrm{F}$ for the $\mathrm{Cm}_{2} \mathrm{O}_{3}$ and $\mathrm{PuO}_{2}$ FIB's respectively.

One aspect of the post-impact safety assessment which will be investigated in the development program is interdiffusion between the fuel and the clad. This evaluation will involve:

- calculating the fuel/clad interface temperatures for various post-impact situations

o evaluating the diffusion rates at the anticipated post-impact temperatures

o assessing the hazard resulting from the diffusion processes.

Only burial or partial burial situations will result in temperatures capable of causing fuel/ceramic interdiffusion. Consequently, only a limited hazard is anticipated. Similar post-impact conditions for alternative metallic clads would be expected to result in more serious fuel release mechanisms. 


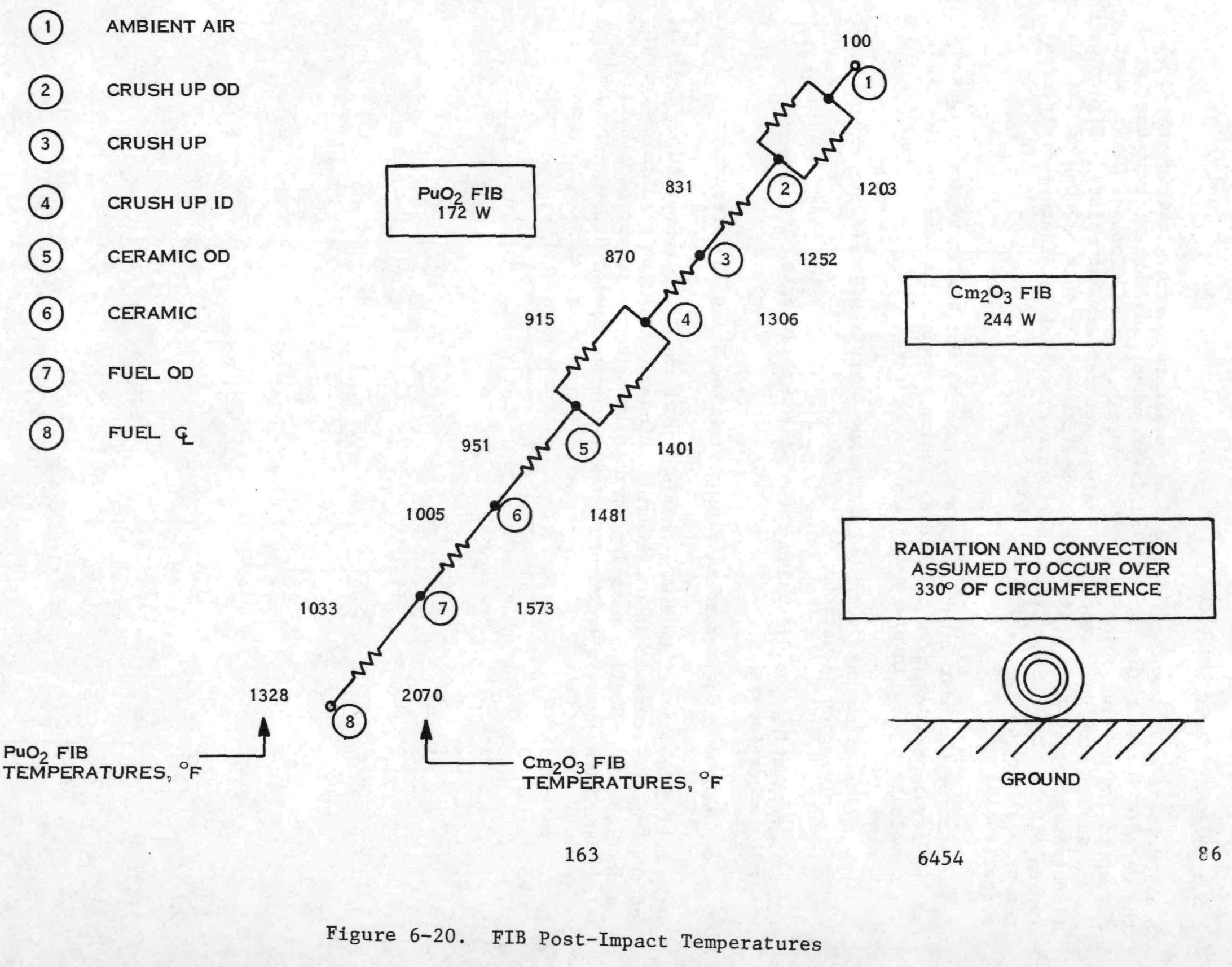


SECTION 7.0

SPACECRAFT INTEGRATION

This section describes four aspects of integrating the MB-ERTG with the spacecraft: dynamic interaction with the spacecraft attitude control system, shielding the spacecraft from the nuclear heat source, structural design of the MB-ERTG and attachment to the spacecraft and thermal integration. Two quantitative aspects of the spacecraft integration problem have been specified in the USAF - System Performance Objectives:

- maintain 5 year neutron dose level below $10^{12}$ nvt (dose plane was assumed to occur at spacecraft interface by General Electric)

o limit thermal input to spacecraft to less than 100 watts

These requirements, which are met by the MB-ERTG Reference Design are also addressed in the following discussion.

\subsection{DYNAMIC INTERACTION WITH ATTITUDE CONTROL SYSTEM}

A dynamic RTG introduces several phenomena which should be evaluated prior to the design of the SURVSATCOM attitude control system. The following design considerations were addressed and were found to present no spacecraft integration problem:

- start-up of the BRU

- rotor induced torques

o working fluid momentum changes

7.1.1 BRU START-UP

The single item of rotating machinery of concern is the turbine-compressoralternator rotor, which has the following estimated characteristics:

1. Weight

2. Inertia

3. Nominal Speed

4. Speed Tolerance

5. Time to achieve Normal Speed
$2.01 \mathrm{~b}$

$0.0001 \mathrm{ft}-1 \mathrm{~b}-\mathrm{sec}^{2}$

$52,000 \mathrm{rpm}$

\pm 2 percent

18 seconds

The momentum of concern is therefore about $0.5 \mathrm{ft}-1 \mathrm{~b}-\mathrm{sec}$. Assuming constant acceleration, the start-up torque is about $0.03 \mathrm{ft}-1 \mathrm{~b}$. 


\subsubsection{BRU START-UP (continued)}

Assuming the rotor is brought to speed after separation from the Titan III C transtage, a control torque of about $0.03 \mathrm{ft}-1 \mathrm{~b}$ will be required to maintain attitude during this transient (bringing the rotor up to speed while attached to the transtage would eliminate this requirement). The torque required is well within the capability of any conventional mass expulsion system. The removal of the momentum from the system by mass expulsion would require only $0.005 \mathrm{lbm}$ of Freon, which has the lowest specific impulse of gases normally used for attitude control.

\subsubsection{ROTOR INDUCED TORQUES}

Rotor induced torques arise from two sources: cross coupling torques due to the orientation of the rotor aboard the spacecraft and torques resulting from rotor speed variations. Both of these effects are discussed below with regard to the use of a zero momentum attitude control system.

\subsubsection{Orientation Effects}

The effect on the attitude control performance of an earth oriented three-axis stabilized spacecraft due to an on-board rotating device, such as the turbine rotor of the MB-ERTG, is a function of the magnitude of the rotor momentum and the orientation of the rotor spin axis with respect to the plane of the orbit. This effect arises from the fundamental law of conservation of momentum which states that the momentum of any closed system will remain inertially fixed unless acted upon externally.

In explanation, consider a typical attitude control system in simplistic terms composed of $\mathrm{x}, \mathrm{y}$ and $\mathrm{z}$ axis attitude error sensors, associated conditioning electronics, and $\mathrm{x}, \mathrm{y}$ and $\mathrm{z}$ axis (orthgonally mounted) momentum storage devices (flywheels). Should body rates exist from any source, these rates will result in attitude errors which will be sensed by the attitude error sensors which via conditioning electronics accelerate the appropriate flywheel. Since conservation of momentum must be satisfied, the body slows down as the wheel accelerates until the point is reached where the change in flywheel momentum matches original body momentum. The body is now at rest with momentum having been transferred to the wheel, and with an attitude error sufficient such that when multiplied by the gain of the electronics will supply the necessary power to the flywheel to supply the flywheel operating losses at that speed.

Now add to this spacecraft whose $t_{x}$ axis is along the orbit velocity vector and $t_{z}$ toward the earth, and $+y$ such that $\vec{x} \times \vec{y}=\vec{z}$, a rotating device such as the MB-ERTG turbine rotor with constant momentum $H$ directed along the $+_{x}$ axis, Figure 7.1. Presuming that momentum originating with the initial acceleration of the device was removed during cold-gas mass expulsion techniques and again accommodating conservation in momentum it is seen in (Figure 7-1) that as the vehicle traverses on orbit the inertial orientation of $H$ has gone through a 360 degree rotation. If inertial conservation of momentum is to be satisfied as the vehicle moved from position 1 to position 2 , as it must, then the " $\mathrm{"} \mathrm{axis} \mathrm{wheel} \mathrm{must} \mathrm{have} \mathrm{had} \mathrm{to} \mathrm{change} \mathrm{in} \mathrm{speed} \mathrm{(negatively)} \mathrm{a} \mathrm{delta-}$ momentum equal to $-\mathrm{H}$ at position 3 , return to original momentum, change to $+\mathrm{H}$ 


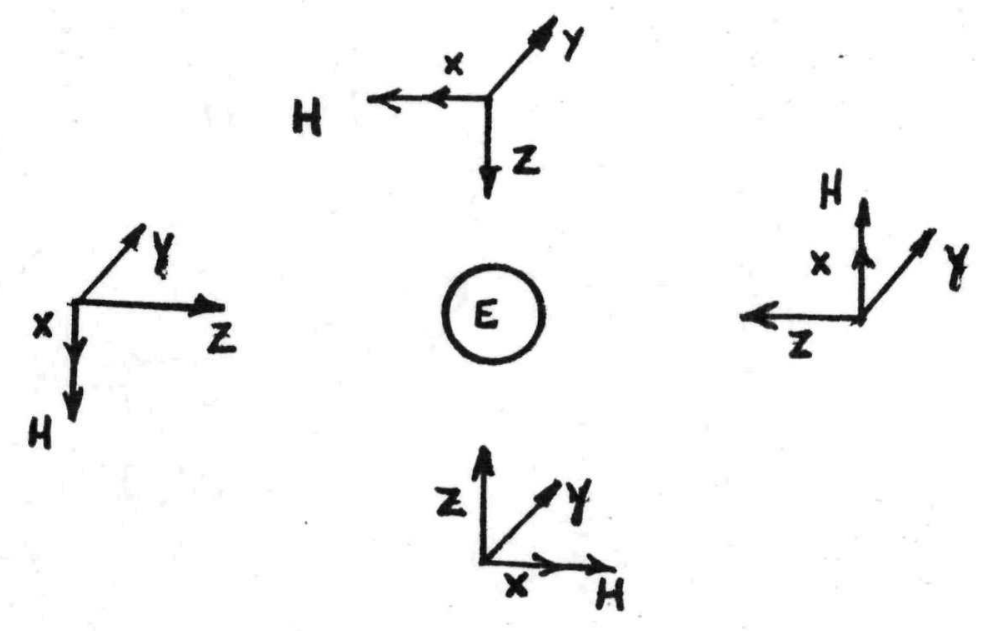

Figure 7-1. Change in Momentum Vector During Orbit

\subsubsection{Orientation Effects (continued)}

at position 4, and back to the original momentum at position 1 . The $x$ wheel will go through a similar profile 90 degrees out of phase with the $Z$ wheel, such that the vector sum of the two wheel momentum at all times equals, inertially, the momentum of position 1 , the initial condition.

In summary, for the assumed case, the flywheels of the control loops associated with the spacecraft axes in the orbit ( $x \& y$ ) plane will vary sinusoidally as a function of orbit position ninety degrees out of phase with each other in order to maintain the inertial momentum summary of the spacecraft fixed in inertial space. A similar profile will occur also for any orientation of the turbine spin axis in the $x-z$ plane. Wheels in the $x-z$ plane will vary similarly also to store momentum accumulated from external sources.

In reference to Figure 7-1 should $H$, the spin axis of the MB-ERTG, be located along the $y$ axis, the axis normal to the orbit plane, the direction of $\mathrm{H}$ would remain fixed inertially as the spacecraft traverses an orbit hence the momentum swap present in the "H along the $\mathrm{X}$ axis case" does not exist and the presence of a constant $\mathrm{H}$ on-board will go unnoticed by the control system. This discussion is summarized in Figure 7-2. 

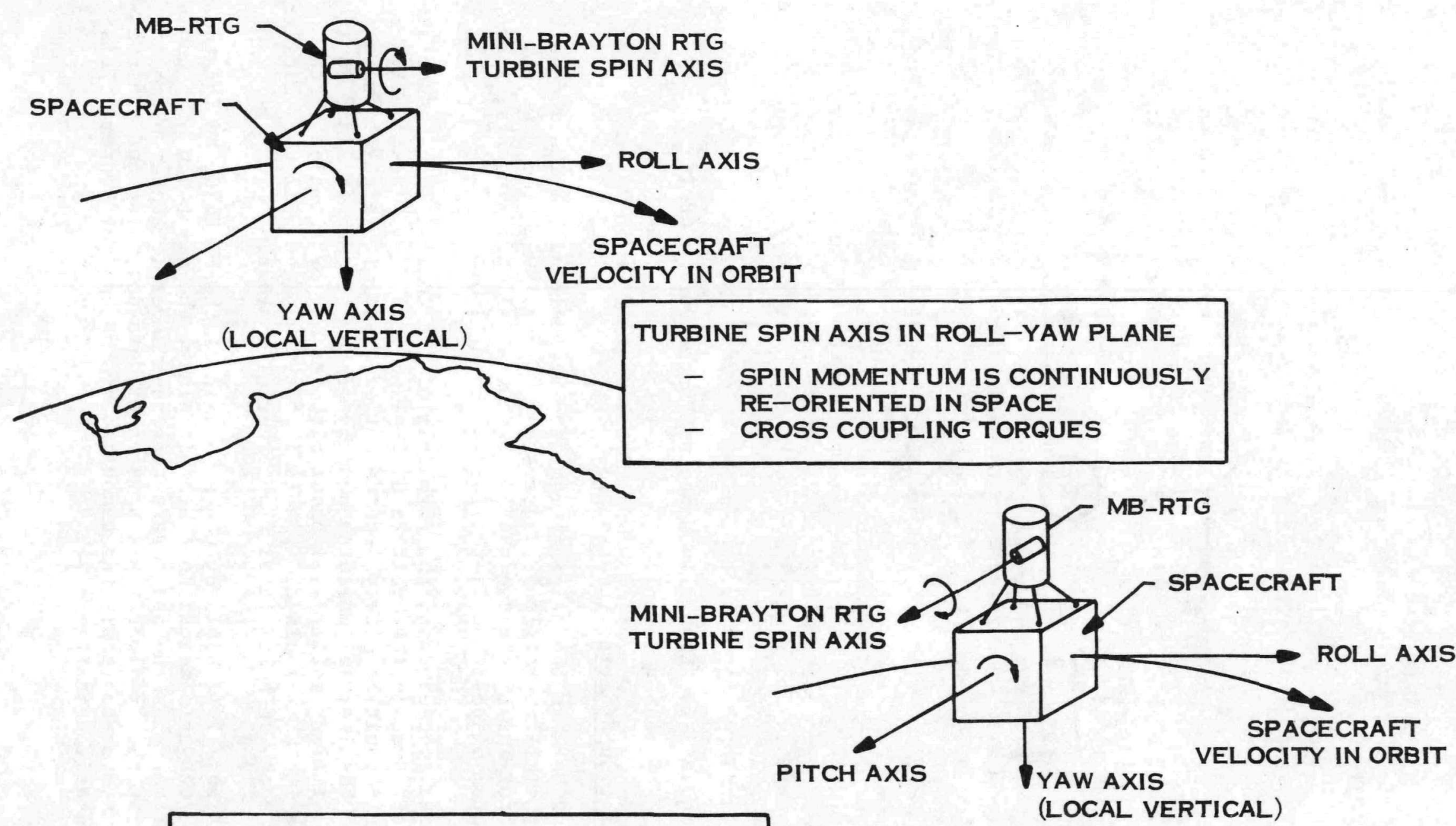

TURBINE AXIS PARALLEL TO PITCH AXIS

- NO DISTURBING TORQUES

- SIMPLIFIED ACS 


\subsubsection{Orientation Effects (continued)}

Should the $\mathrm{H}$ vector of the turbine be located elsewhere off of the $\mathrm{x}-\mathrm{z}$ plane the effect on ACS performance will be somewhere between the two cases just discussed and be directly proportional to the component of $\mathrm{H}$ that can be projected vectorially into the $x-z$ plane.

\subsubsection{Rotor Speed Variation Effects}

It has been estimated that the speed variation of the turbine could be as great as one (1) percent with a period of 0.2 seconds. A sustained or damped oscillation of $5 \mathrm{~Hz}$ frequency is far beyond the frequency response of typical spacecraft control loops. Consequently, the speed (momentum) variation will appear in the body of the spacecraft diminished by the inertia ratio between the body and the turbine as a result of the conservation of momentum law. Since the control loop flywheel cannot operate quickly enough to absorb and give up momentum varying at $4 \mathrm{~Hz}$, the body must respond to maintain a net inertial momentum change of zero. In doing so, a peak amplitude (attitude error) will be reached; for a $300 \mathrm{~s} 1-\mathrm{ft}^{2}$ inertial spacecraft about the axis of interest and a 1 percent $5 \mathrm{~Hz}$ variation of the flexible BRU, a peak amplitude attitude error of approximately $0.5 \times 10^{-4}$ degrees would be reached with an attendant maximum rate of about $0.002 \mathrm{deg} / \mathrm{sec}$. Attitude error resulting from the MB-ERTG is plotted in Figure 7-3 for spacecraft of varying inertias for both the 400 We and the flexible BRU.

Though the dynamic effect is small, it is conceivable that the error resulting from dynamic variations in the turbine angular velocity could be compensated for. As an example, a motor of appropriate inertia could be driven in a direction opposite to that of the turbine in a manner to negate all or part of the momentum variation resulting from turbine dynamics.

\subsubsection{WORKING FLUID MOMENTUM CHANGES}

Torques due to fluid momentum changes were evaluated for worst case conditions. The resulting net angular momentum calculated was a fraction of that due to rotor speed variations and the comments applying to the rotor are equally true for this effect. Therefore, the working fluid dynamics can be ignored for anticipated attitude control design requirements.

\subsection{NUCLEAR SHIELDING}

The USAF-System Performance Objectives specify maximum integrated dose limits of $10^{12} \mathrm{nvt}$ and $10^{6}$ rads gamma (silicon) to the spacecraft over the 5 year mission. Both $\mathrm{Pu}-238$ and $\mathrm{Cm}-244$ emit neutrons and gamma rays, in addition to the alpha particles which are the source of thermal energy. Evaluations indicate that for both $\mathrm{Pu}-238$ and $\mathrm{Cm}-244$ the gamma radiation is inconsequential, however, neutron radiation is significant.

Shielding studies were performed at Oak Ridge National Laboratory to evaluate the thickness of lithium hydride shielding required to meet the $10^{12}$ nvt 5 year neutron dose. ORNL investigated four different cases using $\mathrm{Cm}_{2} \mathrm{O}_{3}$ fuel: the conceptual design heat source and the Reference Design heat sources in both vertical and horizontal positions. These calculations included the effect of 


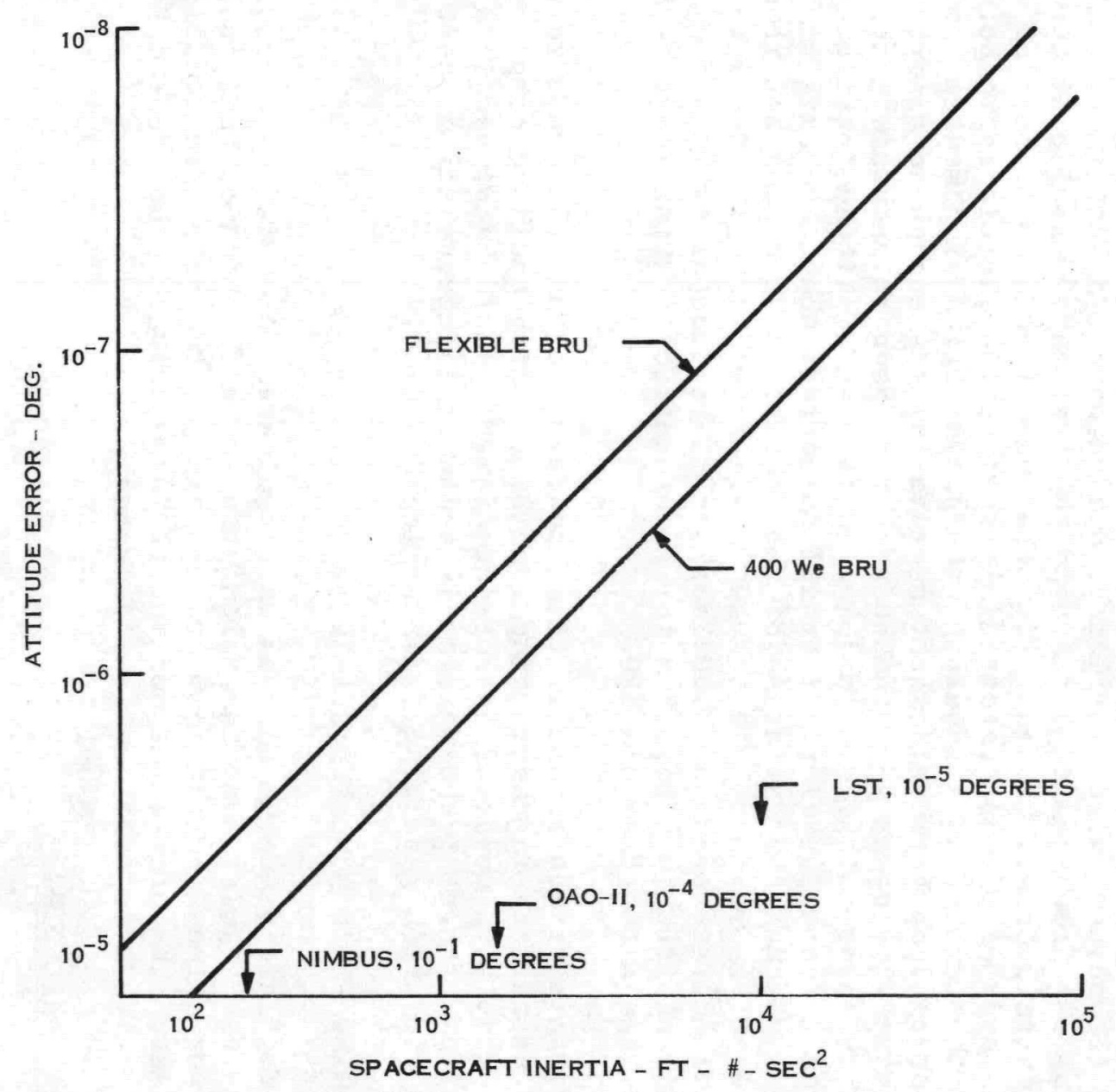

Figure 7-3. Attitude Error Caused By Rotor Speed Variations 


\subsection{NUCLEAR SHIELDING (continued)}

neutron scattering from the cylindrical radiator. Neutron shielding requirements for the $\mathrm{PuO}_{2}$ fuel were calculated by General Electric Company.

Results of the ORNL investigation are summarized in Figure 7-4. For the four cases investigated the lithium hydride shield thickness was essentially the same, $10 \mathrm{~cm}$. Scattering from the radiator is insignificant - is $2 \times 10^{10} \mathrm{nvt}$.

The $\mathrm{PuO}_{2}$ shielding investigation indicated that neither neutron or gamma shielding is required. Figure $7-5$ shows the required lithium hydride shield thickness as a function of integrated neutron dose for $\mathrm{PuO}_{2}$.

\subsection{STRUCTURAL INTEGRATION}

The MB-ERTG system configuration shown in Figure 7-6 has been designed to withstand loads associated with a Titan III C launch. Assumed launch conditions include:

- Launch acceleration - 5.0g lateral, 10.0g longitudinal

o Qualification load - 1.5 design limit

o Component mounting dynamic load - 50g

o System fundamental frequency - 40 cps minimum

Each of the component packages, the HSA, neutron shield and BRU/recuperator are supported separately by struts attached to the radiator internal stiffening rings. Independent mounting of the components alleviates thermal stresses between the components and the individual support concept allows the components to elongate freely. The cylindrical radiator is a load bearing member which supports the individual components and carries these loads to the interface ring to which the radiator is attached.

Electronic components are suspended from a support cone which is also attached to the interface ring. The interface ring then carries the loads from the MB-ERTG to the spacecraft.

\subsection{THERMAL INTEGRATION}

The USAF System Performance Objectives specify a maximum heat leak from the MB-ERTG into the spacecraft of 100 watts. Consequent1y, the design of the MB-ERTG minimizes the transfer of heat by (1) locating the high temperature components away from the spacecraft and (2) by attaching the cold end of the radiator to the spacecraft interface ring.

Heat transfer to the spacecraft can occur by direct radiation or by conduction. Therefore, a detailed calculation of the heat leak into the spacecraft requires an accurate knowledge of the MB-ERTG temperatures and surface characteristics, design of the attachment points and spacecraft characteristics. However, a cursory analysis illustrates that limitation of the heat leak to 100 watts is achievable with the present design concept. 

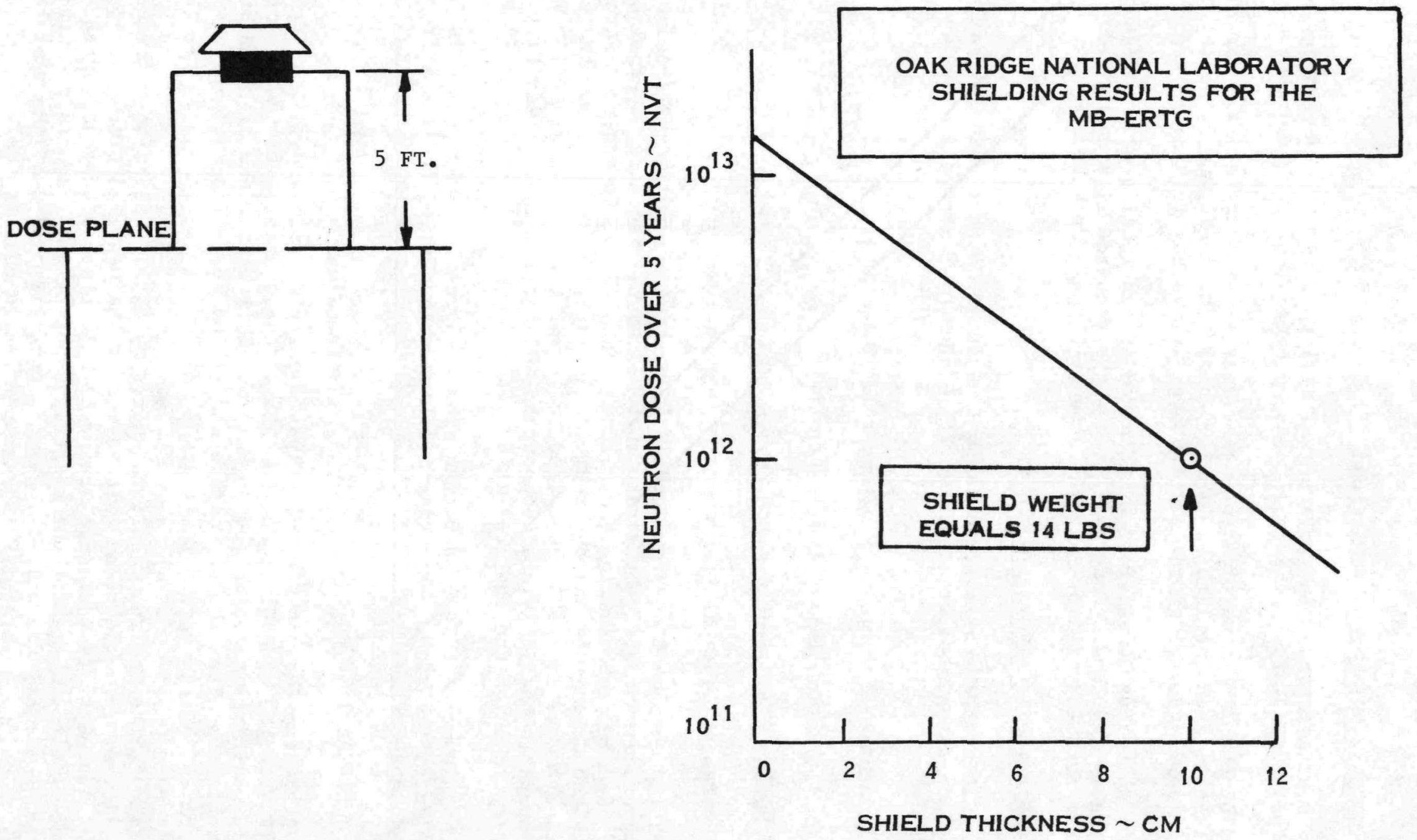


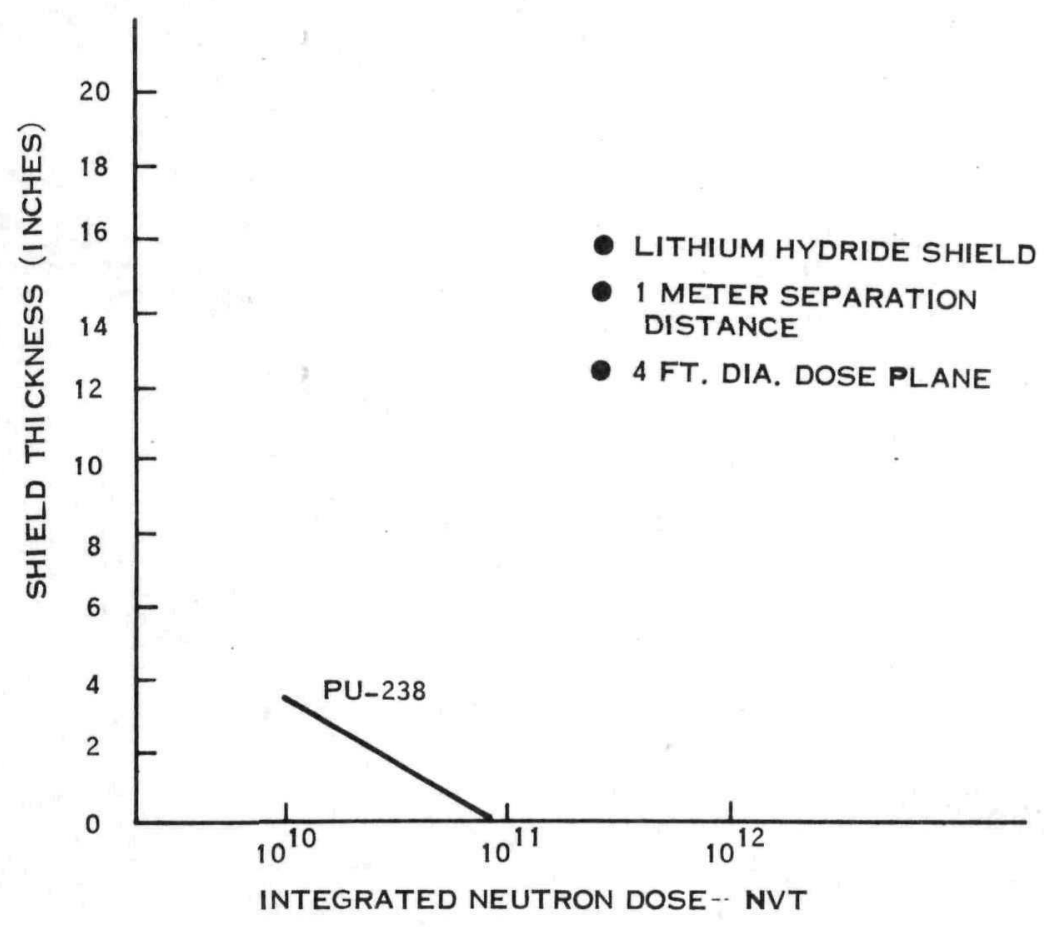

Figure 7-5. Pu-238 Neutron Shielding Requirements

\subsection{THERMAL INTEGRATION (continued)}

Assuming the spacecraft interior temperature to be approximately room temperature, conduction from the radiator into the spacecraft is impossible since the radiator outlet fluid temperature is $60^{\circ} \mathrm{F}$. Therefore, radiation to the spacecraft is the only heat transfer mechanism available. A conservative calculation indicates that less than 1 pound (10-1 mil layers) of aluminized mylar insulation will maintain the heat leak to below 100 watts. Depending upon the final spacecraft/MB-ERTG design even this small requirement may be unnecessary. 
1. HEAT SOURCE ASSEMBLY

2. HEAT SOURCE

3. FUEL IMPACT BODY (FIB)

4. RADIATION SHIELD ASSEMBLY $(L, H)$

5. BRU (TURBINE, ALTERNATOR, COMPRESSOR)

6. TURBINE

7. ALTERNATOR

8. COMPRESSOR
9. RECUPERATOR

10. INLET HEADER

11. OUTLET HEADER

12. RADIATOR FEED TUBE

13. PRIMARY RADIATOR

14. ELECTRONICS EQUIPMENT

15. PARASITIC LOAD RADIATOR

16. SPACECRAFT INTERFACE RING
17. ELECTRONICS STRUCTURAL SUPPORT CONE

18. LONGERONS (4)

19. STIFFENING RING (3)

20. HSA SUPPORT STRUCTURE

1. BRU/RECUPERATOR MOUNTING FRAME

22. BRU/RECUPERATOR SUPPORT STRUCTURE

23. SHIELD ASSEMBLY SUPPORT STRUCTURE
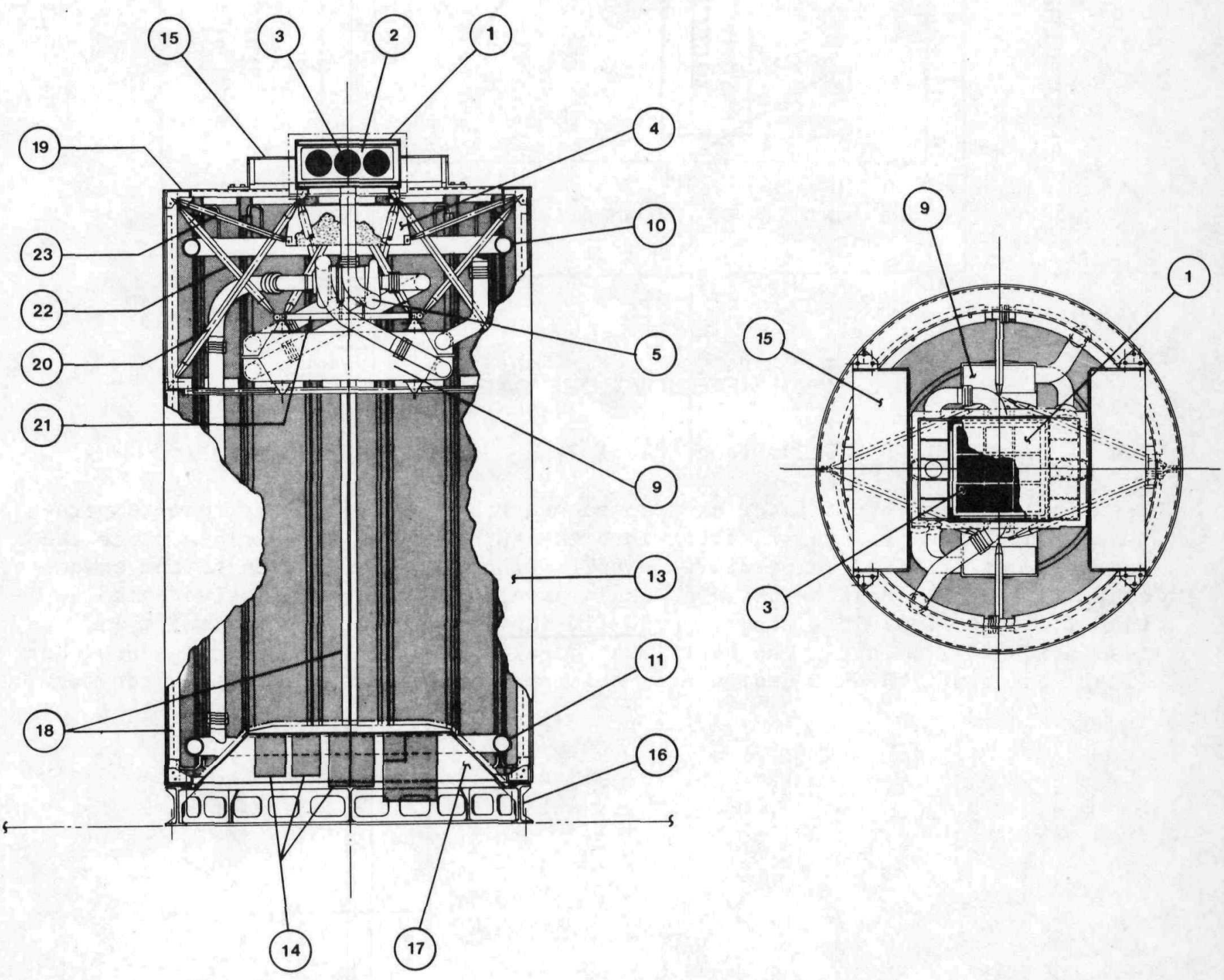

Figure 7-6. MB-ERTG Support System 


\section{SECTION 8.0}

COST ASSESSMENT

This section presents the costs for developing and fabricating the MB-ERTG on a production basis. Section 8.1 describes the overall philosophy on which the development and production phases are based. The costs incurred for development of the components and total system are given in Section 8.2 and MB-ERTG unit costs are shown in Section 8.3.

The costs presented for the Brayton components were generated on the basis of hardware experience at General Electric and the AiResearch Companies. The Oak Ridge National Laboratory (ORNL) prepared costs for the following activities:

o heat source development support

o fabrication and test of prototype and qualification heat source

- fabrication of flight heat source units

\subsection{DEVELOPMENT PLAN}

The Development Plan generated, assumed 5 overall phases:

- Phase 1, System Studies

- Phase 2, Technology and Component Demonstration

o Phase 3, System Development and Qualification

o Phase 4, Flight System

- Phase 5, Production

This breakdown was provided to General Electric by the AEC (Appendix I).

The MB-ERTG development plan recognizes the Brayton work conducted by NASALewis and the high temperature work performed by the AEC. It utilizes the experience gained in the 10 year development activity and emphasizes areas not previously investigated. The Development plan is based on the Reference Design, however, alternate heat source concepts can be utilized depending on the results of Phase 2 and the availability of $\mathrm{Cm}_{2} \mathrm{O}_{3}$. The next three sections present descriptions of the development program, potential alternatives as the program progresses and the production program.

\subsubsection{DEVELOPMENT PROGRAM}

The MB-ERTG Development Program is shown in Figure 8-1. Phase 1, System Studies, has been completed in the current effort. 


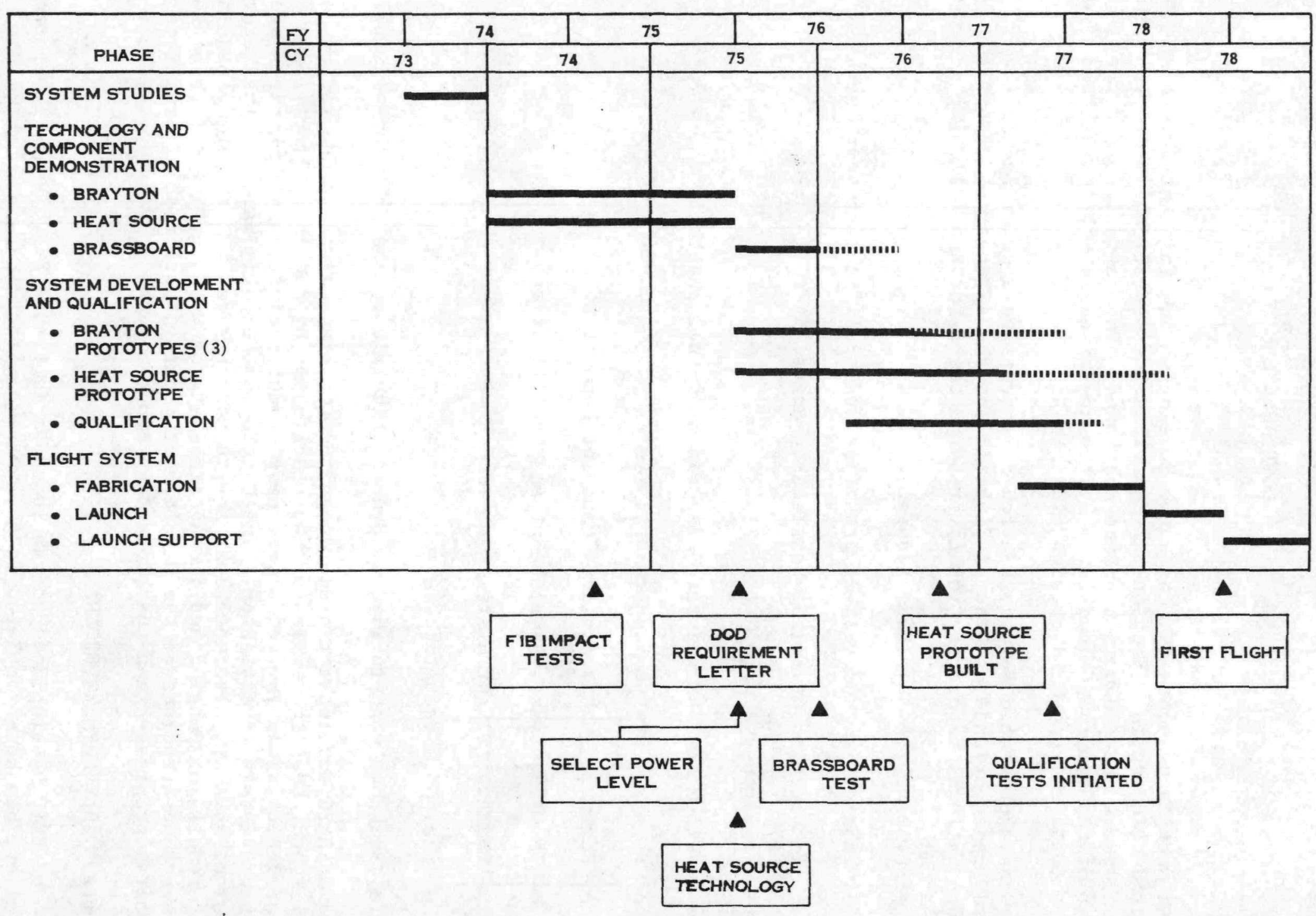




\subsubsection{DEVELOPMENT PROGRAM (continued)}

Phase 2, Technology and Component Demonstration begins $1 / 74$, as specified by the AEC, and extends through 6/76 with the Brassboard testing. The intent of phase 2 is to develop the Brayton component technology, fabricate and assemble the components into the brassboard unit, and test the brassboard with an electrical heat source. The long lead Brayton component in this effort is expected to be the BRU which will require a full 18 months to develop. In a parallel effort the ceramic clad heat source technology will be developed. This work will consist of fabrication technology development, compatibility testing and impact testing. Prior to July 1975 a final evaluation of the ceramic clad approach and a decision regarding the heat source concept selection will be made.

Prototype system development will be initiated in July 1975, coincident with the assumed (assumed by General Electric and the AEC) receipt of the DOD requirement Letter by the AEC. Design, fabrication and assembly of the first PCS prototype will require 1 year. Therefore, this task will benefit from the experience gained in the Brassboard unit which will be put on test during this period. The first prototype will be completed in June 1976 and undergo performance testing, shock and vibration testing and performance testing for a second time. Performance testing will be done at the systems contractor facility in a vacuum chamber. The second and third prototype will be placed on endurance test in September and December of 1976, respectively. Costs have been included in the development program for 15,000 hours of prototype testing; continuation of the endurance tests should be considered. It is anticipated that fabrication of each prototype is preceded by a limited redesign effort necessitated by the experience gained from the previous work.

A prototype, or demonstration, heat source will also be developed in Phase 3 . This activity will involve reentry testing, impact testing, heat source design and a safety assessment; the work will require approximately 20 months and is shown to be performed from July 1975 to February 1977.

During mid-1976 a prototype heat source will be fabricated and placed on test at ORNL. The heat source will be put on test in the fall of 1976 and operated for 6 months; it will then be disassembled and destructively tested over a 6 month period.

The system qualification portion of the program is scheduled to begin in February 1976. This task will consist of a final design effort, fabrication of one qualification unit and qualification testing. The heat source will be qualification tested separately from the power conversion system (PCS) at the ORNL. Qualification of the heat source at the contractors facility would involve substantial expense ( $>$ \$250K) due to the need of building a nuclear safe test facility. The PCS can be qualification tested at the contractor's facility with a "dummy" heat source. Qualification testing of the system is scheduled for completion in September 1977.

Fabrication of the first flight units will be initiated in April of 1977 so as to be completed and delivered to the launch facility at the end of the year. Two identical units would be available for flight, with the first flight occurring in mid-1978. Ground support personnel will be made available 6 months subsequent to flight to monitor the operation of the system. 


\subsubsection{DEVELOPMENT PLAN OPTIONS}

The MB-ERTG Reference Design and associated development plan has been defined to provide a cost effective program that provides the flexibility to accept changes to the basic plan without introducing major dislocations in development time or cost. In particular, the plan is structured to accommodate the following:

- curia or plutonia fuel

- metallic or ceramic fuel encapsulation materials

o increases in power level from 400 We to 3000 We

\subsubsection{Fue1 Flexibility}

The MB-ERTG has been designed to easily accommodate either a curia or plutonia fueled heat source. The impact of the fuel selection decision on the development program and the Reference Design will depend on when that decision is made. An early decision on curia availability may only affect the duration of the heat source technology effort (Phase 2), whereas, a decision made at the end of Phase 2 could necessitate a change in the encapsulation concept in order to meet the flight date.

During the first 6 months of the heat source technology development effort a decision regarding the availability of curia is expected to be made. This would have a relatively minor effect on the overall development effort, since, the fabrication procedures and techniques instituted for the ceramic encapsulation of curia are directly applicable to plutonia. Compatibility testing and venting tests would have to be performed for the plutonia and ceramic, however, this need not delay the overall heat source development timetable.

If a decision to utilize plutonia is made at the end of Phase 2 the mid-1978 flight date could still be met by utilizing the MHW FSA in the rectangular prism configuration shown in Figure 8-2. This change would not affect the MB-ERTG development costs, but, would result in an increase in unit costs due to the more expensive fuel.

A switch from curia to plutonia may also affect the conduct of the qualification program and subsequent delivery and ground handling procedures at the launch facility. Facilities exist at General Electric to qualification test a plutonia fueled MB-ERTG. Therefore, the heat source could be shipped from the fueling agency to the system contractor for qualification or acceptance testing. At the launch facility, the minimal shielding requirements of the plutonia would enable the heat source to be installed in the PCS in the assembly building. The entire MB-ERTG would be installed on the spacecraft as a single unit.

\subsubsection{Fuel Encapsulation Flexibility}

The Reference Design ceramic clad heat source provides low unit cost heat sources with excellent post-impact containment capability. Two areas of 

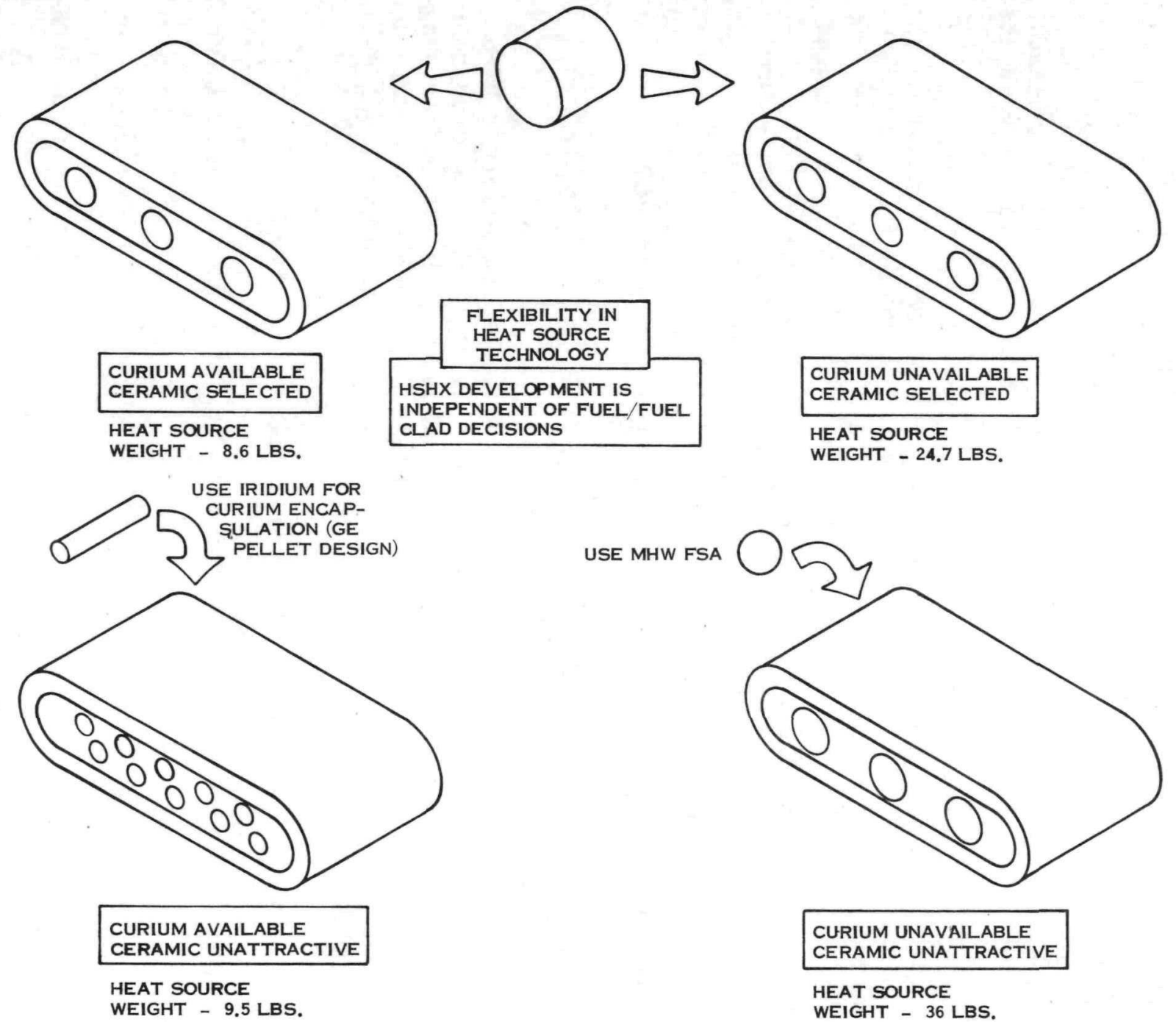


\subsubsection{Fuel Encapsulation Flexibility}

investigation must be undertaken in Phase 2 to firmly establish the attractiveness of this approach, namely:

o impact protection requirements (weight)

- compatibility of candidate ceramics with curia

Since the impact testing and compatibility test results will be available, it is anticipated that a decision on the ceramic clad can be made 1 year after the start of Phase 2 .

In the event that the ceramic concept is not attractive an iridium encapsulation concept can be used. Direct substitution of curia fuel in the MHW FSA cannot be done due to the higher power density of the curia, however, the MHW FSA can be used with a diluted curia or plutonia fuel in the rectangular prism heat source configuration. The curium pellet design shown in Figure 8-2 is an approach compatible with the rectangular prism heat source. Use of this concept would require some limited fabrication development and impact testing. However, the iridium fabrication experience gained on the MHW program plus the impact protection requirements built into the Reference Design for the ceramic clad would appear to make the transition from a ceramic to an iridium clad technically acceptable.

\subsubsection{Power Level Flexibility}

A major feature of the Reference Design is the use of a BRU with a Rice alternator having a power output capability of about $3 \mathrm{kWe}$. This approach permits delay of the power level decision up to 18 months without causing an increase in program costs. Therefore, Phase 2, Technology and Component Demonstration, can proceed with confidence, with a final power level decision occurring at the beginning of Phase 3.

Use of the flexible BRU provides this advantage because:

o the mini-BRU is the long lead PCS item in Phase 2, requiring 18 months to develop

o the design concepts used in the mini-BRU are sensitive to power level

- the design principles and concepts used in the remainder of the PCS components are insensitive to power level (for the range under consideration)

Therefore, development of a flexible BRU allows that component design to be used in the prototype systems regardless of the power level decision made at the beginning of Phase 3. The remaining component designs can be scaled with regard to power level and would not require additional development time or money. 


\subsubsection{PRODUCTION PROGRAM}

The production program can start any time subsequent to the first flight. In accordance with AEC direction, the production program was assumed to consist of either 10 or 20 units in addition to the 2 first flight units. One MB-ERTG is required every two months. This schedule is consistent with manufacturing capability at General Electric Company, AiResearch Company and the Oak Ridge National Laboratory.

During the production program it was assumed that each PCS unit would be acceptance tested at the contractors facility and the heat source would be tested at ORNL. Program management, ground handling, ground support personnel and shipping costs were included in the unit costs.

\subsection{DEVELOPMENT COSTS}

This section provides the total MB-ERTG costs for the development plan presented in Section 8.1. The total cost of the program consists of system contractor expenditures plus those of the Oak Ridge National Laboratory.

An overview of the estimated development costs is shown in Figure 8-3. The total cost to the AEC is approximately $\$ 23$ million. Of this total $\$ 16.4$ million is utilized by the system contractor in developing the technology, building and testing the prototypes and qualification systems and providing the flight units. An additional $\$ 5.2$ million is needed by ORNL (operating and capital equipment costs) to support the system contractor's heat source development program and to fabricate a prototype, qualification and two flight heat sources. The curia fuel used in the development program for various tests and in the 4 heat sources is estimated to cost an additional $\$ 1.3$ million.

Sections 8.2.1 and 8.2.2 present a breakdown of the total cost given here. In Section 8.2.1 a discussion is presented on the activities and cost involved in developing each of the major components in the MB-ERTG. The intent of Section 8.2.1 is to provide a detailed explanation of the individual component development requirements. This background is useful in understanding the breakdown of the total system costs discussed in Section 8.2.2.

\subsubsection{COMPONENT DEVELOPMENT ASSUMPTION AND COSTS}

The principal components in the system are the heat source assembly, consisting of the heat source and HSHX/insulation blanket, the BRU, recuperator, controls and radiator. Assumptions and development costs for each of these components is presented below.

\subsubsection{Heat Source}

Development of the ceramic clad heat source will comprise a major development effort in the program. The tasks identified for the heat source development are presented in Figure 8-4. The Phase 2, technology development, portion of the program encompasses those tasks resulting in the Heat Source Preliminary Design. This part of the program is designed to determine the attractiveness 


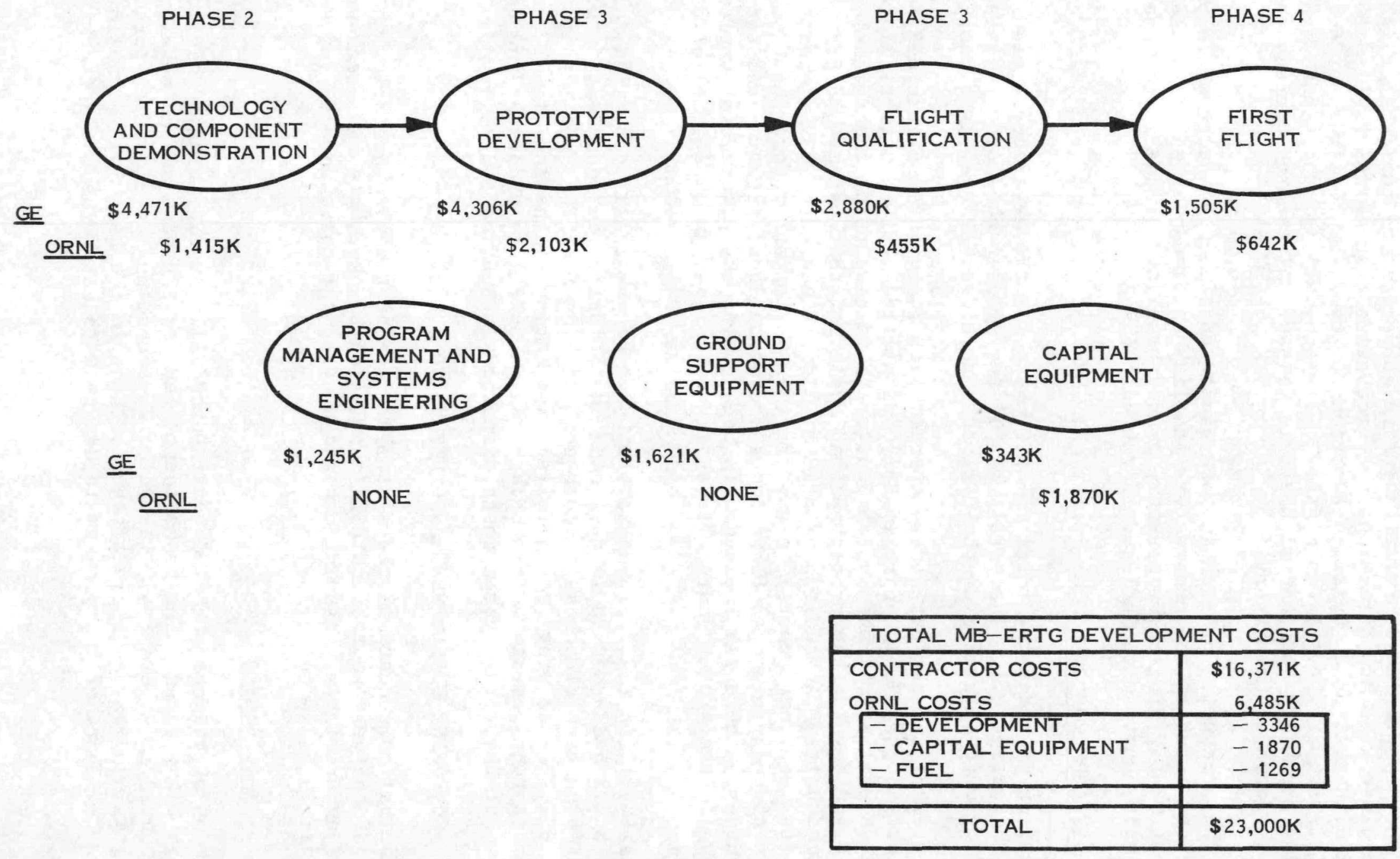




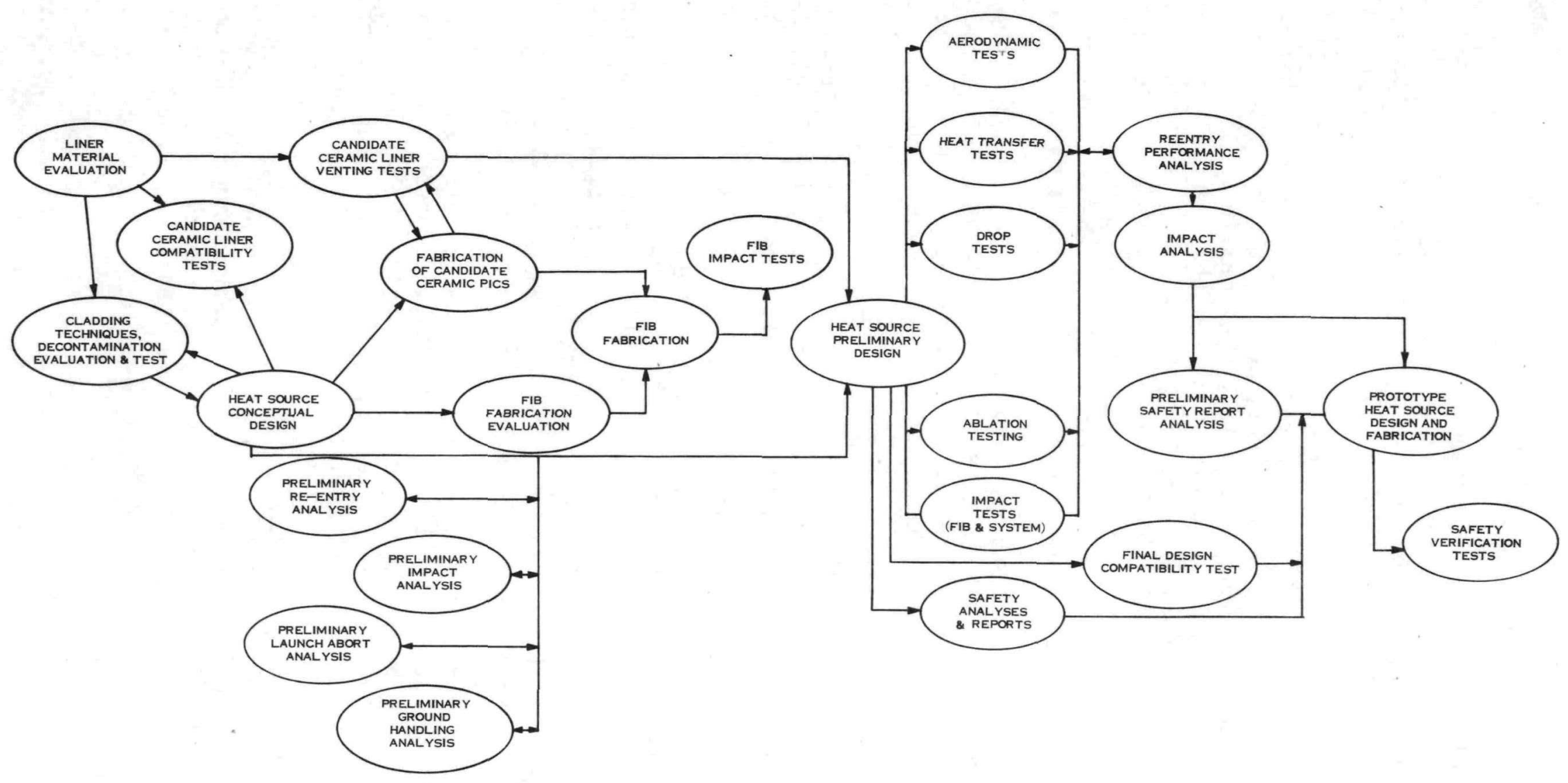




\subsubsection{Heat Source (continued)}

of the ceramic clad heat source within a 12 to 18 month period. The component development part of the development program Phase 3 , occurs subsequent to the heat source preliminary design task. A development schedule for the Reference Design heat source is shown in Figure 8-5.

The program is initiated with the ceramic clad development activity which consists of analytical evaluations of candidate ceramic clads, fabrication techniques for co-pressing the clad and fuel, compatibility testing and helium vent testing through the ceramic material. The result of this task would be the selection of one or more clad materials and the identification of a fabrication technique for the post-impact containment shell (PICS) assembly. This activity would be supported by heat source conceptual design study which would relate the PICS design to the overall system requirements. Inherent in the conceptual design are the safety aspects which must be considered; these preliminary assessments will affect the heat source design early in the program.

Fabrication procedures will also be developed for the Thornel-50 impact shell; the resulting assembly of the PICS within the individual impact shells is referred to as the fuel impact body or FIB. Subsequent to the design and fabrication of the FIB, impact tests using a fuel simulant will be conducted to verify the design.

In a parallel effort the heat source conceptual design will continue. Information obtained from the preliminary safety evaluations, compatibility tests, venting tests, fabrication and impact tests will lead to the preliminary heat source design.

The heat source technology development effort will be supported during this period by the ORNL. Compatibility tests between various ceramics with curia fuel will be conducted by the ORNL, as will helium tests through the ceramic liner. Subsequent to the identification of a PICS fabrication technique by General Electric with fuel simulant, the ORNL will initiate a PICS fabrication program using curia fuel. Upon completion of the PICS fabrication development, curia fueled FIB's will be fabricated by ORNL, and impact tested.

The component development portion of the heat source program is assumed to be initiated with receipt by the AEC of a DOD requirement letter. The earliest date established by the AEC for this event is July, 1975. This effort will begin with two main tasks: reentry testing and performance analyses, and safety studies. The reentry work will include aerodynamic, heat transfer, ablation, drop and impact testing.

Results obtained from these tests combined with the analytical evaluations will define the design of the prototype heat source. Design of the prototype heat source is scheduled to be completed by October 1976. During this period of time a preliminary safety analysis report (PSAR) and an updated safety analysis report (USAR) will be written.

Safety verification tests consisting of pad abort sequential tests, heat source reentry impact tests, and loss of cooling tests will also be performed during 1976. A final safety report (FSAR) will be written upon completion of these 


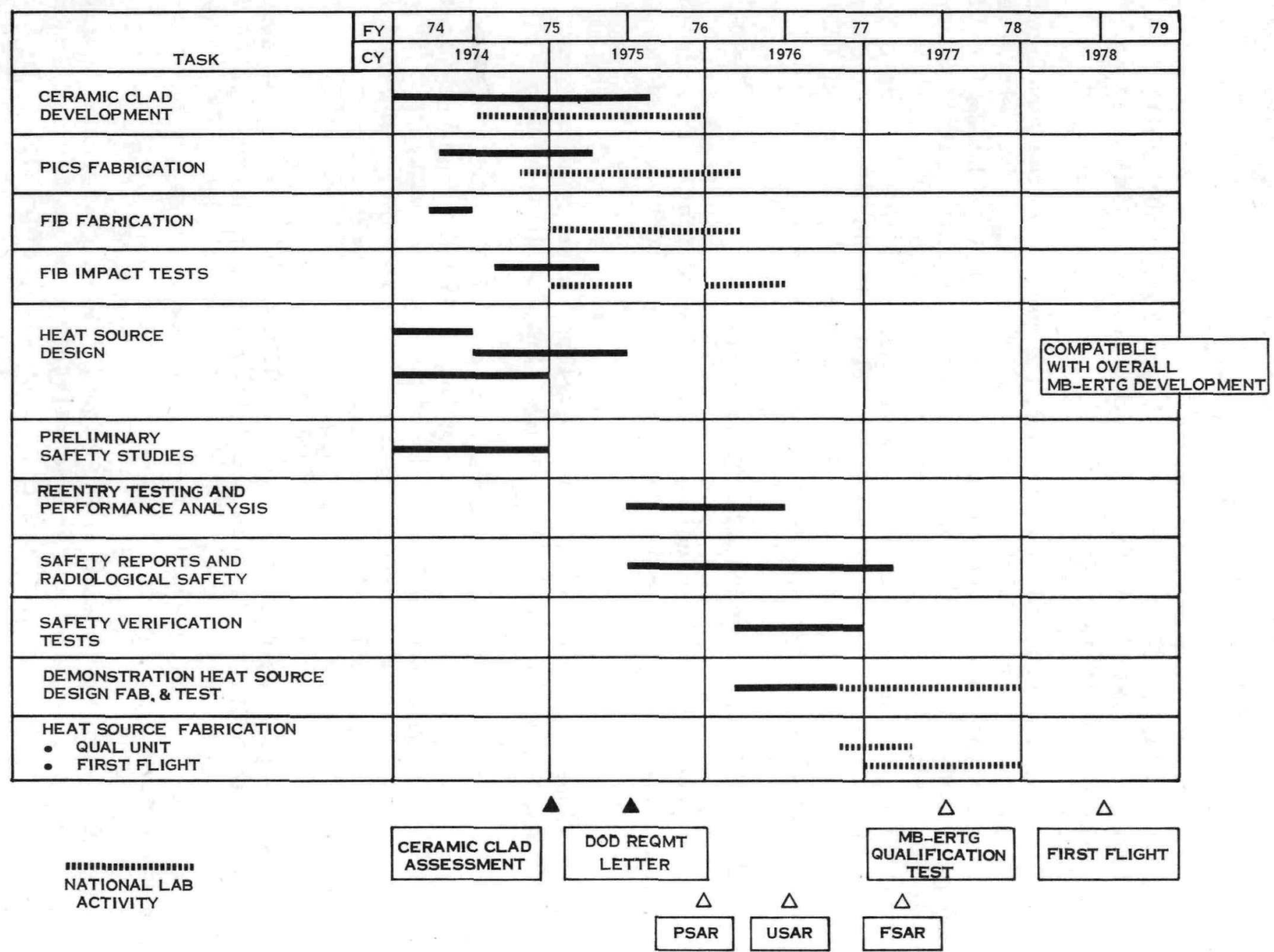




\subsubsection{Heat Source (continued)}

tests.

The prototype heat source will be fabricated at ORNL and placed on test for 6 months; at the end of this period the heat source will be disassembled and destructively tested in accordance with AEC plans.

Subsequent to fabrication of the prototype heat source, ORNL will fabricate one qualification and two flight heat source units. Qualification of the heat source is scheduled for July, 1977.

The detailed estimate of the contractor costs incurred in the development of the ceramic clad heat source is summarized in Table 8-1. The safety related tasks constitute 40 percent of total contractor's costs. The ORNL estimated their operating and capital equipment costs for participating in the ceramic heat development program; these costs are given in Figure 8-3 with a summary of the total heat source costs for Phases 2, 3 and 4. These figures include the cost of curia fuel ( $\$ 100 /$ watt) needed to perform the impact tests and to build the prototype, qualification and 2 flight heat source units. Total cost for the heat source development program is 10.2 million dollars.

\subsubsection{Heat Source Heat Exchanger Development}

The heat source heat exchanger development will be initiated in Phase 2 . The Phase 2 effort will consist of a technology development effort and a component development effort.

The technical areas requiring additional development are the emergency cooling system, material characterization and fabrication development.

The emergency cooling concept identified uses multifoil insulation which melts when there is a loss of cooling so as to maintain the isotope heat source below critical temperature levels. Work is planned to demonstrate this concept by a combination of analysis, design, and subscale testing. Included in the cost is a test rig which will allow the performance evaluation of the insulation as well as the melting feasibility test.

The refractory alloys presently selected, $\mathrm{Nb}-103$ and $\mathrm{Nb}-1 \mathrm{Zr}$, require better characterization in order to develop a weight effective design having a maximum of 1 percent creep in 5 years. Therefore, tests to quantify creeprupture, low-cycle fatigue, tensile properties, and thermal properties for the time-temperature life are required.

Although the HSHX concept appears to be a fairly straightforward fabrication job, it will be necessary to qualify the refractory parts fabrication and the diffusion bonding technique with the columbium alloy of choice. In addition, subscale HSHX samples will be made for evaluation. This task will lead to a qualified manufacturing process for this critical component.

The component development tasks in Phase 2 lead to construction of full-scale HSHX units. Three full size units will be built, one of stainless steel (or similar inexpensive material) for fit-up and cold-flow tests, and two of 


\begin{tabular}{|l|c|}
\hline \multicolumn{1}{|c|}{ DEVELOPMENT TASKS } & $\begin{array}{c}\text { CONTRACTOR } \\
\text { COSTS }\end{array}$ \\
\hline - CERAMIC CLAD DEVELOPMENT AND FABRICATION & $\$ 112 \mathrm{~K}$ \\
- FUEL IMPACT BODY FABRICATION & 243 \\
- FIB IMPACT TESTING & 242 \\
- PRELIMINARY HEAT SOURCE DESIGN ACTIVITIES & 423 \\
- BACK-UP HEAT SOURCE DESIGN ANALYSIS & 52 \\
- PRELIMINARY SAFETY STUDIES & 66 \\
- REENTRY TESTS - AERO, HEAT TRANSFER, ABLATION, & 209 \\
IMPACT, DROP & 314 \\
- REENTRY PERFORMANCE ANALYSES & 505 \\
- SAFETY REPORTS AND RADIOLOGICAL SAFETY & 1068 \\
- SAFETY VERIFICATION TESTS & 454 \\
\hline DEMONSTRATION HEAT SOURCE DESIGN, FABRICATION, & $\$ 3688 \mathrm{~K}$ \\
\hline TESTING & \\
\cline { 2 - 2 } &
\end{tabular}




\subsubsection{Heat Source Heat Exchanger Development. (continued)}

refractory metal, one for evaluation independently of the rest of the HSA, and one for incorporation into the Brassboard System. The cost of the facility necessary for the testing of complete HSA units and HSHX units alone is included. This facility will serve for the remainder of the program for acceptance testing.

Two full sets of insulation will be produced; one for independent testing and evaluation, and one for the first complete HSA. Included in this phase are design studies as well as fabrication and testing.

The objective of Phase 3 is to qualify the entire MB-ERTG system. The system contractor will build 5 HSHX units, one Brassboard Unit, three prototype units, and one qualification unit. The only testing costs in Phase 3 are those involved in assuring that HSHX units meet specifications. System testing is specifically not performed. No new facilities appear necessary. It is assumed that the three prototype units and the qualification unit are essentially identical. Quality control costs are included.

In Phase 4 two flight units will be produced and delivered in mid-1977 for incorporation into the first flight system (one flight and one spare). Costs for development of the HSHX are as follows:

Phase 2 - \$865K

Phase 3 - $\$ 1228 \mathrm{~K}$

Phase 4 - \$280K

\subsubsection{Brayton Rotating Unit Development}

The mini-BRU component technology development program is initiated at the outset of Phase 2 and will take 18 months to complete. As discussed in previous sections, a flexible BRU will be developed which will have a power capability in the one-half to multi-kilowatt electric range.

The rotating unit development plan and associated schedule are shown in Figure 8-6 and Table 8-2, respectively. Component technology development of the four major components of the BRU (turbine, alternator, compressor and bearings) will be initiated with a computer design effort based on hardware experience. Test rigs will be designed to accommodate each of the components and to simulate the engine environment. The compressor and turbine test rigs will be closed loops which can operate with either kypton or argon as the working fluid. Both of these components will be mounted on low loss bearings and thermally isolated to insure accurate evaluations. Sufficient data will be taken to define the turbine and compressor operating regimes and to verify aerodynamic efficiencies. At the same time the alternator will be tested in its rig to determine performance in start up and steady state mode. The gas bearings will be tested in its simulator with dummy masses and will then be mated to the alternator to determine performance of these components under motor loads and steady state operation. Finally, the complete unit will be assembled and spun hot in a closed loop with a simulated heat source to verify overall performance. At the end of 18 months a mini-BRU will be available for use in the Brassboard system. 
1. DEsten COMPRESSOR MAPPING RIG DESIGN COMPRESSOR SECTION
- 6. COMPREsSOR MAPPINO TESTS

7. DIFFUSER AND HEAT - $X$ PERFORIMANCE TESTS

2. DESIGN TURBINE MAPPIMC RIG

5. FABRICATE

DESIGN TURBINE HARDWARE SECTION

8. TURBINE MAPPING TESTS

3. DESIGN

ALTERNATOR

DESIGN MTU

(MAGNETIC

TEST UNIT)

DESIGN MOTOR

TEST RIG

5. FABRICATE HARDWARE

9. MTU TESTS ROTOR SPIN TESTS

(a) GROWTH

(b) BURST

11. SEMULATOR TESTS

(a) MOTORING

4. DESIGN GASBEARINGS

b. FABRICATE HARDWARE

10. SIMULATOR TESTS

(a) GAS BEARINGS

b) ALTERNATOR PERFORMANCE

DESIGN DYNAMIC

(b) ROTOR DYNAMICS

(c) THERMAL MAPPING 


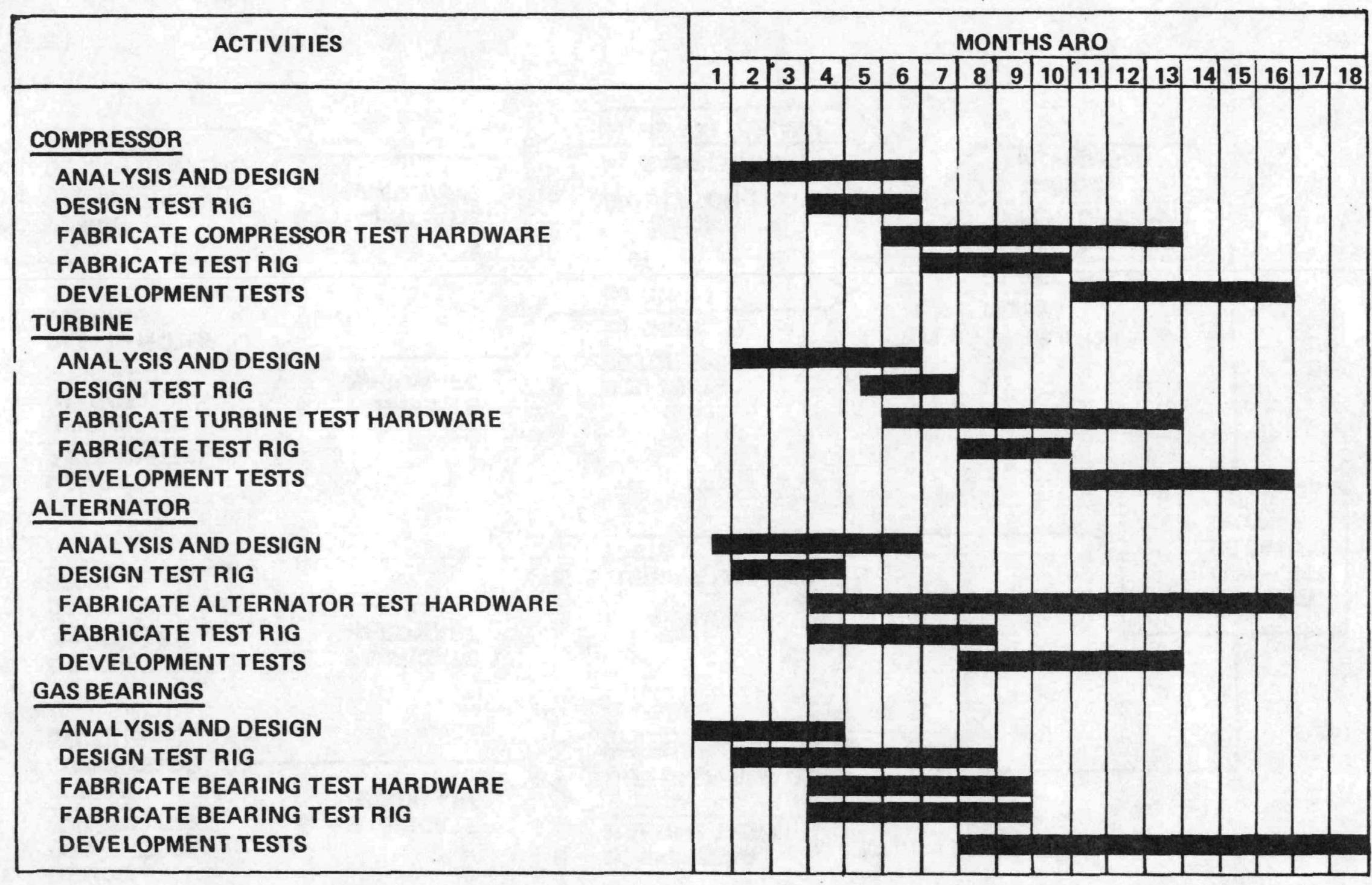




\subsubsection{Brayton Rotating Unit Development (continued)}

In Phase 3 a total of 4 mini-BRU's (plus spare parts) will be fabricated. Three of these units will be used in the system prototypes and one in the qualification unit. The development plan assumes that some redesign on each unit will be performed as a result of the experience gained from previous tests.

Two mini-BRU's will be fabricated for the Phase 4 effort, one flight and one spare. These units will be identical to the qualification mini-BRU.

Costs for development of the mini-BRU are:

$\begin{array}{ll}\text { Phase 2 } & \$ 1282 \mathrm{~K} \\ \text { Phase 3 } & \$ 1304 \mathrm{~K} \\ \text { Phase 4 } & \$ 310 \mathrm{~K}\end{array}$

\subsubsection{Recuperator Development}

The recuperator development will also be initiated at the start of Phase 2 . Development will begin with a design effort and subscale pressure drop and heat transfer testing of that design. Start/shutdown tests will also be run in order to verify the integrity of the double containment design described in Section 4.3.5.

Based on these initial tests a full scale heat exchanger will be designed and assembled. This unit will be used to demonstrate total gas pressure drop and thermal performance at the design point conditions. The development plan assumes that the prototype will be tested under start/shutdown conditions until a failure occurs or 1000 cycles have been accumulated. A second recuperator will be built during Phase 2 for use in the Brassboard System.

Four recuperators will be built during the Phase 3 effort and 2 units for the Phase 4 flight program.

Total recuperator development costs are as follows:

$$
\begin{array}{ll}
\text { Phase 2 } & \$ 430 \mathrm{~K} \\
\text { Phase 3 } & \$ 809 \mathrm{~K} \\
\text { Phase 4 } & \$ 175 \mathrm{~K}
\end{array}
$$

\subsubsection{Control Development}

Development of the control system will begin subsequent to the BRU development in Phase 2. Total development time required is expected to be less than 1 year. 


\subsubsection{Controls Development}

The control system will require a DC to AC converter, used in the BRU start-up and a parasitic load control system to maintain desired rotating speed. In addition, the control system will adjust the BRU speed over the mission life to compensate for the variable radioisotope heat into the system. This will be accomplished by sensing either the turbine outlet or inlet temperature. The electronic circuitry must be designed to provide protection to the system based upon a failure mode effects analysis and vehicle requirements.

The control system will be checked out by means of the mini-BRU dynamic simulator. The developed unit will then be used in the Brassboard Unit.

Control systems will be developed for each of the 4 systems in Phase 2 and the 2 systems in Phase 3.

Total development costs are:

$\begin{array}{ll}\text { Phase 2 } & \$ 403 \mathrm{~K} \\ \text { Phase 3 } & \$ 849 \mathrm{~K} \\ \text { Phase 4 } & \$ 150 \mathrm{~K}\end{array}$

\subsubsection{Radiator Development}

The Reference Design utilizes an aluminum radiator which does not require technology development. The design of the radiator is similar to configurations fabricated in the past by both the General Electric Company and AiResearch.

In order to complete the fabrication and testing of the MB-ERTG systems, 7 radiators will be built in the course of the development program. One unit will be used in the Brassboard System, 3 in the Prototype systems, 1 in the Qualification unit and 2 for the First Flight units.

Radiator costs including design, fabrication, tooling costs, assembly and check-out testing are:

$\begin{array}{ll}\text { Phase 2 } & \$ 24 \mathrm{~K} \\ \text { Phase } 3 & \$ 74 \mathrm{~K} \\ \text { Phase 4 } & \$ 30 \mathrm{~K}\end{array}$

\subsubsection{MB-ERTG DEVELOPMENT COSTS}

This section provides a detailed breakdown of the total MB-ERTG development costs for Phase 2, 3 and 4. Costs are presented for the system contractor and for ORNL. The system contractor costs include all identifiable items such as overhead, $G$ and $A$, subcontractor costs, spare parts, transportation and quality control. The systems contractor fee is not included. ORNL costs consist of operating, capital equipment and fuel costs. 


\subsubsection{MB-ERTG DEVELOPMENT COSTS (continued)}

As presented in Section 8.2, total Reference MB-ERTG development cost is $\$ 23$ million; $\$ 16.4$ million to the systems contractor and $\$ 6.5$ to ORNL. A breakdown of these costs is shown in Figure 8-3. Over $\$ 4.4$ million of the total cost is expended by the systems contractor in bringing the Brayton components and ceramic clad heat source to technology readiness (Phase 2). An additional $\$ 7.1$ million is required in Phase 3 for system prototype development and qualification of the power conversion system by the system contractor. Phase 4 expenditures by the system contractor are $\$ 1.5$ million; this is the cost of building and delivering the first flight units.

Cumulative system contractor development costs are shown in Figure 8-7 as a function of time. The major portion of the spending occurs in the end of FY 75, FY 76 and the beginning of FY 77, the end of Phase 2 and beginning of Phase 3. The peak spending rate is less than $\$ 6$ million per year. Costs for program management, capital equipment and ground support equipment are also shown. These areas constitute a relatively small portion of the total cost.

Figure 8-8 illustrates the ORNL costs on a yearly basis. The ORNL operating costs include the following expenses:

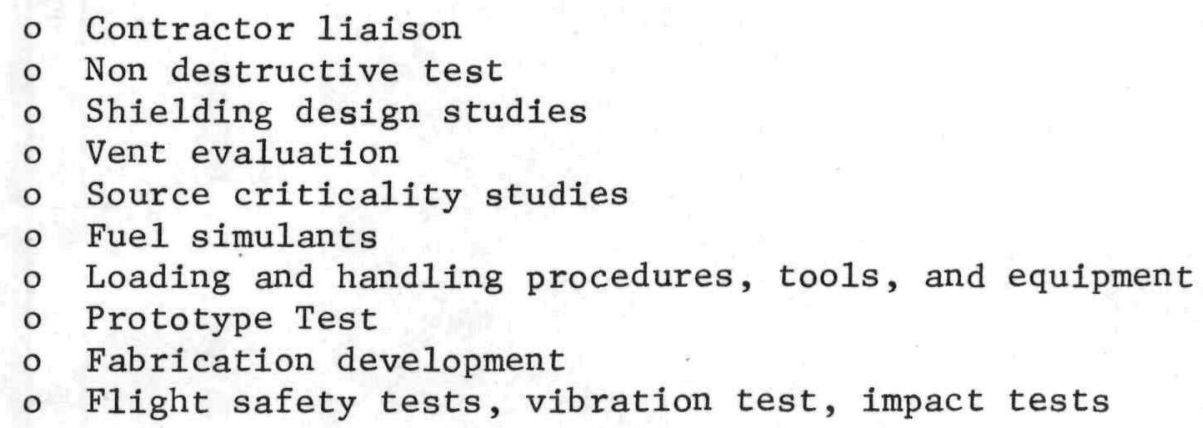

Significant areas of expenditure at ORNL include $\$ 1.2$ million for non-destructive testing of the ceramic clad/fuel encapsulation and interface structure, $\$ 0.5$ million for the prototype heat source test and $\$ 0.4$ million for fabrication development.

\section{Ground Support Equipment}

Table 8-3 1ists the ground support equipment costs identified for the development program. The major cost item, $\$ 540 \mathrm{~K}$, is the MB-ERTG Fueling Facility which is to be located at the launch facility. This equipment will contain the MB-ERTG when the "check out" loading of the heat source into the HSHX is made. Second in cost is test support equipment, $\$ 385 \mathrm{~K}$, to check-out the operation of the BRU, control system and recuperator.

Another cost item is the heat source transfer assembly which is used to load the heat source into the HSHX while the MB-ERTG is on the pad. This mobile unit, consisting of manipulators and a water shield was estimated to cost $\$ 125 \mathrm{~K}$. Additional expense for 2 heat source shipping containers, 4 electrical heat sources and power supply consoles contributed significantly to the total GSE costs (see Table 8-3). 


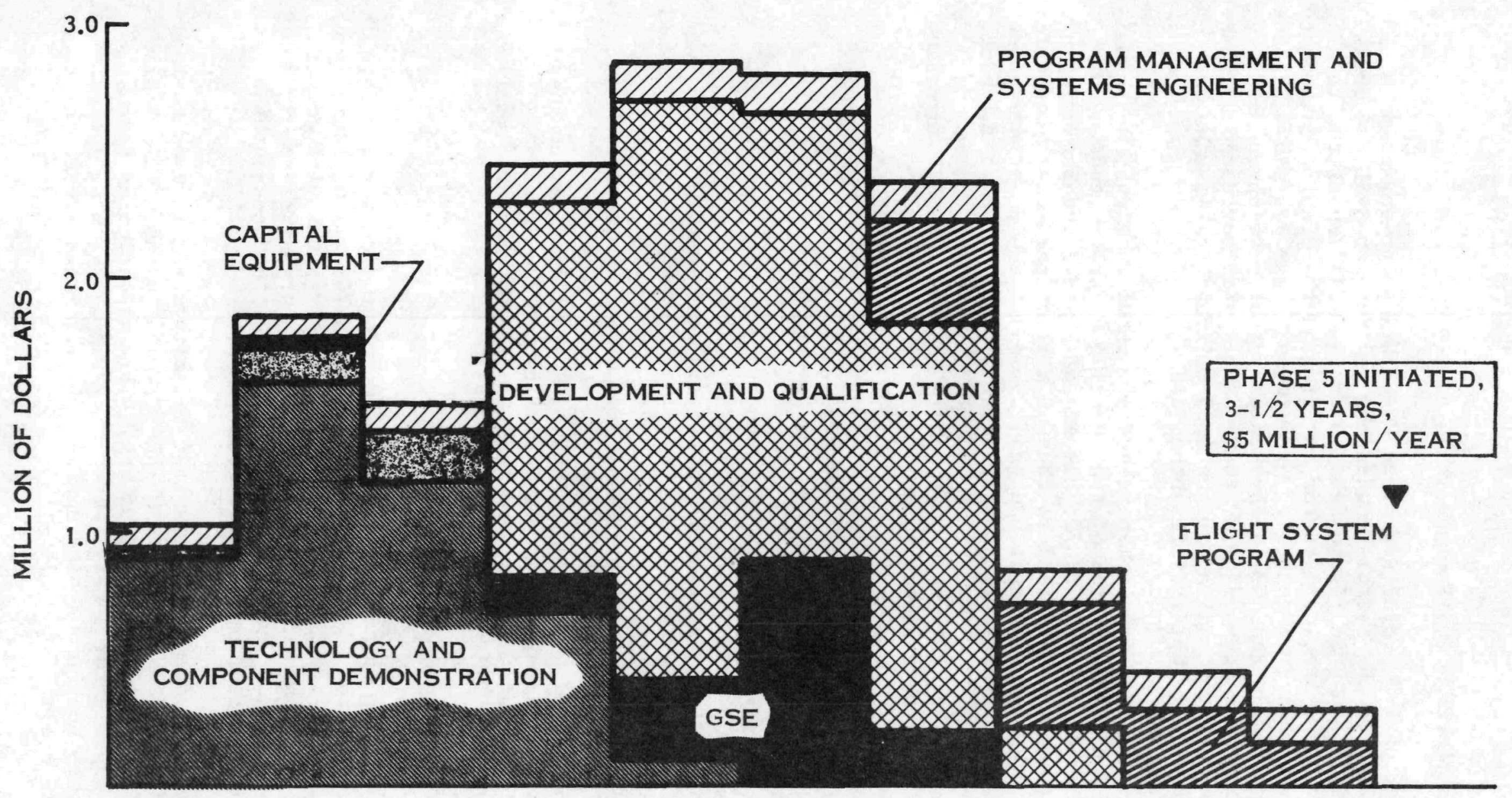

CUMULATIVE COSTS ( $\$ \times 10^{-6}$ )

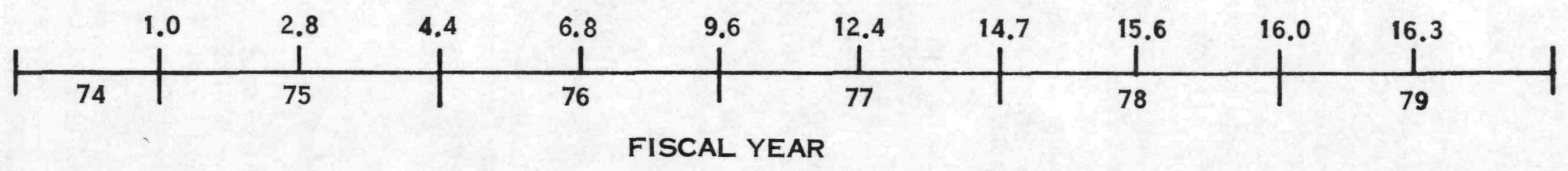




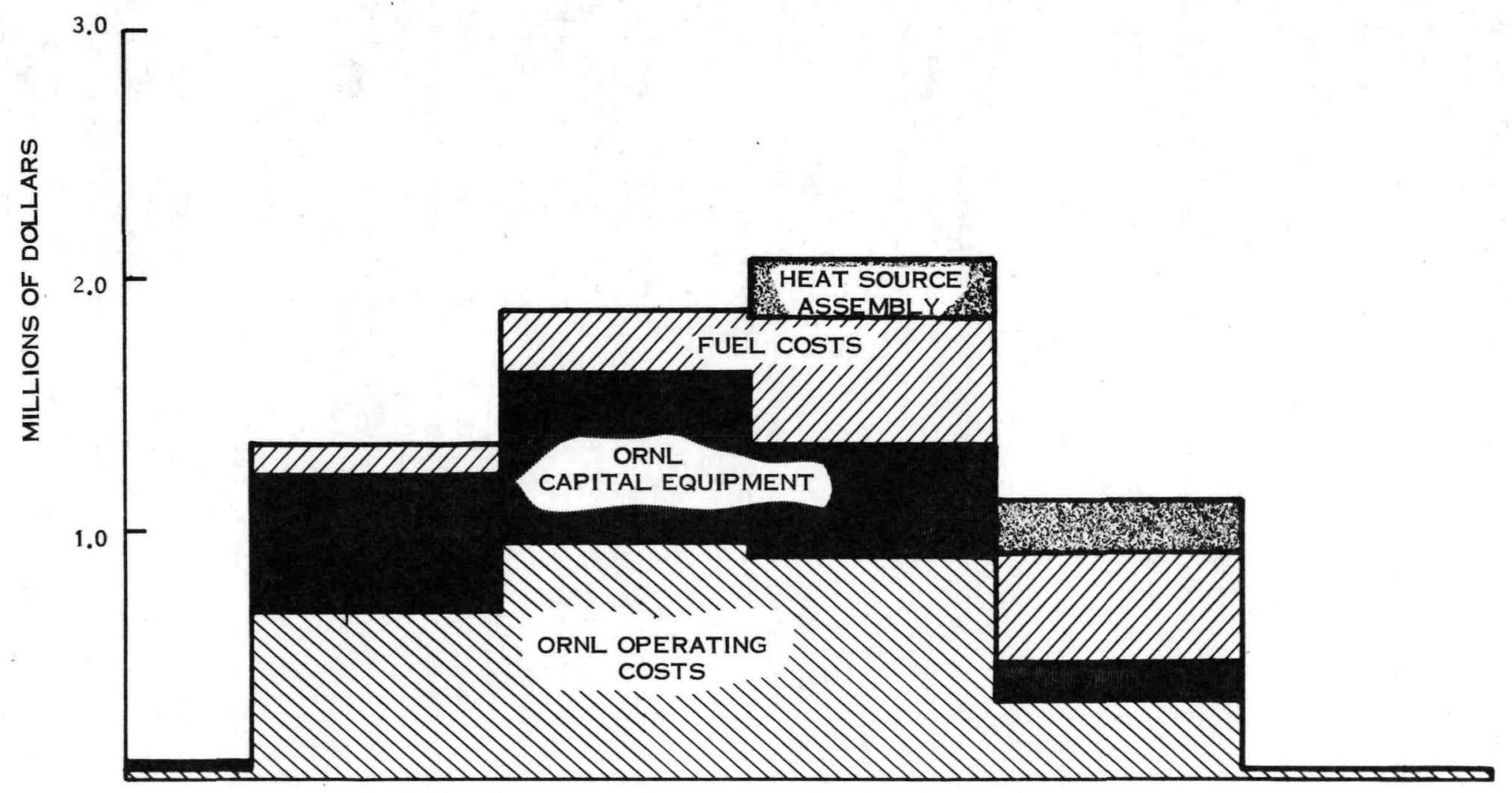

CuMULATIVE COSTS $-\$ \times 10^{-6}$

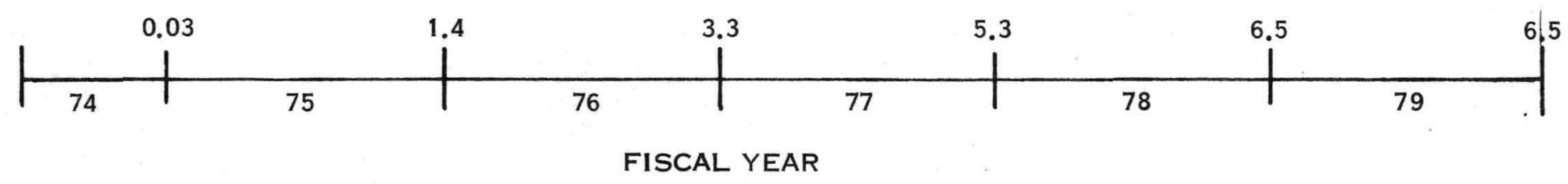




\section{Capital Equipment and Facilities}

Three capital equipment items are required, all during Phase 2, for the development program; these are listed in Table 8-4. The HSHX test facility will be used to run pressure drop and heat transfer tests on the completed units in vacuum. A melting insulation test rig will be needed to run the subscale heat transfer tests on candidate insulation systems. Hot tests on the BRU will be run in a special vacuum facility with a He/Xe gas loop. Total capital equipment costs will approximate $\$ 343 \mathrm{~K}$.

Capital equipment items which could be supplied by General Electric were not added to the total cost. These include:

- Thermal vacuum chambers for the MB-ERTG

- Shock and vibration facility (adequate for $\mathrm{PuO}_{2}$ fueled MB-ERTG)

o Impact test facility (non-nuclear)

\subsubsection{System Contractor Cost Breakdown - Phase 2}

Total system contractor cost for Phase 2, Technology and Component Demonstration, is $\$ 5.1$ million. A breakdown of this cost is provided in Table 8-5. The costs for the major components have already been covered in Section 8.2.1; in addition, costs are shown for bimetallic joint and refractory turbine scroll development and the Brassboard test.

Bimetallic joints will be made between the recuperator and HSHX, recuperator and radiator, and turbine scroll to BRU. Although no major technology breakthroughs are required to effect these bimetallic connections, some fabrication development will be needed in order to gain experience with the specific component geometries.

A refractory turbine scroll is required for this application as a result of the 5 year mission duration and the $1705^{\circ} \mathrm{F}$ turbine inlet temperature. Use of a superalloy scroll is unacceptable due to the high vapor pressure (and mass transfer) of the nickel and chromium which causes a degradation in the material properties over extended periods of time. The turbine scroll will be manufactured from the same material as the HSHX. Several potential manufacturing techniques have been identified; these will be investigated during Phase 2. The components developed in Phase 2 will be used in the Brassboard Test. Assembly of the components and subsequent performance testing has been costed at $\$ 137 \mathrm{~K}$. Data obtained from the Brassboard Test will provide a useful design input to the Phase 3 activity.

\subsubsection{System Contractor Cost Breakdown - Phase 3}

Total system contractor costs for Phase 3, Prototype Development and Qualification, is $\$ 9.4$ million. The Phase 3 costs are shown in Table $8-6$;for clarity costs relating to the prototype development have been distinguished from the qualification program.

Phase 3, Prototype Development, costs consist primarily of designing, building and testing three complete systems using electrical heat sources. 
Table 8-3. Ground Support Equipment Costs

\begin{tabular}{|l|c|}
\hline \multicolumn{1}{|c|}{ COST ITEM } & COST \\
\hline EHS (4) & $87 \mathrm{~K}$ \\
EHS POWER SUPPLY CONSOLE (4) & 99 \\
EHS LOADING FIXTURE (2) & 31 \\
RECUP. BRU \& CONTROLS SUPPORT & 385 \\
READ-OUT CONSOLE (2) & 67 \\
PCS SHIPPING CONTAINERS (2) & 30 \\
HS SHIPPING CONTAINER (2) & 140 \\
STORAGE PROTECTION CONTAINER & 20 \\
(HANDLING FIXTURES) (2) & 14 \\
HS HANDLING FIXTURE (2) & 23 \\
STORAGE PROTECT CONT. (2) & 540 \\
MB-RTG FUELING FACILITY & 50 \\
AUX. COOLING SYSTEM (MOBILE) (2) & 10 \\
QUAL \& ACC. TEST FIXTURE & 125 \\
HEAT SOURCE TRANSFER ASSEMBLY & $\$ 1,621 \mathrm{~K}$ \\
\hline \multicolumn{2}{|c|}{ TOTAL }
\end{tabular}

Table 8-4. Capital Equipment and Facilities Costs

\begin{tabular}{|c|c|}
\hline COST ITEM & COST \\
\hline HSA TEST FAC. & $\$ 114 \mathrm{~K}$ \\
\hline $\begin{array}{l}\text { MELTING INS. } \\
\text { TEST RIG }\end{array}$ & 29 \\
\hline BRU TEST LOOPS & 200 \\
\hline TOTAL & $\$ 343 \mathrm{~K}$ \\
\hline
\end{tabular}


Table 8-5. Phase II Contractor Costs Technology and Component Demonstration

\begin{tabular}{|c|c|c|}
\hline COMPONENT & COST & COMMENT \\
\hline $\begin{array}{l}\text { HEAT SOURCE } \\
\text { HEAT EXCHANGER }\end{array}$ & $\$ 478 \mathrm{~K}$ & $\begin{array}{l}\text { MATERIAL CHARACTERIZATION, FABRICATION } \\
\text { DEVELOPMENT, AUXILIARY COOLING }\end{array}$ \\
\hline MELTING INSULATION & 341 & FEASIBILITY TESTS \\
\hline HEAT SOURCE & 1138 & CERAMIC CLAD FABRICATION DEVELOPMENT \\
\hline $\begin{array}{l}\text { HEAT SOURCE ASSEMBLY } \\
\text { COMPONENT INTEGRATION }\end{array}$ & 46 & SYSTEMS ENGINEERING TASK \\
\hline FLEXIBLE BRU & 1282 & $400-3000$ We CAPABILITY \\
\hline RECUPERATOR & 430 & DEVELOPMENT UNDER WAY \\
\hline Bi-METALLIC JOINTS & 65 & RECUPERATOR/HSHX INLET \\
\hline REFRACTOR Y SCROLL & 100 & $\begin{array}{l}\text { SUPERALLOY SCROLL UNACCEPTABLE FOR } \\
5 \text { YEAR VACUUM OPERATION }\end{array}$ \\
\hline CONTROLS & 430 & CIRCUIT DEVELOPMENT AND CHARACTERIZATION \\
\hline RADIATOR & 24 & REQUIRED FOR BRASSBOARD \\
\hline $\begin{array}{l}\text { BRASSBOARD ASSEMBLY } \\
\text { AND TEST }\end{array}$ & 137 & 6 MONTH PERFORMANCE TEST \\
\hline $\begin{array}{l}\text { CAPITAL EQUIPMENT } \\
\text { AND FACILITIES }\end{array}$ & 343 & \\
\hline GSE & 50 & \\
\hline $\begin{array}{l}\text { PROGRAM MANAGEMENT } \\
\text { AND SYSTEMS ENGINEER ING }\end{array}$ & 251 & \\
\hline TOTAL & $\$ 5115 \mathrm{~K}$ & \\
\hline
\end{tabular}




\begin{tabular}{|l|c|c|c|c|}
\hline \multicolumn{1}{|c|}{ COST ITEM } & $\begin{array}{c}\text { PHASE 3 } \\
\text { PROTOTYPE DEVELOPMENT }\end{array}$ & $\begin{array}{c}\text { PHASE 3 } \\
\text { QUALIFICATION PROGRAM }\end{array}$ & $\begin{array}{c}\text { PHASE 4 } \\
\text { FLIGHT SYSTEM FROGRAM }\end{array}$ & \begin{tabular}{c} 
TOTAL \\
\hline HEAT SOURCE ASSEMBLY
\end{tabular} \\
\hline RECUPERATOR & $\$ 1,616 \mathrm{~K}$ & $\$ 1,798 \mathrm{~K}$ & $570 \mathrm{~K}$ & $\$ 3,984 \mathrm{~K}$ \\
\hline FLEXIBLE BRU & 578 & 231 & 310 & 984 \\
\hline RADIATOR & 934 & 370 & 30 & 1,614 \\
\hline CONTROLS & 54 & 20 & 150 & 104 \\
\hline SHIELD & 578 & 271 & 22 & 999 \\
\hline DUCTING & 19 & 18 & 56 & 59 \\
\hline STRUCTURE + MOCK-UP & 100 & 40 & 20 & 196 \\
\hline ASSEMBLY & 70 & 17 & 68 & 107 \\
\hline TEST & 115 & 35 & 104 & 218 \\
\hline CAPITAL EQUIPMENT & 242 & 80 & 0 & 426 \\
\hline GSE & 0 & 0 & 1,121 & 0 \\
\hline PROGRAM MANAGEMENT \\
AND SYSTEMS ENGINEERING
\end{tabular}




\subsubsection{System Contractor Cost Breakdown - Phase 3 (continued)}

The first system will be shock and vibration tested as well as performance tested; therefore, a neutron shield will be included in that unit. The second and third prototypes will be endurance tested. Costs reflect the anticipation of design iterations between prototype fabrications.

The largest cost item in this portion of Phase 3 is the HSA development, $\$ 1616 \mathrm{~K}$. The breakdown for this figure is:

$\begin{array}{ll}\text { HSHX/insulation (3) } & \$ 640 \mathrm{~K} \\ \text { Reentry Tests } & \$ 208 \mathrm{~K} \\ \text { Reentry Performance Analyses } & \$ 314 \mathrm{~K} \\ \begin{array}{l}\text { Prototype Heat Source Design } \\ \text { and Fabrication }\end{array} & \$ 454 \mathrm{~K}\end{array}$

Total Phase 3 Prototype Development costs are calculated to be $\$ 5.2$ million.

Phase 3 - Qualification Program, costs approximated $\$ 4.2$ million. Over 40 percent of this cost, $\$ 1798 \mathrm{~K}$ is attributed to the heat source assembly fabrication and qualification. The breakdown for this figure is as follows:
Heat Source Piece Parts
$\$ 225 \mathrm{~K}$
Safety Reports and Radiological Safety
$\$ 505 \mathrm{~K}$
Safety Verification Tests
$\$ 1068 \mathrm{~K}$

The GSE costs during this portion of the program are also significant, $\$ 1121 \mathrm{~K}$. Although not directly attributable to the Qualification Program, money will be spent during this time period for the MB-ERTG Fueling Facility, $\$ 540 \mathrm{~K}$, Heat Source Transfer Assemb1y, $\$ 125 \mathrm{~K}$, Heat Source Shipping Containers, \$140K, Mobile Auxiliary Cooling Systems, \$50K, and other items.

\subsubsection{System Contractor Breakdown - Phase 4}

As shown in Table 8-6, System contractor costs for Phase 4 are $\$ 1.9$ million. This cost reflects the expense of fabricating two units, acceptance testing and delivering the units to the launch facility. In addition, the cost of providing ground support personnel 6 months prior and subsequent to the first flight has been included (see Appendix I). Individual component costs for the Phase 4 activity are higher in some cases than that quoted in Phase 5 , Unit costs. This is a result of the more efficient utilization of manpower in the Production Program and the fabrication experience gained in the development program.

\subsection{PHASE 5 - UNIT COSTS}

This section describes the unit costs for the Reference Design based on the production rate of 6 units per year with a total production of 20 units. The costs calculated for each unit provides a complete cost and includes the expense of assembly, acceptance testing, ground support personnel at the launch facility, ground handling and shipping and program management. In addition, spare parts for the BRU, recuperator and HSHX as well as tooling costs were 


\subsection{PHASE 5 - UNIT COSTS (continued)}

accounted for.

\subsubsection{REFERENCE DESIGN UNIT COSTS}

Total unit cost of the MB-ERTG is $\$ 748,000$. This includes $\$ 607,000$ for material and component fabrication costs, plus $\$ 141,000$ for system assembly, acceptance testing, transportation and program management.

Table 8-7 presents the Reference Design unit costs for the first, tenth and twentieth units. A small decrease in total cost, 7 percent, is shown from the first to the twentieth unit as a result of a decrease in the HSHX, heat source piece parts and $B R U$, recuperator and controls package. These cost decreases are expected to result from the experience gained on previous units.

The heat source assembly cost (less the heat source) is $\$ 119 \mathrm{~K}$. Fuel costs assume curia fuel at $\$ 100$ per thermal watt. Piece parts for the heat source include the cost of the thoria clad, impact shells, aeroshell impact core and aeroshell. Heat source assembly costs are estimated at $\$ 77 \mathrm{~K}$ by ORNL; the assembly procedure is outlined in Figure 8-9. Four separate working areas are used in the fabrication procedure.

The cost for the BRU, recuperator and controls package was obtained from AiResearch. This figure, $\$ 120 \mathrm{~K}$, includes their cost of performance checking the components prior to shipment to General Electric.

Radiator cost, $\$ 15 \mathrm{~K}$, was estimated from previous experience on similar components. The shield cost, $\$ 9 K$, was calculated on the basis of quoted lithium hydride prices with additional costs included for manufacture in the geometry identified.

Miscellaneous costs, $\$ 8 \mathrm{~K}$, include structure, fittings and ducting for the MB-ERTG.

\subsubsection{VARIATION OF UNIT COSTS WITH POWER LEVEL}

The variation of unit cost with power level was investigated. As power requirements increase the main impact on cost will be the fuel cost. The cost of the BRU, controls and recuperator will stay essentially the same as power level increases and the radiator and HSHX costs will increase less than proportionally with power level.

Results of the investigation are shown in Figure 8-10. Due to the increase in the MB-ERTG efficiency and the assumed constancy of the component costs, the cost per Watt decreases significantly with increasing power level. Unit costs for a curia fueled MB-ERTG are $\$ 1900 /$ Watt at the 400 We level and $\$ 600$ per Watt at the 3000 We level. A similar decrease is shown for a plutonia fueled MB-ERTG which decreases from $\$ 4000 /$ Watt to $\$ 2100 /$ Watt over the same power range. 


\begin{tabular}{|l|c|c|c|}
\hline \multicolumn{1}{|c|}{ COMPONENT } & UNIT 1 & UNIT 10 & UNIT 20 \\
\hline HEAT SOURCE ASSEMBLY & $\$ 139 \mathrm{~K}$ & $\$ 130 \mathrm{~K}$ & $\$ 119 \mathrm{~K}$ \\
HEAT SOURCE & & & \\
FUEL & 219 & 219 & 219 \\
PIECE PARTS & 45 & 43 & 40 \\
ASSEMBLY & 77 & 77 & 77 \\
BRU, RECUPERATOR AND & 150 & 128 & 120 \\
CONTROLS & 15 & 15 & 15 \\
RADIATOR & 9 & 9 & 9 \\
SHIELD & 8 & 8 & 8 \\
MISCELLANEOUS & $\$ 662 \mathrm{~K}$ & $\$ 629 \mathrm{~K}$ & $\$ 607 \mathrm{~K}$ \\
\hline SUBTOTAL & 141 & 141 & 141 \\
\hline ADDITIONAL UNIT COSTS & $\$ 803 \mathrm{~K}$ & $\$ 770 \mathrm{~K}$ & $\$ 748 \mathrm{~K}$ \\
\hline TOTAL COSTS & & & \\
\hline
\end{tabular}




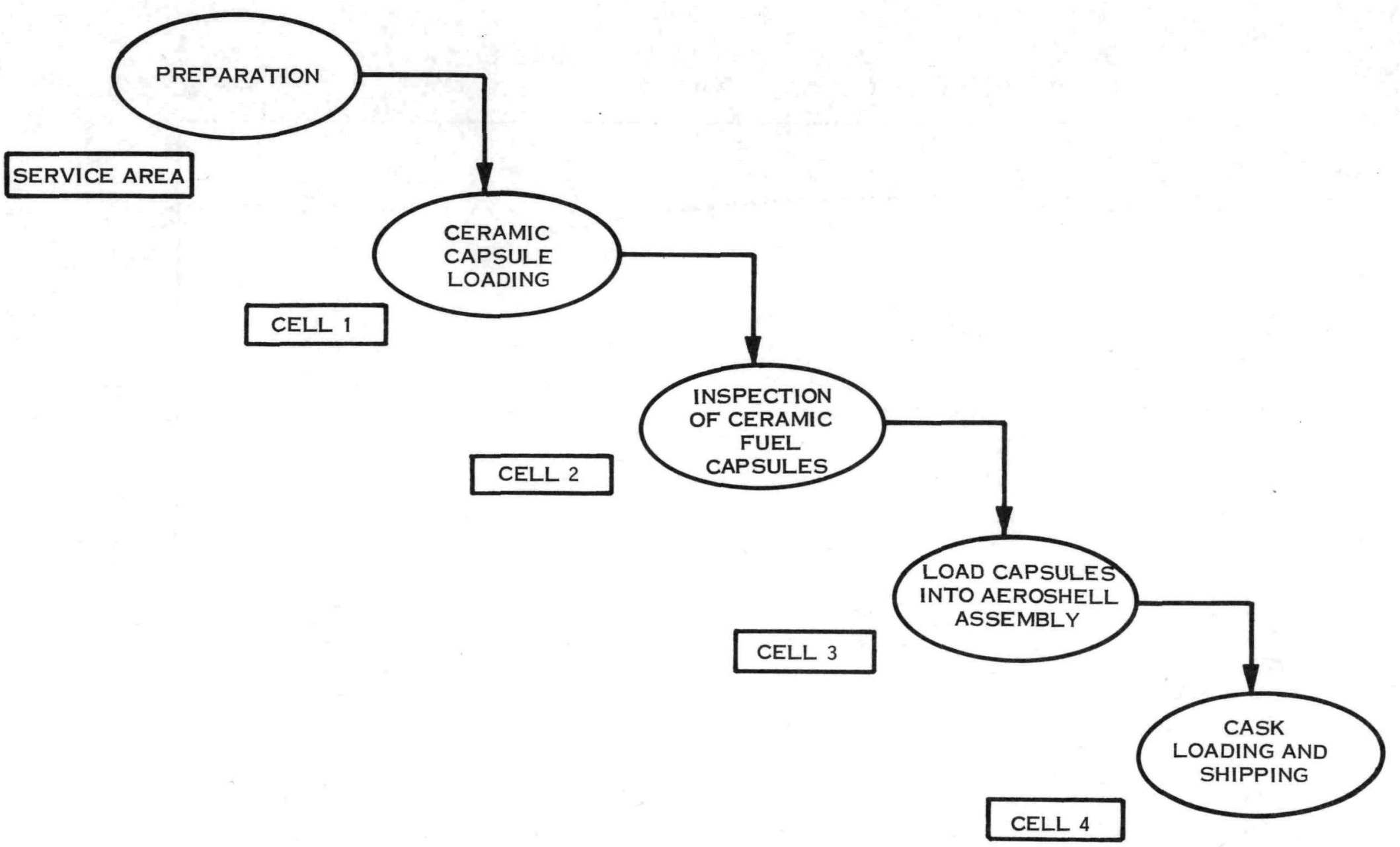




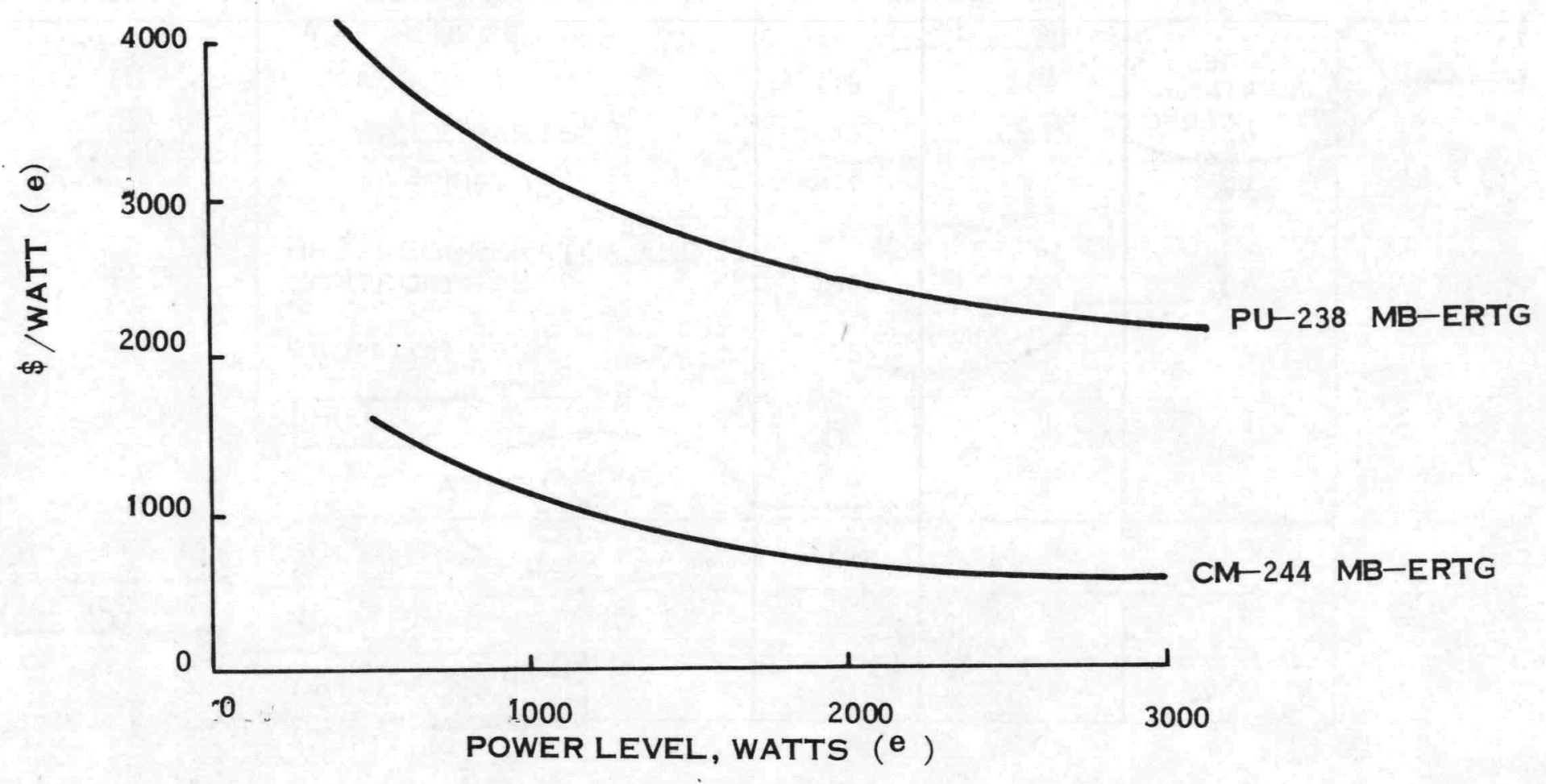


SECTION 9.0

REFERENCES

3.1-1 Loeffler, I.J., S. Lieblein, and N. Clough, "Meteoroid Protection for Space Radiators," In "Progress in Astronautics and Aeronautics, Vo1 II, Power Systems for Space Flight," Academic Press, New York, 1963.

3.1-2 Clough, N., Lieblein, S., McMillan, A.R., "Crater Characteristics of 11 Metal Alloys Under Hyper-Velocity Impact Including Effects of Projectile Density and Target Temperature", NASA TN D-5135, April 1969.

6.5-1 Burns, J.J., Vorreiter, J.W., Pitts, W.C. and Conway, T.W., "Plutonium Aerodynamic Disc (PAD) Safety Feasibility Study," SNS 975, Nov. 1972

6.5-2 Hoerner, S.F., "Fluid Dynamic Drag," 1965

6.5-3 Klett, R.D., "Drag Coefficients and Heating Ratios for Right Circular Cylinders in Free Molecular and Continuum Flow from Mach 10 to 30," SC-RR-64-2141, Dec., 1964 
APPENDIX I 


\section{UNITED STATES \\ ATOMIC ENERGY COMMISSION \\ WASHINGTON, D.C. 20545}

SEP 211973

$\mathrm{Mr}$. R. E. Killen

General Electric Company

Space Division

P. 0. Box 8555

Philadelphia, Pennsylvania 19101

Dear Mr. Killen:

Subject: Project Development Plan and Cost Estimates for ERTG Program, Contract SNSO-6

As a part of Contract SNSO-6, you are required to prepare a development plan and associated cost estimates for the development of a power system similar to your reference design for use in an operational spacecraft, as well as for the follow-on production of an additional 10-20 power units for use in an operational space program.

Since the non-recurring costs, as well as the recurring unit costs for follow-on systems, and schedules for the development program are important factors in selecting a system(s) for further development by the AEC, it is necessary for the development plans and cost estimates for the various systems under consideration to be prepared on comparable bases. Therefore, you are requested to use the following guidance in preparing your development plans and cost estimates under the current contract.

Technology and/or Component Demonstration (Phase 2)

As the next step beyond the current design study, you should assume that the program will include a technology and/or component demonstration phase starting in the 3rd quarter of FY 1974 and continuing through FY 1975 (or longer, if necessary). This 18 month (or longer) phase 2 shall include the type of effort which you will have identified as requiring emphasis prior to the time the AEC could initiate a flight system development program in response to a firm 
requirement from the DOD/Air Force, assumed to be no earlier than the lst quarter of FY 1976. The objective of this phase 2 would be to provide essential technical data in identified problem areas in your system design and/or to demonstrate hardware components which are critical to the performance of the power system which may not have been adequately demonstrated heretofore or must be reduced to hardware for proof-of-principles which are either impossible or, at best, very difficult to predict analytically. In other words, this phase of the program should be planned in a way to increase confidence in the system design prior to commitment to a larger development program required to meet a planned flight date. The level of effort for this phase of the program should be the minimum required consistent with the above directions.

The approach to be used for contracting for this next followon effort shall be to minimize the overall system contractortype efforts and to maximize the use of available resources at the component or sub-system levels. In this regard, you should assume that the AEC will not duplicate similar technology areas at various contractors, but will place system peculiar efforts as well as more generally applicable efforts with the most appropriate contractor(s).

You can further assume that the on-going AEC technology programs in the areas of fuels production and development and safety which are relatively independent of system designs will be continued through Phase 2, even though the work content may be modified based on the results of the current system design efforts.

System Development and Qualification (Phase 3)

Assuming that at least one system option is pursued through Phase 2, the next phase of the program would include the development and qualification of one or more systems for use on a spacecraft with a planned flight date. This assumes that the AEC will have received a requirement from a user agency defining the system requirements and schedules, including the definition of launch vehicles and spacecraft so that the proper interfaces can be defined and the hardware deliveries to the user agency can be specified and properly 
scheduled or that the AEC will be in a position to pursue such a development program on a technology development basis independent of a specific end-user requirement (e.g. in conjunction with the development of a standardized nuclear spacecraft).

You can assume that one, or more, system contractors will be selected by the AEC to pursue the Phase 3 program. All aspects of a system development program shall be included in the plan providing cost estimates for Program Management, Technical, Administrative, and Support-type personnel which you think is reasonable and adequate for the tasks to be performed. The development plan should include a definition of the tasks to be performed, the time and labor required, the facilities and equipment needed, and the division of responsibilities between the contractor and/or its subcontractors and the Government and/or other Government contractors.

Phase 3 shall include the design, fabrication and test efforts required at the component and system levels to logically proceed as economically and as rapidly as practical from the end of Phase 2 to an electrically heated engineering prototype(s) and then to a qualification system (both electrically heated and fueled, if required) by the end of Phase 3. You should include an electrically heated prototype for delivery to the user program for mass, thermal, and electrical integration tests with a prototype spacecraft prior to the end of Phase 3. The duration of Phase 3 is system design dependent and shall be determined by the contractor. The equipment required to support the Phase 3 program shall be included, such as any special handling equipment or shipping casks needed for a fueled system test.

The contractor shall provide all test hardware and test facilities, except for unique type facilities which exist only at Government laboratories, e.g. arc-jet facilities and nuclear test facilities. The contractor shall be responsible for arranging for such unique Government facilities and including appropriate cost estimates where possible. Plans for testing of nuclear materials shall be 
determined based on cost, safety, and other such considerations. Generally, all cold (non-nuclear) tests will be performed by the contractor and all hot (nuclear) tests will be performed by the AEC, with the possible exception of the fueled RTG system.

In the area of nuclear heat sources, you can assume that the AEC will perform fuels development and testing in support of the program and that the AEC fueling facility will load the fuel in contractor furnished hardware in accordance with previously agreed upon procedures. Any testing of fueled hardware shall be accomplished as specified above.

In the area of nuclear flight safety, Phase 3 will include those tests and analyses required to produce a preliminary safety analysis report during Phase 3. Feasibility reports or safety analyses will also be required to support tests involving nuclear materials.

In the area of quality control and reliability, the planned effort shall be design dependent and the contractor shall use his best judgement in determining the level of quality control and reliability effort required, at what point in the program, to assure a reproducible product which will meet the performance and reliability requirements specified for the flight program. Configuration control will be maintained after appropriate design freezes have been effected. By the end of Phase 3, a flight-qualified sys tem design and associated fabrication procedures suitable for producing a flight system should be available.

Flight System Fabrication (Phase 4)

Assuming that at least one system has been successfully qualified in Phase 3, the flight system(s) will be fabricated, tested, delivered and launched in Phase 4. The program should provide one flight system and a back-up or spare system for delivery to the spacecraft contractor for mating with the flight spacecraft, assumed to be six months prior to launch. Flight systems should be interchangeable. If the system does not allow for substitution 
of the nuclear heat source for an electrical heater, an electrically heated system shall be delivered in addition to the fueled systems. The contractor shall plan on conducting flight acceptance tests on the hardware prior to delivery. All necessary support equipment shall also be provided. The contractor shall plan on providing technical assistance to the spacecraft contractor during testing of the power system and during pre-launch and launch activities at the launch site. Post-launch analysis of data from orbit shall be included for a 6-month period.

A final safety analysis report shall be included for delivery approximately 6 months prior to launch. Contractor support shall be provided during the interagency safety review for flight approval.

Follow-on Pro duction (Phase 5)

Immediately following a successful development program and flight test of the first flight system (Phase 4), you should assume that a follow-on order for 10-20 systems will be placed. The production schedule should be based on an optimum cost manufacturing plan, but you should also assume the need dates are for 2-4 flight systems every six-months after the initial delivery during Phase 5. The costs of manufacturing tooling, support equipment, etc. which are not available from the development program should be included in the manufacturing costs for Phase 5. The plan should provide for acceptance testing of each unit and contractor support of spacecraft testing and launch site activities involving the power supply.

In each of the phases identified above, you should attempt to identify the cost uncertainties associated with the cost estimates which you provide and to determine the effect of these cost uncertainties on the total estimated cost of the program. 
If you have any questions concerning the above guidance, please contact me.

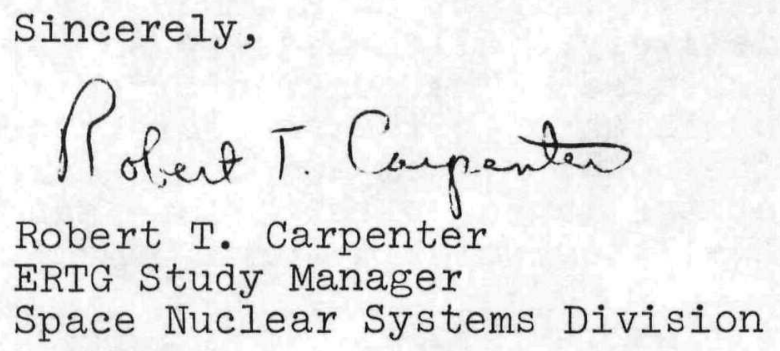

cc: G. L. Kimball, SNS 
